\title{
Public Sector Economics I/2O22
}
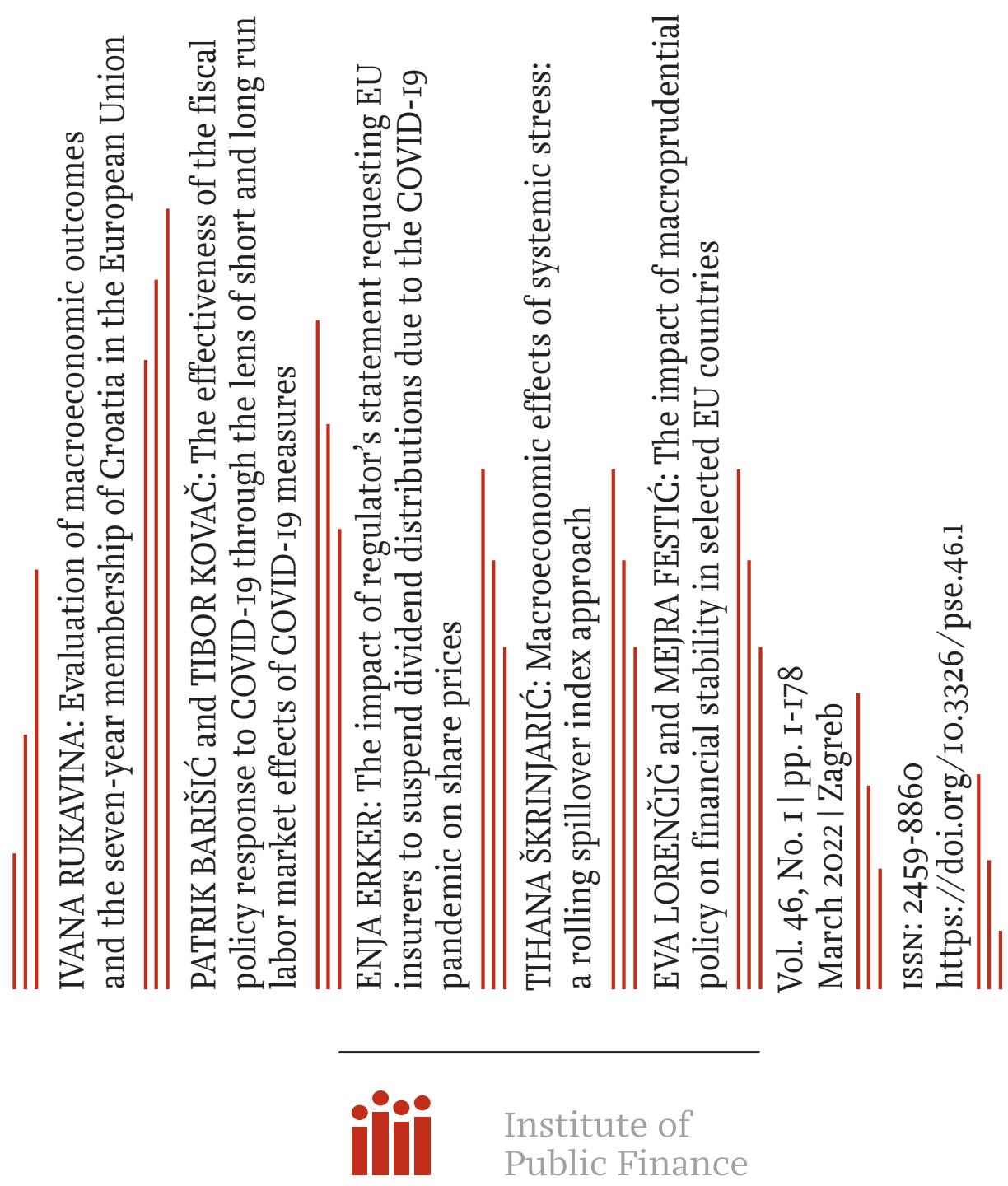


\section{Public Sector Economics \\ I/2O22}

Vol. 46, No. I I pp. I-I78 I March 2022 I Zagreb

\section{TABLE OF CONTENTS}

\section{Articles}

IVANA RUKAVINA

Evaluation of macroeconomic outcomes and the seven-year membership of Croatia in the European Union

43 PATRIK BARIŠIĆ and TIBOR KOVAČ

The effectiveness of the fiscal policy response to COVID-19 through the lens of short and long run labor market effects of COVID-19 measures

\section{ENJA ERKER}

The impact of regulator's statement requesting EU insurers to suspend dividend distributions due to the COVID-19 pandemic on share prices

109 TIHANA ŠKRINJARIĆ

Macroeconomic effects of systemic stress: a rolling spillover index approach

141 EVA LORENČIČ and MEJRA FESTIĆ

The impact of macroprudential policy on financial stability in selected EU countries

\section{Book review}

171 MICHAEL KEEN and JOEL SLEMROD

Rebellion, Rascals, and Revenue: Tax Follies and Wisdom through the Ages (Dubravko Mihaljek) 


\section{Evaluation of macroeconomic outcomes and the seven-year membership of Croatia in the European Union}

IVANA RUKAVINA, Ph.D.*

\section{Article $^{* *}$}

JEL: F15, O52, O11, C23

https://doi.org/10.3326/pse.46.1.1

\footnotetext{
* The author would like to thank two anonymous referees whose comments have contributed to the final version of the paper.

The article won the award for the best paper in the annual 2021 Prof. Dr. Marijan Hanžeković Trust Competition.

${ }^{* *}$ Received: June 1, 2021

Accepted: December 5, 2021
}

Ivana RUKAVINA

Independent researcher

e-mail: irukavina01@gmail.com

ORCiD: 0000-0002-9899-2129 


\begin{abstract}
The paper evaluates the Croatia's seven-year membership in the European Union based on selected macroeconomic indicators by using a methodological approach, counterfactual analysis, and a synthetic control method. The results showed that the effect of the accession stimulated the economic growth and components of aggregate demand, income, savings and sectoral productivity. Also, strong disturbances with the onset of the crisis in 2009 were detected, the effects of which ultimately had a negative consequence in terms of more successful economic integration. Accession to the EU halted the decline in macroeconomic indicators and began a mild, but still insufficient recovery. The research confirms a strong trend of export development after 2013, a strong turn and increase in savings, a strong and significant decline in the value added of the agriculture sector as well as not recovered consumption. Also, the positive effect in the reduction of government expenditures is expressed.
\end{abstract}

Keywords: European Union, integration, Croatia, macroeconomics, synthetic control method

\title{
1 INTRODUCTION
}

With the opening of pre-accession negotiations in 2005, Croatia was awaiting the moment of accession, which took place on July 1, 2013. Croatia's accession to the European Union (EU) was a necessary step towards further economic integration. Based on theoretical assumptions, economic integration and accession to the EU generally brings numerous benefits, while more rigorous research warns of the existence of numerous structural determinants and shortcomings that hinder the full exploitation of the potentials. What Croatia has achieved on this issue is explored in this paper. Numerous factors were tested: selected macroeconomic indicators, gross domestic product per capita (GDP pc), components of aggregate demand, income, savings, labour productivity, as well as productivity of industry, agriculture and services. We were interested in what effects would have been recorded if Croatia had never joined the EU. In order to adequately answer this question, we use the synthetic control method that provides a counterfactual situation on the basis of which the impact of membership is assessed. Although the COVID-19 pandemic brought a strong economic downturn, in this paper we do not touch on its impact and consequences. The reason is the lack of data for 2020 and the feature of global systematics.

In Croatia, research on the impact of membership is still rather scarce and has mostly been performed with partial approaches. Certain analyses were performed by Butorac (2019) where the existence of divergence processes in the macroeconomic indicators of Croatia in relation to the existing transition countries of the EU (countries that joined the Union in 2004 and 2007) as well as certain export achievements that are accompanied by a loss of competitiveness and lagging behind in the technological complexity of the product were found. In the analysis of the economic and fiscal effects of joining the Union, Deskar-Škrbić (2019) points to an increase in imports and strong integration through exports, as well as the absence of a 
section describes the methodology, data and sample. The fourth part presents an analysis of the baseline findings in which basic initial dynamic estimates of the effects of membership on macroeconomic variables are given. Section five controls the robustness of the obtained results. Within this chapter, the impact analysis detected strong changes in the observed indicators caused by the 2009 crisis, which led to certain prognostic errors and indicated the absence of crisis shock absorbers, as well as further emphasizing the need for strong and stable macroeconomic fundamentals. The sixth section discusses the results in which they are set in the context of economic issues, supplementing it with adequate research findings. The seventh part is the conclusion.

\section{THEORETICAL FRAMEWORK AND RESEARCH REVIEW}

\subsection{THEORETICAL FRAMEWORK}

The starting point in the overall evaluation of the economic impact of European integration on the domestic economy can be counterfactually explain it by two different theoretical assumptions of the economic growth model. The neoclassical theory of growth (Solow, 1956; Swan, 1956; Mankiw, Romer and Weil, 1992) bases its evolution on the investment of a portion of production through each period under the assumption of the law of diminishing returns on investment in capital. This theory further points to the fact that the long-term dynamics of growth per capita are determined solely by the exogenous impact of the rate of technological change with the possibility of including exogenous effects of the change in rate of savings, investment, or population. In the context of economic integration, the opening of borders that implies a redistribution of labour and capital among states results in temporary changes in increasing growth rates. Over the long term, economic growth determined by the rate of technological change, under the influence of integration, constantly adjusts its growth rate to the new equilibrium, which implies that savings, accumulation of capital or knowledge have a level effect but not scale effects on economic growth. The endogenous theory of economic growth (Romer, 1990) nullifies the assumption of a reduction in the return of capital investment by assuming a positive relationship between the accumulation of savings, knowledge, investment, and long-term economic growth rates. The assumption that knowledge and innovation are public goods that produce positive external and economic effects and that the accumulation of capital that increases core capital is unlimited makes long-term growth rates endogenous by allowing the free market (economic integration) to produce constantly higher growth rates. Vanhoudt (1999) further emphasizes the fact that the historical internal improvement, recovery, and innovation of economies have been driven by endogenous market and institutional strength, and that market opening can change incentives in favour of faster technological change and thus economic growth.

Although the explained effects provide unequivocal implications for economic growth, the overall dynamics of growth and development based on described models is extended through many other determinants. Additional factors that motivate countries to participate in economic integration, such as development perspectives, macroeconomic coordination, effects of productivity and production 
specialization, competitiveness and complementarity, benefits of trade diversion and GDP increases as well as acceleration and increase intra-regional trade can be found in the literature (for a detailed explanation see: Marinov, 2014).

However, the extent to which the potential of European integration will be used depends mostly on the accession country itself. In fulfilling EU standards and with joining the EU, numerous demands are made, related to strengthening the development component of the public governance system, such as challenges in improving fiscal governance. Significant amounts are transferred from the EU budget (EU funds) to help member states strengthen their economic and social cohesion by producing direct and indirect effects on growth potential. Although some legislative harmonization has been made with EU accession, the institutional and administrative structure is constantly being upgraded. Participation in EU funds emphasizes the importance of internal strengthening through institution building and increasing efficiency, and the successful use of funds is determined by the institutional absorption capacity. The contribution of administrative capacity and in this sense the institutional quality and good political governance are highlighted as an important factor in explaining the different success of participation in EU funds (Tigănaşu, Încalțărău and Pascariu, 2018; Incaltarau, Pascariu and Surubaru, 2019; Van Wolleghem, 2020).

\subsection{RESEARCH REVIEW}

Empirical research on the effects of economic integration on national growth often provides conflicting evidence. In general, it can be said that integration leads to growth benefits that are confirmed through increased investment in physical capital, technology and technology transfer (Alhmeida and Fernandes, 2008; Crespo, Ritzberger-Grünwald and Silgoner, 2008; Ehigiamusoe and Lean, 2019), more efficient resource allocation (Henrekson, Torstensson and Torstensson, 1997), more knowledge spillover (Torstensson, 1999), but also the increased magnitude of trade openness (Romer, 1990). Other benefits of the approach to economic integration have been empirically confirmed through the initial adequacy of the institutional framework and sound macroeconomic fundamentals (Klein and Olivei, 2008), the initial adequacy of the implementation of economic reforms that bring cost-effectiveness after integration (Campos and Coricelli, 2012), improving the business environment (Glodowska and Pera, 2019; Škrinjarić and Čižmešija, 2020), as well as reinforcements of convergence processes for small countries (König, 2015) as well as EU countries (Mikulić, Lovrinčević, Nagyszombaty, 2013). Other observations emphasize the importance of different structural intra-state characteristics such as the pension system, social benefits, direct and indirect taxes, foreign remittances, the size of the unofficial economy, etc. as well as inadequate standards and insufficient mutual recognition, problems with public procurement, fiscal barriers and barriers to the diffusion of knowledge and innovation (Rocher and Stierle, 2015; Ilzkovitz et. al., 2007). Thus, opposing views on the impact of economic integration indicate a permanent, negative and downward growth shift (Vanhoudt, 1999), precisely because of social policies, the impact of economic integration on fiscal policy independence 
as well as income redistribution strategies (Bertola, 2010), inefficient institutional EU structures in mitigating growing trends of socio-economic inequalities (Busemayer and Tober, 2015). Furthermore, one can find the importance of the issue of structural characteristics of CEE countries especially prominent in times of crisis (Alexe, 2012), limiting role of the geographical position in convergence processes, and the clear separation of EU core countries and CEE countries (Borsi and Metiu, 2013). Also, Campos and Coricelli (2012) highlight a key problem of younger democracies or the existence of a high concentration of power of economic elites, which democratic processes alone do not necessarily correct.

Research on the impact of EU Funds is mainly focused on regional growth, but the issue of the impact of funds on macroeconomic growth is also quite important because the funds, among other things, serve to promote economic growth and are an important source of investment financing. In his report, Siefheit (2008) highlights several important factors for macroeconomic progress related to EU Funds: (i) EU Funds have a marginal effect on growth, (ii) strong institutional and legal frameworks prevent significant loss of earmarked funds, (iii) the experience of old member states indicates that transfers cannot be a substitute for good economic policy, (iv) EU Funds can be useful for increasing domestic development policy, but are not a magic bullet for solving national problems. Research on this issue is rather scarce, but it can be said that there is a consensus regarding the connection between institutional efficiency and growth. Interesting implications are provided by the research of Bornschier, Herkenrath and Ziltener (2004) where the benefits to economic growth from EU accession are confirmed, although these benefits are primarily the result of interstate redistribution within the EU, i.e., the result of intra-community transfer payments. Ederveen, de Groot and Nahuis (2006) indicate the differentiation of resource allocation according to the key of productivity or according to the key of rent-seeking. The results of their research indicate that European support through the Structural Funds only has a conditionally positive contribution to growth. The Structural Funds are not in themselves an effective mechanism for growth; however, if they are determined by institutional quality then they promote economic growth. Albulescu and Goyeau (2013) show that the Funds do not have clear effects on growth and point out that without the necessary structural reforms, growth based solely on investments through EU Funds represents risky growth.

\section{METHODOLOGICAL FRAMEWORK}

\subsection{METHODOLOGY}

In evaluating the success of Croatia's accession to the EU, evaluating the selected set of macroeconomic indicators after 2013, this paper uses an innovative synthetic control method (SCM) and appropriate counterfactual analysis initially developed and presented by Abadie and Gardeazabal (2003) and in later stages further supplemented and developed by Abadie, Diamond and Hainmueller (2010; 2015).

SCM allows for the comparison of the result of a treatment-affected unit with the result of synthetic non-treatment control units, thus permitting the achievement of 
an unbiased and objective view of the overall effect of treatment, in our example of EU accession. SCM design is conceived as a case study method that uses a weighting process to create a counterfactual situation providing a rigorous quantitative framework for conducting a comparative case study. In doing so, it is important to provide a set of control units that have no connection with the treatment that is the subject of the research, in this example a set of non-EU countries. The weighting process ensures that the control group is as similar as possible to the treatment unit for the pre-treatment period. The SCM uses these procedures to construct a synthetic control unit from a pool of all potential control units with the result that the obtained synthetic control unit best approximates the most relevant characteristics of the unit exposed to the event/treatment of interest (Abadie, Diamond and Hainmueller, 2010: 494). The basic principle of the SCM procedure is to project the future path of the synthetic control that will mimic the path that would occur in the treated unit in the absence of treatment, thus obtaining a clear picture of the effect of treatment. The advantage of using the SCM approach stems from the fact that an evaluation made using for example a trend or difference in differences (DID, as one of evaluation method) approach may reflect the bias of the results which occur from time-varying factors between the compared units/ countries if it is assumed that the fixed effect is constant over time as well as from the application of SCM weights which ensure that the produced pre-treatment trend from the control group is as similar as possible to the unit under the influence of treatment. Also, the advantage of SCM derives from the transparency of weights in the range between 0 and 1 , which are subject to deviation comparison and form an integral part of SCM. In addition, SCM represents a dynamic estimate, while DID is a static estimate.

This methodology can be presented in the formal version as follows. Suppose that we have a $J+1$ unit (in our example a country) in a $T$ period (years) and that the unit $J=1$ is a subject (Croatia) of a certain treatment (political decisions on EU accession). In this case, units $2, \ldots, J+1$ represent potential donors or control units. Period $T$ is divided into two time periods, $T_{0}$ represents the number of years of the pre-treated period (period before Croatia's accession to the EU) and $T_{1}$ represents the post-treated period (period after 2013), so that $1<T_{0}<T$ is valid. Suppose the following, $Y_{i t}{ }^{1}$ is a variable of interest with known values before and after treatment, while $Y_{i t}^{0}$ is a counterfactual variable whose estimate is unknown and represents the outcome that would be observed for unit $j$ in time $t$ in the absence of treatment. Let $a_{1 t}$ be an estimated effect of the treatment that unit $J=1$ receives at time $T_{1}$, which corresponds to:

$$
a_{1 t} \equiv Y_{i t}^{1}-Y_{i t}^{0}
$$

As $Y_{i t}{ }^{1}$ is known and observed after treatment, only $Y_{i t}^{0}$ which representing counterfactual variable should be evaluated to find the effect of $a_{1 t}$ intervention. The essence of SCM lies in finding a suitable control group of units that can provide a reasonable assessment of this potential missing outcome. As stated, SCM is 
defined by the weighted average of untreated donor units (countries). Suppose further that $W=\left(w_{2}, \ldots, w_{J+1}\right)$ is a vector of weights with $w_{j} \geq 0$ for $j=2, \ldots, J+1$ and that $w_{2}+\ldots+w_{J+1}=1$. Each value of $W$ represents a potential synthetic control with the goal of making the weighted average of all countries in the donor pool as similar as possible to the treated unit (Croatia) in the pre-intervention period. Formally written:

$$
W \equiv \sum_{j=2}^{J+1} w_{j}^{*} Y_{j t}=Y_{1 t}
$$

Equation (2) corresponds to the estimate of the counterfactual trend $Y_{i t}^{0}$. Set up in this way, it allows us to compare the synthetic control unit with the country of interest in the outcome variable in the post-EU period in order to assess the causal effect (Croatia's accession to the EU).

Suppose further that for each observed variable a certain number of covariates is taken according to the theoretical framework. Let $X_{1}$ represent $\left(K^{*} 1\right)$ the vector of their pre-intervention values for the treated country which is further aligned with the predictor matrix or the corresponding covariate values for each variable of interest for the pre-EU period of possible control units defined by $X_{0}$ which is $\left(K^{*} J\right)$ matrix. The vector $X_{1}-X_{0} W$ defines the difference between Croatia and each country within the donor pool for each of the pre-EU covariates of the selected variable. The vector of optimal weights is:

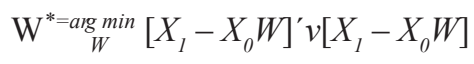

Where $\mathrm{v}$ is the $\left(k^{*} k\right)$ matrix which shows the relative importance of each covariate in minimizing the equation. As the optimal weight depends on $v$, it is important to choose a $v$ that will minimize the difference in the pre-intervention trend of the selected variables of synthetic control and treated unit. The difference is given by root mean squared prediction error (RMSPE).

\subsection{DATA AND SAMPLE}

The evaluation of the decision on Croatia's accession to the EU from 2013 was made over a 25-year time span and includes 18 pre-EU years (1995-2012) and 7 post-EU years (2013-19). The variables used in the research are related to economic growth and/or its generators, including GDP per capita, which measures economic growth, and the variable GDP per employee, which measures labour productivity. The study includes components of aggregate demand or consumption, investment, expenditures, import and export. Also, the variables income and savings as well as the gross value added of industry, agriculture, and services as the three most important sectors of the economy are included. As the homogeneity of the values of variables and the reduction of possible deviations between countries to the lowest possible level are important for the application of this methodology, variables are expressed in per capita terms. The coverage of variables in per capita terms does not exclude, i.e., does not reduce or increase the robustness of the 
assessment and does not create bias. However, in the obtained results, it should be borne in mind that all estimates contain a negative migration balance of Croatia to some extent. We could have opted for a different data coverage, e.g., in logarithmic value or in percentage of GDP, but this would reduce the analytical possibility of the desired estimate in absolute amounts and also some estimates would be largely biased in any combination of the mutual movement of the two indicators.

Covariates for the mentioned macroeconomic indicators were selected according to theoretical assumptions. The determinants of growth and aggregate demand components have been extensively researched in the literature, so this paper uses variables such as trade openness, population growth, share of investment in GDP, share of educated inhabitants as an approximator of human capital (more detailed explanation can be found at: Henreksen, Torstensson and Torstensson, 1997; Gyoerk, 2017). To determine the income and savings rate, additional variables of unemployment rate, GDP growth, dependency ratio were selected (see: Nicolescu-Aron and Mihăescu, 2012; Rocher and Stierle, 2015; Furceri and Ostry, 2019). In modelling the productivity, i.e., added value in industry, agriculture and services, variables such as human capital, the share of employees in a particular sector, the area of agricultural land, trade openness, GDP growth are used (explanation can be found in: Bravo-Otega and Lederman, 2004; Eun Kim and Loayza, 2019; Kakar, Kiani and Baig, 2016; Maroof, Husain and Jaward, 2019). Data are mainly collected from the World Bank database and are described descriptively in the appendix. The set of covariates used for each variable, narrowly specified to contain predictor balance for all macroeconomic indicators and country weighs of donor units can also be found in the appendix (table A2). The existence of missing data in predictors in the pre-EU period is generally not a problem in the analysis because all covariates in the model will be generated on averages throughout the pre-EU period.

The next important step lies in the appropriate selection of countries that make up a potential donor pool. Here the donor pool is taken from Campos et al. (2019) research that also evaluated the impact of EU membership using the SCM approach. OECD countries and Mediterranean North African countries are included in the research. These are Albania, Argentina, Australia, Brazil, Canada, Switzerland, Chile, China, Colombia, Egypt, Hong Kong, Indonesia, Iceland, Israel, Japan, Korea, Morocco, Mexico, Northern Macedonia, Malaysia, New Zealand, the Philippines, Russia, Thailand, Tunisia, Turkey, Ukraine, and Uruguay. As the SCM approach requires a complete balance of data for outcome variables, some countries have been left out due to data that are missing in some estimates.

\section{BASELINE RESULTS}

Based on the previously described methodology, the results are presented below. The real movement of a series of variables of interest in Croatia in the period from 1995 to 2019 is shown with a solid line. The dashed line composed of a weighted set of donor countries is synthetic Croatia, and reflects the situation of non-accession to European integration. The dashed vertical line marks the year of EU 
accession and the start of a seven-year treatment. After estimating the selected set of macroeconomic variables shown in figures 1, 4, and 7 based on Eq. (1), the results of Croatia's accession to the EU will be converted into percentage terms. Also based on the obtained results, in order to attain a clear visualization of the movement of the two series and highlight the changes that occurred after integration, an additional methodological step which includes constructing of trends in real and synthetic Croatia after 2013 was made. The mutual movement of the series was recalculated based on an index with a common base in the year of accession to the $\mathrm{EU}, 2013=100$. This way of presenting the results primarily arises from the methodological limitations in the application of the SCM method. Namely, in certain macroeconomic series, the crisis that Croatia faced in 2009 caused significant idiosyncratic shocks that the methodology was not able to overcome, and which led to greater deviations of real and synthetic Croatia in the year of EU accession. Therefore, with an additional analysis of the obtained results through closing the deviations of the two series, we want to show the pure trend of the observed macroeconomic changes that occurred after accession to the EU.

For the sake of clarity, the SCM results are presented separately in three parts, GDP pc and aggregate demand components, the second part gives the results for income and savings, while the third part comprises the results for productivity.

\subsection{RESULTS FOR ECONOMIC GROWTH}

The real and synthetic movement of GDP pc (figure 1.1) was determined by the negative deviation which corresponds to the assessment of the accession effect. Synthetic GDP pc very closely replicates the real trend of Croatian GDP pc until 2011, which indicates the resemblance of synthetic control with the actual data set, but also the potential risk in forecasting given the recorded deviations in 2011. The difference between the real and synthetic unit is most prominently visible in 2016, when it begins to gradually decrease and in 2019 reaches a positive level. The average effect was calculated at a negative $4.4 \%$, with the strongest deviation of $-7 \%$ in 2014 and a positive deviation of $1.2 \%$ in 2019 (figure 2). The graded reduction of the difference also speaks of an upward-phase cycle and a fastergrowing Croatian GDP pc, which was preceded by a five-year decline. On the other hand, when the initial deviation is closed, the results (figure 3.1) indicate positive jumps in GDP pc only after 2016. The results indicate that since 2016 there has been a further increase in GDP pc, which corresponds to a way out of the crisis of the Croatian economy. Also, these positive developments, despite the initial deviations, led to the final results presented by the SCM method, that Croatia's GDP pc exceeded the synthetic line in 2019. The results suggest a potential positive future trend of Croatian GDP pc, which implies that a positive outcome in Croatian GDP pc may be visible only in the medium term.

In figure 1.2 a synthetic assessment of the impact of Croatia's accession to the EU on the example of household consumption is presented. The negative and persistent divergence after 2013 is visually clearly highlighted. Also, there are certain 
divergences until 2013 in the pre-EU period, to be discussed more in the next section, which make it impossible to accurately project the complete and real consumption outcomes of EU accession. Observing the movement of the synthetic consumption, the beginning of the deviation in 2011 was highlighted, when synthetic consumption began to recover, while Croatian consumption continued to decline, which ultimately led to a marked negative gap in the post-EU period. Real consumption compared to synthetic in the period from 2013 to 2019 fell by $-9.2 \%$. Data (figure 2), indicating a decrease in the lag started in 2015 and a deviation of the two lines of $-6.5 \%$ in 2019 versus a deviation of $-8.9 \%$ in 2013 and $11.3 \%$ in 2014. Data of the mutual movement after 2013 (figure 3.2) indicate that the movement of Croatian consumption does not differ significantly from the movement of synthetic consumption, more specifically only after 2018 is a micro separation of Croatian consumption in relation to synthetic shown. Although these are micro shifts for the seven-year period, it should be noted that since 2014 when a strong five-year decline in consumption was stopped, consumption begins to recover and grow. Nevertheless, based on the results in the short term, negative deviations are not expected to close soon. Croatian consumption doesn't provide clear evidence of more intense positive future developments, especially if we consider that the level of consumption from 2008 was reached in 2019.

Real investments are also marked by the presence of idiosyncratic shocks that can create certain prognostic deviations due to the impossibility of complete replication by the synthetic line (figure 1.3). These shocks were pronounced on the eve of Croatia's accession to the EU, i.e., since 2011 when the line of synthetic investments recorded an increase, while the line of Croatian investments shows a further decline. Nevertheless, the specificity of the post-EU period is marked in two ways. Negative three-year deviations were replaced by a positive $15.7 \%$ deviation in 2019. Also, given the depth and permanence of the crisis in the year of EU accession, 2014 was a turning point in the constant reduction of investments. According to the SCM method, the results suggest that the four-year post-EU period (201316) can be seen as a kind of bridge for the realization of future positive investments (2017-19) with a further future trend of positive investment. The results presented in figure 3.3 also confirm that investments are recovering after Croatia's accession to the EU; since 2014 there has been a constant and positive growth trend which implies a future positive investment outcome. Ultimately, the obtained investment outcomes point to the recovery of the investment cycle after accession to European integration, as well as the upward trend of investment. However, the fact that Croatian investments in 2019 are below the level recorded in 2008 should not be overlooked.

The results of the synthetic control unit for government expenditures follow very well the real trend of government spending in the pre-EU period (figure 1.4). After 2013, there is a clearly visible separation between real and synthetic expenditures, which suggests that with the accession, Croatia achieved lower expenditures compared to the situation in which it remained outside the EU. Certain benefits in 
percentage terms (figure 2) indicate a cycle of $-3.0 \%$ in 2013 , a maximum of $-5.7 \%$ in 2016 , and a minimum of $-1.9 \%$ in 2019 . Overall, the results suggest lower real expenditures compared to synthetic with an average difference of $-3.6 \%$. However, the line convergence also suggests the possibility of closing the gap and rising the line of real expenditures above the line of synthetic in the coming periods. The results from figure 3.4, which equalize the start position of actual and synthetic expenditure in the year of accession to the EU, confirm obtained results on reduced expenditures, but also show us that the gap is closed after 2018 when Croatian expenditures rise above the level of synthetic expenditure. In total, both the obtained and the derived results indicate a positive outcome and a reduction in government spending after EU accession.

As for the results of imports (figure 1.5), idiosyncratic shocks in the pre-EU period and certain deviations between the two series are noticeable. Two years before accession, i.e., from 2011 there was a deviation of two lines, synthetic imports show an increase, while the line of Croatian imports is at lower levels, which creates certain prognostic limitations and shortcomings. In the period after 2013, the two series continue the parallel trend until 2015, when a certain level of divergence is observed, expanded additionally in 2019. On average, a 5.4\% increase in real imports was generated compared to the synthetic one (figure 2). The results of SCM suggest that real imports have been constantly increasing since 2015, and future import achievements are also related to this trend. In figure 3.5 when the initial methodological deviations are reduced to zero, the positive results of imports are more pronounced after 2014, which implies that in the Croatian economy there was a certain positive effect of integration visible in imports with a tendency for further growth.

In figure 1.6 results for exports indicate a very good imitation of real Croatian exports in the pre-EU period. The estimates indicate a strong divergence in real and synthetic exports, suggesting that Croatia has benefited significantly from EU accession. After 2013, the discrepancies between the two series indicate that actual Croatian exports significantly exceed the amounts that would have been recorded if Croatia had remained outside the EU. In the seven-year period, Croatian exports increased by $20.5 \%$ compared to synthetic exports (figure 2). A constant growth of real exports is present, at the highest level in 2019 and at a difference of $41.2 \%$ compared to synthetic. Results of mutual movement with a common base in 2013 (figure 3.6) strongly confirm the originally obtained results. The overall results suggest a tendency for further growth and the creation of additional benefits for the Croatian economy. It is still worth noting the reciprocity in the movement of imports and exports. Although the logical question is whether the increase in exports is neutralized by increased imports, it should be noted that the values of imports and exports differ in the pre-EU period in which the value of imports is at higher levels. Therefore, it can be said that there was indeed a purely export effect within the consequences of economic integration. 


\section{Figure 1}

Results of synthetic control method for GDP pc and aggregate demand components

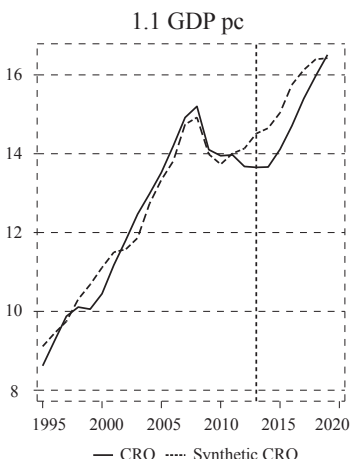

1.4 Expenditures

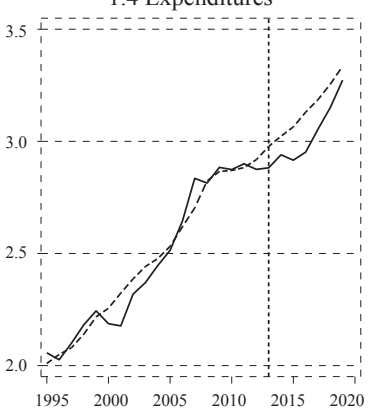

- CRO .... Synthetic CRO

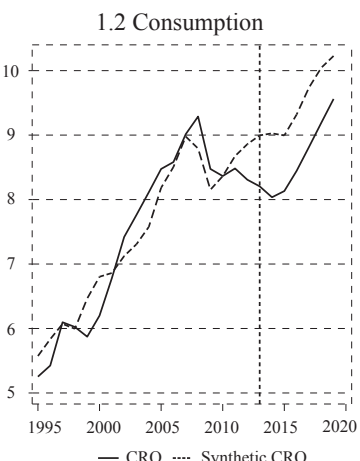

1.5 Import

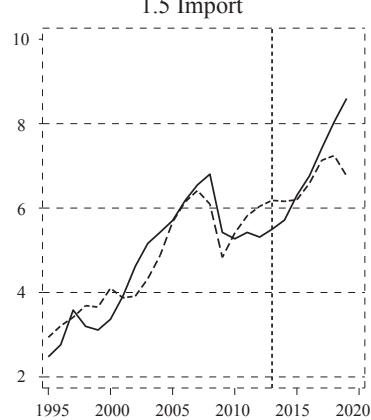

- CRO -.... Synthetic CRO

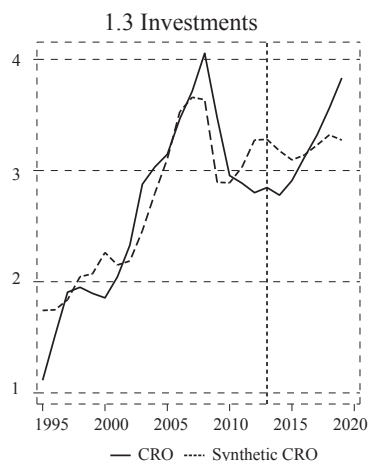

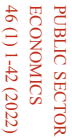

1.6 Export

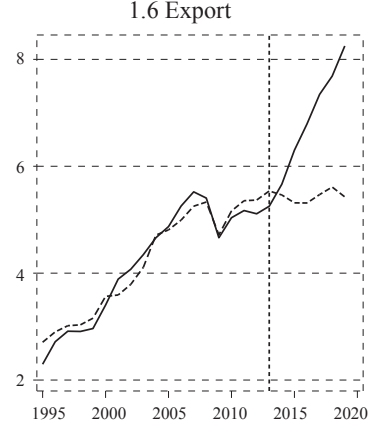

- CRO -.... Synthetic CRO

Note: All series are expressed in per capita terms (in thousands, constant 2010 US\$).

Source: Author.

\section{Figure 2}

Difference in GDP pc and aggregate demand components after Croatia's accession to the EU (in percent)

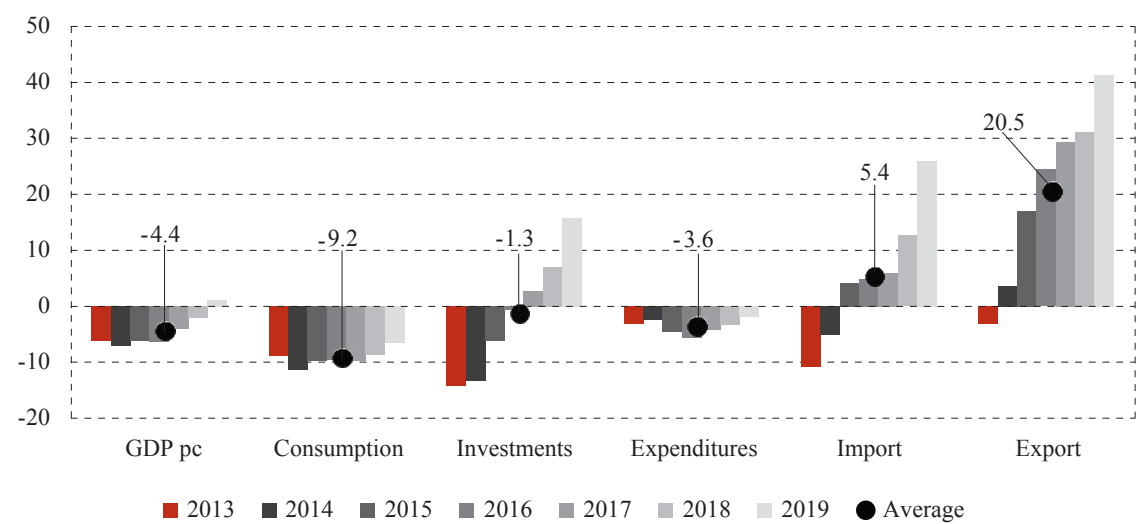

Note: The percentage difference between real and synthetic value, where a positive (negative) value indicates that the real series is greater than (smaller than) the synthetic series by that percentage. Source: Author's calculation based on results of synthetic control method estimations. 
3.1 GDP pc

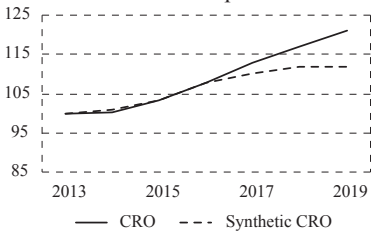

3.4 Expenditures

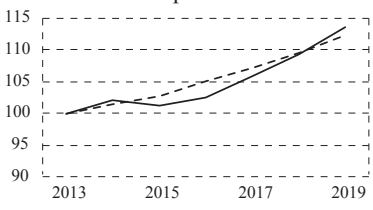

— CRO - -. Synthetic CRO

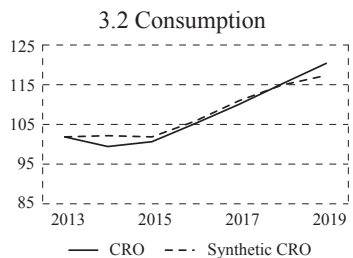

3.5 Import

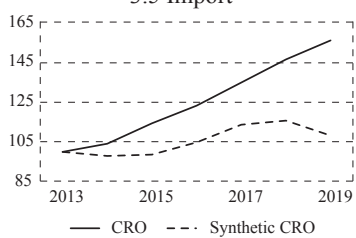

3.3 Investments

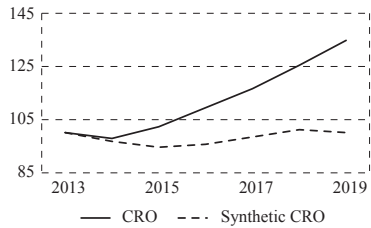

3.6 Export

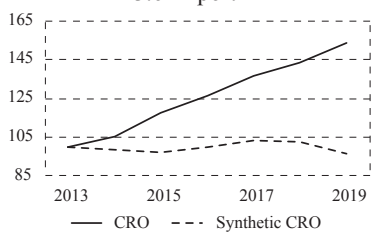

Note: The mutual movement is based on an index with a common base 2013=100. Changes after 2013 show the movement of the Croatian series and its estimated synthetic controls. Divergence between two lines is seen as changes that occurred after joining the EU.

Source: Author's calculation based on results of synthetic control method estimations.

\subsection{INCOME AND SAVINGS}

Regarding the results for income and savings shown in figure 4, certain rises are visible in series. The results for income indicate the deviation of the series between real and synthetic Croatia after 2013. But also, the deviation is clearly highlighted two years before accession, in 2011 when synthetic income begins to recover and shows an upward trend, while Croatian income remains below that level, i.e., at lower levels than synthetic income. Such prognostic deviations need to be considered in the further evolutionary context of the analysis, as this leads to an initially larger negative difference in the first two years of membership. Although the effect of the increase in income in the period 2013-18 is visible in its increase by an average of 2.3\% (figure 5 ), the presence of certain deviations in the pre-EU period suggests caution in the conclusions. The results of the mutual movement (figure 6) reduced to the same base $(2013=100)$ confirm that Croatian income with positive performances stands out after 2015. A noticeable trend of income growth and a stronger separation of the real Croatia from the synthetic creates assumptions that in the future, the real income could significantly preponderate the synthetic line. In income modelling, one of the limitations is the incompleteness of income data in 2019, which had to be left out, and which would certainly contribute to stronger visibility of results and a stronger conclusion.

Synthetic savings excellently follow the pattern of Croatian savings in the pre-EU period. After 2013, the divergence of the two series is clearly visible, with Croatian savings increasing by an average of $10.2 \%$ from 2013 to 2019 . As there is a persistent upward trend with a maximum of $14.6 \%$ of GDP recorded in 2019 and as further divergence of the two lines is visible in the future, an even more pronounced increase in savings can be expected. These results suggest that after 2013, a certain cumulative of protective and depreciation pillars is created, and 
also imply a heightened perception of the uncertainty of future economic development opportunities. However, it is necessary to mention the strong decline in synthetic savings after 2013, which may also reflect potential momentum in the faster recovery of other synthetic macroeconomic indicators. Given that the crisis in Croatia lasted much longer than in other countries, possible explanations are found in the large accumulation of national savings which could be placed on the market in the form of investments. Also, the highlighted and significant decline in synthetic savings is certainly influenced by the savings trends of the countries that make up the synthetic savings line (see table A2 in the appendix).

\section{Figure 4}

Results of synthetic control method for income and savings
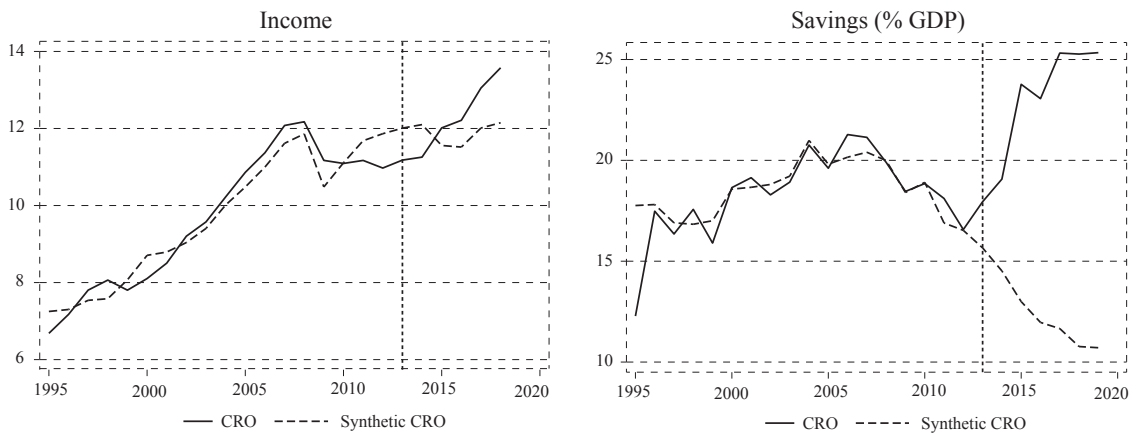

Note: Income was originally expressed in absolute per capita terms (in thousands, constant 2010 US\$). Savings were originally expressed in percentage of GDP.

Source: Author.

\section{Figure 5}

Difference in income and savings after Croatia's accession to the EU (in percent)

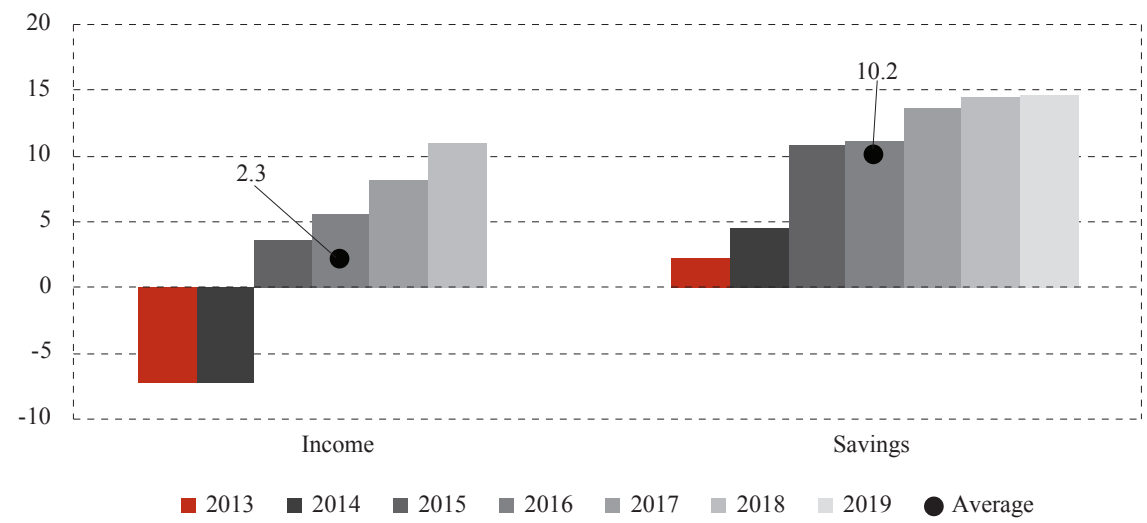

Note: Income was originally modelled in absolute terms (constant 2010 US\$) and it is graphically expressed as the percentage difference between real and synthetic value, where a positive (negative) value indicates that the real series is greater than (smaller than) the synthetic series by that percentage. Savings were originally expressed in percentage of GDP and graphically expressed as the simple difference between the real and synthetic value.

Source: Author's calculation based on results of synthetic control method estimations. 

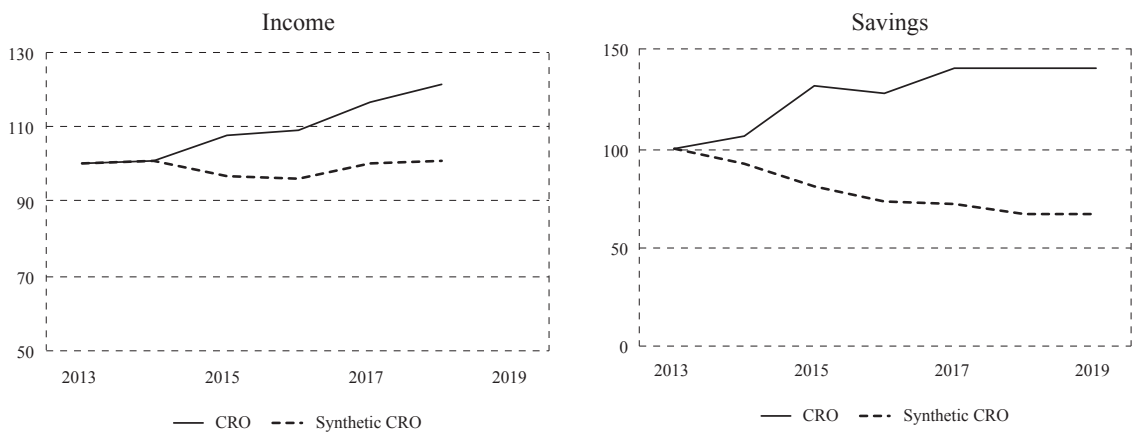

Note: The mutual movement is based on an index with a common base 2013=100. Changes after 2013 show the movement of the Croatian series and its estimated synthetic controls. Divergence between two lines is seen as changes that occurred after joining the EU.

Source: Author's calculation based on results of synthetic control method estimations.

\subsection{LABOUR PRODUCTIVITY, INDUSTRY, AGRICULTURE AND SERVICES PRODUCTIVITY}

Figure 7 shows the results related to labour productivity expressed as a ratio of GDP per employee, and sectoral productivity of industry, agriculture and services measured by per capita value added of a particular sector. It is immediately noticeable that in each figure the line of the real Croatia is below the line of the synthetic series for Croatia, i.e., that deviations are present.

The labour productivity (figure 7.1) of synthetic Croatia follows well the real movement of Croatia in the pre-EU period. It can be seen from the figure that after 2013 a stronger and more persistent divergence was observed with a $4 \%$ average decline in labour productivity (figure 8 ). In the post-EU period, a stronger one-off decline in real labour productivity is noticeable immediately after 2013 lasting one year when productivity takes on an upward trend. Such a one-off decline caused further persistent deviations that did not decrease until 2019 without a clearly visible tendency for the gap to be closed and for mutual convergence to be achieved in the medium term.

The results for productivity in industry shown in figure 7.2 indicate the presence of idiosyncratic shock from 2009 which resulted in an incomplete possibility of synthetic control to cover the approximate movement of Croatian industrial productivity in the pre-EU period, specifically in 2012. Separation of two lines can best be seen in 2010 when there is a strong growth in synthetic industry productivity, while the Croatian productivity line continues to decline until 2013. Such high deviations emphasize the unreliability of results because the synthetic line is not able to fully reproduce real productivity trends. Therefore, these results need to be observed under the influence of methodological limitations, or the impossibility of projecting the real Croatian industry productivity trend. This is further discussed 
in the next chapter when robustness is checked. Nevertheless, the figure shows a strong discrepancy between real and synthetic Croatia that generated an average gap of $-10.7 \%$ (figure 8). It should be noted that immediately after 2013 , a positive rise in the line of Croatian industrial productivity was recorded, which decreased from the initial 17\% lag behind synthetic Croatia in 2013 to $5.3 \%$ in 2019 . Although it was not possible to close the gap due to methodological limitations, figure 9.2 shows the mutual movement when the obtained lines are reduced to a common base $(2013=100)$ to get a more detailed picture of the outcome. The figure clearly shows that the line of Croatian industrial productivity begins to stand out positively after 2014, with a tendency to continue positive results, which actually corresponds to the recalculated effects of the decline in the lag in the obtained results. Although a strong negative deviation was initially recorded in SCM, one can notice a positive trend of declining deviation, which, when we take into account the performed calculations with a common base, suggests an existing potential to compensate for the initial stagnation of industrial productivity. The suggestion must also be considered through the overall lost industrial productivity from 2009 till 2019, i.e., it has not been compensated even after 10 years.

\section{Figure 7}

Results of synthetic control method for labour productivity, productivity in industry, agriculture and services
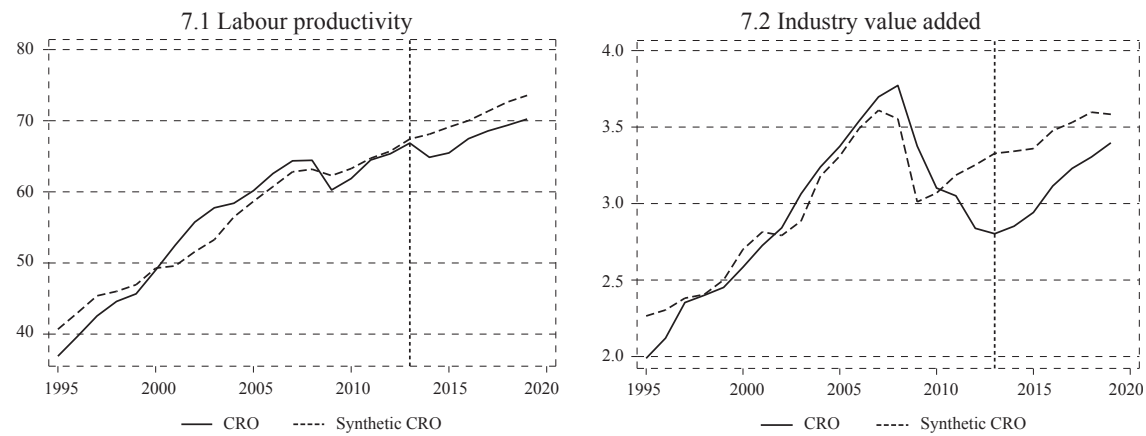

7.3 Agricultural value added

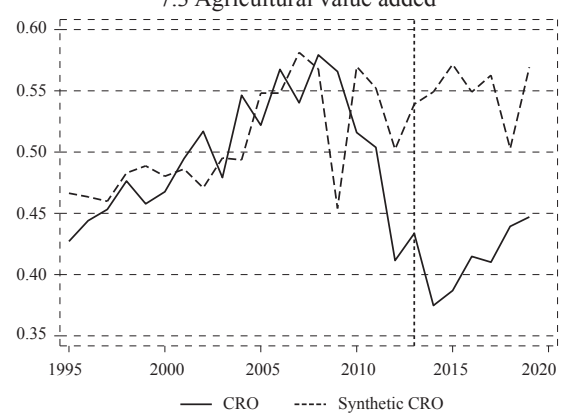

7.4 Services value added

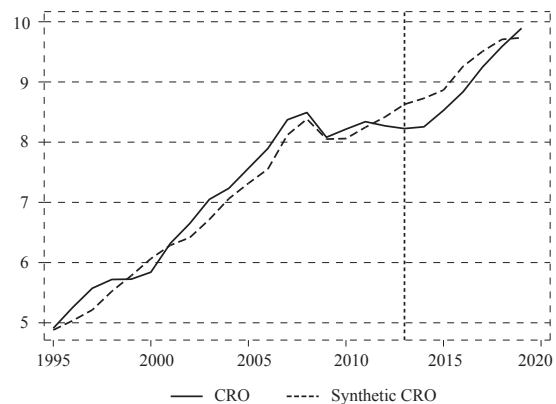

Note: Labour productivity is expressed as GDP per employee (in thousands, constant 2017 PPP $\$$ ) while sectoral productivity i.e., industry, agriculture and services is expressed in per capita value added (in thousands, constant 2010 US\$).

Source: Author. 
Further in figure 7.3 the added value in agriculture or productivity of the agricultural sector is shown. The figure indicates the presence of idiosyncratic shocks on the Croatian agricultural industry throughout the pre-EU period. The presence of this type of cyclicality indicates certain structural shortcomings that dramatically lowered the potential of agricultural productivity with the onset of the crisis in 2009, which fell below the level recorded in 1995, while the line of synthetic investments remained at higher levels. The results indicate that agriculture recorded a significant deviation in the post-EU period, with an average seven-year gap between Croatia and synthetic Croatia of a negative $28 \%$. The largest deviation between real and synthetic Croatia was recorded immediately after accession to the EU, in 2014 (37.7\%) and 2015 (38.5\%). Although a cyclical, but also positive trend of Croatian agricultural productivity is visible after 2014, it is still insufficient to close the gap created by the deviation in the near future, so the potential for real agricultural productivity to exceed the synthetic productivity line cannot be seen even in the long run. That conclusion coincides with the result of the series when they are reduced to a common base (figure 9.3) where it is evident that even with the same base $(2013=100)$ the line of Croatian agricultural productivity lies below the synthetic line.

\section{Figure 8}

Difference in labour productivity, productivity in industry, agriculture and services after Croatia's accession to the EU (in percent)

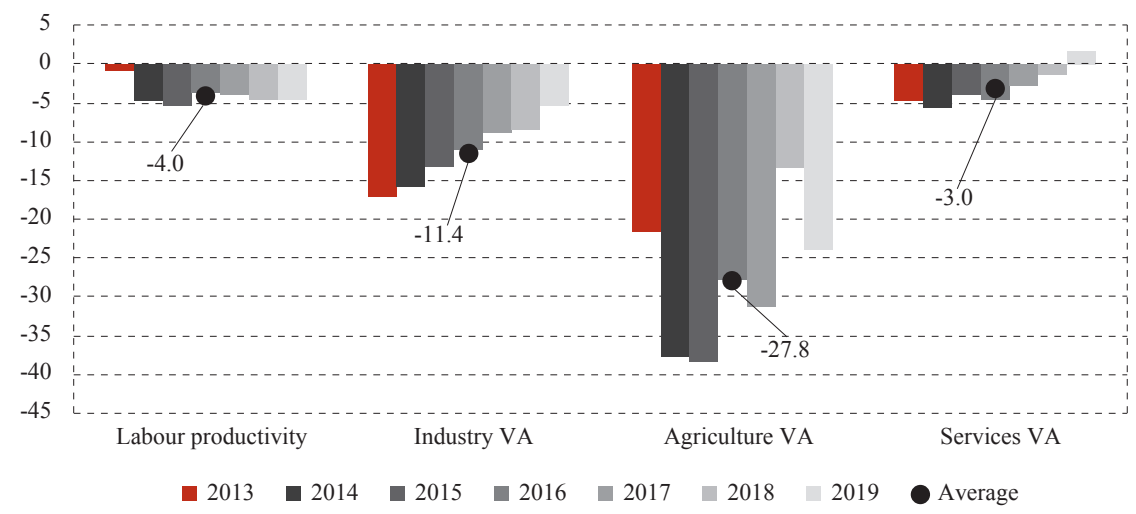

Note: The percentage difference between real and synthetic value, where a positive (negative) value indicates that the real series is greater than (smaller than) the synthetic series by that percentage.

Source: Author's calculation based on results of synthetic control method estimations.

Regarding the productivity of the service sector (figure 7.4), the synthetic Croatia line well reproduces the real trend of the Croatian series in the pre-EU period, till 2011. However, it can be observed that the deviations of the two lines from 2011 generated certain deviations after 2013. Although negative differences were recorded in this example after 2013, the trend of their reduction is noticeable due to the acceleration of productivity of the Croatian service sector. These 
results suggest that with the continuation of this dynamic, the productivity of the service sector will continue to grow above the synthetic line in the near future, recording additional increases in productivity. Although the effects are calculated at an average negative $3.0 \%$ they are influenced by initial deviations. When the initial gap is closed (figure 9.4), it is evident that the productivity of the Croatian service sector after 2016 is actually at higher levels, but weaker dynamics are observed.

\section{Figure 9}

Results of mutual movement synthetic and real line with same base (2013=100)
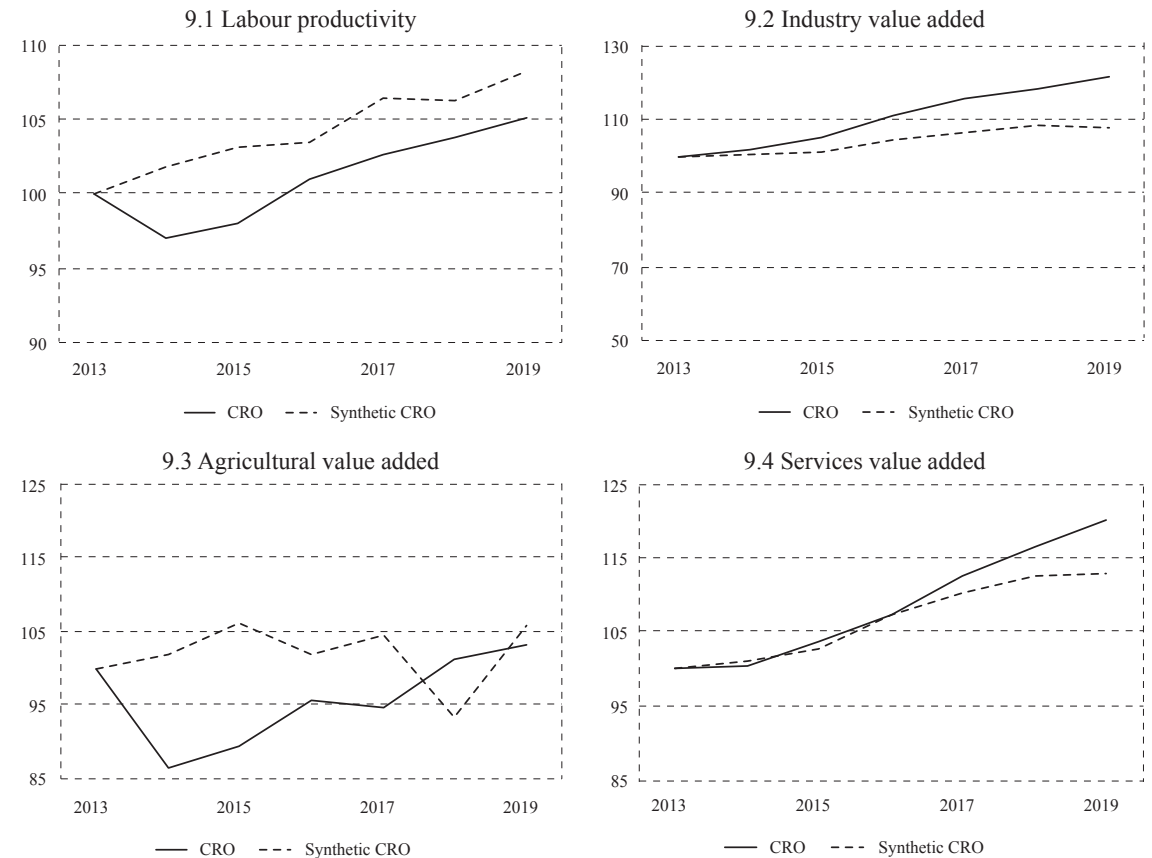

Note: The mutual movement is based on an index with a common base 2013=100. Changes after 2013 show the movement of the Croatian series and its estimated synthetic controls. Divergence between two lines is seen as changes that occurred after joining the EU.

Source: Author's calculation based on results of synthetic control method estimations. 


\subsection{IN-SPACE PLACEBO STUDY}

An in-space placebo study determines whether significant differences can be found between the real country under treatment (Croatia) and the corresponding synthetic control unit. The study iteratively applies SCM to each country, in each iteration each of the control countries is assigned treatment from 2013. If the initial results are robust, the method is expected to assess the insignificant effects of treatment on donor countries compared to Croatia, which would be shown by separating the Croatian line from the set of other lines on the chart. If, on the other hand, the series for Croatia fits well into the spectrum of other donor pool series, there is a possibility that the original synthetic counterfactual analysis did not record a significant treatment effect because it suggests that other countries, which did not receive treatment, show greater treatment effects and the initially recorded results could be derived from unobserved factors rather than the impact of accession to European integration. The results for all variables are shown in figure 10 .

Regarding the results of the greatest robustness for export, savings, and productivity of agriculture (figures 10.6, 10.8, and 10.11), a clear separation of the Croatian line in relation to other lines is visible, suggesting that significant deviations after accession were recorded. However, related to exports, it can be noticed that two lines are above the line of Croatian exports. But, their separation is noticeable before 2013 so robustness still holds. These results are free to be interpreted in accordance with the originally obtained estimates. In the case of GDP pc and aggregate demand components, the separation of lines recorded only in the first years of membership is noticeable, after which they fit into the spectrum of other lines (GDP pc and investments) (figures 10.1 and 10.3), retention of lines on the edge of other lines (consumption households and government expenditures) (figures 10.2 and 10.4), line separation in the last year (import) (figure 10.5) and mention separation of the export line (figure 10.6) which suggests a certain significance of the impact of treatment. The results for savings (figure 10.8) are significantly separated from other lines, especially after 2014, and it can be argued that the originally obtained estimates are robust, while the same argument cannot be identified for income because the separation of the line is not recorded; their line is found within the spectrum of other lines (figure 10.7). In terms of productivity, the results for agricultural productivity (figure 10.11) show a significant path. In the placebo study of service productivity (figure 10.12), the results do not indicate the certainty of the obtained estimate, although the separation of the line is visible in 2014, while labour productivity fits well within other lines and does not represent robust accession effects (figure 10.9). Results for industrial productivity (figure 10.10) show uncertainty of baseline estimation, line of Croatian industry fits well in the spectrum of other lines. 
Figure 10

Results of the in-space placebo study (all macroeconomic indicators)

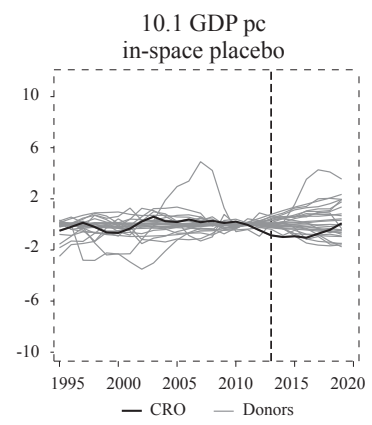

10.4 Expenditures in-space placebo

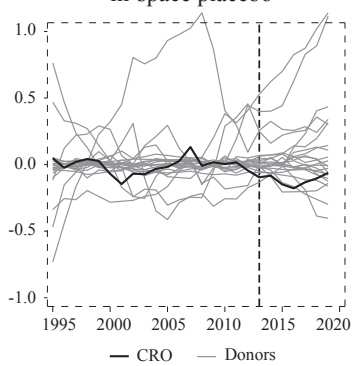

10.7 Income

in-space placebo

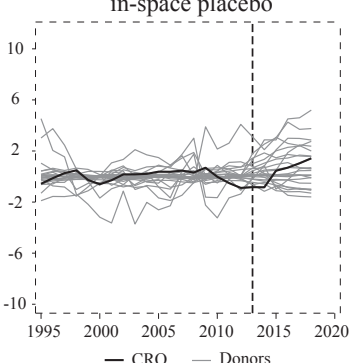

- CRO - Donors

10.10 Industry value added in-space placebo

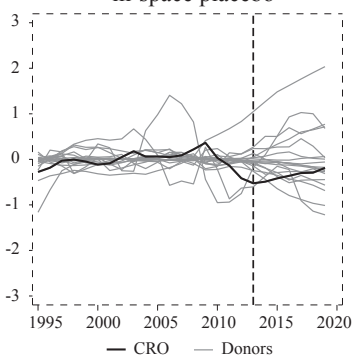

10.2 Consumption

in-space placebo

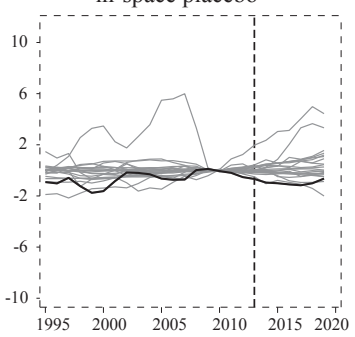

- CRO - Donors

10.5 Import

in-space placebo

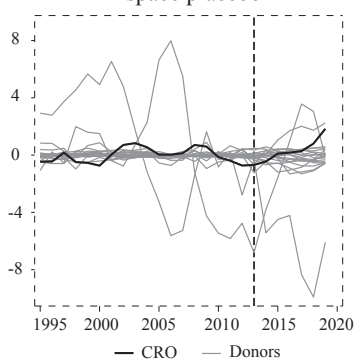

10.8 Savings in-space placebo

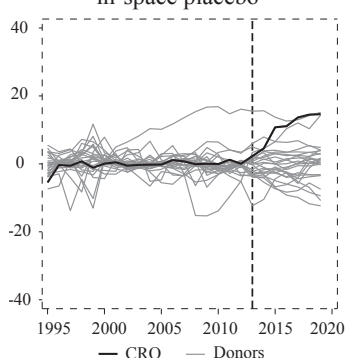

10.11 Agricultural value added in-space placebo

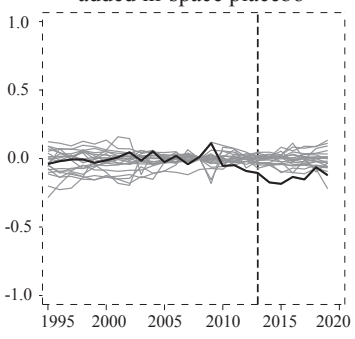

10.3 Investments

in-space placebo

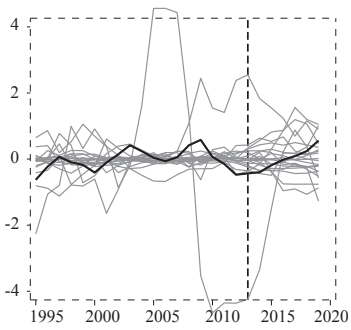

— CRO — Donors

10.6 Export

in-space placebo

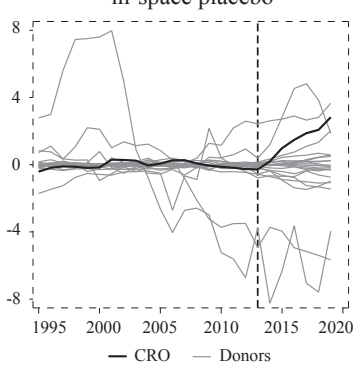

10.9 Labour productivity in-space placebo

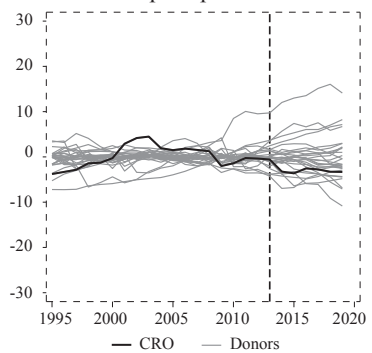

10.12 Services value added in-space placebo

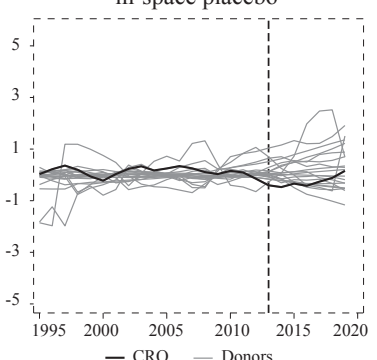

Note: Black line represents the difference (effects) between actual and synthetic Croatia and shows the estimated impact of EU's accession while the grey lines represent the estimated placebo effects for each country in the sample.

Source: Author. 
The in-time placebo study consists of stochastically assigning a treatment and assessing the effect of the treatment at a time when it did not actually occur. Also, a method of falsification of a treatment which limits the sampling period until the date of full application of the treatment for the reason of avoiding recording its effect. All covariates in the estimates remain as in the original SCM estimates. In essence, these are identical methodological procedures, only in this example for the period from 1995 to 2012. If the application of in-time placebo studies shows significant discrepancies between real and synthetic Croatia, it would mean that the originally obtained results were initiated by chance or through the lack of predictive power of SCM. In order to conduct this study 2005 was chosen, which is also the year of the opening of pre-accession negotiations with the EU, which makes a falsified post-EU period of eight years. The results of the in-time placebo studies shown in figure 8 reflect marked heterogeneity in movements. Unlike Croatia's actual accession to the EU in 2013, our false accession to the EU in 2005 has no visible effects in household consumption (figure 11.2), investment (figure 11.3), expenditures (figure 11.4), income (figure 11.7), savings (figure 11.8) which gives importance to the originally obtained estimates.

Furthermore, what attracts special attention is the separation of synthetic and real Croatia with the onset of the global financial crisis in 2008 and drastic deviations in the series of exports, imports, labour productivity, industry and agriculture (figures 11.5, 11.6, 11.9, 11.10, and 11.11). In examples of imports and exports, it should be noted that the separations show negative deviations, which after the accession to the EU show positive deviations. As for the other findings, we can say that they are strongly influenced by the crisis which led to a shift in the lines. So, these results partly give importance to the initially obtained estimates because the crisis represents a certain idiosyncratic shock which, on the example of Croatia, acted much more strongly in comparison with synthetic control and cannot be attributed to coincidences. However, the shock can cause strong deviations and inaccurate estimates if the synthetic unit does not provide the possibility of replication, which proved to be correct, for example the productivity of industry in the in-space placebo study (figure 10.10). These results also show a strong impact of the global financial crisis on the Croatian economy manifested in the mentioned indicators. The last two variables subjected to the in-time placebo study, GDP pc and service productivity (figures 11.1 and 11.12) reveal the beginning of the divergence of synthetic and real Croatia immediately after 2005, which suggests certain shortcomings in the robustness of the originally obtained estimates because it implies the existence of a false effect in the right treatment. 
Figure 11

Results of the in-time placebo study (all macroeconomic indicators)

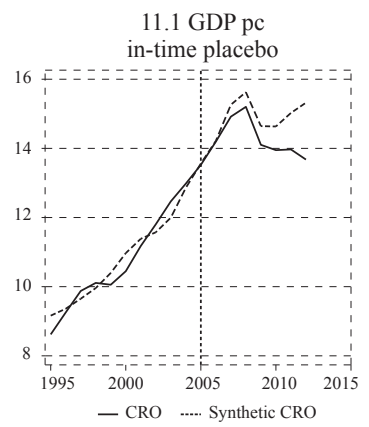

11.4 Expenditures in-time placebo

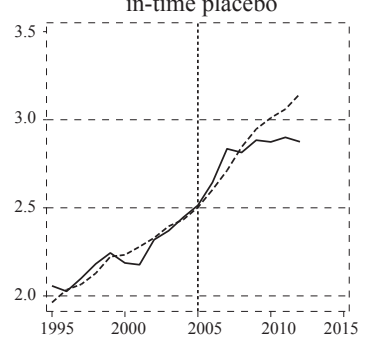

- CRO ..... Synthetic CRO

11.7 Income in-time placebo

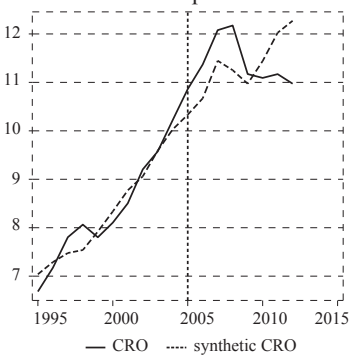

11.10 Industry value added in-time placebo

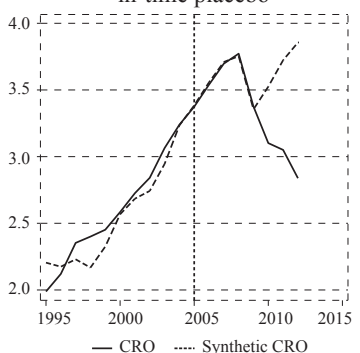

Source: Author.

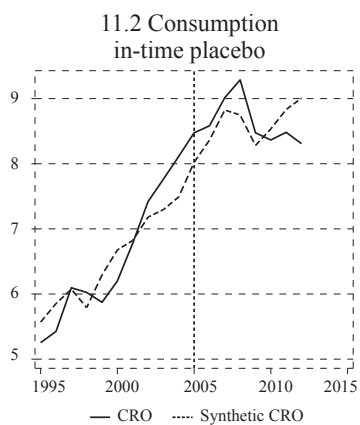

11.5 Import

in-time placebo

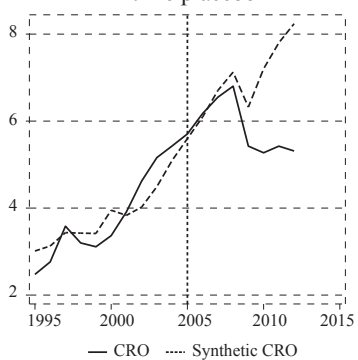

11.8 Savings

in-time placebo

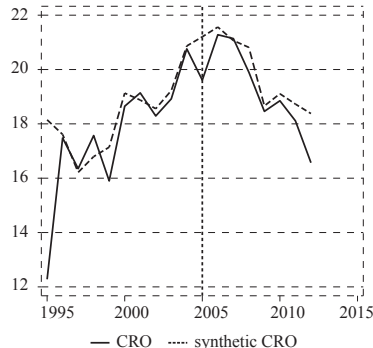

11.11 Agricultural value added in-time placebo

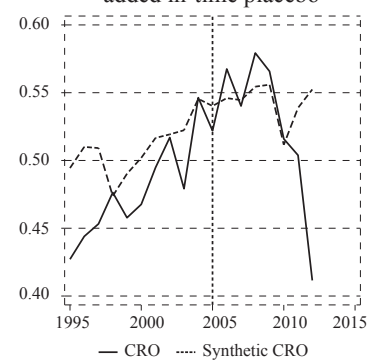

11.3 Investments in-time placebo

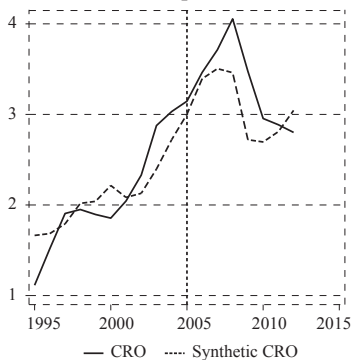

11.6 Export

in-time placebo

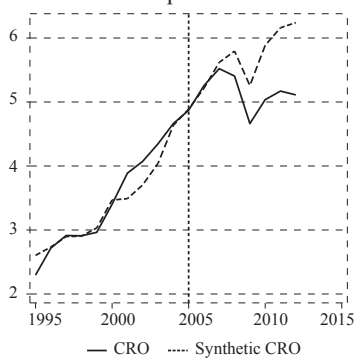

11.9 Labour productivity in-time placebo

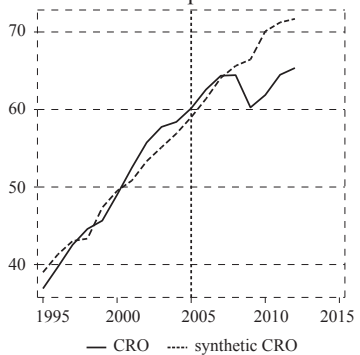

11.12 Services value added in-time placebo

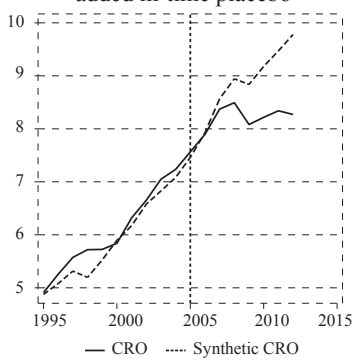


Due to the problem that we faced i.e., strong pre-EU deviations in some macroeconomic indicators and due the recognition of the fact that our primarily obtained results may be influenced by certain characteristics of donor countries, in this respect they can reflect a certain bias of the estimated results. Also, donor countries may be affected by the spillover effects of Croatia's EU accession. If there were a spillover effect like the diversion of trade caused by EU membership to a non-EU country that is a part of a donor pool, it would lead to an upward shift in our results. Conversely, if a country in a donor sample experienced another form of idiosyncratic shock, this would lead to a downward shift in our primary results.

Considering the above problems, Campos, Coricelli and Moretti (2019) proposes the use of a simple and new approach to robustness testing: constructing 1,000 alternative counterfactuals based on alternative donor samples which involves countries randomly selected from the entire donor sample (which contains 159 countries), for each macroeconomic variable. In doing so, each alternative donor sample, randomly selected from a large number of countries, contains the same number of countries as in our baseline assessment. The obtained estimates of the outcomes caused by Croatia's membership in the EU are converted into a percent and then compared to our baseline estimates. A list of countries for entire donor sample, used in the alternative assessment can be found in the appendix at the end of the paper.

The results of the random donor sample effects, presented in table 1, compare our baseline results and estimated effects of EU membership with the effects obtained using 1,000 alternative and randomly selected samples. The results indicate certain characteristics of the Croatian economy that indicate certain deviations in the estimated effects.

In terms of GDP pc and aggregate demand components, all macroeconomic indicators, except exports, indicate the effects of both overestimating the accession's effects (investment, imports) and underestimating the accession's effects (GDP pc, government expenditures and household consumption). Observing the results, the effects of GDP pc are proven interesting, in which the average effect of our baseline estimate is $-4.4 \%$ while the mean (median) of alternative estimates is positive and amounts to $1.3 \%(0.7 \%)$. The results are even more pronounced if we look the best pre-treatment fit in which the effect on the GDP outcome is shown to be positive. Also, government expenditures, which led our primary results to a high level of underestimation, recorded an average (median) difference from 3.5 percentage points (2.7) while the best pre-treatment effect holds negative coefficient as our baseline estimation. What attracts attention are import results which do not provide clear effects and unambiguous conclusions. Namely, the estimated average effect is $5.4 \%$, while the effect of best pre-treatment fit is negative (-4.5\%). Also, $76 \%$ of the estimates had an average negative effect. The results for household consumption indicate deviations of mean (median) effect from 3.4 percentage points (2.7) while best pre-treatment estimation is in line with our baseline estimates. It can also be said that the baseline obtained effects of investments are deeply overestimated, the mean (median) difference between the baseline obtained estimates of effects and the effects generated through 1,000 alternative iterations is 6.2 percentage points (2.7). 


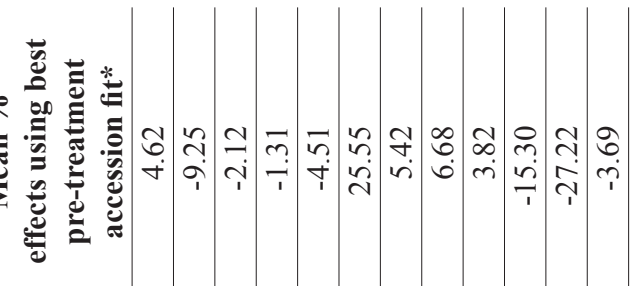

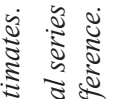

隶

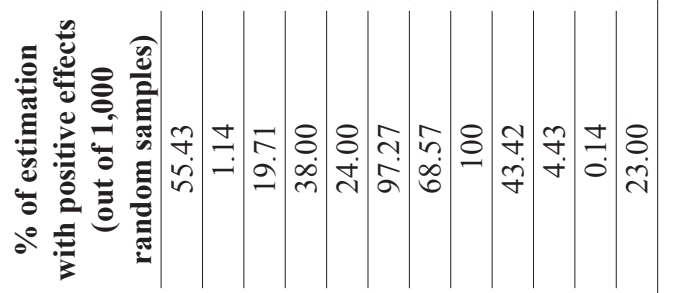

¿

₹

ह 5

去䓎

ㄴำ

就方量

รั

है

国 衤 $\frac{0}{2}$

$\stackrel{2}{5}$

हิ่

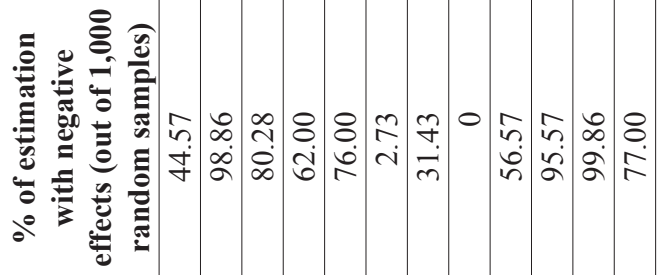

- 2 ป

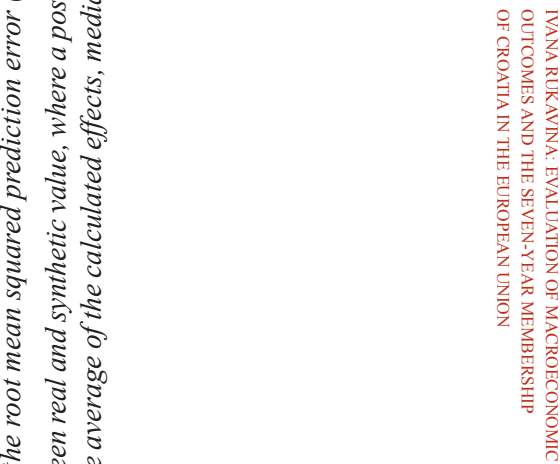

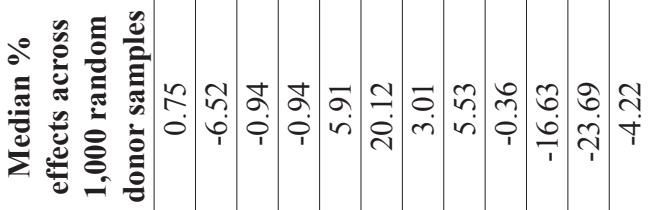

ป

है छे

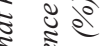

को 3

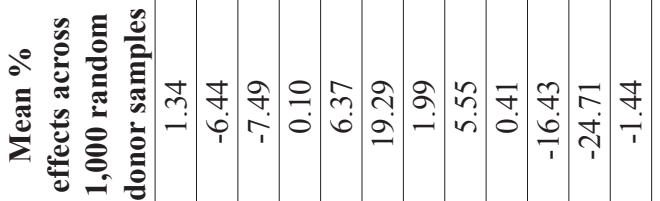

है

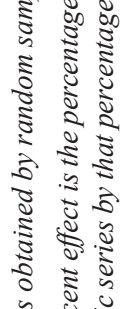

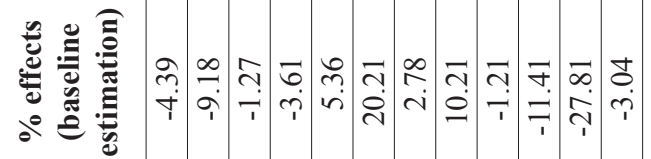

离

हु दे

ป है

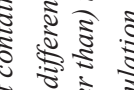

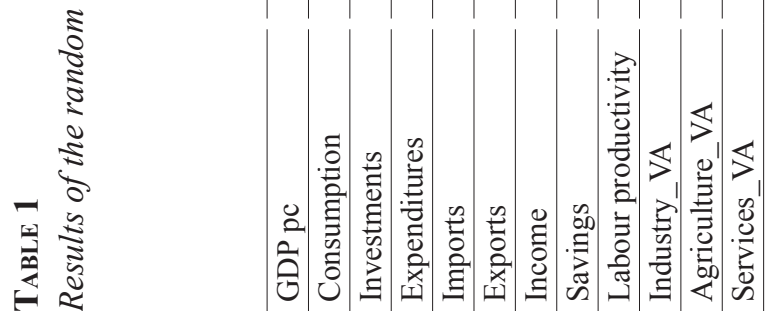

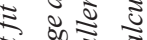

ป ฐ

范

है

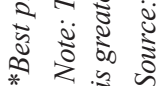


However, the best pre-treatment fit estimates support to our primary findings. While income results are within the average, savings results show high deviations of mean and median up to a level of about 5 percentage points. Furthermore, substantial deviations of outcomes are found in productivity in industry at mean (median) from approximately 5 percentage points. Labour productivity seems to tend to be positive in both assessments. As for other macroeconomic outcomes, the value added of the service sector and agriculture the results of our baseline effects do not show serious deviations as compared with the effects obtained through alternative donor samples.

\subsection{DIFFERENCE-IN-DIFFERENCES APPROACH}

Finally, robustness testing is examined by using a difference in differences (DID) approach which estimates average changes over time in the outcome variable of a treated unit relative to average changes in the same variable of an untreated unit. The linear parametric form, the method of ordinary least squares, is most often used as a method of estimating DID and associated standard errors. In relation to SCM, which provides dynamic analysis, estimation via DID is based exclusively on static inference and in this paper is used exclusively as a supplement to SCM estimates in robustness testing procedures. With the use of the DID method it is not possible to record accurately how the effect of Croatia's accession to the EU changes through time, but it can serve as a tool for additional control of the findings obtained using the synthetic control method (for more about the DID method, limitations, and methods for solving certain DID problems please see: Card and Krueger, 1994; Bertrand, Duflo and Mullainathan, 2001; Abadie, 2005).

The basic equation for this estimate is:

$$
y_{i t}=\alpha+\beta_{1} \text { treated }_{i}+\beta_{2} \text { time }_{t}+\delta\left(\text { treated }_{i}^{*} \text { time }_{t}\right)+\theta Z_{i t}+\varepsilon_{i t}
$$

Where $y_{i t}$ represents a variable of interest, treated $_{i}$ is a dummy variable that identifies the treated country (Croatia), time ${ }_{t}$ is a dummy variable that identifies the treated period (2013-2019), treated $_{i}^{*}$ time $_{t}$ is an interactive DID variable that aims to capture the effect of treatment, $Z_{i t}$ are the covariates explained in section 2 and specified for each variable can be found in table A2 in the appendix.

The robustness control by the DID method mainly confirmed our primary conclusions regarding the application of SCM with calculate average changes. However, attention should be paid to the negative coefficient for exports, which showed a positive time effect in the dynamic analysis for SCM. The observed discrepancy in export results can be partly explained by the average changes in the value of exports which are taken into account when estimating using the DID method. Also, the DID estimate takes in all sample countries regardless of missing data, which can lead to certain methodological discrepancies. The average changes (increase) in exports in some countries in the sample may thus reflect a larger increase in exports compared to Croatian exports as well as trend differences, which is ultimately reflected in the obtained results. The appearance of a negative coefficient in exports could primarily be caused by methodological problems that can be found in the application of the 
DID methodology. Due to the sensitiveness of the application of the DID method, for additional security, an additional SCM assessment of exports (on logarithmic values) was made, which confirmed the stronger robustness of export performance throughout the entire period. The results are in figure A1 in the appendix.

TABLe 2

Results of difference in differences estimation

GDP product and aggregate demand components

\begin{tabular}{|c|c|c|c|c|c|c|}
\hline & GDP pc & Consumption & Investment & Expenditures & Import & Export \\
\hline DID & $\begin{array}{l}-0.42 * * * \\
(0.13)\end{array}$ & $\begin{array}{l}-0.52 * * * \\
(0.14)\end{array}$ & $\begin{array}{l}-0.48 * * * \\
(0.12)\end{array}$ & $\begin{array}{l}-0.38 * * * \\
(0.14)\end{array}$ & $\begin{array}{l}0.39 * * * \\
(0.14)\end{array}$ & $\begin{array}{l}-0.32 * \\
(0.16)\end{array}$ \\
\hline _cons & $\begin{array}{l}4.15^{* * * *} \\
(0.13)\end{array}$ & $\begin{array}{l}6.84^{* * *} \\
(0.15)\end{array}$ & $\begin{array}{l}5.56^{* * *} \\
(0.18)\end{array}$ & $\begin{array}{l}5.37 * * * \\
(0.18)\end{array}$ & $\begin{array}{l}4.37 * * * \\
(0.27)\end{array}$ & $\begin{array}{l}4.70^{* * *} \\
(0.26)\end{array}$ \\
\hline R2 & 0.48 & 0.47 & 0.43 & 0.43 & 0.57 & 0.59 \\
\hline
\end{tabular}

Income and savings

\begin{tabular}{|c|c|c|}
\hline & Income & Savings \\
\hline DID & $\begin{array}{l}0.26^{* * * *} \\
(0.12)\end{array}$ & $\begin{array}{l}6.48^{* * * *} \\
(0.96)\end{array}$ \\
\hline _cons & $\begin{array}{l}10.98^{* * *} \\
(0.28)\end{array}$ & $\begin{array}{l}38.9 * * * \\
(2.17)\end{array}$ \\
\hline R2 & 0.17 & 0.28 \\
\hline
\end{tabular}

Labour productivity, industry, agriculture and services value added

\begin{tabular}{|c|c|c|c|c|}
\hline & Productivity & Industry VA & Agriculture VA & Services VA \\
\hline DID & $\begin{array}{r}-0.07 \\
(0.06)\end{array}$ & $\begin{array}{l}-0.03 \\
(0.13)\end{array}$ & $\begin{array}{l}-0.19 * * * \\
(0.06)\end{array}$ & $\begin{array}{l}-0.24 * * * \\
(0.07)\end{array}$ \\
\hline _cons & $\begin{array}{l}10.67^{* * * *} \\
(0.08)\end{array}$ & $\begin{array}{l}7.15^{* * *} \\
(0.22)\end{array}$ & $\begin{array}{l}6.44 * * * \\
(0.11)\end{array}$ & $\begin{array}{l}2.29 * * * \\
(0.15)\end{array}$ \\
\hline $\mathrm{R} 2$ & 0.14 & 0.05 & 0.35 & 0.80 \\
\hline
\end{tabular}

Note: All variables are expressed in original per capita terms and then expressed in logarithmic value, exception was made for savings which is expressed in percentage of GDP. The estimate is based on a total sample of 29 countries.

*** represents significance at $1 \%$, * represents significance at $10 \%$. In parentheses are robust standard errors.

Source: Author.

\section{DISCUSSION}

Although the results are largely inconsistent with theoretical predictions, they point to important implications for structural internal weaknesses, and although this is a very complex correlation structure, it seems appropriate to replicate some summaries of previous research that may partially provide adequate complementarity to poor (good) macroeconomic results.

The crisis that Croatia faced in 2009, lasting until 2014, can be linked to the obtained results. The results of SCM and placebo studies showed crisis effects that 
left Croatia with stronger negative imbalances that were not automatically resolved by the accession to the EU but were stopped. In the overall crisis situation, the moment of EU accession has had a significant role. As the results have shown, although with a lag, that EU accession has led to a reduction in the differences between real and synthetic macroeconomic indicators, the Croatian macroeconomic reversal to an upward trend, and new development perspectives have certainly been provided. However, the results of the static DID analysis indicate that the upward trends of macroeconomic variables started after 2013 have not yet generated significant positive effects, more precisely, mostly negative average effects are recorded. The exceptions are the positive effects on income and savings.

Although our baseline results for GDP pc did not prove significant, in the context of the overall outcome they are analysed. The results of GDP pc are directly comparable with the results from Mirguseinova (2018) which show an identical outcome in Croatian GDP pc obtained by the same methodological procedures on different sets of donor countries. These results single out Croatia as the only country in the CEE group with a negative effect. However, it should also be noted that robustness control using alternative donor samples found that our primary results were underestimated to some extent and that the average GDP pc outcome in the alternative estimate was positive. Also, we should keep in mind the results of the baseline estimation when the lines of real and synthetic Croatia are reduced to the same reference point $(2013=100)$ that Croatian GDP pc shows a positive step after 2016 and in the coming years it is above the synthetic line. Given this, one should be careful in making conclusions about positive or negative GDP pc outcomes. Research by Campos, Coricelli and Moretti (2019) using the same methodology, which included EU members (1973-2004), indicated significant heterogeneity among countries in terms of GDP pc growth performance with Greece highlighted as the only country which recorded a negative effect. The reasons that led to the positive effects on growth were found by the authors in the actual implementation of pre-accession agreements which provided incentives for economic growth. Although this paper did not directly address this type of analysis, the in-time placebo study (figure 11.1) shows that with the opening of accession negotiations in 2005 , Croatia initially diverged from the synthetic unit and opened a deeper negative gap over the years, culminating with the crisis of 2009. However, the divergence that started in 2005 and the divergence in 2013 are separated into two completely opposite phases of the economic cycle. In both cases, the GDP gap was at high levels (see Jovičić, 2017), signalling certain economic imbalances. Therefore, it seems justified to place an even greater emphasis on the complete lack of exploitation of positive (pre-accession and accession) time advantages in solving structural problems and the risks that arise from it.

Despite a slight growth in household consumption, SCM results suggest a decline after EU accession. The baseline results indicate a strong deviation of the two lines in the run-up to EU accession, which speaks to the methodological challenges in projecting real consumption. Furthermore, when the data are reduced to the same 
reference point $(2013=100)$, Croatian consumption indicates micro separation only in 2019. Other robustness tests (DID and donor resampling) add arguments to the baseline findings. Finally, the in-space placebo study indicates a retention of the Croatian consumption line at the lower edge, where it should either fit into the pool in case of insignificant results or stand out on the upper line in case of a positive and significant outcome. It is also worth noting here that Croatian consumption still indicates a certain upward trend after 2014, but the maximum recorded level of 2008 was exceeded only in 2019. The reasons why a significant increase in personal consumption did not occur after 2013 are primarily reflections of the consequences of the protracted financial crisis of 2009, followed by low purchasing power of the population and the postponement of structural economic shortcomings. We can mention the rigidity of the labour market where some interventions which have led to certain improvements in employment policies have occurred (Tomić, 2019), but the issue of efficiency remains unresolved (Zoretić, 2018). Also, some legislative and structural changes have been made with the aim of releasing a portion of income, such as an amendment to the 2015 Income Tax Act, a package of tax reforms started in 2017 and an administrative salary increase started in 2019, the effects of which have yet to be seen. However, it is to be hoped that the potential income effects will be positively correlated with productivity (Orsini and Perić, 2021). Certain conclusions with accumulated savings can also be drawn here. However, it should be borne in mind that about $80 \%$ of the population own only $3.5 \%$ of the savings (Jermić and Vrbanc, 2020), which entails other economic implications related to savings issues.

The results of government expenditures significantly indicate its decline after 2013, which can be directly correlated with the successfully implemented fiscal consolidation from 2014, which created the fiscal space. However, the obligation to meet the Maastricht criteria, different budgetary rules, and the adoption of the recommendations of the European Semester should also be mentioned. Although the results of robustness are not maintained after 2017, it is enough to mention that the budget surplus was realized that year, which created the preconditions for the implementation of the comprehensive tax reform. In this context, the current COVID-19 crisis should be mentioned, but also two strong earthquakes in 2020 that require significant financial amounts for their recovery, which again bring high rates of public debt and deficit, with the difference that this time Croatia is struggling on a background of healthier fiscal fundamentals. However, despite these positive outcomes in government spending, it should be mentioned that robustness control showed that they were slightly overestimated, i.e., the average effect in the donor resampling assessment was a bit lower than in our baseline estimation.

The results related to exports indicate its increase, which is in line with the theoretical assumptions of approaching economic integration. After 2013, not only was an increase in exports recorded, but also an accelerated growth or jump, which indicates successful market integration. Similar considerations can be found in Valdec and Zrnc (2014) who point to higher sales growth of export 
companies leading to faster company growth, which is supplemented by Šelebaj (2020) who concludes from the evaluation of the EU's impact on manufacturing exports that there is an increase in the share of small and medium-sized export companies, a concentration of exports, and the emergence of new export companies that have accelerated the recovery of manufacturing productivity as well as the presence of a more prominent gap between the productivity of export and non-export companies. Also, these understandings are confirmed by Orsini and Perić (2021) who point to new opportunities for Croatian companies, the acquisition of new market shares and the expansion of new export products. However, when it comes to trade and exports, one should also consider the so-called Rotterdam effect (Rotterdam-Antwerpen effect), which to some extent affects Croatian export performance. It is about quasi-transit transactions and inflating trade in a way that involves only the flow of goods through Croatia thereby increasing the value of trade flows. Thus, Ranilović (2017) warns that after 2013 there was a significant increase in the volume of trade transactions, including transactions related to the transport of goods across the Croatian borders. Nevertheless, according to overall analysis, the potential substitution of the generator of economic growth is noticeable in the movement of exports, i.e., the orientation towards the export sector, which provides additional stability for economic growth.

Agricultural productivity is reflected through significant losses after the gaining of access to market integration. It is important to point out that even before 2013, agriculture revealed certain structural problems, to which attention had previously been drawn. Thus, Mihaljek (2003: 36-37) states that agricultural products are considered uncompetitive on the EU market; since the level of agricultural protection has been very high in the past, it is estimated that agriculture will be most sensitive to trade liberalization. Tomić (2013), analysing the problems in agriculture, states numerous Croatian agricultural potentials and economic implications. Boulanger et al. (2013), based on simulation models, predicted an increase in the production volume of most agricultural products and a decrease in most food products, indicating shortcomings in competitiveness. Grgić, Krznar and Bratić (2019) point to the results in the increase of agricultural production compared to the pre-accession period of $2.6 \%$ and a significant decrease in the value of agricultural production by about $24 \%$ the consequence of which is a reduction of the share of Croatian agriculture in total EU agriculture of about $32 \%$. The results of this study indicate the alternation of agriculture and remaining at significantly lower levels, implying that in addition to structural deficiencies, the agricultural sector suffers from a resource equipment lack and technological representation that could lead to some progress and competitiveness. Combined with the continued emigration of the younger population, the complex procedures for implementing the Aliens Act (NN, 133/20) make it difficult for the agricultural sector to provide a vision of future growth potential. 
This paper evaluates Croatia's seven-year membership in the EU on macroeconomic data for GDP pc, components of aggregate demand, income, and savings as well as labour productivity, productivity in industry, agriculture, and the service sector. Using counterfactual analysis and the synthetic control method, the possibility of direct evaluation and the answer to the question "what outcomes would have occurred if Croatia had not joined the EU in 2013" was given. To obtain such an evaluation, it is necessary to use macroeconomic data from non-EU countries, which in a process of weighting, gives us a copy of the case study of Croatia's non-accession to the EU. Although this method initially obtained certain conclusions mainly oriented towards the reduction of macroeconomic variables, additional robustness control filtered certain benefits, i.e., the costs of association. The results indicate that the greatest achievement occurred in exports, which recorded successful integration with high growth rates and a tendency for further growth, which suggests a potential departure from traditional consumer-oriented economic growth. Furthermore, government expenditures recorded a significantly lower level, which also corresponds to the successful fiscal consolidation of 2014. Imports are still trying to break through, and although the evaluation is not significant until 2018, it should be noted that there are slight traces of robust estimates for 2019 where imports also show a significant increase. Additionally, savings also proved to be significantly higher after 2013, which suggests an increase in existing domestic capacity, but also implies additional problems related to trust and uncertainty. In the end, household consumption proved unrecovered and was hit harder by the 2009 crisis as it remained outside the transition framework and indications of transition to positive and stable rising growth rates. The productivity of the agriculture sector recorded the largest robust decline. The agriculture sector from 1995-2019 points to the significant structural shortcomings that culminated in the onset of the 2009 crisis. Mere accession to the EU and access to finance for the recovery of agriculture have not had any positive effect in increasing added value. The results suggest that there are certain internal problems that require urgent management.

Other macroeconomic indicators upon which accession has not made any visible or significant impact should also be mentioned. The analysis of the impact of accession on investments showed that they enjoyed recovery and positive growth. However, the growth did not record any very strong shifts that would lead to the possibility of a significant assessment, at least not within this period. Although there are indications that investments could make significant progress in the long run, for such a step it would first be desirable to return investments to pre-crisis levels, on a stable macroeconomic basis. Income proved to be rising with an indication of a further upward trend. Certainly, the methodological impossibility of projecting the actual line of movement proved to be a limitation in income modelling, but there are strong indications that income in longer time series may show significant positive steps. In our analyses, labour productivity shows a negative path after integration. However, due to the existence of a positive outcome in 
donor resampling, this results is subject to further empirical validation with a longer time series of data. Industry and services productivity were exposed to a strong idiosyncratic shock from 2009 that showed a negative outcome in these two variables. Although there are indications that there is a slight growth of the observed series, it should be noted that industrial productivity has not yet recovered, given that it has not yet reached the level of 2009, while the productivity of the service sector is very slowly separating from the synthetic by an upward trend, but with slower dynamics than is expected.

The limitation of synthetic control method analysis is that it cannot directly test the relative importance of a particular factor or transmission mechanism, identify specific causes or provide insight into the real reasons for poor macroeconomic outcomes, but it can provide insights into the existence of shortcomings and conduct a comparative analysis through time movements and the dynamics of changes over time that can track specific shifts and evaluate desired outcomes. Given the overall results and the time of accession when Croatia was in a deep crisis, the short post-EU period can be cited as a limiting factor in the research. Continuing the previous claim, the idiosyncratic crisis shock that hit the Croatian economy in 2009 led to an incomplete possibility of projecting certain macroeconomic series in the year of accession, which in some indicators created larger deviations compared to the synthetic line, which consequently hindered proper comparison. Finally, the lack of a comparative analysis of the results achieved with those of other EU countries that could help to better position the results obtained can also be singled out.

Hence, future research would do well to focus on a comparative study of these results with CEE countries to dispel doubts that a particular outcome is the result of domestic policy, for example in declining agricultural productivity, and to make an appropriate comparison of Croatia's performance with that of EU countries. Also, in order to re-evaluate the outcomes in view of the observed upward trend of macroeconomic indicators, it would be useful to repeat the analysis in a longer period. It is also advisable to investigate the causes that have led to the increased volume of savings that can provide growth potentials; however, it can also generate deeper negative risks that need to be detected. Furthermore, it would be recommendable to try to investigate the direct causes of poor macroeconomic outcomes in productivity, and in particular the reasons for lagging agricultural productivity. As this research did not provide insights into the depths of individual indicators, it would be useful to conduct an additional evaluation that would include a purposeful examination of all the essential factors of each indicator.

\section{Disclosure statement}

The author declares that there is no conflict of interest. 
1. Abadie, A. and Gardeazabal, J., 2003. The Economic Costs of Conflict: A Case Study of the Basque Country. American Economic Review, 93(1), pp. 113-132. https://doi.org/10.1257/000282803321455188

2. Abadie, A., 2005. Semiparametric Difference-in-Differences Estimators. Review of Economic Studies, 72(1), pp. 1-19. https://doi.org/10.1111/0034-6527.00321

3. Abadie, A., Diamond, A. and Hainmueller, J., 2010. Synthetic Control Methods for Comparative Case Studies: Estimating the Effect of California's Tobacco Control Program. Journal of the American Statistical Association, 105(490), pp. 493-505. https://doi.org/10.1198/jasa.2009.ap08746

4. Abadie, A., Diamond, A. and Hainmueller, J., 2015. Comparative Politics and the Synthetic Control Method. American Journal of Political Science, 59(2), pp. 495-510. https://doi.org/10.1111/ajps.12116

5. Albulescu, C. and Goyeau, D., 2013. EU Funds absorption rate and the economic growth. Timisoara Journal of Economics and business, 6(20), pp. 153-170.

6. Alexe, I., 2012. How does economic crisis change the landscape of real convergence for Central and Eastern Europe? Romanian Journal of Fiscal Policy, 3(1), pp. 1-8.

7. Alhmeida, R. and Fernandes, A. M., 2008. Openness and technological innovations in developing countries: Evidence from firm-level surveys. Journal of Development Studies, 44(5), pp. 701-27. https://doi.org/10.1080/00220380802009217

8. Bertola, G., 2010. Inequality, integration, and policy: issues and evidence from EMU. Journal of Economic Inequality, 8(3), pp. 345-65. https://doi.org/ 10.1007/s10888-009-9126-3

9. Bertrand, M., Duflo, E. and Mullainathan, S., 2001. How much should we trust difference-in-differences estimates. MIT Working paper, No. 01-34.

10. Bornschier, V., Herkenrath, M. and Ziltener, P., 2004. Political and economic logic of Western European integration: A study of convergence comparing member and non-member states, 1980-98. European Societies, 6(1), pp. 71-96. https://doi.org/10.1080/1461669032000176323

11. Borsi, M. T. and Metiu, N., 2013. The evolution of economic convergence in the European Union. Deutsche Bindesbank, Discussion paper, No 28-2013. https://doi.org/10.2139/ssrn.2796921

12. Boulanger, P. [et al.], 2013. Analysis of the impact of Croatia's accession to the EU on the agri-food sectors. Luxembourg: Publications Office of the European Union. http://dx.doi.org/10.2791/79648

13. Bravo-Otega, C. and Lederman, D., 2004. Agricultural Productivity and Its Determinants: Revisiting International Experiences. Estudios de Economía 31(2), pp. 133-163.

14. Busemayer, M. R. and Tober, T., 2015. European integration and the political economy of inequality. European Union Politics, 16(4), pp. 536-557. https:// doi.org/10.1177/1465116515591832

15. Butorac, G., 2019. Gospodarski rast, konvergencija i članstvo u EU: empirijski dokazi iz Hrvatske. Ekonomski pregled, 70(2), pp. 173-208. https://doi. org/10.32910/ep.70.2.2 
16. Campos, N. F. and Coricelli, F., 2012. Financial liberalization and reversals: political and economic determinants. Economic Policy, 27(71), pp. 483-513. https://doi.org/10.1111/j.1468-0327.2012.00288.x

17. Campos, N. F., Coricelli, F. and Moretti, L., 2019. Institutional integration and economic growth in Europe. Journal of Monetary Economics, 103, pp. 88-104. https://doi.org/10.1016/j.jmoneco.2018.08.001

18. Card, D. and Krueger, A. B., 1994. Minimum wages and employment: A case study of the fast-food Industry in New Jersey and Pennsylvania. The American Economic Review, 84(4), pp. 772-93. https://doi.org/10.3386/w4509

19. Crespo, J., Ritzberger-Grünwald, D. and Silgoner, M. A., 2008. Growth, convergence and EU membership. Applied Economics, 40(5), pp. 463-456. https://doi.org/10.1080/00036840600749524

20. Deskar-Škrbić, M., 2019. Ekonomski i fiskalni učinci pridruživanja Hrvatske Europskoj uniji. Političke analize, 9(35), pp. 3-13.

21. Ederveen, S., de Groot, H. L. F. and Nahuis, R., 2006. Fertile soil for Structural Funds? A panel data analysis of the conditional effectiveness of European cohesion policy. Tinbergen Institute Discussion Paper, No. 2002-096-3. https://doi.org/10.2139/ssrn.338060

22. Ehigiamusoe, K. and Lean, H. H., 2019. Do economic and financial integration stimulate economic growth? A critical survey. Kiel, 13(4), pp. 1-27. https://doi.org/10.5018/economics-ejournal.ja.2019-4

23. Eun Kim, Y. and Loayza, N. V., 2019. Productivity growth: patterns and determinants across the World. World Bank Group. Policy Research Working Paper, No. 8852.

24. Furceri, D. and Ostry, J. D., 2019. Robust determinants of income inequality. Oxford Review of Economic Policy, 35(3), pp. 490-517.

25. Glodowska, A. and Pera, B., 2019. On the relationship between economic integration, business environment and real convergence: The experience of the CEE countries.Economies, 7(2),pp. 1-19. https://doi.org/10.3390/economies7020054

26. Grgić, I., Krznar, S. and Bratić, V., 2019. Poljoprivredna proizvodnja Republike Hrvatske prije i nakon pristupanja EU. 47 ${ }^{\text {th }}$ Symposium "Actual tasks on agricultural engineering" Opatija, Croatia.

27. Gyoerk, E., 2017. Economic Costs and Benefits of EMU Membership from the Perspective of a Non-member. Open Economies Review, 25(5), pp. 893921. https://doi.org/10.1007/s11079-017-9466-8

28. Henreksen, M., Torstensson, J. and Torstensson, R., 1997. Growth Effects of European Integration. European Economic Review, 41(8), pp. 1537-1557. https://doi.org/10.1016/S0014-2921(97)00063-9

29. Ilkovitz, F. [et al.], 2007. Steps towards a deeper economic integration: the internal market in the $21^{\text {st }}$ century a contribution to the single market review. European Commission, Economic Papers, No. 271.

30. Incaltarau, C., Pascariu, G. C. and Surubaru, N. C., 2019. Evaluating the determinants of EU Funds absorption across old and new member states - the role of administrative capacity and political governance. Journal of Common Market Studies, 58(4), pp. 941-961. https://doi.org/10.1111/jcms.12995 
31. Jemrić, I. and Vrbanc, I., 2020. Anketa o financijama i potrošnji kućanstava provedena u Republici Hrvatskoj 2017. HNB Statistička i metodološka istraživanja, M-1.

32. Jovičić, G., 2017. Procjena potencijalnog rasta i jaza BDP-a u Hrvatskoj. HNB Pregledi, P-38.

33. Kakar, M., Kiani, A. and Baig, A., 2016. Determinants of Agricultural Productivity: Empirical Evidence from Pakistan's Economy. Global Economic Review, 1(1), pp. 1-12. https://doi.org/10.31703/ger.2016(I-I).01

34. Klein, M. W. and Olivei, G. P., 2008. Capital account liberalization, financial depth, and economic growth. Journal of International Money and Finance, 27(6), pp. 861-875. https://doi.org/10.1016/j.jimonfin.2008.05.002

35. König, J., 2015. European integration and the effects of country size on growth. Journal of Economic Integration, 30(3), pp. 501-531. https://doi.org/ 10.11130/jei.2015.30.3.501

36. Mankiw, N. G., Romer, D. and Weil, D. N., 1992. A contribution to the empirics of economic growth. Quarterly Journal of Economics, 2(2), pp. 407-437. https://doi.org/10.2307/2118477

37. Marinov, E., 2014. Economic integration theories and the developing countries. In: R. Dutov [et al.], eds. Proceedings of the 9th Annual South-East European Doctoral Student Conference, pp. 164-177.

38. Maroof, Z. [et al.], 2019. Determinants of industrial development: a panel analysis of South Asian economies. Quality and Quantity, 53(3), pp. 13911419. https://doi.org/10.1007/s11135-018-0820-8

39. Mihaljek, D., 2003. Macroeconomic aspects of Croatia's accession to the European Union. In: K. Ott, ed. Croatian accession to the European Union: Economic and legal challenges. Zagreb: Institute of Public Finance and Friedrich Ebert Stiftung, Zagreb, Croatia, pp. 25-65.

40. Mikulić, D., Lovrinčević, Ž. and Nagyszombaty, A. G., 2008. Regional convergence in the European Union, new member states and Croatia. South Eastern Journal of Economic and Business, 8(1), pp. 7-19. https://doi.org/10.2478/ jeb-2013-0001

41. Mirguseinova, E., 2018. Estimating The Benefits Of EU Membership For Central And Eastern European Countries Using Synthetic Control Method. Master Thesis. Wien: Central European University.

42. Nicolescu-Aron, I. and Mihaescu, C., 2012. Modelling the impact of economic, demographic and social determinants on household saving rate in the former socialist countries (Central and Eastern Europe). Procedia Economics and Finance, 10(2014), pp. 104-113. https://doi.org/10.1016/S2212-5671 (14)00283-4

43. Orsini, K. and Perić, A., 2021. Understanding the Croatian Export Boom. European Commision, European Economy Economic Briefs, No. 065.

44. Ranilović, N., 2017. Primjena gravitacijskog modela u analizi utjecaja ekonomske integracije na hrvatsku robnu razmjenu. HNB Istraživanja, I-50. 
45. Rocher, S. and Stierle, M. H., 2015. Household savings rates in the EU: Why do they differ so much. European Commission Discussion paper, No. 005.

46. Romer, P. M., 1990. Endogenous Technological Change. Journal of Political Economy, 98(5), pp. 71-102. https://doi.org/10.1086/261725

47. Sierheit, R., 2008. EU Funds in EU new member states: available resource and possible economic impact. Society and Economy, 30(2), pp. 191-193. https://doi.org/10.1556/SocEc.30.2008.2.2

48. Solow, R. M., 1956. A contribution to the theory of economic growth. Quarterly Journal of Economics, 70(1), pp. 65-94. https://doi.org/10.2307/1884513

49. Swan, T. W., 1956. Economic growth and capital accumulation. Economic Record, 32(2), pp. 334-361.https://doi.org/10.1111/j.1475-4932.1956.tb00434.x

50. Šelebaj, D., 2020. Mikroekonomski aspekti izvoza hrvatske prerađivačke industrije nakon ulaska u Europsku uniju. HNB Istraživanja, I-59.

51. Škrinjarić, T. and Čižmešija, M., 2020. Has the accession of Croatia to the EU affected business sentiment in industry? Synthetic control method approach. Društvena istraživanja, časopis za opća društvena pitanja, 29(4), pp. 643663. https://doi.org/10.5559/di.29.4.07

52. Tigănaşu, R., Încalțăău, C. and Pascariu, G. C., 2018. Administrative Capacity, Structural Funds Absorption and Development. Evidence from Central and Eastern European Countries. Romanian Journal of European Affairs, 18(1), pp. 39-59.

53. Tomić, F., 2013. Stanje i mjere unaprjeđenja Hrvatske poljoprivrede u svjetlu pristupa Europskoj uniji. Civitas Crisiensis, 1, pp. 129-142.

54. Tomić, I., 2019. Employment protection reforms and labour market outcomes in the aftermath of the recession: Evidence from Croatia. Public Sector Economies, 44(1), pp. 3-39. https://doi.org/10.3326/pse.44.1.1

55. Torstensson, R. M., 1999. Growth, knowledge transfers and European integration. Applied Economics, 31(1), pp. 97-106. https://doi.org/10.1080/000368499324598

56. Valdec, M. and Zrnc, J., 2014. The direction of causality between exports and firm performance: microeconomic evidence from Croatia using the matching approach. Financial Theory and Practice, 39(1), pp. 1-30. https://doi. org/10.3326/fintp.39.1.1

57. Van Wolleghem, P. G., 2020. Does administrative capacity matter? The absorption of the European Fund for the integration of migrants. Policy Studies, pp. 1-19. https://doi.org/10.1080/01442872.2020.1770209

58. Vanhoudt, P., 1999. Did the European unification induce economic growth? In search of scale effects and persistent changes. Weltwirtschaftliches Archiv, 135(2), pp. 193-220. https://doi.org/10.1007/BF02707252

59. Zakon o strancima, NN 133/20.

60. Zoretić, G., 2018. Određivanje kompetencija službenika u javnoj upravi pregled Republike Hrvatske i odabranih zemalja EU. FIP-Financije i pravo, 6(1), pp. 53-74. 
TABLe A1

Variables of macroeconomic indicators and its covariates

Indicators

Designations

GDP pc GDP pc

Households and NPISHs final consumption expenditure (constant 2010 US\$)

Consumption

Gross fixed capital formation (constant 2010 US\$) Investments

General government final consumption expenditure (constant 2010 US\$)

\begin{tabular}{|c|c|}
\hline Imports of goods and services (constant 2010 US\$) & Import \\
\hline Exports of goods and services (constant 2010 US\$) & Export \\
\hline $\begin{array}{l}\text { Adjusted net national income per capita } \\
\text { (constant } 2010 \text { US\$) }\end{array}$ & Income \\
\hline Gross savings $(\%$ of GDP) & Savings \\
\hline GDP per person employed (constant 2017 PPP \$) & Labour productivity \\
\hline $\begin{array}{l}\text { Industry (including construction), value added } \\
\text { (constant } 2010 \text { US\$) }\end{array}$ & Industry VA \\
\hline $\begin{array}{l}\text { Agriculture, forestry, and fishing, value added } \\
\text { (constant } 2010 \text { US\$) }\end{array}$ & Agriculture VA \\
\hline Services, value added (constant 2010 US\$) & Services VA \\
\hline \multicolumn{2}{|l|}{ Population, total } \\
\hline Covariates & Designations \\
\hline Trade $(\%$ of GDP) & Trade \\
\hline Population growth (annual \%) & Pop_gr \\
\hline Gross fixed capital formation ( $\%$ of GDP) & Inv_GDP \\
\hline School enrollment, tertiary (\% gross) & Sch_TE \\
\hline Real effective exchange rate & REER \\
\hline $\begin{array}{l}\text { Employment in agriculture (\% of total employment) } \\
\text { (modeled ILO estimate) }\end{array}$ & Empl_agri \\
\hline Agricultural land (\% of land area) & Agri_land \\
\hline $\begin{array}{l}\text { Employment in services (\% of total employment) } \\
\text { (modeled ILO estimate) }\end{array}$ & Empl_ser \\
\hline $\begin{array}{l}\text { Employment in industry (\% of total employment) } \\
\text { (modeled ILO estimate) }\end{array}$ & Empl_ind \\
\hline $\begin{array}{l}\text { Unemployment, total (\% of total labor force) } \\
\text { (national estimate) }\end{array}$ & Un_empl \\
\hline Age dependency ratio ( $\%$ of working-age population) & Dep_ratio \\
\hline
\end{tabular}

Source: World Bank, WDI (accessed 5 April 2021), Bruegel database (accessed 5 April 2021). 
TABLE A2

Pre-EU predictor characteristic for all macroeconomic indicators and its compositions of country weighs of donor units

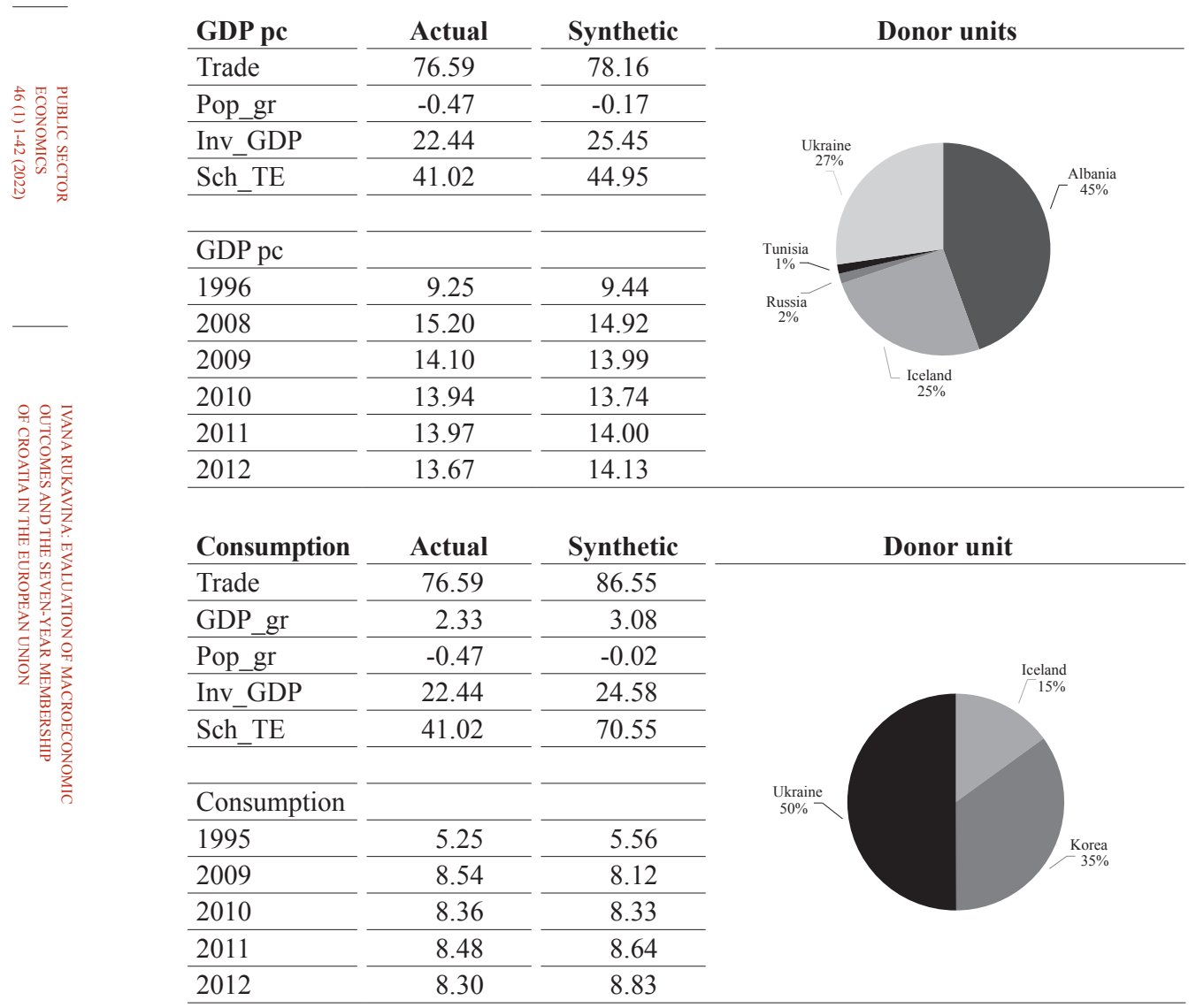

\begin{tabular}{|c|c|c|}
\hline Investments & Actual & Synthetic \\
\hline Trade & 76.59 & 82.70 \\
\hline GDP_gr & 2.33 & 2.28 \\
\hline Pop_gr & -0.47 & -0.26 \\
\hline Sch_TE & 41.02 & 65.33 \\
\hline \multicolumn{3}{|l|}{ Investments } \\
\hline 1996 & 1.51 & 1.74 \\
\hline 2000 & 1.85 & 2.26 \\
\hline 2007 & 3.71 & 3.65 \\
\hline 2008 & 4.05 & 3.63 \\
\hline 2009 & 3.47 & 2.89 \\
\hline 2011 & 2.88 & 3.03 \\
\hline 2012 & 2.80 & 3.27 \\
\hline
\end{tabular}

Donor units

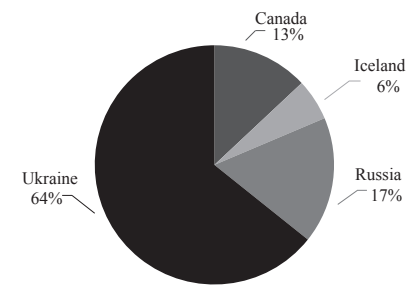




\begin{tabular}{|c|c|c|c|c|}
\hline Expenditures & Actual & Synthetic & Donor units & \\
\hline Trade & 76.59 & 70.38 & \multirow{11}{*}{$\begin{array}{l}\text { Uruguay } \\
31 \% \%\end{array}$} & \\
\hline GDP_gr & 2.33 & 3.24 & & \\
\hline Pop_gr & -0.47 & 0.30 & & \\
\hline Inv_GDP & 22.44 & 21.99 & & \\
\hline Sch_TE & 41.02 & 56.90 & & \\
\hline \multicolumn{3}{|l|}{ Expenditures } & & \\
\hline 1996 & 2.02 & 2.04 & & \\
\hline 1999 & 2.24 & 2.21 & & \\
\hline 2002 & 2.31 & 2.38 & & \\
\hline 2009 & 2.88 & 2.86 & & \\
\hline 2012 & 2.87 & 2.91 & & \\
\hline
\end{tabular}

\begin{tabular}{|c|c|c|c|c|}
\hline Import & Actual & Synthetic & Donor units & \\
\hline Trade & 76.59 & 99.95 & & \\
\hline Pop_gr & -0.47 & -0.29 & & \\
\hline Inv_GDP & 22.44 & 20.73 & & \\
\hline GDP_gr & 2.33 & 1.92 & & \\
\hline REER & 95.75 & 94.45 & & \\
\hline Sch_TE & 41.02 & 59.32 & & \\
\hline \multicolumn{5}{|l|}{ Import } \\
\hline 1995 & 2.47 & 2.93 & & \\
\hline 1996 & 2.76 & 3.21 & & \\
\hline 2004 & 5.42 & 4.88 & & \\
\hline 2008 & 6.80 & 6.06 & & \\
\hline 2009 & 5.42 & 4.82 & & \\
\hline 2011 & 5.42 & 5.79 & & \\
\hline 2012 & 5.31 & 5.99 & & \\
\hline
\end{tabular}

\begin{tabular}{|c|c|c|c|c|}
\hline Export & Actual & Synthetic & Donor units & \\
\hline Trade & 76.59 & 95.78 & \multirow{13}{*}{\multicolumn{2}{|c|}{$\begin{array}{l}\text { Hong Kong } \\
\quad 4 \% \\
\text { Russia } \\
-10 \%\end{array}$}} \\
\hline Pop_gr & -0.47 & -0.19 & & \\
\hline Inv_GDP & 22.44 & 20.92 & & \\
\hline GDP_gr & 2.33 & 2.51 & & \\
\hline REER & 95.75 & 95.7 & & \\
\hline Sch_TE & 41.02 & 60.58 & & \\
\hline \multicolumn{3}{|l|}{ Export } & & \\
\hline 1996 & 2.71 & 2.90 & & \\
\hline 1998 & 2.90 & 3.03 & & \\
\hline 2000 & 3.40 & 3.56 & & \\
\hline 2003 & 4.34 & 4.10 & & \\
\hline 2008 & 5.40 & 5.33 & & \\
\hline 2012 & 5.11 & 5.36 & & \\
\hline
\end{tabular}




\begin{tabular}{|c|c|c|}
\hline Income & Actual & Synthetic \\
\hline Trade & 76.59 & 81.41 \\
\hline GDP_gr & 2.33 & 2.39 \\
\hline Un_empl & 12.58 & 8.67 \\
\hline Dep_ratio & 48.96 & 45.48 \\
\hline \multicolumn{3}{|l|}{ Income } \\
\hline 2000 & 8.10 & 8.71 \\
\hline 2008 & 12.17 & 11.84 \\
\hline 2012 & 10.97 & 11.88 \\
\hline
\end{tabular}

Donor units

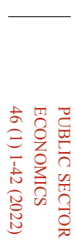

\section{Savings}

Trade

GDP_gr

Un_empl

Dep_ratio

Savings

1996

2001

2003

2005

2008

2012

\section{Labour}

productivity

Trade

GDP_gr

Inv_GDP

Pop_gr

Labour

productivity

\begin{tabular}{|c|c|c|}
\hline 1995 & 36.90 & 40.67 \\
\hline 1999 & 45.66 & 46.94 \\
\hline 2002 & 55.74 & 51.57 \\
\hline 2005 & 60.15 & 58.65 \\
\hline 2008 & 64.43 & 63.17 \\
\hline 2009 & 60.26 & 62.28 \\
\hline 2010 & 61.86 & 63.27 \\
\hline 2012 & 65.35 & 65.71 \\
\hline
\end{tabular}

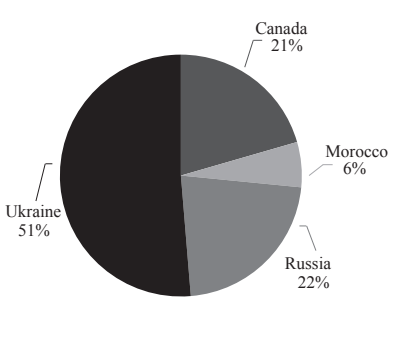

Donor units

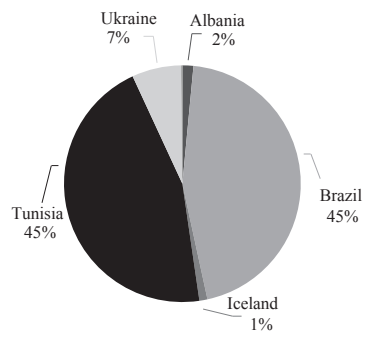

Donor units

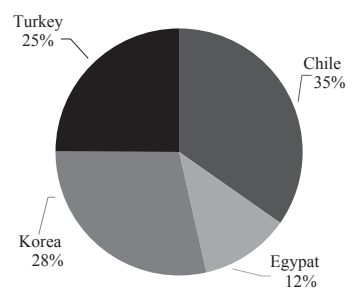


Industry

value added

Actual

Synthetic

Donor units

\begin{tabular}{|c|c|c|}
\hline Trade & 76.59 & 83.01 \\
\hline GDP_gr & 2.33 & 2.43 \\
\hline Inv_GDP & 22.44 & 20.45 \\
\hline Empl_ind & 29.25 & 25.84 \\
\hline Pop_gr & -0.47 & -0.24 \\
\hline \multicolumn{3}{|l|}{$\begin{array}{l}\text { Industry } \\
\text { value added }\end{array}$} \\
\hline 1996 & 2.12 & 2.30 \\
\hline 2008 & 3.77 & 3.55 \\
\hline 2009 & 3.37 & 3.01 \\
\hline 2012 & 2.83 & 3.25 \\
\hline
\end{tabular}

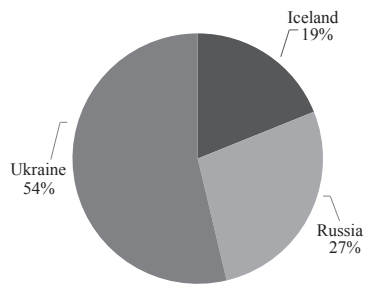

\begin{tabular}{|c|c|c|}
\hline $\begin{array}{l}\text { Agricultural } \\
\text { value added }\end{array}$ & Actual & Synthetic \\
\hline Trade & 76.59 & 47.08 \\
\hline GDP_gr & 2.33 & 2.82 \\
\hline Inv_GDP & 22.44 & 19.34 \\
\hline Empl_agri & 15.85 & 9.77 \\
\hline Agri_land & 26.22 & 49.86 \\
\hline \multicolumn{3}{|l|}{$\begin{array}{l}\text { Agricultural } \\
\text { value added }\end{array}$} \\
\hline 2008 & .57 & .56 \\
\hline 2012 & .41 & .50 \\
\hline
\end{tabular}

\begin{tabular}{|c|c|c|}
\hline $\begin{array}{l}\text { Services } \\
\text { value addded }\end{array}$ & Actual & Synthetic \\
\hline Trade & 76.59 & 84.53 \\
\hline GDP_gr & 2.33 & 2.60 \\
\hline Inv_GDP & 22.44 & 21.64 \\
\hline Empl_ser & 54.89 & 57.30 \\
\hline \multicolumn{3}{|l|}{$\begin{array}{l}\text { Services } \\
\text { value added }\end{array}$} \\
\hline 1995 & 4.90 & 4.88 \\
\hline 2000 & 5.84 & 6.06 \\
\hline 2005 & 7.56 & 7.31 \\
\hline 2009 & 8.08 & 8.05 \\
\hline 2012 & 8.27 & 8.41 \\
\hline
\end{tabular}
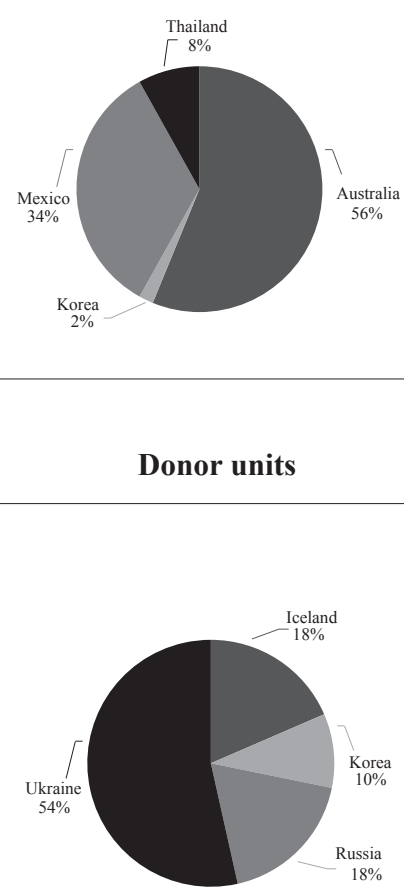

Note: All macroeconomic indicators are expressed in per capita terms (in thousands, constant 2010 US\$), exception are savings which is expressed in percentage of GDP and labour productivity which is expressed in thousands, constant 2017 PPP \$.

Source: Author. 
Ln_Export

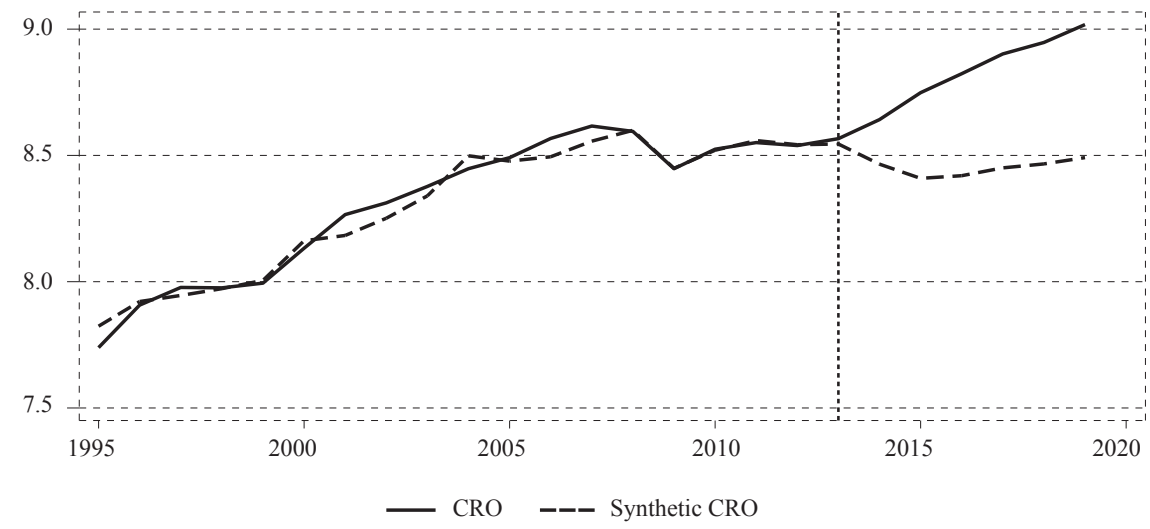

Ln_Export in-space placebo

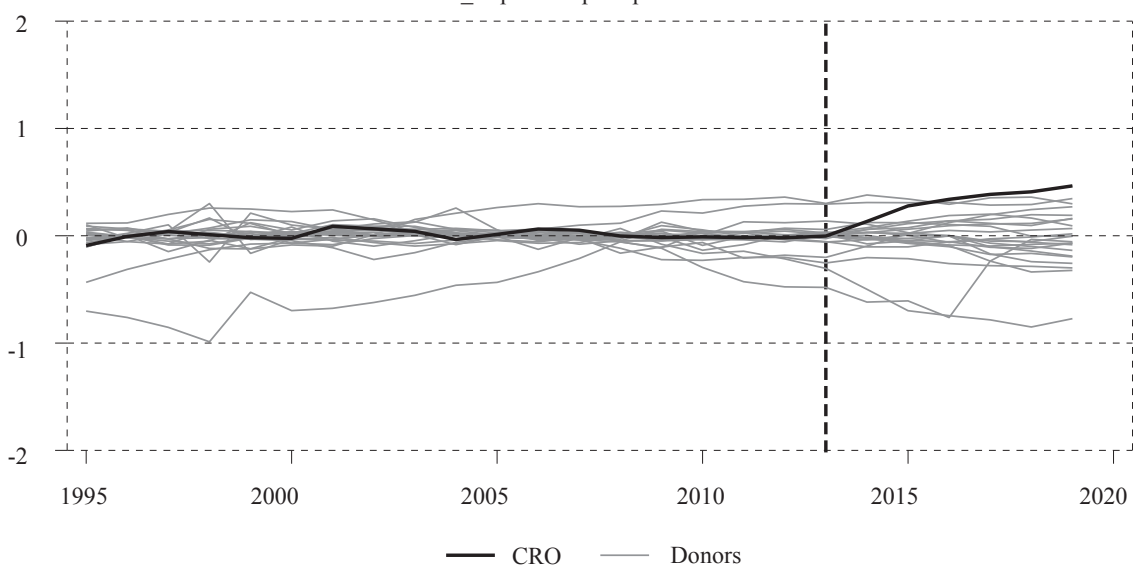

List of countries for random donor sample: Afghanistan, Albania, Algeria, Angola, Antigua and Barbuda, Argentina, Armenia, Australia, Azerbaijan, The Bahamas, Bahrain, Bangladesh, Barbados, Belarus, Belize, Benin, Bermuda, Bhutan, Bolivia, Bosnia and Herzegovina, Botswana, Brazil, Brunei Darussalam, Burkina Faso, Burundi, Cabo Verde, Cambodia, Cameroon, Canada, Central African Republic, Chad, Chile, China, Colombia, Comoros, Congo Dem. Rep., Congo Rep., Costa Rica, Cote d'Ivoire, Cuba, Djibouti, Dominica, Dominican Republic, Ecuador, Egypt Arab Rep., El Salvador, Equatorial Guinea, Eritrea, Ethiopia, Fiji, Gabon, The Gambia, Georgia, Ghana, Grenada, Guatemala, Guinea, Guinea-Bissau, Guyana, Haiti, Honduras, Hong Kong SAR China, Iceland, India, Indonesia, Iran Islamic Rep., Iraq, Israel, Jamaica, Japan, Jordan, Kazakhstan, Kenya, Kiribati, Korea Rep., Kuwait, Kyrgyz Republic, Lao PDR, Lebanon, Lesotho, Liberia, Libya, Macao SAR China, Madagascar, Malawi, Malaysia, Maldives, Mali, Marshall Islands, Mauritania, Mauritius, Mexico, Micronesia Fed. Sts., Moldova, Mongolia, Montenegro, Morocco, Mozambique, Namibia, Nepal, New Zealand, Nicaragua, Niger, Nigeria, North Macedonia, Norway, Oman, Pakistan, Palau, Panama, Papua New Guinea, Paraguay, Peru, Philippines, Puerto Rico, Qatar, Russian Federation, Rwanda, Samoa, Sao Tome and Principe, Saudi Arabia, Senegal, Serbia, Seychelles, Sierra Leone, Singapore, Solomon Islands, Somalia, South Africa, Sri Lanka, St. Kitts and Nevis, St. Lucia, St. Vincent and the Grenadines, Sudan, Suriname, Switzerland, Syrian Arab Republic, Tajikistan, Tanzania, Thailand, Timor-Leste, Togo, Tonga, Trinidad and Tobago, Tunisia, Turkey, Turkmenistan, Uganda, Ukraine, United Arab Emirates, United States, Uruguay, Uzbekistan, Vanuatu, Venezuela RB, Vietnam, Yemen Rep., Zambia, Zimbabwe. (Accessed 1.10.2021).

Source: Author. 


\section{The effectiveness of the fiscal policy response to COVID-19 through the lens of short and long run labor market effects of COVID-19 measures}

PATRIK BARIŠIĆ, mag. oec." TIBOR KOVAČ, mag. oec."

Article**

JEL: E62, E32, E27, O40

https://doi.org/10.3326/pse.46.1.2

\footnotetext{
* The views presented in this paper are the authors' own and do not necessarily reflect the official position of the Croatian National Bank nor the Institute of Economics, Zagreb. We want to express gratitude towards our university professor doc. dr. sc. Ozana Nadoveza Jelić. Her insights have been invaluable in the creation of this research paper. Also, we would like to thank two anonymous reviewers for their thoughtful comments and efforts, which have improved our paper.

The article won the award for the best student category paper in the annual 2021 Prof. Dr. Marijan Hanžeković Trust Competition.

${ }^{* *}$ Received: June 1, 2021

Accepted: November 4, 2021

\section{Patrik BARIŠIĆ}

Croatian National Bank, Trg hrvatskih velikana 3, 10000 Zagreb, Croatia

e-mail: patrikbarisic97@gmail.com

ORCiD: 0000-0002-0199-4102

Tibor KOVAČ

The Institute of Economics, Zagreb, Trg J.F. Kennedy 7, 10000 Zagreb, Croatia

e-mail: tibor.kova97@gmail.com

ORCiD: 0000-0003-2941-6934
} 
Abstract

Lack of information on the adequacy of fiscal measures undertaken in the COVID19 crisis and its long-term adverse effects on economic growth and labor market outcomes has raised debates about the impact of fiscal austerity and fears of slower recovery from the ongoing economic downturn. This paper analyzes the short and long-term effects of the fiscal policy measures undertaken in the COVID19 crisis in the EU-27. For the short-term estimation, we use Okun's law. To examine the long-run effects, we use the concept of potential output using a production function approach. The findings from this paper are that in the short-term, fiscal measures were generally effective. In the long-term, the COVID-19 crisis would have had a negative and permanent effect on the potential GDP growth if the policymakers had undertaken no fiscal measures.

Keywords: COVID-19, fiscal response, unemployment, Okun's law, potential output

\section{INTRODUCTION}

The coronavirus disease 2019 (COVID-19), which appeared in most countries at the beginning of 2020, was soon declared by World Health Organization (WHO) a Public Health Emergency of International Concern or a Pandemic. Up to date, over 159 million people have been infected by the disease, and over 3 million have lost their lives. ${ }^{1}$ The COVID-19 pandemic has caused a vast health crisis and triggered an unprecedented economic crisis around the world. As COVID-19 poses a significant threat to human lives, policymakers implemented lockdowns and other measures, such as social distancing, to prevent and contain the spread of the disease. By implementing these measures, policymakers saved many lives (Yoo and Managi, 2020). As these measures involved multiple restrictions on flows of people, goods, and services, many businesses were shut down, producing a significant economic crisis called the COVID-19 crisis.

Each country has been affected differently by the pandemic and accordingly responded differently (Brauner et al., 2021). As responses varied across countries, this also caused different impacts on economies and their growth prospects. The global financial crisis was characterized as an event that had prolonged effects on the economy, affecting firms, investors, workers, and consumers, because policymakers had not given enough or adequate policy support to their economies (Ball, 2014; Rawdanowicz et al., 2014; Reifschneider, Wascher and Wilcox, 2015; Cerra and Saxena, 2017). This raised the question about adequate policy support in the ongoing COVID-19 crisis since literature offers plenty of evidence that fluctuations of GDP can be persistent, which means that any shock that occurs in the economy can have scarring effects for years after the initial shock has taken place. Thus, these cyclical fluctuations of GDP affect the trends, a relationship known as hysteresis and it is important that policymakers counteract low aggregate demand and bring the economy back to its full working capacity.

${ }^{1}$ As of May 12, 2021 (WHO, 2021). 
In order to assess the economic damage that the COVID-19 crisis has done, this paper aims to analyze the short-run effectiveness of the fiscal policy support in the first two quarters of 2020 and possible long-run impacts on the potential GDP through the lens of estimated labor market effects. Our analysis is based on the sample of all European Union (EU) countries, with the exclusion of Luxembourg since it is an outlier, which will be further explained in the paper.

The paper is organized as follows. After the introduction, the second chapter provides a literature overview and empirical evidence of how COVID-19 has affected output in the short term and how it can affect it in the long term. This chapter focuses on the hysteresis effect, where crises such as the ongoing COVID-19 crisis cause deviations of GDP from its natural level in the short term and possibly leave scars in the long term. The chapter also emphasizes the importance of implementing stabilization policies to reduce deviations of GDP from its natural level. Those fluctuations tend to be persistent and can have adverse effects on the economy that remain present for years after the shock. The third chapter briefly describes Okun's law, a methodology used to assess the short-term effects and the potential effects of fiscal measures in the long run, using potential output that is estimated using the production function method. The results of this paper are presented in the fourth chapter. Results indicate that selected European countries' fiscal policy measures taken in the COVID-19 crisis were generally effective in the short run. However, the long-term effects of the COVID-19 crisis would have had an adverse and permanent effect on the potential GDP growth if the policymakers had undertaken no fiscal measures. The last chapter summarizes the main findings and concludes with implications for economic policies.

\section{LITERATURE REVIEW}

There is not much evidence in the literature on how pandemic-type crises such as that of COVID-19 can affect short-term and long-term output dynamics. However, several theoretical frameworks have been created during the past year to assess the potential impact of the COVID-19 crisis on both short-term and longterm output (Fornaro and Wolf, 2020; Bodnár et al., 2020). Furthermore, research into past crises, such as the global financial crisis, and other studies which examine impacts of different epidemiological (Barro, Urs'ua and Weng, 2020; Jord'a, Singh and Taylor, 2020) and environmental factors (Bloom et al., 1998; Barrios, Strobl and Bertinelli, 2010) can be good indicators of how the COVID-19 crisis can affect economic activity (Gonzales-Castillo et al., 2020).

The macroeconomic shock caused by the COVID-19 pandemic affected both supply and demand at the same time. The pandemic started as a supply-side shock because government interventions imposed unprecedented supply-side restrictions to contain the spread of the virus. This supply-side shock appeared as a combination of several supply-side restrictions, such as lockdowns, supply chain disruptions, firm bankruptcies, unemployment that downgraded workers' skills, and corporate debt that creates zombie firms. The nature of this supply-side shock is that it is supposed to be temporary because closure measures have been assumed to be 
temporary. It is expected that supply-side shock should disappear after the conditions for the abolition of closure measures are created, i.e., when there are fewer infections. In the meantime, this supply-side shock has turned into a demand-side shock because high uncertainty tends to appear in tough times, which are now related to the pandemic (Bloom, 2009). All of this led to a fall in consumption and a rise in savings, and the concomitant fall in aggregate demand. In the short term, as aggregate demand falls, a fall in output is created, which causes a fall in employment, a rise in unemployment, and a decline in investments. A drop in aggregate demand is usually linked with output fluctuations around potential output, creating business cycle fluctuations. A fall in aggregate demand and overly pessimistic forecasts of lower long-term growth of output can impact the economy through underinvestment or loss of innovation potential and cause fiscal tightening due to policymakers having to enact fiscal consolidation because of lower long-run growth in output (Fornaro and Wolf, 2020; Benedetti, Sedláček and Ster, 2020; Heimberger, 2020). The problem occurs if the supposed temporary supply-side shock becomes permanent, leading to a supply-side constraint. All these cause worries related to "hysteresis", which economists often use to explain the long-lasting damage effects of sharp recessions on output (Blanchard and Summers, 1986).

After pioneering papers by Nelson and Plosser (1982) and Campbell and Mankiw (1989), who showed that fluctuations in output tend to be persistent in the United States (US) and G7 countries, in the last decade there has been a growing body of research that has examined the impact of recessions on long term output dynamics. Research conducted by Cerra and Saxena (2008) and Reinhart and Rogoff (2009) concluded that deep recessions, such as the COVID-19, have persistent effects on output. Ball (2014) also quantified the damage in 23 countries of the Organization for Economic Co-operation and Development (OECD) that the global financial crisis did in 2008-2009. The author concluded that most countries had experienced strong hysteresis effects. Moreover, potential output losses accumulate over time (Rawdanowiczi et al., 2014; Reifschneider, Wascher and Wilcox, 2015; Cerra and Saxena, 2017). Blanchard, Cerutti and Summers (2015) found that a high number of recessions have been followed with lower output and lower output growth, and they concluded that demand shocks could affect output permanently.

The development of endogenous growth models created a vast number of potential sources that could cause hysteresis. Some of these theories emphasize the importance of changes in capital and knowledge accumulation (King, Plosser and Rebelo, 1988; King and Rebelo, 1988), human capital, and learning by doing as the key sources in explaining the long-run growth of output, as their procyclicality directly affects long-run growth (Stadler, 1986; 1990; Stiglitz, 1993). Stadler (1990) showed that investment and R\&D expenditures tend to be lower or subdued during the recession period compared to the "normal" periods. Also, some authors (e.g., Haltmaier, 2013, and Reifschneider, Wascher and Wilcox, 2015) show that cyclical variations of total factor productivity (TFP) are responsible for explaining long-lasting effects on output growth because recessions damage economies' labor force and productivity, which reduces potential output. 
Thus, empirical evidence raises concerns about the effects of the COVID-19 crisis on output in both the short and long run since output fluctuations seem to be persistent. The hysteresis effect, which is particularly pronounced in the labor market, impacts policymakers too. Pessimistic views about future potential output levels provide incentives for inadequate policy support and enact fiscal consolidation, consequently creating persistence and, thus, lowering the potential output even more (Heimberger, 2020). Research by Fatas and Summers (2018) provides evidence that countries that implemented large fiscal consolidations during the recession periods experienced much more severe persistent effects on GDP. Similarly, Gechert, Horn and Paetz (2019) produced the same conclusion and provided additional confirmation. Also, DeLong and Summers (2012) showed that fiscal consolidation in an economy in a recession could be self-defeating because it can increase debt. Furthermore, IMF (2009), Cerra, Panizza and Saxena (2012), and Ma, Rogers and Xhou (2020) showed that in the aftermath of a recession, macroeconomics policies such as more aggressive fiscal and monetary stimuli tend to help economies to have lower output losses over the medium term.

The goal of policymakers is to reduce deviations of actual output from its potential level. Implementation of stabilization policies reduces deviations of actual GDP around its potential level and can also potentially raise its average level (Cohen, 2000; Dupraz, Nakamura and Steinsson, 2019). To overcome the shortrun costs of the COVID-19 crisis and its possible scarring effects in the long run, many scientists and policymakers emphasized the need for adequate economic (especially fiscal) policy support. This paper assesses the effectiveness of discretionary fiscal policy support to combat the COVID-19 crisis in the short term, given in the first two quarters of 2020, and analyzing the impact of the COVID-19 crisis on potential GDP, and assessing what would have been the level of potential GDP without these fiscal measures. There are several transmission mechanisms by which COVID-19 has spilled over into the economy that can influence potential output in the long run. However, in this paper, we focus on the labor market performance because many governments have tried to mitigate the effects in that market due to the possible existence of hysteresis.

The existence of hysteresis on the labor market in Europe was first brought up by Blanchard and Summers (1986) after the economic crisis in the 1970s, after which unemployment rates stayed at a higher level than would have been expected based on macroeconomic and labor market frictions (Blanchard and Summers, 1986). In addition, they argue that this could lead to the rise of non-accelerating inflation rate of unemployment. Furthermore, labor market hysteresis presence was confirmed in euro area countries, especially in Germany (Loageay and Tober, 2005). The same results were found in some Central and Eastern European countries (Gozgor, 2013). There are several proposed sources of hysteresis, such as the insider-outsider model of the labor market (Blanchard and Summers, 1986) or the design of institutions (Di Tella and MacCulloch, 2006). Keeping that in mind, recessions produce disruptions in labor markets (Hershbein and Stuart, 2020), and 
the last recession in 2008 increased rates of long-term unemployment (Kroft et al., 2014), which plays a crucial role in the presence of hysteresis (Bell, 2009). The human capital of the unemployed decreases over time, possibly to the level under the reservation wage (Blanchard, 1991), making long-term unemployed workers unattractive to employers. To fight long-term unemployment, active labor policies should be used (Bentolila, García-Pérez and Jansen, 2017).

\section{DATA AND METHODOLOGY}

This paper uses data for 26 EU countries, with only Luxembourg being left out. Luxembourg is the only country in the sample that experienced constant growth of unemployment rate regardless of changes in GDP, and due to that, we decided to leave it out.

To test the effectiveness of COVID-19-induced fiscal policy measures in the short run, we estimate and forecast unemployment rates in selected European countries. To do so, we use Okun's law relation, which relates unemployment and output. Furthermore, for examining long-run effects, we use the concept of potential output, which is estimated with a production function. We use standard production function, with working-age population, participation rate, and output elasticities of labor. Table 1 shows a description of all data used in the analysis.

\section{TABLE 1}

Description of the variables

\begin{tabular}{|c|c|c|c|c|}
\hline Variable & Period & Frequency & Database & Description \\
\hline $\begin{array}{l}\text { GDP at } \\
\text { market prices }\end{array}$ & $\begin{array}{l}\text { 1999Q1-2020Q4 } \\
\text { (Malta from 2000) }\end{array}$ & Quarterly & Eurostat & $\begin{array}{l}\text { Unite }=\text { chain linked } \\
\text { volumes, index } \\
2015=100, \\
\text { seasonally and } \\
\text { calendar adjusted } \\
\text { data }\end{array}$ \\
\hline $\begin{array}{l}\text { Unemployment } \\
\text { rate }\end{array}$ & $\begin{array}{l}\text { 1999Q1-2020Q4 } \\
\text { (Bulgaria from 2000; } \\
\text { France from 2003) }\end{array}$ & Quarterly & Eurostat & $\begin{array}{l}\text { Unite=percentage } \\
\text { of population in } \\
\text { the labor force, } \\
\text { sex=total, trend } \\
\text { cycle data }\end{array}$ \\
\hline $\begin{array}{l}\text { Working age } \\
\text { population }\end{array}$ & $\begin{array}{l}2000-2020 \\
\text { (France from 2003) }\end{array}$ & Annual & Eurostat & $\begin{array}{l}\text { Unite=number, } \\
\text { sex=total }\end{array}$ \\
\hline $\begin{array}{l}\text { Active (persons) } \\
\text { population }\end{array}$ & $\begin{array}{l}2000-2020 \\
\text { (France from 2003) }\end{array}$ & Annual & Eurostat & $\begin{array}{l}\text { Unite }=\text { percentage } \\
\text { of total population, } \\
\text { sex=total }\end{array}$ \\
\hline $\begin{array}{l}\text { Output elasticity } \\
\text { of labor }\end{array}$ & 2000-2019 & Annual & $\begin{array}{l}\text { Penn World Table } \\
\text { (Feenstra, Inklaar } \\
\text { and Timmer, 2015) }\end{array}$ & \\
\hline
\end{tabular}

Source: Authors. 
To test the short-run effectiveness of COVID-19 fiscal measures, we estimate and forecast unemployment rates in selected European countries, for which Okun's law relation is used. The well-known Okun's (1962) law relates output and unemployment. Okun's law relation is one of the most frequently used relations in the economy, commonly used by the European Central Bank (e.g., Anderton et al., 2014), and provides helpful information to policymakers. The main reason behind choosing Okun's law to assess the effects of the fiscal policy response to the coronavirus pandemic is due to its simplicity and relevance. Furthermore, Okun's law is robust when applied to European countries (Economou and Psarianos, 2016), and it stayed consistent during the Great Recession in the USA (Ball, Leigh and Loungani, 2013). Although simple, this approach allows us to estimate how the unemployment rate would change due to actual changes in GDP if no fiscal measures were imposed, as opposed to the actual rates. Due to the lack of detailed data and uncertainty regarding the pandemic, this approach can be used as a benchmark for future research when more detailed data on fiscal stimulus structure become available.

Two main approaches of Okun's law are commonly used in the analysis. The first focuses on the relationship between the GDP growth rate and change in unemployment, and the second relates the deviation of the unemployment rate from its natural level and the deviation of GDP from its potential level (or growth). The following equation typically represents the first approach:

$$
\Delta u_{\mathrm{t}}=\alpha+\beta \Delta y_{\mathrm{t}}+\varepsilon_{\mathrm{t}}
$$

where $\Delta u_{\mathrm{t}}$ stands for the change in the unemployment rate at the time $t, \Delta y_{\mathrm{t}}$ is a change in output in time $t$, and $\varepsilon_{\mathrm{t}}$ is an error term that is normally distributed $\operatorname{IID}(0$, $\sigma^{2}$ ). Considering coefficients, $\alpha$ is a constant representing the long-run growth trend in unemployment, $\beta$ represents Okun's coefficient, which measures the response of the unemployment rate to changes in output. Response of unemployment due to change in output is expected to be negative, which arises from the general relationship between unemployment and output. That is, a higher output generally leads to lower unemployment. The second approach is associated with unemployment and output gap and is typically estimated using the following equation:

$$
u_{\mathrm{t}}-u_{\mathrm{t}}^{*}=\alpha+\beta\left(y_{\mathrm{t}}-y_{\mathrm{t}}^{*}\right)+\varepsilon_{\mathrm{t}}
$$

where $u_{\mathrm{t}}-u_{\mathrm{t}}^{*}=u_{\mathrm{t}}^{c}$ is a gap (cycle) between observed and potential unemployment rate, $y_{\mathrm{t}}-y_{\mathrm{t}}^{*}=y_{\mathrm{t}}^{c}$ is a gap (cycle) between observed and potential output. However, as Jovičić (2017) demonstrates, all commonly used methods of estimating potential output are particularly uncertain in real-time because estimates at the end of the sample can change significantly with the publication of new data, which is also called the end-of-sample problem. This property of potential output (or natural 
unemployment rate) estimates can result in significant revisions of current and historical potential output as new information throughout time arrives. Also, in periods of economic crisis when the future is completely uncertain, the difficulty of assessing potential output is especially pronounced. This uncertainty and potentially significant revisions are problematic because that information on the output gap is least certain at the very moment when it is most important to economic policymakers. This uncertainty can lead to unreliable estimates of the output gap that can result in wrong decisions and moves by monetary and fiscal authorities. Because of the mentioned problems, we will not estimate equation (2), and therefore, only the first approach is used in this paper. Also, we estimate equation (1) as of 2019:Q4, and then we forecast the unemployment rate level conditionally on the realized rates of change in GDP.

To have technically correct estimations of equation (1), which we estimate using the ordinary least squares method (OLS), it is necessary to ensure the external and internal validity of regression analysis (Stock and Watson, 2011). External validity is associated and achieved with a representative sample, while internal validity is associated and achieved if the estimator is unbiased and consistent and if standard errors are valid. To achieve internal validity, assumptions of homoskedasticity and autocorrelation must be satisfied. Therefore, it is necessary to test for problems of heteroskedasticity and autocorrelation that may arise when estimating equation (1). Potential problems are detected by diagnostic tests, where for the potential problem of heteroskedasticity, the Breusch-Pagan test is used, which is a commonly used test to detect the problem of heteroskedasticity. For detection of the potential problem of autocorrelation, the Breusch-Godfrey test is used, which is also a standard test in literature.

The problem of autocorrelation is solved by adding one or up to two lags of the dependent variable, depending on the country. The reason for using up to two lags is that, by adding more than two lags, the problem of autocorrelation is not being solved and remains persistent, no matter how many lags of the dependent variable are added. However, by adding more than two lags of the dependent variable, the fit of the model is still strongly robust. Because of the problem of heteroskedasticity, the variance is stabilized by following Stockhammar and Oller (2012) and using the generalized autoregressive conditional heteroskedastic model (GARCH), estimated by the following equation:

$$
\sigma_{t}^{2}=\alpha_{o}+\alpha_{1} \varepsilon_{t-1}^{2}+\beta_{1} \sigma_{t-1}^{2}
$$

where equations (1) and (3) represent the GARCH $(1,1)$ model, which is used in this paper, where in equation (3), variance $\sigma_{t}^{2}$ in time $t$ is a function of lagged squared error terms $\varepsilon_{t-1}^{2}$ and lagged variance $\sigma_{t-1}^{2} \cdot \alpha_{o}$ represents intercept, $\varepsilon_{t-1}^{2}$ represents the ARCH term and $\sigma_{t-1}^{2}$ represents the GARCH term. This procedure is also used if the problem of autocorrelation is still present after up to two lags of the dependent variable are added. 
As for tackling the problem of autocorrelation, on the right side of equation (1), lagged values of growth of GDP will be added. This will turn equation (1) into a dynamic version of Okun's law. This dynamic version of Okun's law is fundamentally different from the simple difference version, as it does not capture the contemporaneous relationship between changes in the growth of GDP and unemployment. The advantage of the dynamic version is that it is not restrictive when considering the timing of the connection between changes in the growth of GDP and unemployment. The drawback of the dynamic version is that it does not have a simple interpretation as compared to the version with the growth of the GDP in time $t$ (Knotek, 2007).

To determine the effectiveness of discretionary fiscal policy in fighting the COVID-19 crisis, equation (1) is estimated for each country. To satisfy technical requirements, as mentioned above, lags of the GDP and unemployment are added, and the GARCH is used if needed. Additionally, equation (1) with only two lags of GDP is estimated. These results are used to test robustness. Equations are estimated until 2019:Q4, and then after that, we use these estimations to forecast future values of unemployment for the first two quarters of 2020 based on the actual fall in GDP. Forecasted values represent unobservable unemployment rates that are consistent with the actual drop in GDP, and we use these predicted values to approximate unemployment changes in a situation in which no fiscal measures were imposed to fight the ongoing crisis. It is important to emphasize that although in this situation we assume that there are no fiscal measures imposed, we do not neglect the existence of imposed measures to fight the spread of the virus, rather we assume that they are imposed and are affecting GDP. Therefore, their impact is contained in the fall in GDP itself. In the end, we compare whether actual values of the unemployment rates, i.e., those that are under the influence of fiscal stimulus proposed to combat the COVID-19 crisis, are higher or lower than those forecasted. If the forecasted are higher than the actual values, we conclude that countries' fiscal policy measures were effective, and vice versa.

\subsection{LONG-RUN EFFECTS OF THE COVID-19 FISCAL MEASURES}

Firstly, it is important to emphasize that even though we examine effects three years ahead, which can hardly be characterized as the long run, we do estimate potential output effects, which are generally perceived as a long-run variable, so we use the term "long-run effects". In addition, the reason for examining effects only three years ahead comes from the ARIMA forecasting technique we are using. Forecasting too much ahead leads towards the long-term average, which leads to the equalization of unemployment rates with and without fiscal measures. Furthermore, here also lies the reason for using annual data. With annual data, we forecasted values only three years in advance, while with quarterly data, we should forecast 12 quarters in advance, which would, in our opinion, increase uncertainty, and convergence towards the long-term average would occur earlier. To estimate the potential long-run effects of fiscal measures, we use the concept of potential output estimated using the production function approach based on the Cobb-Douglas production function. Due to the simplicity of the Cobb-Douglas 
production function, labor contribution to potential output can be easily isolated and interpreted. More precisely, the impact of the fiscal policy measures on unemployment in the short-term to potential output can be estimated.

In doing so, we construct two scenarios. In the first scenario, we assume that in the absence of a fiscal policy response (but, as mentioned earlier, in the presence of measures that aim to fight the spread of the virus) the unemployment rate would rise to a level consistent with Okun's law and we then forecast the three-year unemployment rate using a simple AR model. In the second scenario, we use actual data and forecast the unemployment rate in the same way. All other components of the production function are assumed to be the same in both scenarios. Using forecasted unemployment rates, we calculate two alternative paths of potential output and calculate the difference between the forecasted growth rate of potential GDP in both scenarios. The difference between the two scenarios gives us an estimate of the effects of the fiscal measures on the potential output and its growth on the prognostic horizon.

For estimating the effect of change in the unemployment rate on potential output and its growth rate, we use the standard Cobb-Douglas production function (4):

$$
Y=A L^{\alpha} K^{\beta}
$$

where $Y$ is total production, $L$ is labor input, $K$ is capital input, $A$ is total factor productivity (TFP), and $\alpha$ and $\beta$ are the output elasticities of labor and capital, respectively. TFP and capital are kept unchanged between the two scenarios to isolate the effect of differences in unemployment rates on potential output and growth. By log differencing equation (4) and taking partial derivative with respect to labor, we get:

$$
d\left(\ln Y_{t}\right)=\alpha \times d\left(\ln L_{t}\right)
$$

where $Y$ represents potential GDP, $\alpha$ stands for output elasticities of labor, and $L$ is labor. Labor (employment) is given by the following identity:

$$
L_{t}=\left(1-u_{n t}\right) \times \text { part }_{n t} \times r s s_{t}
$$

In equation (6), $u_{n t}$ represents natural unemployment rate, part $_{n t}$ is trend participation rate and $r s s_{t}$ stands for the working-age population. To see the effect of fiscal measures, we need to compare the expected growth of potential GDP between two scenarios (with and without fiscal measures) which affected the unemployment rate. To do that, we estimate the natural unemployment rate from actual unemployment data, representing situations with fiscal measures using the HodrickPrescott (HP) filter. For the situation without fiscal measures, we modify data in 2020 based on estimations and forecast of our models (Okun's law), and again, using the HP filter, we estimate the alternative natural unemployment rate path. ${ }^{2}$

\footnotetext{
${ }^{2}$ Although the mentioned end-of-sample problem could be an issue, as explained in the previous section, we acknowledge that it is less of an issue in this case because we use forecasted values here, which lower the endof-sample bias uncertainty. However, forecasted values also bring their own uncertainty.
} 
Natural unemployment rates are kept the same for the period before 2020. As we want to see the effect of fiscal measures on future periods using ARIMA forecasting techniques, we forecast unemployment rates for the three-year horizon (up to 2023). Furthermore, we need a trend participation rate and working-age population for the same period. For that, we use the same procedure. $\alpha$ is not forecasted for a future period, just kept fixed at its last observed value. Once we have all values of all variables until 2023, based on equations (5) and (6) we are ready to make a comparison of potential GDP growth in two scenarios.

\section{RESULTS}

\subsection{SHORT RUN EFFECTIVENESS OF COVID-19 MEASURES}

In this section, the results of the effectiveness of COVID-19 fiscal measures for selected countries are presented. To determine the effectiveness of discretionary fiscal policy in fighting the COVID-19 crisis, equation (1) is estimated for each country. The results from equation (1) that are technically correct are used as main results to determine if fiscal policy measures implemented to tackle the COVID19 crisis in the first two quarters of 2020 were effective. Additionally, equation (1) with only two lags of GDP is estimated, and results are used to test robustness. Equations are estimated until 2019:Q4 and then are forecasted for the first two quarters of 2020. If the forecasted values are higher than actual values, countries' fiscal policy measures were effective, and vice versa.

First of all, equation (1) is estimated with GDP at time $t$, and after that, lagged values of GDP at time $t-1$ and $t-2$ are added, because fitted values of change in the unemployment rate better suit the actual values of the unemployment rate. Adding more than two lagged values of GDP to the equations does not significantly change the fit of the models. To check if equation (1) is technically correct, diagnostic tests of autocorrelation and heteroskedasticity are carried out. To tackle the problem of autocorrelation, lagged values are added, where for some countries, only one lag is added, and for some, two lags are added. The addition of lags increased model fit and has solved the problem of autocorrelation. In countries where adding lags was not enough to solve OLS assumptions, violation problems were solved using the GARCH $(1,1)$ model. ${ }^{3}$ The results for each country from equation (1), with basic OLS estimation, OLS estimation with no autocorrelation problem, and OLS estimation with no heteroskedasticity problem, are presented in appendix A, which shows that those results are very similar, and thus this represents robustness of the given estimations.

Results for equation (1) are presented in figure 1. Figure 1 shows the difference between estimated and actual values of change in the unemployment rate in EU-26

\footnotetext{
${ }^{3}$ The country where GARCH $(1,1)$ model is used in the equation is Ireland due to heteroskedasticity. For the problem of autocorrelation, it is used in Belgium, Estonia, Germany, Greece, Ireland, and Poland. Results are strongly robust. Also, we have estimated different models with different numbers of lags by using either independent variables or a combination of independent and dependent variables and with or without the GARCH $(1,1)$ model. In either case, results remain strongly robust and are available upon request.
} 
countries, where positive values indicate that the fiscal measures implemented do mitigate the increase of unemployment as compared to a situation in which no fiscal stimulus has been given. Negative values indicate that estimated values are lower than actual values, and therefore, the negative impact of fiscal policy measures on the change in the unemployment rate.

\section{Figure 1}

Difference between estimated and actual values of the change in the unemployment rate, 2020:Q1 and 2020:Q2

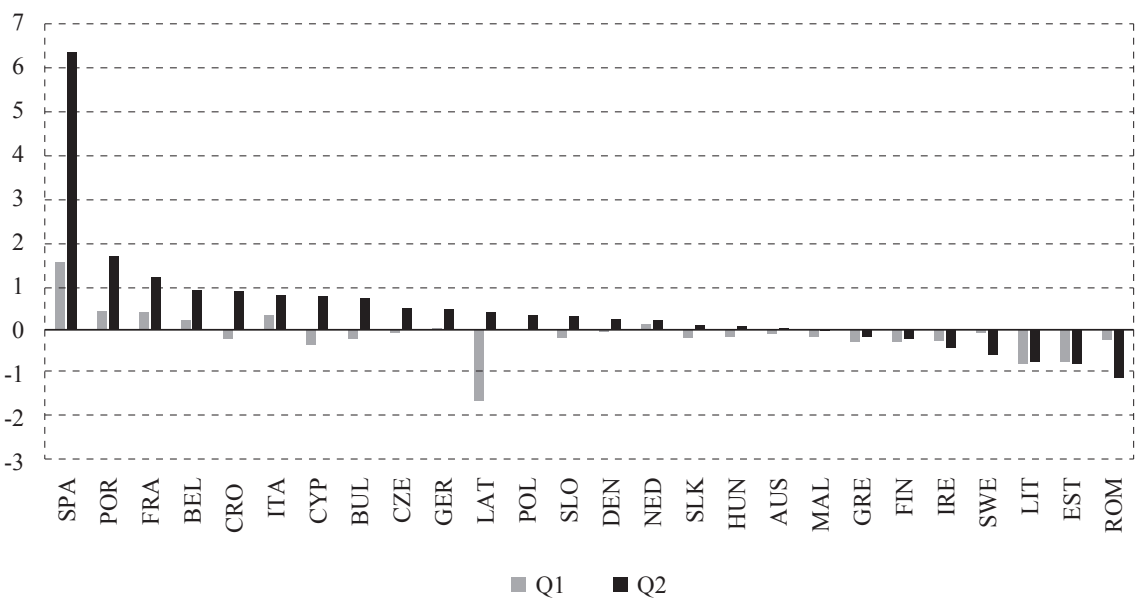

Source: Authors' own calculation based on Labor force survey (LFS) unemployment data by Eurostat (2021).

It can be seen in figure 1 that, in the first quarter of 2020, Spain, Portugal, France, Belgium, Italy, Germany, Poland, and the Netherlands had a positive difference, with Spain first and followed by other mentioned countries, which means that the estimated unemployment rate was higher than the actual unemployment rate, and that indicates the success of implemented fiscal policy measures. The rest of the countries had a negative difference in the first quarter, with Baltic countries having the most ineffective fiscal policy measures undertaken in the first quarter of 2020. However, since the COVID-19 crisis in some countries started after the first quarter, estimated results in the first quarter should be taken with caution. According to that, our focus lies on the second quarter. Results for the second quarter indicate that all countries, except Malta, Greece, Finland, Ireland, Sweden, Lithuania, Estonia, and Romania, had effective fiscal policy measures in the second quarter of 2020, with Spain on top of that list and leading by far which makes Spain the country whose fiscal measures mitigated unemployment growth the most. Countries with effective fiscal policy measures in both quarters are Spain, Portugal, France, Belgium, Italy, Germany, Poland, and the Netherlands.

Furthermore, figure 2 shows the discretionary fiscal response to the COVID-19 crisis, as additional spending or foregone revenue in the non-health sector in the percentage 
of GDP in our EU-26 countries, as of September 11, 2020. ${ }^{4}$ In appendix B, there is a brief summary of non-health fiscal policy measures undertaken in each country from the sample ${ }^{5}$. It shows that countries mostly imposed similar fiscal policies in order to fight the ongoing crisis. In order to preserve employment, countries are mostly subsiding wages and providing financial support for the maintenance of business activity. At the time of writing this paper, we do not have detailed and precise information on the amount of money provided for each fiscal measure, or for the terms under which they are implemented, or what goal a specific fiscal measure has. However, this indicator contains these measures and is currently the best approximation for currently available fiscal measures used to cushion the labor market effects of COVID-19.

\section{Figure 2}

Discretionary fiscal response to the COVID-19 crisis as additional spending or foregone revenue in the non-health sector, as of September 11, 2020 (percentage of GDP)

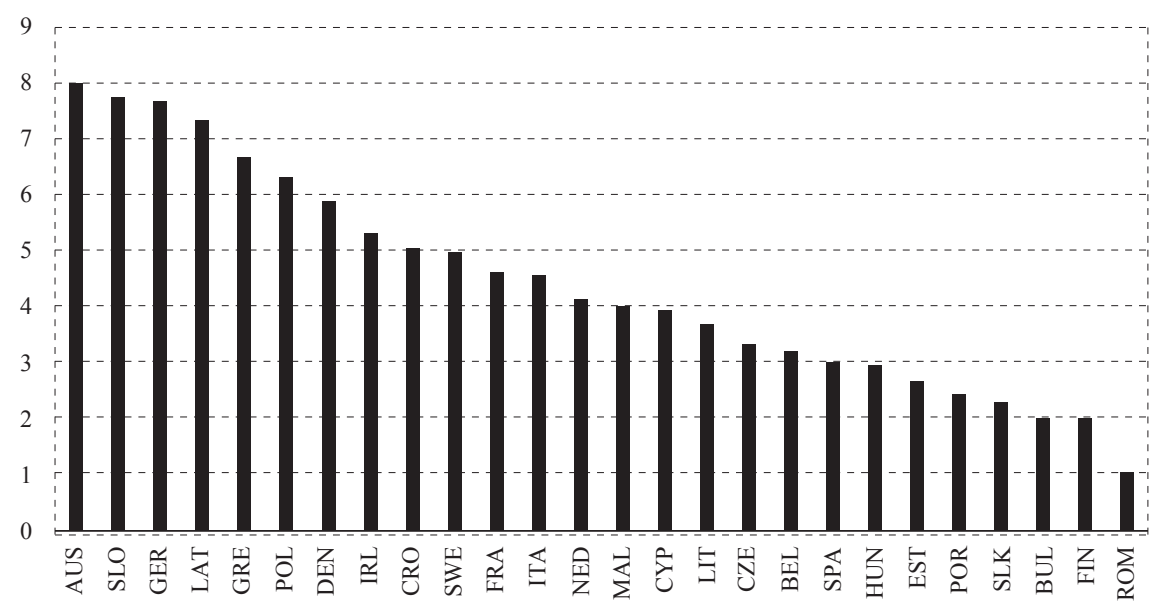

Source: IMF (2020).

It can be seen in figure 2 that Austria, Slovenia, and Germany had the highest nonhealth fiscal response to the COVID-19 crisis, while Bulgaria, Finland, and Romania had the lowest. Comparing figure 2 to figure 1, it can be seen that Spain, Portugal, and Belgium, which were very successful in fighting the COVID-19 crisis in both quarters, spent significantly less in percentage of GDP. Also, Austria, Slovenia, and Germany, which had the highest fiscal response of selected countries, were much less successful in fighting the COVID-19 crisis labor market effects than their peers. All of this can indicate that size of the fiscal response does not necessarily imply the results on the success of fighting against the COVID-19 crisis labor market effects.

Figure 3 shows the ratio between the estimated effectiveness of fiscal measures (shown in figure 1) and discretionary fiscal response (shown in figure 2) for Q2 in 2020.

\footnotetext{
${ }^{4}$ IMF also has available data up to June 12, 2020, but data for most selected countries in this paper is not available.

${ }^{5}$ For a detailed version of measures, one should visit the IMF website.
} 
Estimated effectiveness of fiscal measures and discretionary fiscal response ratio, 2020:Q2

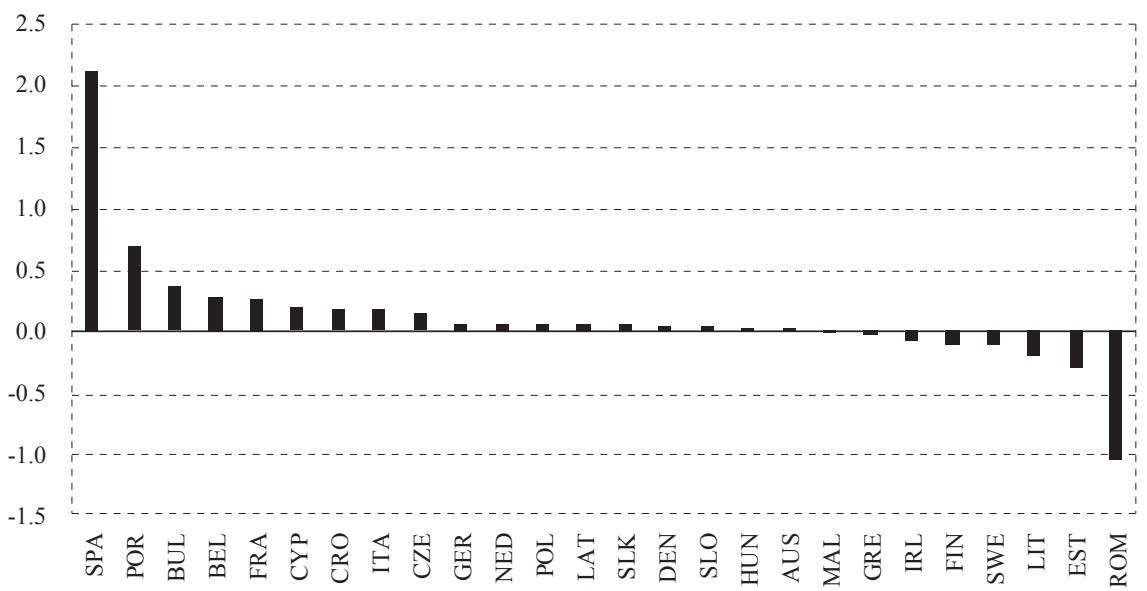

Source: Authors' own calculation based on LFS unemployment data by Eurostat (2021) and IMF (2020).

Analysis suggests that Spain had the highest ratio, which also indicates that their fiscal response got the highest returns in terms of mitigating the growth of unemployment. For one percentage point of their fiscal stimulus, they mitigate the growth of unemployment by around two percentage points. On the other hand, Romania had by far the biggest negative ratio, followed by Estonia. Furthermore, even though countries like Austria, Germany, and Slovenia had big fiscal stimulus programs, their ratio is very low, which could again indicate that size of the fiscal response is no guarantee for the successful fight against crises, even though unemployment in these countries is significantly lower and less volatile than in countries where fiscal measures seem to prevent more unemployment growth.

\subsection{LONG RUN EFFECTIVENESS OF THE COVID-19 MEASURES}

Effects of fiscal measures can be analyzed in the short run, as has just been done, and in the (mid to) long run as we do in this section. For that purpose, we present the possible implications of the fiscal measures on potential output and GDP growth from 2021 to 2023. As described earlier, we assume that all factors of production are the same in two scenarios (with and without fiscal measures). Differences in growth rates will be solely the result of estimated differences in the contribution of labor factor to potential GDP, given the different unemployment rates implied by the two scenarios. Due to limitations, as mentioned earlier in section 3.2 , in the forecasting technique and the availability of quarterly data for some variables from equations (5) and (6), we use annual data in this exercise.

The models used in this calculation are equivalent to the models used in the previous section for measuring the effectiveness of COVID-19 fiscal measures. 
Drawing on those models, we now made a forecast of the unemployment rate until 2020:Q4. After that, we transform quarterly data for unemployment into annual data by using an average of the Q1-Q4 period for each year. Using the HP filter from annual data, we estimated the natural unemployment rate for both scenarios, with (real values) and without fiscal measures (estimated values), after which we forecasted unemployment rates until 2023 in both scenarios (actual - with fiscal measures and counterfactual - without fiscal measures). Then, using equations (5) and (6), we calculated the contribution of labor to the growth of potential output every year. Finally, we compared the contributions of both scenarios for the period from 2021 to 2023 by simply summing values for the situation with fiscal measures and then deducting from it summed values of the situation without fiscal measures. Calculation ${ }^{6}$ was done by equation (6), which is based on equation (5), as follows:

$$
\sum_{t=2021}^{2023} d\left(\ln Y_{t}\right)_{\text {with measures }}-\sum_{t=2021}^{2023} d\left(\ln Y_{t}\right)_{\text {without measures }}
$$

If the difference is positive, fiscal measures have been effective and have positively impacted the growth of potential output during the forecasting horizon. On the other hand, if the difference is negative, fiscal measures have not been effective, which will have a negative effect on the growth of potential output in the future.

Figure 4 shows the cumulative difference in the labor effect on the growth of potential output between scenarios (with and without fiscal measures) for the 2021-2023 period.

\section{Figure 4}

Cumulative difference of the labor effect on the growth of potential output between scenarios with and without fiscal measures for period 2021-2023

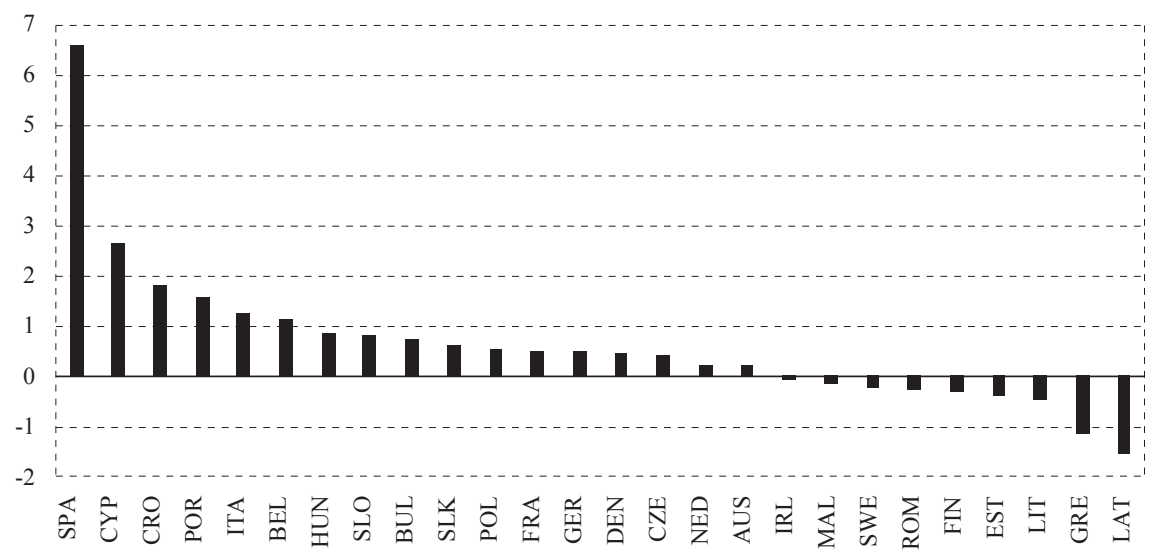

Source: Authors' own calculation based on LFS unemployment data by Eurostat (2021) and Penn World Table (Feenstra, Inklaar and Timmer, 2015).

\footnotetext{
${ }^{6}$ E.g., period 2021-2023 - With fiscal measures: 1\%, 2\%, 3\%; Without fiscal measures: -1\%, -2\%, 2\% -> Summed with fiscal measures - Summed without fiscal measures $=(1+2+3)-(-1-2+2)=7 \%$.
} 
Based on these estimates, it seems that in countries where the fiscal measures significantly mitigated labor market response, it could significantly contribute to the growth rate of potential GDP in the coming period. Furthermore, this contribution could be the largest in the Mediterranean countries. We can see those countries that depend on the tourism and service sector, like Mediterranean ones, experience much more positive long-run effects of COVID-19 fiscal measures. Also, it shows that Spain could experience the biggest positive effect on the growth of potential output, which is in line with the results of the effectiveness of COVID-19 fiscal measures in the previous section. On the other hand, estimates show that Baltic and Scandinavian countries could experience lower growth of potential output than there would be if no fiscal measures had been imposed. Although it is expected that most of the Mediterranean countries could experience a positive impact on potential output, Greece and Malta are expected to experience negative effects.

\subsection{DISCUSSION}

As discussed in the second section, the response of policymakers to the ongoing COVID-19 crisis is of great importance. The results in section 4.1 indicate that the size of the fiscal response is not of great importance. However, the structure of the fiscal response and its compliance with the economy's structure might be crucial in explaining what fiscal measures and structure of these measures there must be to prevent the adverse impacts from the COVID-19 crisis on the labor market, and thus on the economy. It can generally be concluded that countries that depend on the service sector, mainly on accommodation and food service, which in our case are Mediterranean countries, were more susceptible to COVID-19 shocks. However, although they were more prone to these shocks, their response managed to mitigate more unemployment than the others due to their economies being service-dependent. Also, this raises questions about the already known importance of diversifying the structure of the economics so that they can be more resilient to the different shocks.

The importance of the term hysteresis, or the impact of cyclical fluctuations of GDP in a crisis on the potential GDP, has also been discussed in section 2. Results in 4.2 are in line with the literature that emphasizes the existence of hysteresis effects. Thus, the results indicate the presence of hysteresis, in other words, that cyclical fluctuations of the GDP in the ongoing COVID-19 crisis could have a negative and permanent effect on the growth of the potential GDP if the policymakers undertake no fiscal measures. Furthermore, it can be concluded that the Mediterranean countries experience a positive and more significant effect of preventing the rise in unemployment rates than other countries. In other words, they would have experienced significantly higher growth in the unemployment rate if no fiscal measures had been imposed. In addition, these are countries where unemployment rates are usually relatively high and often persistent, making fiscal measures extremely important for reducing the short-, but also and long-term economic costs of the pandemic. According to that, the contribution of labor to the projected growth of the potential GDP is greater in Mediterranean countries than others in our sample. Due to different contributions of labor in the economies of 
different countries, the growth of potential output reacts differently to fiscal measures imposed. Nevertheless, it must be emphasized that although the economies of Mediterranean countries have similar structures with tourism and the service-sector having an important role, not all experienced such positive effects, with Greece and Malta standing out from peer countries. Even though the tourism and service sectors are highly important for Malta, the biggest share of their GDP (272\% in 2020) is influenced by foreign trade, which was hardly affected by the COVID-19 crisis. When talking about Greece, the effectiveness of imposed fiscal measures could be influenced by the previous economic situation in Greece, more precisely by recovery from long-lasting recession and the migration crisis.

Our recommendation to policymakers in times of crisis is that inadequate fiscal support does not only lead to negative effects in the short-term, but also tends to be a problem for the future development of the economy, the potential of which can be harmed. All of that can lower the short- and long-term well-being of citizens. Literature suggests that a crisis increases the long-term unemployment rate (Kroft et al., 2014) and that it plays a crucial role in the existence of hysteresis in the labor market (Ball, 2014). Keeping that in mind, a fiscal reaction in this crisis and its estimated effects could lead to lesser short- and long-term costs of this crisis. Furthermore, we emphasize that a bigger fiscal stimulus does not guarantee better results; one should rather pay more attention to the structure of the fiscal response and its compliance with the structure of the economy, but further research on this topic is needed. Thus, an adequate fiscal stimulus could lead to higher growth of GDP and potential GDP, which would consequently lead to lower and more sustainable levels of budget deficits and public debt.

The limitation of this paper comes from its use of aggregate levels of discretionary fiscal policy measures due to the limitation of available data at the time of writing. The problems with this measure are that the responses vary according to country-specific circumstances, for example, the number of cases of infection. Furthermore, the problem of lack of information exists in the labor market. We do not have information on the details of policies aimed at keeping the unemployment rate low. For example, some countries adopted more flexible approaches by providing social transfers to newly unemployed persons instead of maintaining the unemployment rate by supporting firms that retain workers. Finally, we do not have information on the structure of fiscal support - the question arises as to what proportion of fiscal expenditure was directed at maintaining the employment rate. For future research, one might want to use disaggregate measures of the undertaken discretionary fiscal policy. ${ }^{7}$

Also, there is a need to test the robustness of the results additionally. Okun's law in some countries fits the data better than in others, but we do not distinguish between them. Furthermore, it is practically impossible to separate the supply-side shocks

\footnotetext{
${ }^{7}$ We would like to thank our anonymous reviewer for this paragraph, which is a major contribution to the better positioning of our results in this paper as first approximations. With newly available data, new approximations will be clearer to approximate and connect with existing approximations in this paper.
} 
from the demand-side shocks of COVID-19 at this point. We are aware of this problem; however, its consequences for our analysis are beyond the scope of this paper, and we are focusing on short-term and long-term impact assessment using standard methods, which do not necessarily lead to adequate estimates of the trend (potential), or the cyclical components (either in the case of the unemployment rate or the total output (GDP)).

\section{CONCLUSION}

This paper aimed to examine the effectiveness of the fiscal measures undertaken by the policymakers to the response to the COVID-19 crisis in the analyzed EU countries. Firstly, the short-term effects of the fiscal measures were examined in the analyzed countries. To assess the effectiveness, we have used the trend-cyclical unemployment rate as a benchmark for the effect of the COVID-19 on the economies. We have used Okun's law to estimate and forecast unemployment rates, and then we have compared forecasted values with the actual values of the unemployment rates. Results indicate that the undertaken fiscal measures in the second quarter of 2020 were successful in most EU-26 countries, except in Malta, Greece, Finland, Ireland, Sweden, Lithuania, Estonia, and Romania. In addition, the effect was relatively smaller in the first quarter of 2020 since the COVID-19 crisis in some countries did not occur at the time.

Secondly, we have examined how the familiar labor market hysteresis effect makes these fiscal measures important not only in the short but also in the long run, using the concept of potential output. Our results are in line with the literature that confirms the existence of the hysteresis effects. Namely, in most countries, the estimated growth rate of potential GDP is significantly higher in the actual scenario in which fiscal measures have been implemented than in the counterfactual scenario in which we assume that these fiscal measures have not been implemented.

Furthermore, it can be concluded that most of the Mediterranean countries have experienced a positive effect, more significant in preventing the rise in unemployment rates than other analyzed countries. On the other hand, estimations indicate that Baltic countries did not benefit from imposed fiscal measures. Nevertheless, more successful prevention in the rise of the unemployment rates does not necessarily lead to greater growth of the potential GDP driven by labor due to the different contributions of labor in different economies.

In line with results from this paper, we conclude that inadequate fiscal support can have negative short- and long-term effects on the economy's growth and that adequate fiscal support (was and still) needs to be implemented to fight the current crisis and achieve short- and long-term prosperity.

\section{Disclosure statement}

The authors state that they do not have any financial or other substantive conflict of interest. 
1. Anderton, R. [et al.], 2014. Disaggregating Okun's Law: Decomposing the Impact of the Expenditure Components of GDP on Euro Area Unemployment. ECB Working Paper, No. 1747.

2. Ball, L., 2014. Long-term damage from the Great Recession in OECD countries. European Journal of Economics and Economic Policies: Intervention, 11(2), pp. 149-160. https://doi.org/10.4337/ejeep.2014.02.02

3. Ball, L., Leigh, D. and Loungani, P., 2013. Okun's law: fit at 50? NBER Working Paper, No. 18668. https://doi.org/10.3386/w18668

4. Barrios, S., Strobl, E. and Bertinelli, L., 2010. Trends in Rainfall and Economic Growth in Africa: A Neglected Cause of the African Growth Tragedy. Review of Economics and Statistics, 92(2), pp. 350-366. https://doi.org/10.1162 /rest.2010.11212

5. Barro, R. J., Urs'ua, J. F. and Weng, J., 2020. The Coronavirus and the Great Influenza Pandemic: Lessons from the "Spanish Flu" for the Coronavirus's Potential Effects on Mortality and Economic Activity. NBER Working Paper, No. 26866. https://doi.org/10.3386/w26866

6. Bell, L. M., 2009. Hysteresis in Unemployment: Old and New Evidence. NBER Working Paper, No. 14818. https://doi.org/10.3386/w14818

7. Benedetti, F. C., Sedláček, P. and Sterk, V., 2020. EU start-up calculator: impact of COVID-19 on aggregate employment: Scenario analysis for Denmark, Estonia, Finland, France, Latvia, Lithuania, Portugal and Sweden. Luxembourg: Publications Office of the European Union. http://dx.doi.org/ $10.2760 / 232741$

8. Bentolila, S., García-Pérez, I. J. and Jansen, M., 2017. Are the Spanish longterm unemployed unemployable? SERIES, 8, pp. 1-41. https://doi.org/10.1007/ s13209-017-0155-z

9. Blanchard, O. J. and Summers, L. H., 1986. Hysteresis and the European Unemployment Problem. NBER Macroeconomics Annual, 1, pp. 15-78. https://doi.org/10.1086/654013

10. Blanchard, O. J., 1991. Wage Bargaining and Unemployment Persistence. Journal of Money, Credit and Banking, 23(3), pp. 277-292. https://doi.org/10. 2307/1992746

11. Blanchard, O., Cerutti, E. and Summers, L., 2015. Inflation and Activity - Two Explorations and their Monetary Policy Implications. IMF Working Papers, 15(230). https://doi.org/10.5089/9781513536613.001

12. Bloom, D. E. [et al.], 1998. Geography, Demography, and Economic Growth in Africa. Brookings Papers on Economic Activity, (2), pp. 207-295. https:// doi.org/10.2307/2534695

13. Bloom, N., 2009. The Impact of Uncertainty Shocks. Econometrica: Journal of the Econometric Society, 77(3), pp. 623-685. https://doi.org/10.3982/ECTA6248

14. Bodnár, K. [et al.], 2020. The impact of COVID-19 on potential output in the euro area. Economic Bulletin, (7). 
15. Brauner, J. M. [et al.], 2021. Inferring the effectiveness of government interventions against COVID-19. Science, 371(6531). https://doi.org/10.1126/science. abd9338

16. Campbell, J. Y. and Mankiw, N., 1989. International evidence on the persistence of economic fluctuations. Journal of Monetary Economics, 23(2), pp. 319-333. https://doi.org/10.1016/0304-3932(89)90054-8

17. Cerra, V. and Saxena, S. C., 2008. Growth Dynamics: The Myth of Economic Recovery. American Economic Review, 98(1), pp. 439-457. https://doi.org/10. 1257/aer.98.1.439

18. Cerra, V. and Saxena, S. C., 2017. Booms, Crises, and Recoveries: A New Paradigm of the Business Cycle and its Policy Implications. IMF Working Papers, WP 17/250. https://doi.org/10.5089/9781484325759.001

19. Cerra, V., Panizza, U. and Saxena, S. C., 2012. International Evidence on Recovery from Recessions. Contemporary Economic Policy, 31(2), pp. 424439. https://doi.org/10.1111/j.1465-7287.2012.00313.x

20. Cohen, D. S., 2000. A Quantitative Defense of Stabilization Policy. Finance and Economics Discussion Series, No. 34. https://doi.org/10.17016/FEDS.2000.34

21. DeLong, J. B. and Summers, L., 2012. Fiscal Policy in a Depressed Economy. Brookings Papers on Economic Activity, 43(1), pp. 233-297. https://doi.org/10. 1353/eca.2012.0000

22. Di Tella, R. and MacCulloch, R., 2006. Europe vs America: Institutional hysteresis in a Simple Normative Model. Journal of Public Economics, 90(12), pp. 2161-2186. https://doi.org/10.1016/j.jpubeco.2006.05.013

23. Dupraz, S., Nakamura, E. and Steinsson, J., 2019. A Plucking Model of Business Cycles. NBER Working Paper, No. 26351. https://doi.org/10.3386/w26351

24. Economou, A. and Psarianos, I. N., 2016. Revisiting Okun's Law in European Union countries. Journal of Economic Studies, 43(2), pp. 275-287. https://doi. org/10.1108/JES-05-2013-0063

25. Eurostat, 2021. Eurostat: Unemployment by sex and age (1992-2020) - quarterly data. Eurostat.

26. Fatas, A. and Summers, H. L., 2018. The permanent effects of fiscal consolidations. Journal of International Economics, 112, pp. 238-250. https://doi. org/10.1016/j.jinteco.2017.11.007

27. Feenstra, R., Inklaar, R. and Timmer, M., 2015. The Next Generation of the Penn World Table. American Economic Review, 105(10), pp. 3150-3182. https://doi.org/10.1257/aer.20130954

28. Fornaro, L. and Wolf, M., 2020. Covid-19 Coronavirus and Macroeconomic Policy. Barcelona Graduate School of Economics Working Paper, No. 1168.

29. Gechert, S., Horn, G. and Paetz, C., 2019. Long-term Effects of Fiscal Stimulus and Austerity in Europe. Oxford Bulletin of Economics and Statistics, 81(3), pp. 647-666. https://doi.org/10.1111/obes.12287

30. Gonzales-Castillo, J. R. [et al.], 2020. COVID-19 pandemic and Public Health Policies in Peru: March-May 2020. Rev. salud pública, 22(2). https://doi.org/ 10.15446/rsap.v22n2.87373 
31. Gozgor, G., 2013. Testing Unemployment Persistence in Central and Eastern European Countries. International Journal of Economics and Financial Issues, 3(3), pp. 694-700.

32. Haltmaier, J., 2013. Do Recessions Affect Potential Output? FRB International Finance Discussion Paper, No. 1066. https://doi.org/10.2139/ssrn.2251879

33. Heimberger, P., 2020. Potential Output, EU Fiscal Surveillance and the COVID-19 Shock. Intereconomics, Review of European Economic Policy, 55, pp. 167-174. https://doi.org/10.1007/s10272-020-0895-z

34. Hershbein, B. and Stuart, B. A., 2020. Recessions and local labor market hysteresis. Upjohn Institute Working Paper, No. 20-325. https://doi.org/10.17848/ wp20-325

35. IMF, 2009. What's the Damage? Medium-Term Output Dynamics after Financial Crises. World Economic Outlook, Ch. 4. https://doi.org/10.5089/978158 9068070.081

36. IMF, 2020. Database of fiscal policy reponses to COVID-19: October 2020 database. Washington: IMF.

37. IMF, 2021. Policy Reponses to COVID-19 - Policy Tracker. Washington: IMF.

38. Jord'a, O., Singh, S. R. and Taylor, A. M., 2020. Longer-Run Economic Consequences of Pandemics. Federal Reserve Bank of San Francisco Working Paper, No. 2020-09. https://doi.org/10.24148/wp2020-09

39. Jovičić, G., 2017. Procjena potencijalnog rasta i jaza BDP-a u Hrvatskoj. Pregledi Hrvatske narodne banke, P-38.

40. King, R. and Rebelo, S., 1988. Business Cycles with Endogenous Growth. University of Rochester Working Paper.

41. King, R. G., Plosser, C. I. and Rebelo, S. T., 1988. Production, growth and business cycles: II. New Directions. Journal of Monetary Economics, 21(2-3), pp. 309-341. https://doi.org/10.1016/0304-3932(88)90034-7

42. Knotek, E. S., 2007. How useful is Okun's law? Economic Review, 92(Q IV), pp. 73-103.

43. Kroft, K. [et al.], 2014. Long-term unemployment and the Great Recession: The role of composition, duration dependence, and non-participation. NBER Working Paper, No. 20273. https://doi.org/10.3386/w20273

44. Loageay, C. and Tober, S., 2005. Hysteresis and NAIRU in the Euro Area. Macroeconomic Policy Institute Working Paper, No. 4. https://doi.org/10.1111/ j.1467-9485.2006.00387.x

45. Ma, C., Rogers, J. and Xhou, S., 2020. Modern Pandemics: Recession and Recovery: manuscript. https://doi.org/10.2139/ssrn.3668472

46. Nelson, C. R. and Plosser, C. R., 1982. Trends and random walks in macroeconmic time series: Some evidence and implications. Journal of Monetary Economics, 10(2), pp. 139-162. https://doi.org/10.1016/0304-3932(82)90012-5

47. Okun, A., 1962. Potential GNP: Its Measurement and Significance. Proceedings of the Business and Economics Section of the American Statistical Association, pp. 98-104. 
48. Rawdanowiczi, Ł. [et al.[, 2014. Secular Stagnation: Evidence and Implications for Economic Policy. OECD Economics Department Working Papers, No. 1169. https://doi.org/10.1787/5jxvgg6q27vd-en

49. Reifschneider, D., Wascher, W. and Wilcox, D., 2015. Aggregate Supply in the United States: Recent Developments and Implications for the Conduct of Monetary Policy. IMF Economic Review, 63(1), pp. 71-109. https://doi. org/10.1057/imfer.2015.1

50. Reinhart, C. M. and Rogoff, K. S., 2009. The Aftermath of Financial Crises. American Economic Review, 99(2), pp. 466-472. https://doi.org/10.1257/aer. 99.2.466

51. Stadler, G. W., 1986. Real versus monetary business cycle theory and the statistical characteristics of output fluctuations. Economics Letters, 22(1), pp. 51-54. https://doi.org/10.1016/0165-1765(86)90141-2

52. Stadler, G. W., 1990. Business Cycle Models with Endogenous Technology. American Economic Review, 80(4), pp. 763-778.

53. Stiglitz, J. E., 1993. Endogenous Growth and Cycles. NBER Working Paper, No. 4286. https://doi.org/10.3386/w4286

54. Stock, J. H. and Watson, M. W., 2011. Introduction to Econometrics. 3. ed. London: Pearson.

55. Stockhammar, P. and Oller, L.-E., 2012. A Simple Heteroscedasticity Removing Filter. Communication in Statistics - Theory and Methods, 41(2), pp. 281299. https://doi.org/10.1080/03610926.2010.521289

56. Yoo, S. and Managi, S., 2020. Global mortality benefits of COVID-19 action. Technological Forecasting and Social Change, 160. https://doi.org/10.1016/j. techfore.2020.120231

57. WHO, 2021. Coronavirus disease (COVID-19) pandemic. 
Appendix A presents estimated results of Okun's law in selected European countries. OLS estimation presents equation (1) with GDP at time $t$, and lagged values of GDP at time $t-1$ and $t-2$. OLS_noautocorrelation presents estimation of equation (1) with GDP at time $t$, and lagged values of GDP at time $t-1$ and $t-2$, and with lagged values of change in the unemployment rate in time $t-1$ and/or $t-2$, depending on the autocorrelation problem. Also, if the problem of autocorrelation was present even after adding more than two lags of the dependent variable, GARCH $(1,1)$ model was used to solve it. OLS_nohetero refers to estimated equation (1) that is the same as the OLS_noautocorrelation, but in this case, GARCH $(1,1)$ model is used to solve the problem heteroskedasticity if present. Lastly, dU presents the actual change in the unemployment rate. Suppose estimated values of the change in the unemployment rate are higher than the actual values of the change in the unemployment rate. In that case, this indicates the effectiveness of fiscal policy measures undertaken in the COVID-19 crisis.

\section{Figure A1}

Okun's law in Austria

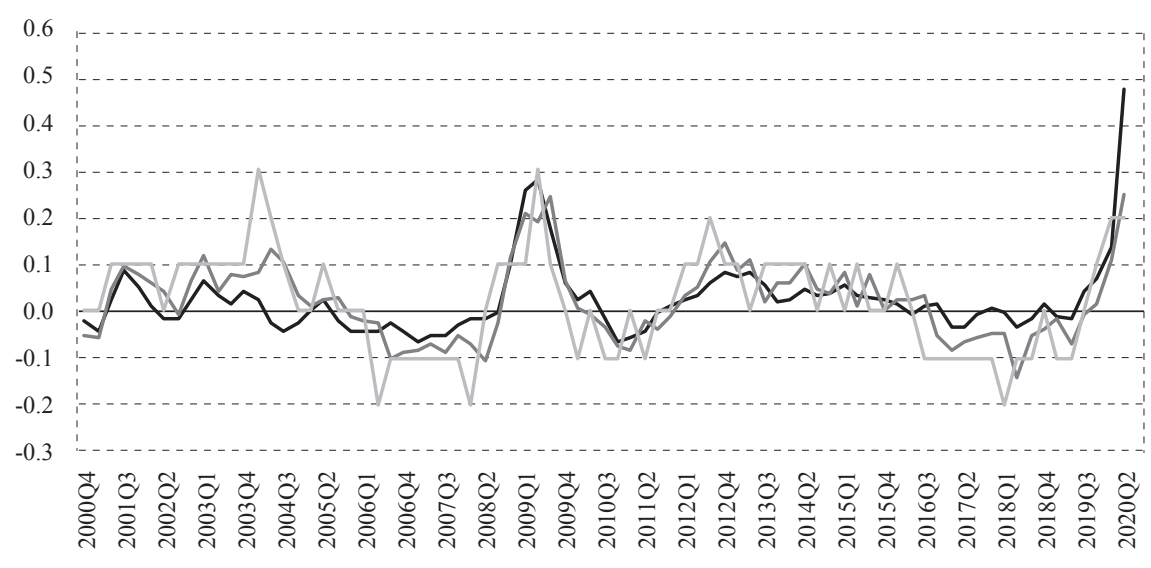

- OLS - OLS_noautocorrelation $\longrightarrow \mathrm{dU}$

Source: Authors'own calculation based on Labor force survey (LFS) unemployment data by Eurostat (2021). 


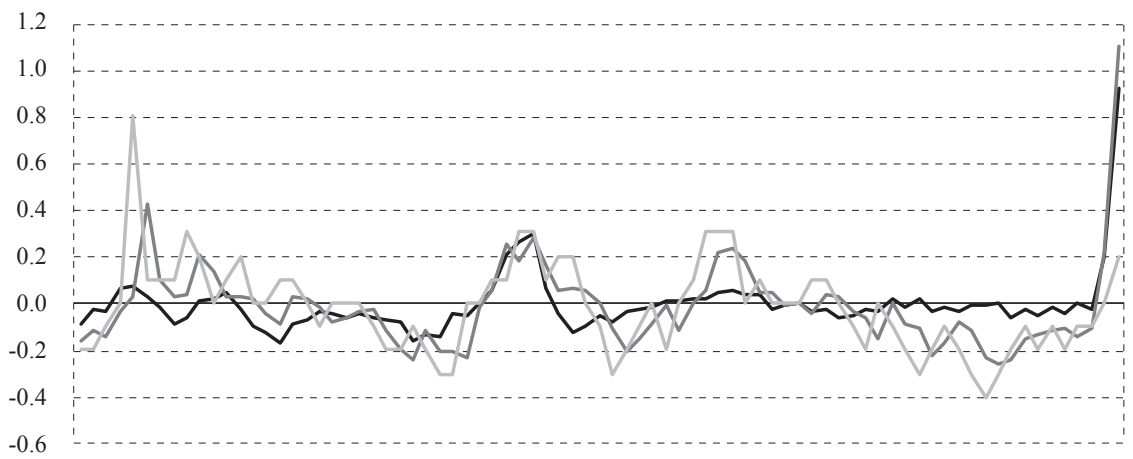

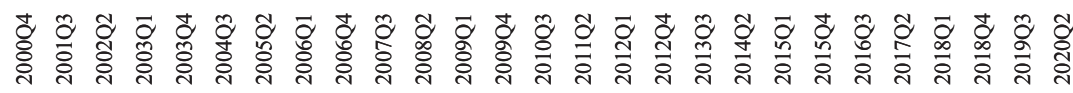
OLS

OLS noautocorrelation $\mathrm{dU}$

Source: Authors' own calculation based on Labor force survey (LFS) unemployment data by Eurostat (2021).

\section{Figure A3}

Okun's law in Bulgaria

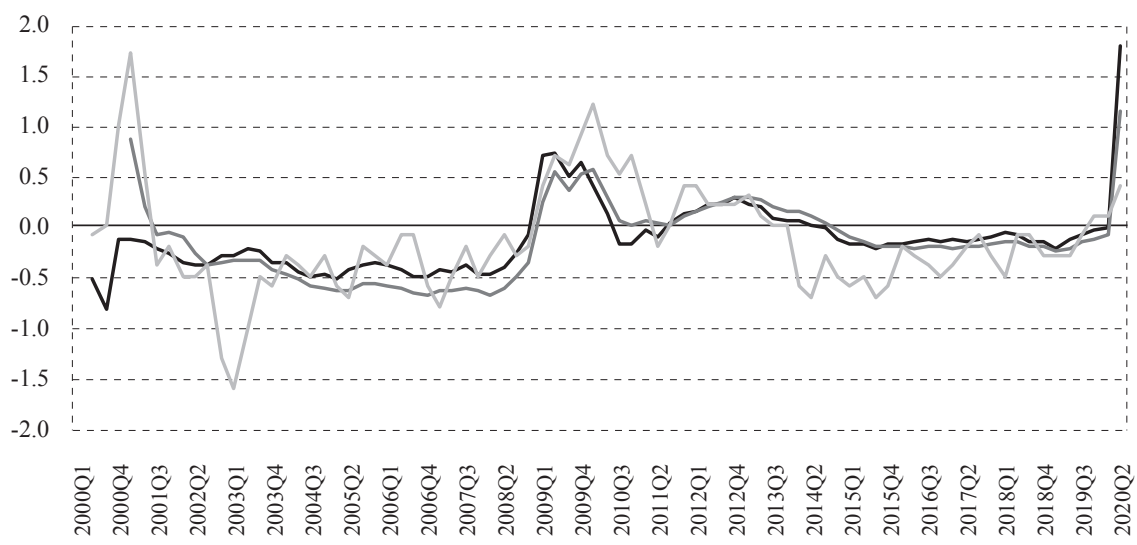

OLS OLS_noautocorrelation $\longrightarrow \mathrm{dU}$

Source: Authors' own calculation based on Labor force survey (LFS) unemployment data by Eurostat (2021). 
Figure A4

Okun's law in Croatia

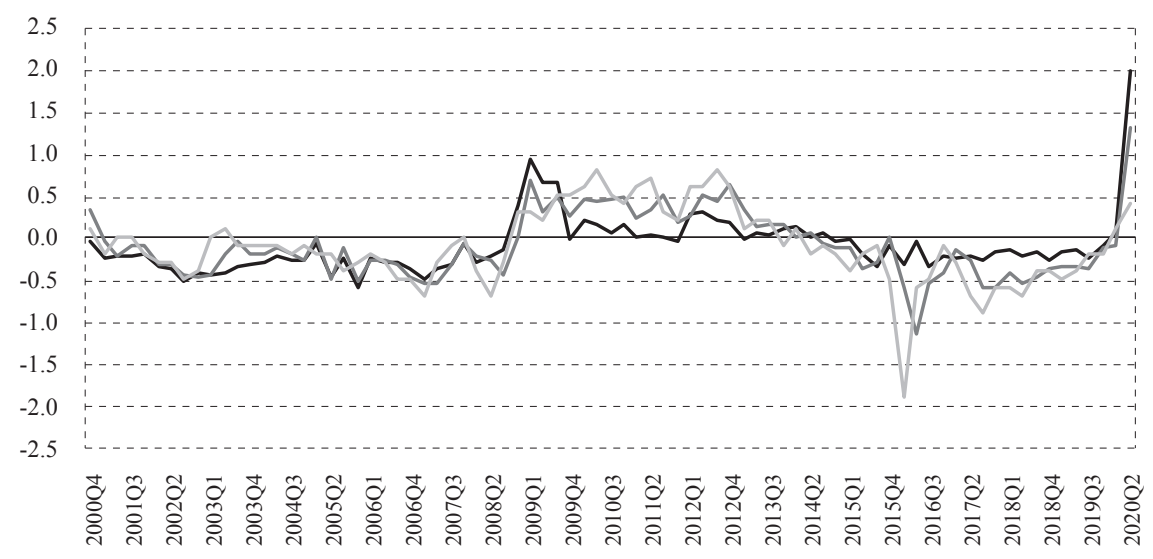

OLS

OLS_noautocorrelation

$\mathrm{dU}$

Source: Authors' own calculation based on Labor force survey (LFS) unemployment data by Eurostat (2021).

\section{Figure A5}

Okun's law in Cyprus

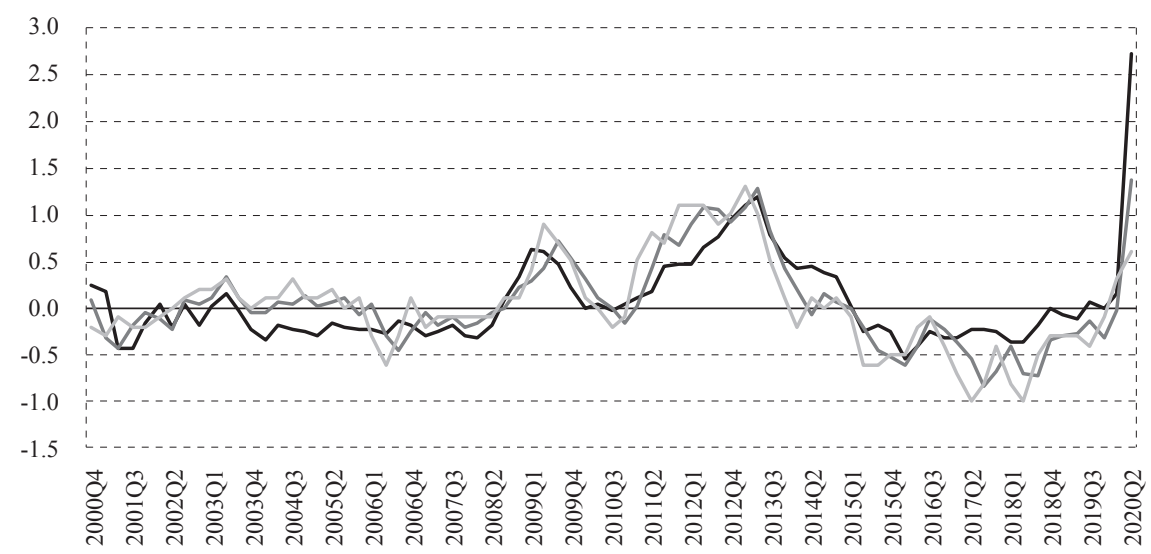

OLS - OLS_noautocorrelation $\longrightarrow \mathrm{dU}$

Source: Authors' own calculation based on Labor force survey (LFS) unemployment data by Eurostat (2021). 
Okun's law in Czechia

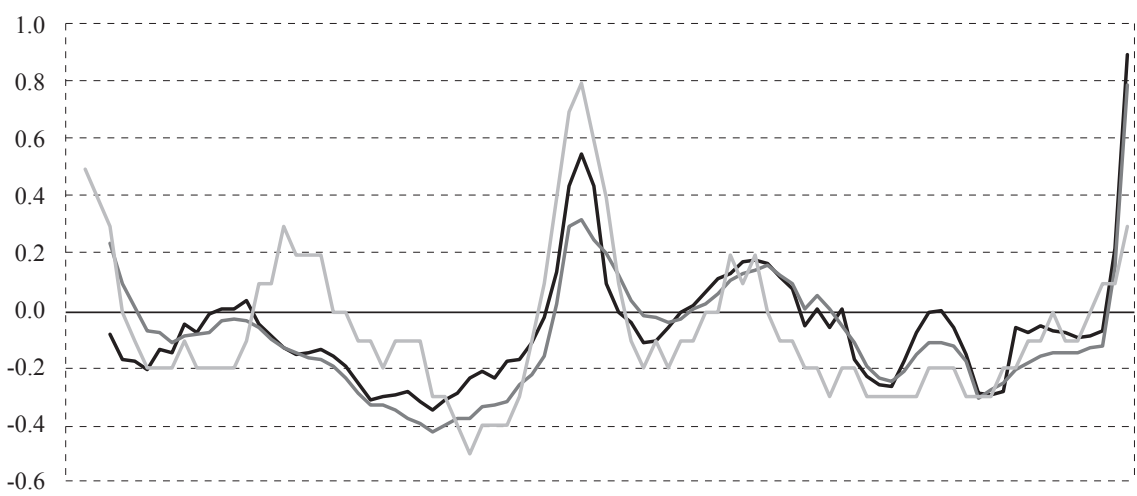

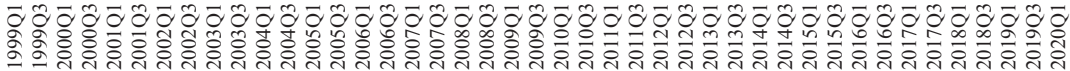

- OLS - OLS_noautocorrelation $\longrightarrow \mathrm{dU}$

Source: Authors' own calculation based on Labor force survey (LFS) unemployment data by Eurostat (2021).

\section{Figure A7}

Okun's law in Denmark

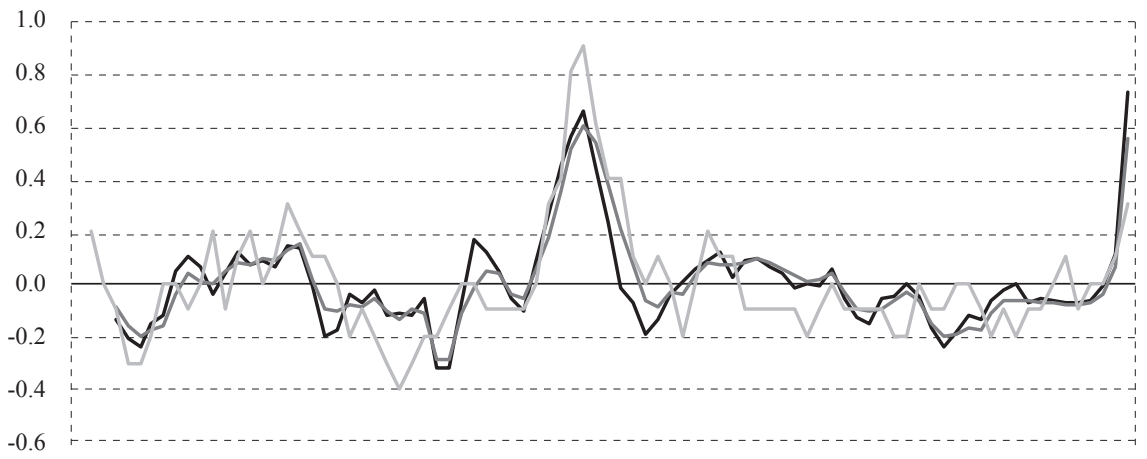

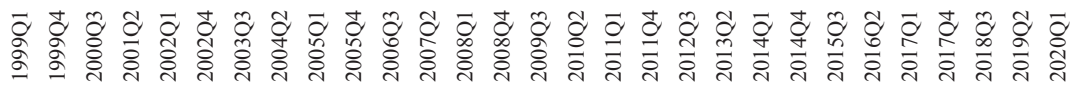
- OLS OLS_noautocorrelation $\mathrm{dU}$

Source: Authors'own calculation based on Labor force survey (LFS) unemployment data by Eurostat (2021). 
Figure A8

Okun's law in Estonia

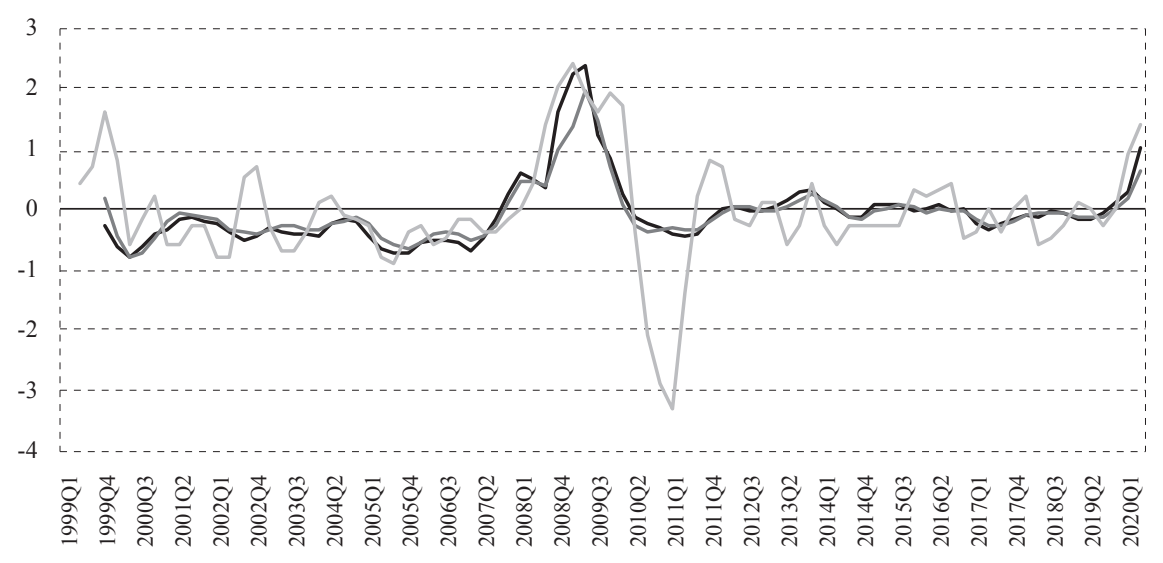

Source: Authors' own calculation based on Labor force survey (LFS) unemployment data by Eurostat (2021).

\section{Figure A9}

\section{Okun's law in Finland}

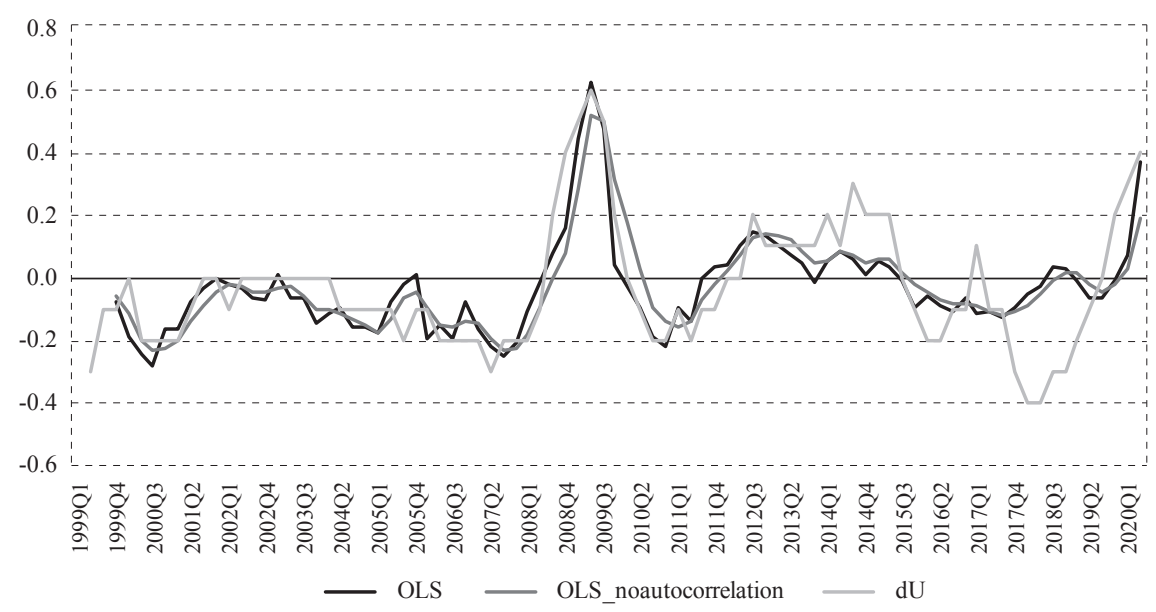

Source: Authors' own calculation based on Labor force survey (LFS) unemployment data by Eurostat (2021). 
Figure A10

Okun's law in France

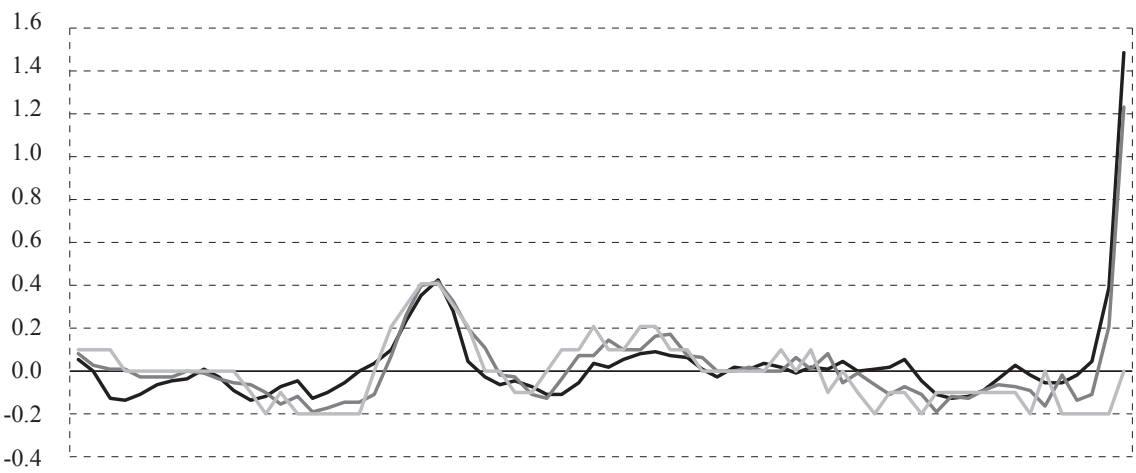

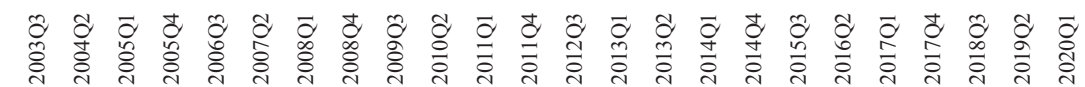

- OLS - OLS_noautocorrelation $\longrightarrow \mathrm{dU}$

Source: Authors' own calculation based on Labor force survey (LFS) unemployment data by Eurostat (2021).

\section{Figure A11}

Okun's law in Germany

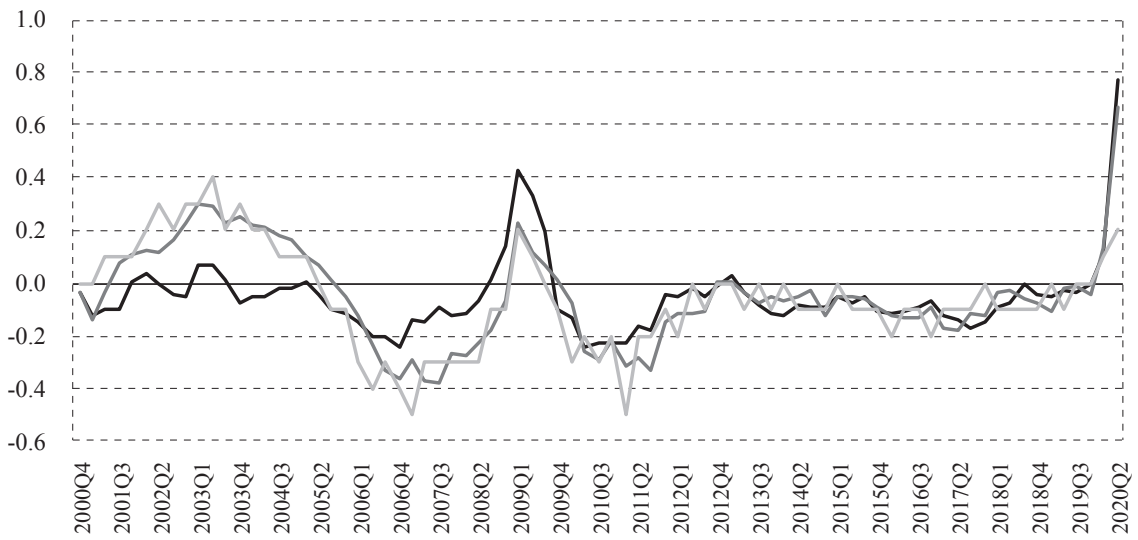

OLS

OLS_noautocorrelation

dU

Source: Authors' own calculation based on Labor force survey (LFS) unemployment data by Eurostat (2021). 
Figure A12

Okun's law in Greece

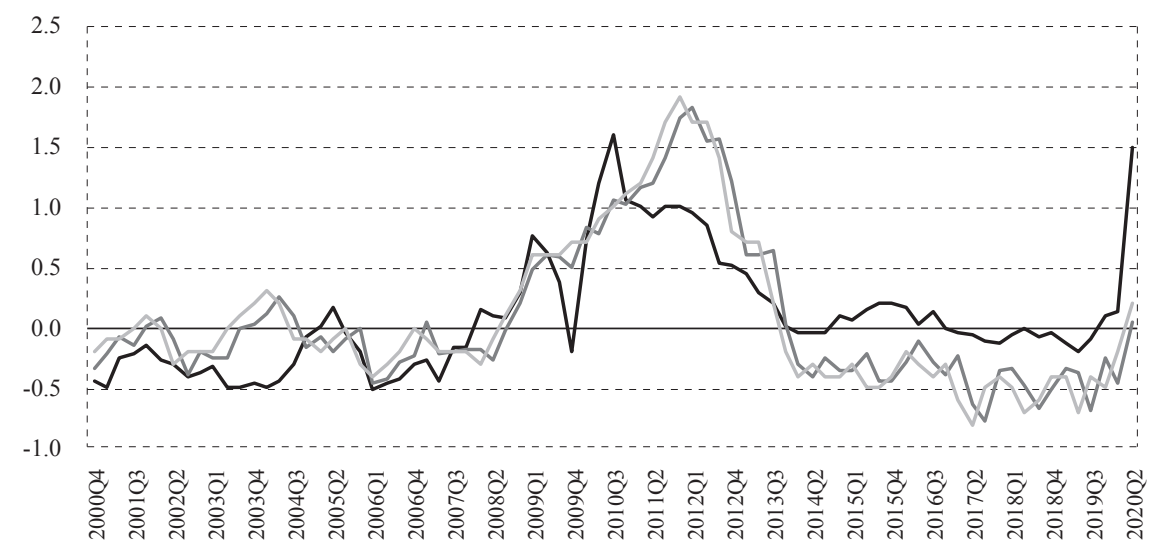

- OLS $\longrightarrow$ OLS_noautocorrelation $\longrightarrow \mathrm{dU}$

Source: Authors' own calculation based on Labor force survey (LFS) unemployment data by Eurostat (2021).

\section{Figure A13}

Okun's law in Hungary

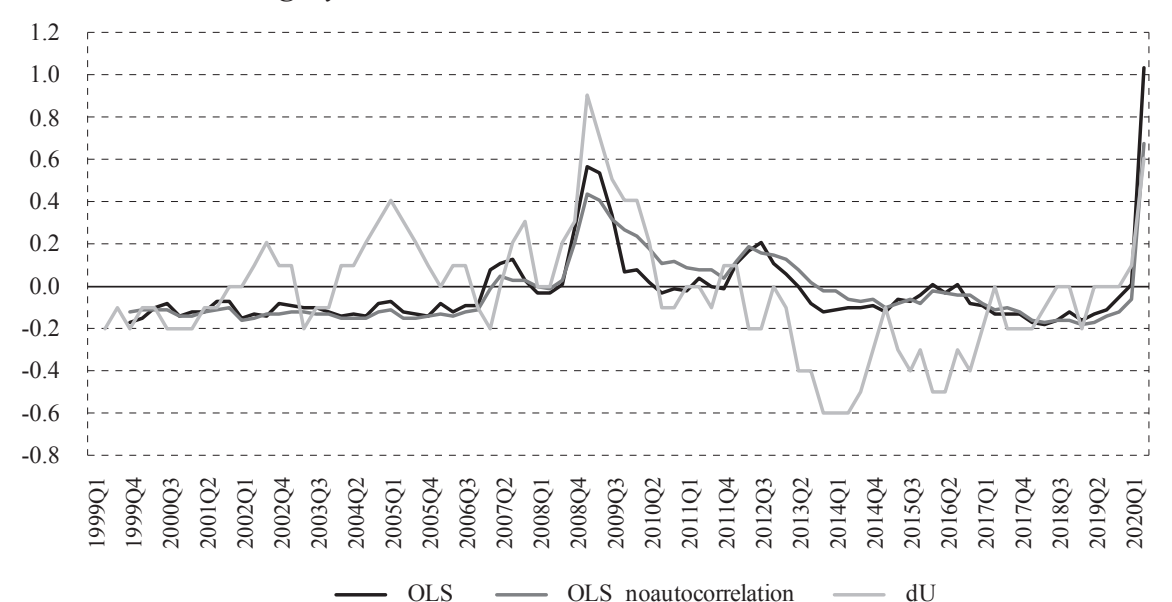

Source: Authors'own calculation based on Labor force survey (LFS) unemployment data by Eurostat (2021). 


\section{Figure A14}

Okun's law in Ireland
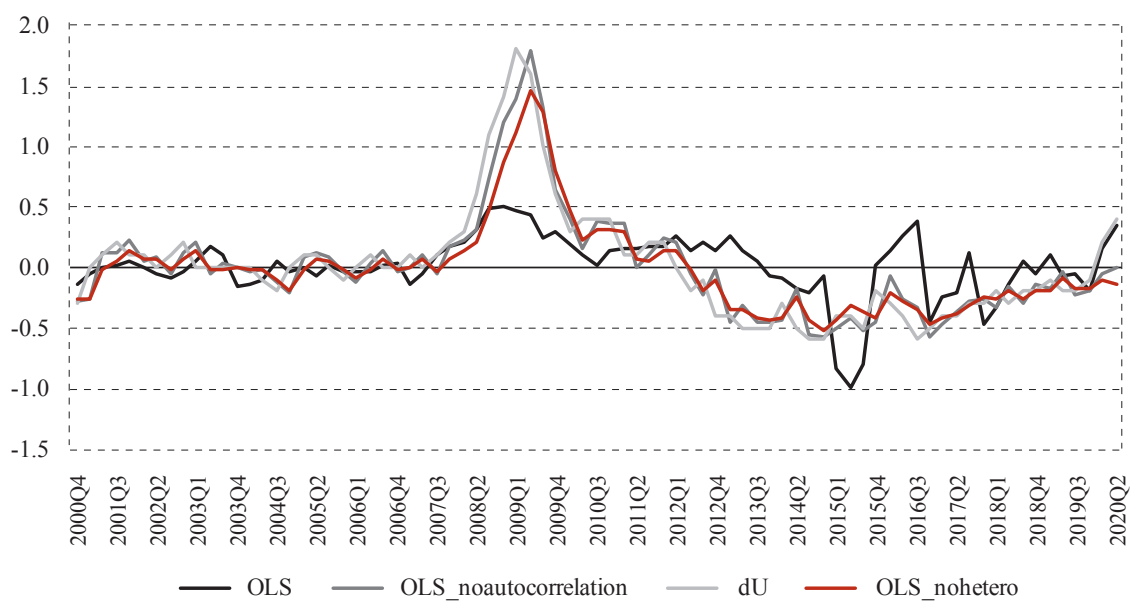

Source: Authors' own calculation based on Labor force survey (LFS) unemployment data by Eurostat (2021).

\section{Figure A15}

Okun's law in Italy

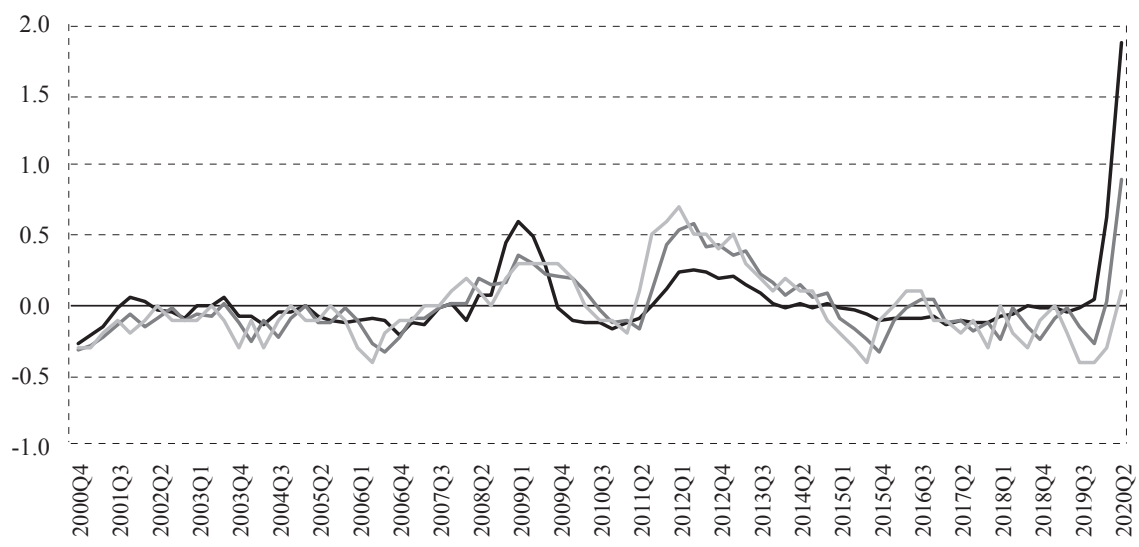

— OLS - OLS_noautocorrelation $\mathrm{dU}$

Source: Authors' own calculation based on Labor force survey (LFS) unemployment data by Eurostat (2021). 
Figure A16

Okun's law in Latvia

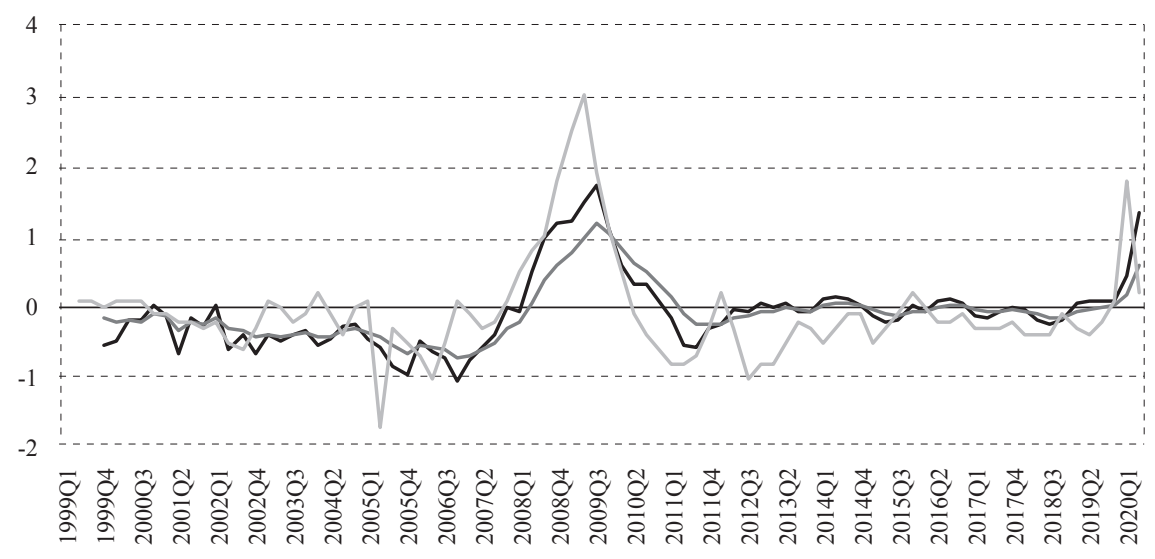

OLS - OLS_noautocorrelation $\longrightarrow \mathrm{dU}$

Source: Authors' own calculation based on Labor force survey (LFS) unemployment data by Eurostat (2021).

\section{Figure A17}

\section{Okun's law in Lithuania}

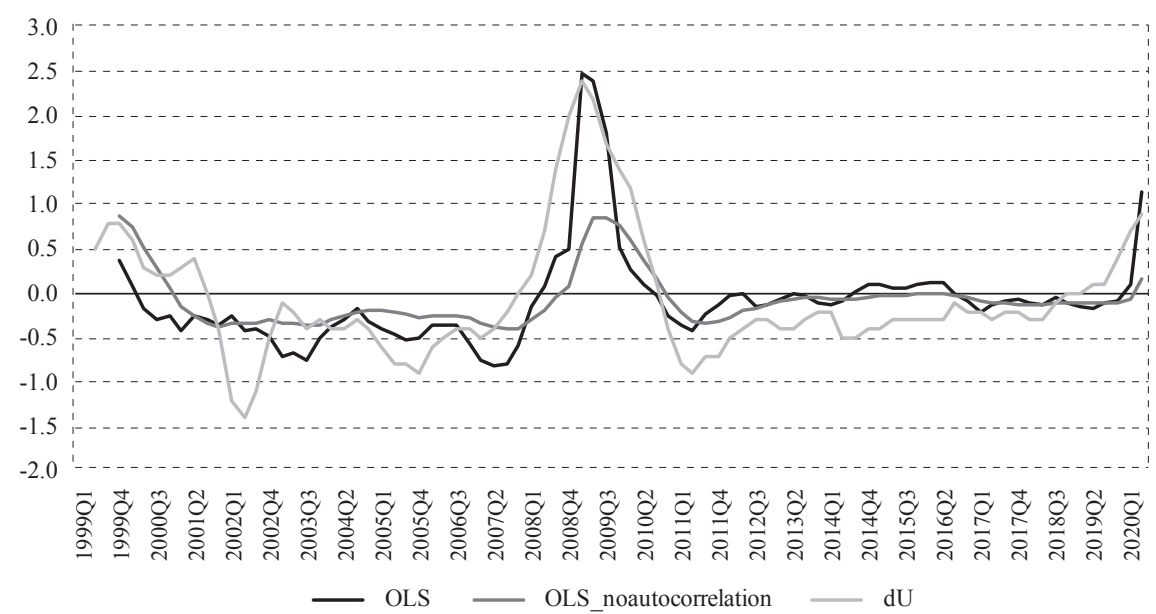

Source: Authors' own calculation based on Labor force survey (LFS) unemployment data by Eurostat (2021). 
Figure A18

Okun's law in Malta

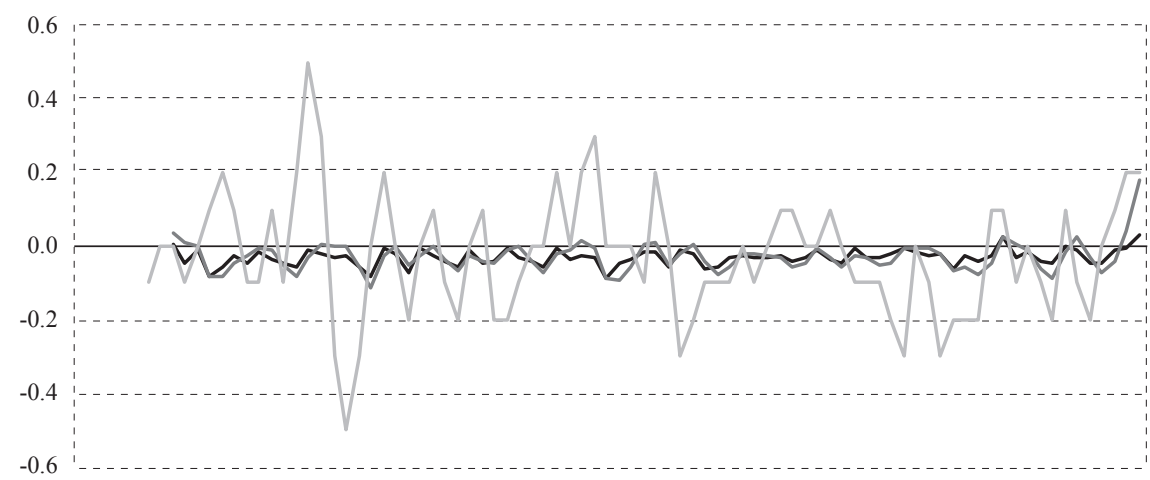

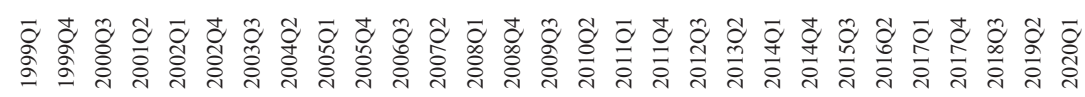

OLS

OLS_noautocorrelation

dU

Source: Authors' own calculation based on Labor force survey (LFS) unemployment data by Eurostat (2021).

\section{Figure A19}

Okun's law in Netherlands

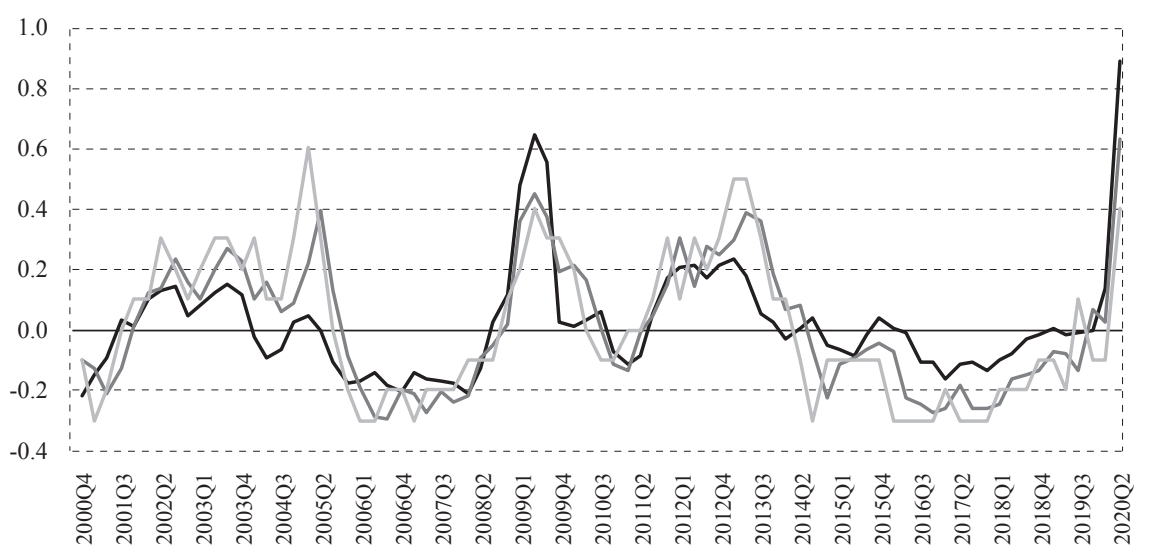

- OLS OLS noautocorrelation

$\mathrm{dU}$

Source: Authors' own calculation based on Labor force survey (LFS) unemployment data by Eurostat (2021). 
Figure A20

Okun's law in Poland

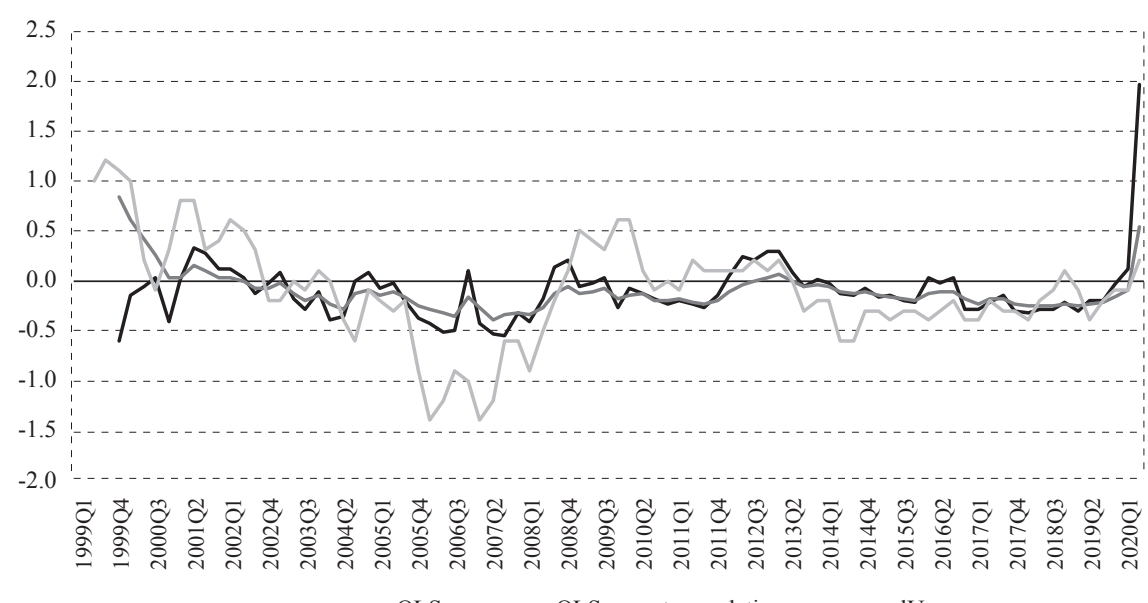

Source: Authors' own calculation based on Labor force survey (LFS) unemployment data by Eurostat (2021).

\section{Figure A21}

Okun's law in Portugal

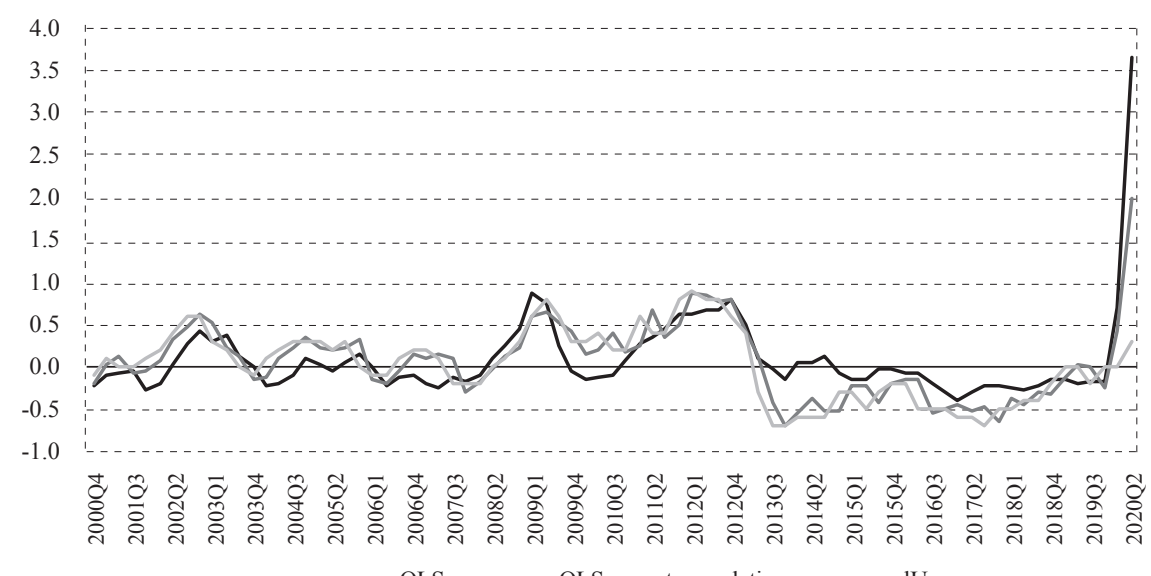

Source: Authors' own calculation based on Labor force survey (LFS) unemployment data by Eurostat (2021). 
Figure A22

\section{Okun's law in Romania}

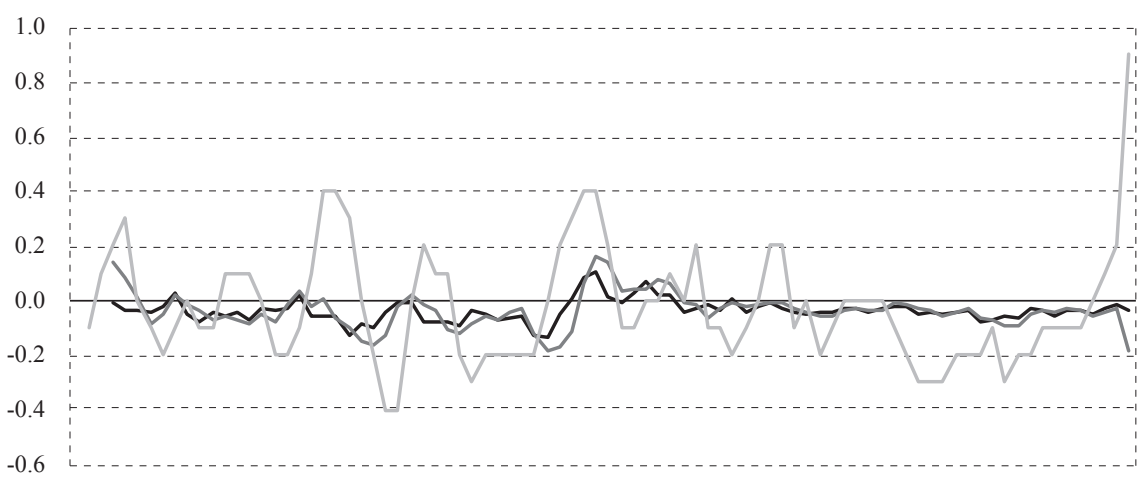

Source: Authors' own calculation based on Labor force survey (LFS) unemployment data by Eurostat (2021).

\section{Figure A23}

Okun's law in Slovakia

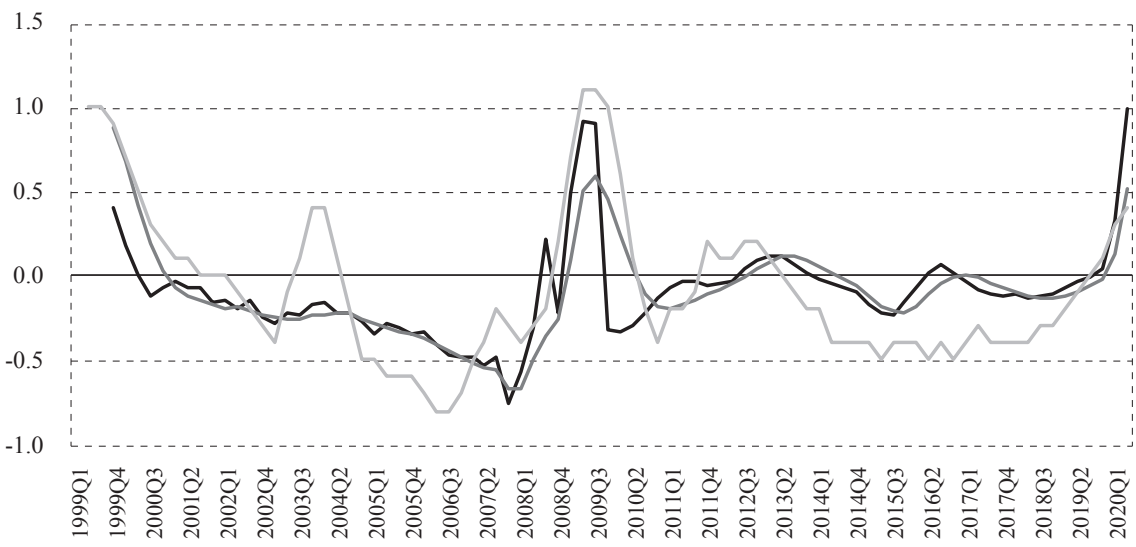

- OLS

OLS noautocorrelation $\mathrm{dU}$

Source: Authors'own calculation based on Labor force survey (LFS) unemployment data by Eurostat (2021). 
Figure A24

Okun's law in Slovenia

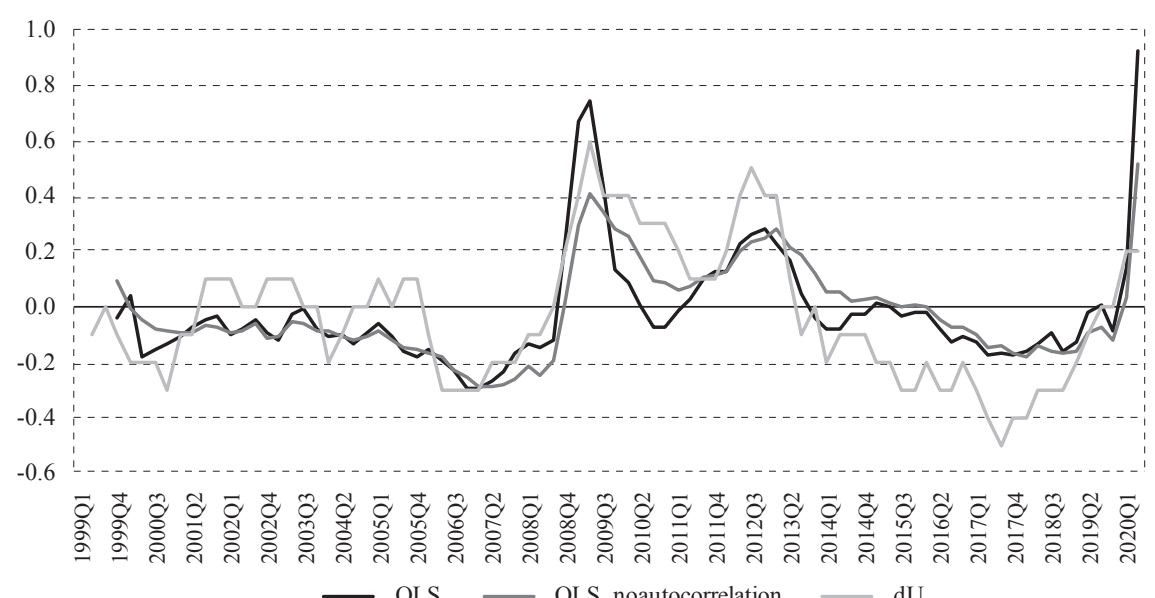

Source: Authors' own calculation based on Labor force survey (LFS) unemployment data by Eurostat (2021).

\section{Figure A25}

Okun's law in Spain

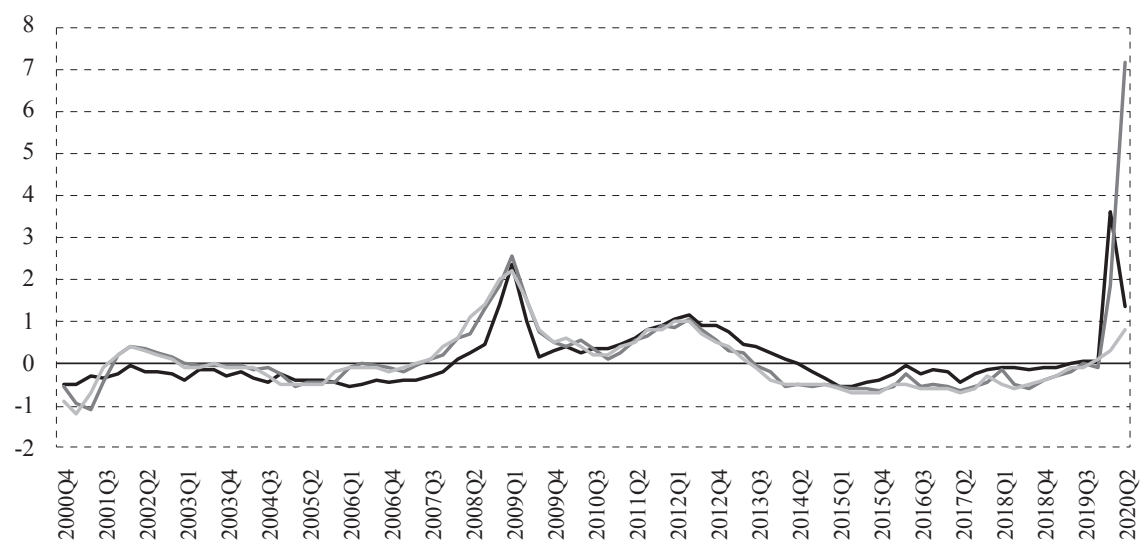

OLS OLS_noautocorrelation dU

Source: Authors' own calculation based on Labor force survey (LFS) unemployment data by Eurostat (2021). 
Okun's law in Sweden

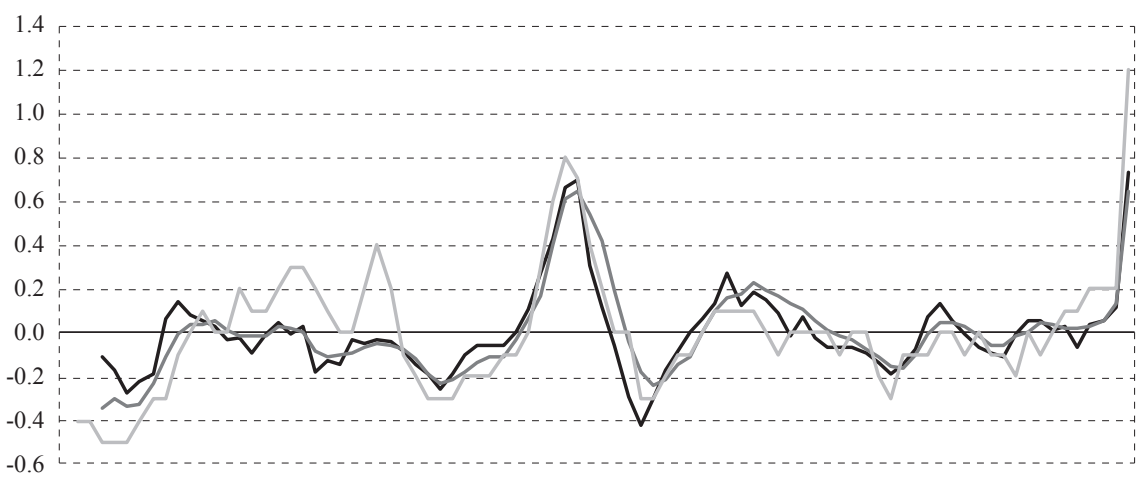

Source: Authors' own calculation based on Labor force survey (LFS) unemployment data by Eurostat (2021). 


\section{TABLE B1}

Description of fiscal measures imposed to fight COVID-19 crisis

\section{Country Fiscal measures (excluding health care system)}

Short-term work arrangement; liquidity support for firms; public loan

Austria guarantees; deferral/reduction of taxes; deferral of social security contributions; government investments to boost the economy

Support for temporary unemployed and self-employed; liquidity

Belgium support; deferral of social security and tax payments; solvency support; support to affected firms/households by subnational governments; a scheme for short-term trade credit insurance

60/40 wage subsidy scheme; support for artists; tourism support; agricultural producers support; tax relief; bonuses to pensions and

Bulgaria minimum pension increase; active labor market policies; increased unemployment benefits; "Keep Me"/ "Employment for you" program; support for workplaces in the hotel and restaurant sector

Deferment of public obligations; deferral of selected parafiscal charges;

Croatia interest-free loans to local governments; subsidization of net minimum; early refund of taxes for individuals; tax obligations of companies reduced/written off; short-time work program

Income support for households; wage subsidy; grants to small

Cyprus businesses and self-employed; support for the tourism sector; tax deferral/reduction; interest subsidy for new business and housing loans; guarantees; supported loans to SMEs

Czechia Wage subsidy; tax deferral/reduction; compensatory bonus for selfemployed persons and small Ltd; public guarantees; grants for tourism

Measures to support workers and businesses affected by the COVID-19

Denmark crisis. Temporary liquidity measures; deferral of tax payments; government guarantees

Cover for wage reduction; business loans to rural companies; guarantees/collateral for bank loans; business loans for liquidity support

Estonia to companies; support to local authorities; investment loans to companies; compensation for direct costs of canceled cultural and sporting events

Lower pension contributions; grants to SMEs and self-employed; expanded parental allowance, social assistance, and unemployment insurance; deferral of tax and pension payments; recapitalization scheme

Finland for state-owned companies; supporting restaurant and catering businesses; guarantees for the Employment Fund, SURE, and the EIB; support to households/businesses; increased public investment; temporary loosening of unemployment insurance benefit eligibility

Public guarantees; liquidity support; deferral of social security and tax payments; accelerated refund of tax credits; support for wages under the short-time work scheme; direct financial support for affected

France microenterprises; deferral of rent and utility payments for affected microenterprises/SMEs; additional investments; nationalizations of companies in difficulty; facilitating granting of exceptional bonuses; extension of unemployment benefits; support for the hardest-hit sectors 
Short-term work subsidy; expanded childcare benefits; easier access to basic income support for the self-employed; grants to small business owners and self-employed persons; interest-free tax deferrals; venture

Germany capital funding for start-ups; temporarily expanded duration of unemployment insurance and parental leave benefits; temporary VAT reduction; grants for hardest-hit SME's; financial support for local governments, credit guarantees for exporters and export-financing banks

Temporary transfers to vulnerable individuals; transfer for employees working in hard-hit firms and for self-employed professionals; extension of unemployment benefits; support for short-term employment,

Greece subsidies to household's loans; liquidity support to hard-hit businesses through loan guarantees, loan and interest payment subsidies, refundable advance payment, rent reductions, and deferred payments of taxes/social security contributions

Employers' social contributions lifted; tax deferral; cancel of tourism development contributions; tax relief for media; subsidizing wages for

Hungary shortened work hours; job creation by supporting investments; support for priority sectors; provision of interest-subsidized and guaranteed credit facilities

Employment wage support scheme: unemployment payment available to those who have lost employment due pandemic; compensation payments to the affected firms; investment in training, education, skills

Ireland development, work placement schemes, recruitment subsidies, job search, and assistance measures; grants for enterprises; waiver of commercial rates; reducing the lending rate for micro and small businesses; support to tourism and culture sector; tax deferral/reduction Measures to preserve jobs and support income of laid-off workers and selfItaly employed; measures to support businesses; tax deferrals; postponement of utility bill payments; measures to support credit supply; state guarantees; measures to support businesses, including grants for SMEs

Loans and guarantees to affected businesses; sectoral support packages;

Latvia use of EU funds to mitigate the impact of the crisis; revenue measures; expenditure measures supporting idle workers and social benefits; investment funds established to support affected large enterprises

Additional funds for support for the self-employed; wage subsidies; co-financing of climate change investment projects; guarantees for agricultural as well as SME loans; increased the borrowing; interest

Lithuania compensation support for SMEs with deferred loans; a new financial instrument for businesses to form portfolios from business loans; cheap loans targeted to hard-hit sectors; launching business support fund; job search allowances; an increase in social benefits; additional funds for the selfemployed and for vocational training; an increase in unemployment benefits

Support individuals unable to work from home; special unemployment benefits; wage subsidies for businesses and self-employed individuals; support for businesses to cover costs of quarantined employees; rent subsidy scheme for SMEs; tax deferral/reduction; in-work benefit and grants Compensation of labor costs for companies; compensation for affected sectors; support for entrepreneurs and self-employed, start-ups and

Netherlands small innovation companies; scaling up of the short-time working scheme; allowances for SMEs to help them finance their fixed costs; deferral of tax; public guarantee schemes 

increased guarantees for enterprises; loans for micro-firms; postponement /cancellation of social insurance contributions; deduction of 2020's losses

Poland for 2021 tax settlement; an allowance for parents of young children related to school closures; solidarity benefit for those who lost job due to crisis; an increase in the unemployment benefit; tourism voucher; interest rate subsidies; support for public investment; liquidity loans and subsidies for micro, small/medium, and large enterprises

Financial support for those temporarily furloughed by their employer; financial incentives to support the progressive reopening and to

Portugal normalize business activity; state-guaranteed credit lines for medium, small and micro enterprises; tax/social security contribution deferrals; financial support for the self-employed; support to the national airline

Covering partially the wages of parents staying home due to school closure;

Romania covering in part the wages of self-employed and workers in danger of being laid off; bonus for corporate income tax payments; deferral of utility payments for SMEs; grants for the businesses; tax deferral/reduction

Wage compensation for affected businesses and self-employed, and

Slovakia subsidies to individuals without income; enhanced unemployment benefits; deferral and waiver of employers' social security contributions; tax deferral; rental subsidies

Tax deferrals; wage subsidies; support to household income; support to

Slovenia corporate liquidity through grants, equity purchase, and government guarantees and credit lines; subsidies for shortened work time; vouchers for tourism

Unemployment benefit for workers temporarily laid off; direct aid for solvency support; tax deferral and reduction; benefit for self-employed workers; assistance programs for vulnerable renters; strengthened unemployment protection; subsidy for vehicle renewal; investment in digitization and innovation in the tourism; benefits for workers who have exhausted unemployment benefits; extension of unemployment Spain benefit to cover workers laid off during the probation period; a temporary monthly allowance for temporary workers; a temporary subsidy for household employees affected by COVID-19; financial assistance to the education system; exemptions of social contributions for impacted companies that maintain employment; deferral of social security debts for companies/self-employed; moratoria of social security contributions for the self-employed and companies in selected industries Liquidity support and guarantees; additional expenditures on wage subsidies for short-term leave, temporary payment of sick leave; loans to SMEs; temporary rent subsidies to vulnerable sectors; temporarily increase of unemployment benefits; expanded active labor market policies; expansion of education, initiatives for green jobs and summer jobs for young people; temporary reduction of employers' social

Sweden security contributions; grants to municipalities and regions; temporary grants to businesses to cover their fixed costs; support to regional public transport, deferral of taxes/social contributions; credit guarantees for Swedish airlines, state credit guarantees for loans to companies; guarantees to the EU for loans to member states, SURE, and to the European Investment Bank for a guarantee fund to support companies 



\section{The impact of regulator's statement requesting EU insurers to suspend dividend distributions due to the COVID-19 pandemic on share prices}

ENJA ERKER, BSc*

Article $^{* *}$

JEL: G28, P43, G22

https://doi.org/10.3326/pse.46.1.3

\footnotetext{
"I would like to express my sincere gratitude to my supervisor, Professor Jaka Smrekar, for his continuous support, invaluable advice and encouragement during my research. The present article is based on a topic, that I discuss mostly from a mathematical point of view in my thesis. I would also like to thank two anonymous referees whose comments have contributed to the final version of the paper.

${ }^{* *}$ Received: June 1, 2021

Accepted: November 21, 2021

\section{Enja ERKER}

University of Ljubljana, Faculty of Mathematics and Physics, Jadranska ulica 19, 1000 Ljubljana, Slovenia e-mail: enja.erker@gmail.com

ORCiD: 0000-0003-3053-5463
} 
Abstract

This article examines the impact of the regulator's statement requesting EU insurers to suspend dividend distributions due to the COVID-19 pandemic on share prices of insurance companies. The purpose of the regulation was to maintain a high level of capitalisation of insurance companies, thus allowing them to pay compensation for any damage incurred during the crisis. The statistical signifcance of the potential negative impact was explored using event study methodology. The empirical results suggest that the negative impact following the statement's release is not statistically significant over the chosen event window. The robustness of the results is confirmed by several statistical tests - parametric and nonparametric. The measure did not result in a fall in share prices in line with economic theory but, rather, contributed to ensuring the financial stability of the European insurance sector, supporting the real economy and consequently allowing quicker economic recovery.

Keywords: COVID-19, regulator's statement, insurance companies, event study, share prices

\section{INTRODUCTION}

The financial stability of the insurance sector is essential in order to ensure access to insurance services. The importance of the insurance sector and of its financial stability is even greater in the current times of uncertainty, during a pandemic. Safeguarding the stability of this sector is relevant from a business continuity perspective and from an individual's perspective. Nowadays one could not imagine a situation in which an insurance company would not be able to make payment on a health insurance claim. However, in pandemic times such a situation might arise. To minimize the risk of the occurrence of such situations, the European and Occupational Pensions Authority (EIOPA) has urged insurance companies to halt dividends, buybacks and bonuses.

This article examines the impact of this statement, a recommendation requesting EU insurers to temporarily suspend dividend distributions due to the COVID-19 pandemic on share prices of insurance companies. The main event is the release of a statement by EIOPA requesting (re)insurers to temporarily suspend all discretionary dividend distributions and share buy-backs aimed at remunerating shareholders. In its core, the regulation is not extremely binding if compared with the restrictions on dividend payments published by the European Systemic Risk Board in June 2020. The EIOPA statement or instrument, proportionate to the perceived risks (binding instrument, recommendation, opinion), is aimed at limiting dividend distributions for the years 2019 and 2020 of insurance and reinsurance companies doing business in the European Union. The purpose of the regulation was to maintain a high level of capitalisation of insurance companies, thus, allowing them to pay compensation for any damage incurred during the crisis. EIOPA stresses that this macro-prudential measure contributes to increasing the resilience of the financial infrastructure to financial shocks, maintains financial 
stability and prevents the emergence of disruption in the financial system with the potential of serious negative consequences for the functioning of the financial system and the real economy (OFS, 2020).

As EIOPA stressed, the purpose of the released statement is to maintain a high capital adequacy ratio enabling smooth payment of potential claims during the crisis. However, proactive regulation could also have an opposite effect. The value of equity, i.e., share price, could fall, which might deter potential new investors in the insurance sector and even encourage current investors to sell their shares. To understand the importance of EIOPA's regulation in its entirety the general circumstances in the insurance sector in the first half of year 2020 should be outlined. Firstly, European insurance companies experienced a slowdown in gross premiums written in 2020, especially in the life sector. Secondly, claims payments increased in the life sector and declined in the non-life sector. Thirdly, the assets of insurers remained mainly invested in bonds. And finally, insurers in the main achieved positive investment gains despite COVID-19 (OECD, 2021).

The aim of the article is to evaluate the issued statement from an economic and a mathematical point of view. Hence, the research question is whether and how the statement requesting insurers to suspend all discretionary dividend distributions and share buy-backs aimed at remunerating shareholders influenced the fall in stock prices of listed insurance companies. A similar challenge was addressed by Petr Jakubik in the article "The Impact of EIOPA Statement on Insurers' Dividends: Evidence from Equity Market" (Jakubik, 2020). Jakubik's article focuses on the relevant issue regarding the influence of regulations of dividend distributions on the European insurance companies. However, in the present study, I tackled the problem a bit differently. I collected data for 33 European insurance companies from the Bloomberg Terminal. The problem was then explored using event study methodology.

The paper is organised as follows. The next section provides the theoretical framework. The third section describes the data sample, i.e., collection of data and data cleaning, while the event study methodology is presented in the fourth section. The penultimate section includes a presentation of the results with discussion. The last section is the conclusion.

\section{THEORETICAL BACKGROUND: THE INFLUENCE OF AN IMPOSED BAN ON THE VOLATILITY OF THE FINANCIAL MARKET}

\subsection{ECONOMIC ASPECT}

In recent years many economic studies have been published examining the influence of a ban or recommendation, issued by governments or international institutions to financial organisations, on the volatility of the financial market (e.g., Baumann and Nier, 2004; Blinder et al., 2008; Shaffer, 1995, and others). These studies analyse indirect disclosure of information about the current financial situation of the economy on various levels, such as company level, national level or even the global level, in the case of the coronavirus crisis. The form of communication of large 
financial institutions plays an important role when adopting and publishing a regulation since it has the ability to influence the monetary policy and consequently the movement of the financial markets. However, the large variation in communication strategies across financial institutions suggests that a consensus has yet to emerge on what constitutes an optimal communication strategy (Blinder et al., 2008).

Greenspan (2003) stresses that banking and insurance companies are at core nontransparent, which cannot be drastically changed by increasing disclosures of information. Moreover, there is no evidence that an increased amount of disclosed information will be sure to increase transparency. It will hold true only on the assumption that the financial market participants correctly interpret the received information, then reasonably put this information in the context given, and finally, respond optimally considering the situation, which is unlikely to occur in practice. Moreover, Baumann and Nier (2004) emphasise that stock price volatility can be an appropriate measure of uncertainty among investors and that disclosure of information can reduce stock price fluctuations. Under their assumptions, an increase in the amount of information disclosed decreases the information asymmetry and uncertainty in the financial markets.

Additionally, Schaffer, in one of his studies (1995), calls attention to the fact that disclosures of information are often cited as particularly costly. The cost of the disclosure includes direct costs; these occur first, when preparing the disclosure, and second when the disclosure occurs. Regarding the event explored in this article, direct costs are costs incurred during the preparation and at the disclosure of EIOPA's statement. Likewise, indirect costs are of great importance too (Baumann and Nier, 2004). They occur when companies use given information to participate more profitably in the financial markets. It is for this reason that banking and insurance companies respond to the disclosures with extreme caution.

As mentioned in the previous section, the disclosure that I will explore in this article was already explored by Jakubik (2020). He believes that the statement could help to reduce uncertainty about potentially adverse evolutions of solvency positions incapable of absorbing the shocks during the crisis. Furthermore, he obtained empirical results that suggest that the negative impact following the announcement was not statistically significant in the chosen time interval.

\subsection{MATHEMATICAL ASPECT}

In addition to the economic studies, analysing the influence of an imposed ban or recommendation on the volatility of the financial market, described in the previous section, there are also various mathematical methods. The best known among them is an event study. This is a statistical method used to assess the impact of an event on the value of a company or its stock price (Hayes, 2020). The earliest studies on event study methodology were published in the 1930s and were later on further developed (e.g., Dolley, 1933; Myers and Bakay, 1948; Fama et al., 1969; Brown and Warner, 1985, and others). 
The author of the first published event study, Dolley (1933), examined stock splits between the years 1921 and 1933. He analysed the influence of stock splits on stock prices. He found out that stock splits, i.e., an increase in the number of stocks, decrease the price of a single stock. He also noted that the total value of all stocks remained almost unchanged during the observed period. As this is the first conducted event study, the statistical basis was not refined, and thus, the results were not satisfactory in terms of reliability and accuracy.

A similar problem was addressed by Myers and Bakay (1948). They wanted to find out whether a company's decision about a stock split influenced its market price. As key impact factors, they indicated the splitting ratio, industrial development at that time and price range following the split. They concluded that in the case of a favourable decision time frame, there might be a positive impact observed, even if a minimal one.

Fama and colleagues (1969) carried out one of the most comprehensive event studies in which they demonstrated that in the past, stock splits were usually related to higher dividends. Their study has proved that stock markets use the announcement of stock split to re-evaluate the expected returns. The authors of the above-mentioned study pointed out that the daily stock return for individual security exhibits substantial deviations from normality, which cannot be noticed when observing monthly data. This suggests that distributions of daily returns are fattailed relative to a normal distribution.

This finding was supported a couple of years later by Brown and Warner (1980; 1985), who used a more modern methodology. Moreover, they added that the daily stock returns differentiated substantially from the usual stock returns in the measures of shape - skewness and kurtosis. They upgraded the already existing research with a random selection of event dates and stocks to simulate event study without any assumption about the distributions of stocks returns. Subsequent event studies, mostly conducted in the new millennium, also examined other events, with particular focus on events in companies (such as changes in the management, the amendments to the Statute, mergers and acquisitions, and others).

\section{DATA SAMPLE}

Secondary data, dividend payments and share prices, are obtained from the Bloomberg Terminal database (2020). Firstly, I explored the dividend policy before this event, which was relatively stable, since in the last few years there was no economic crisis. The last significant one was the financial crisis of 2007-2008. However, there were some individual market shocks, such as the rise of cryptocurrencies, oil crashes and jumps, reopening of the Greek stock market and others (The Center for Financial Stability, 2021).

Secondly, I checked what the actual decision was after the statement was issued - whether insurance companies really suspended dividend distributions. The 
percentage of companies that paid out dividends regardless of the recommendation is $49 \%$. As an example, payments and non-payments of dividends for insurance company Sava Re are presented in figure 1 .

\section{Figure 1}

Payment of dividends - Sava Re

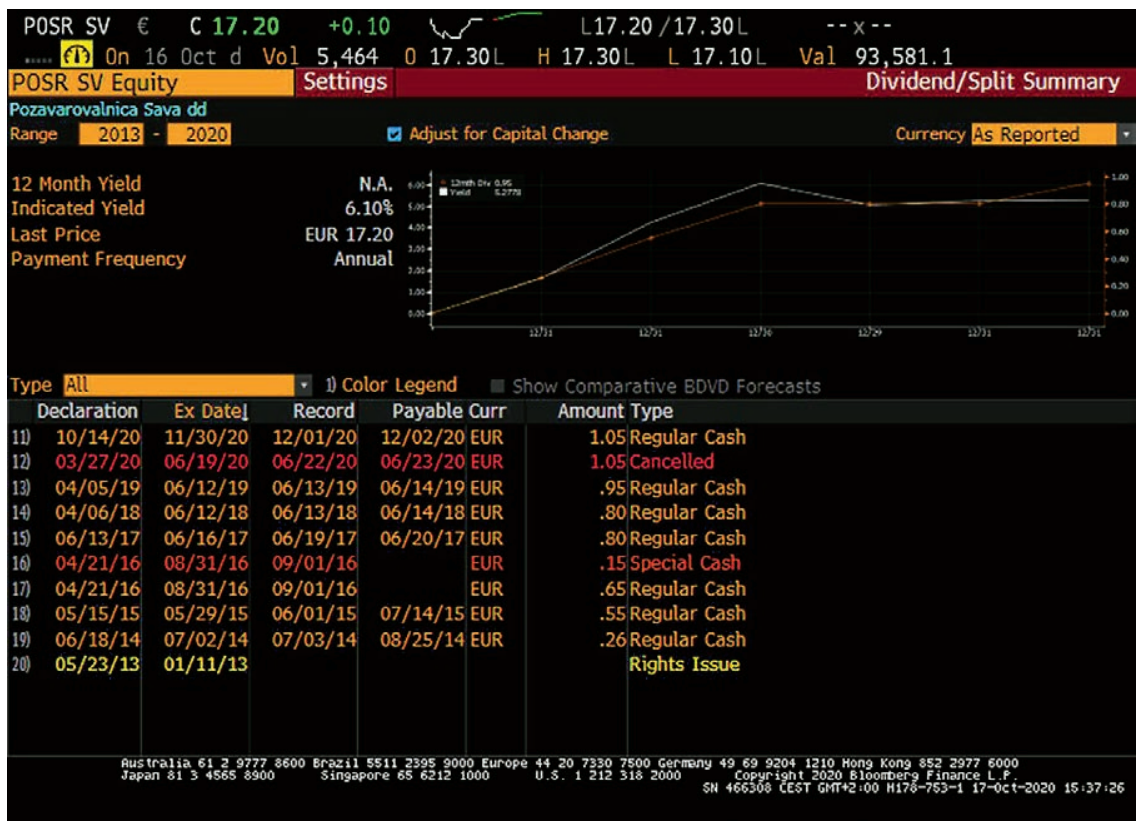

Source: The Bloomberg Terminal.

Thirdly, I cleaned the data of share prices, all non-trading days (Saturdays, Sundays and major holidays) and the insurance companies with missing data were removed. Then, I calculated the return on the share, expressed as a percentage, for each day. From here on, the R programming language and the RStudio development environment were used, partially edited data and S\&P index values were imported into R. Next, I cleaned the data using standard methods and compiled an organised database on which I performed an event study.

\section{EVENT STUDY METHODOLOGY}

In this article, I decided to use the event study methodology for assessing the impact of an event on the value of stock prices. As already mentioned in section 2, event study methodology is a statistical method for analysing the influence of a particular event on a company's value or its stock price (Hayes, 2020). Following Henderson (1990), event studies are typically arranged into four groups:

- market efficiency studies - these are based on the analysis of the speed and the correctness of the response,

- information value studies - these want to find out to what extent the event is reflected in the stock price, 
- metric exploration studies - these studies split data into subsamples and look for abnormal returns in the subsamples,

- methodological studies - these strive to find the most efficient method for taking into consideration the specificity of the data.

The event study conducted in this article falls under information value studies. The aim is to determine to what extent the event of the release of a statement issued by EIOPA requesting insurers to suspend all discretionary dividend distributions is reflected in the stock prices of insurance companies. According to Damodaran (2012), events can be general (impact on the whole market) or specific (impact on a particular company). The event explored in this article, is at core, a general one. However, given the limitation of scope, the event will be addressed more specifically. Sample size determination is based on the principle that the accuracy of estimates increases rapidly when the sample size increases. For that reason, the sample contains all 33 European insurance companies data for which are available in the Bloomberg Terminal. The event study design, according to Damodaran (2012), involves the following steps:

1) event definition

2) examination period definition

3) calculation of abnormal returns

4) data smoothing

5) aggregation of abnormal returns

6) testing procedure.

I followed the scheme above while conducting my event study.

\subsection{EVENT DEFINITION}

In the first step of the research process, the event, which will be explored further below, must be clearly defined. In the examined case, the published information is in the form of a statement issued by EIOPA requesting insurers to suspend all discretionary dividend distributions. The statement was published on April $2^{\text {nd }} 2020$.

On the one hand, supervisory institutions of some European member states (MS) responded even earlier on their own initiative. On the other hand, other MS to which the coronavirus spread later responded to the issued statement with a delay. For individual European MS, I looked up the internal dates of the publication of the regulation and arranged the data systematically (table 1) so that the dates coincide on the so-called day 0 (the day when the regulation was issued).

The dates of the issued regulations range from the $24^{\text {th }}$ of March to the $7^{\text {th }}$ of April 2020 (table 1). The first regulations were issued by Germany and Finland, the last from the chosen European MS to respond was Belgium. A one-month gap between the first and the last response would be expected since the epidemiological situation varied among European MS (Steward, 2020). 
Furthermore, the responses were similar, but still different across member states; some responses seem to be less strict than the EIOPA statement with respect to dividend distribution, for example Germany, Ireland, Italy, Norway and the United Kingdom (ESRB, 2020). The reason for the differences in strictness could be that these European MS are the home states of some of the biggest and the most successful insurance companies in Europe. Therefore, their national regulators probably trusted in their decisions and were not afraid that the possible payment of dividends would result in a low capital adequacy ratio.

\section{TABLe 1}

Dates of the issued regulations of the chosen European member states

\begin{tabular}{|c|c|c|}
\hline Country & Date & Insurance company \\
\hline Austria & $3 / 4 / 2020$ & $\begin{array}{l}\text { Uniqua } \\
\text { Vienna Insurance Group }\end{array}$ \\
\hline Belgium & $7 / 4 / 2020$ & $\begin{array}{l}\text { Ageas SA/NV } \\
\text { KBC Insurance Group }\end{array}$ \\
\hline Finland & $24 / 3 / 2020$ & Sampo Plc \\
\hline France & $3 / 4 / 2020$ & $\begin{array}{l}\text { AXA SA } \\
\text { COFACE } \\
\text { SCOR SE }\end{array}$ \\
\hline Ireland & $2 / 4 / 2020$ & Metlife EU Holding company \\
\hline Italy & $30 / 3 / 2020$ & $\begin{array}{l}\text { Generali } \\
\text { Gruppo Assicurativo Unipol }\end{array}$ \\
\hline Germany & $24 / 3 / 2020$ & $\begin{array}{l}\text { Allianz } \\
\text { HDI } \\
\text { Nuernberger }\end{array}$ \\
\hline Netherlands & $2 / 4 / 2020$ & $\begin{array}{l}\text { Aegon N.V. } \\
\text { NN Group }\end{array}$ \\
\hline Norway & $25 / 3 / 2020$ & $\begin{array}{l}\text { Gjensidige Forsikring ASA } \\
\text { Storebrand ASA }\end{array}$ \\
\hline Poland & $26 / 3 / 2020$ & Capital Group PZU \\
\hline Slovenia & $31 / 3 / 2020$ & $\begin{array}{l}\text { Sava Re Group } \\
\text { The Triglav Group }\end{array}$ \\
\hline Spain & $6 / 4 / 2020$ & $\begin{array}{l}\text { GRUPPO CATALANA OCCIDENTE, S.A. } \\
\text { MAPFRE, S.A. }\end{array}$ \\
\hline United Kingdom & $31 / 3 / 2020$ & $\begin{array}{l}\text { Admiral } \\
\text { Aviva plc } \\
\text { Direct Line } \\
\text { Hiscox } \\
\text { Phoenix Group Holdings } \\
\text { Prudential PLC } \\
\text { RSA Insurance Group plc } \\
\text { Saga } \\
\text { St James Place plc } \\
\text { QBE }\end{array}$ \\
\hline
\end{tabular}

Source: EIOPA - Monitoring of dividends distribution following EIOPA and NCA statement (June 2020). 
The second step is based on the definition of the examination period around the studied event. In a case in which there is less information about the event date, the examination period is wider. Since the date for the studied event is known, I decided to gather daily data. The method is more accurate if the length of the examination period is approximately 250 days (Brown and Warner, 1985). That being the case, I have chosen the following beginning and end of the period under examination: the $24^{\text {th }}$ of June, 2019 and the $12^{\text {th }}$ of April, 2020. Considering the above-mentioned systematic data compilation (the coincidence of day 0 ) and the exclusion of the nontrading days, the length of the time period is 250 days. In addition, the starting date is about four months before the first case of coronavirus infection was identified in the World, thus, when the European financial markets were relatively stable. In midMay 2020, which marks the end of the time period, the majority of European MS had already coped with the first wave of the coronavirus pandemic. The period under examination is presented graphically in figure 2. Other significant events, which accompanied the beginning of the coronavirus crisis, are added as well.

\section{Figure 2}

\section{Examination period}

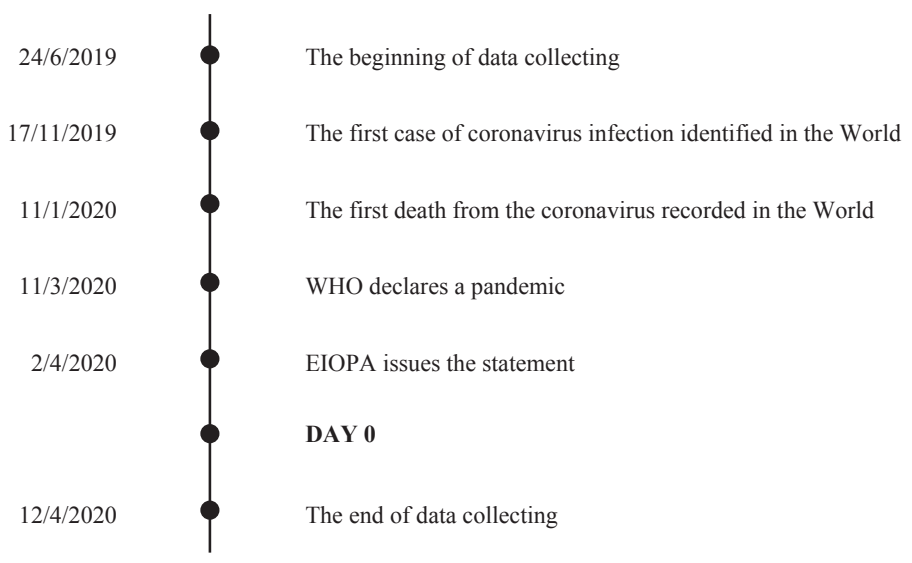

Source: Bryson Taylor (2021).

It is worth remembering here that day 0, in the case of the majority of European MS, came after the $2^{\text {nd }}$ of April 2020 when EIOPA issued the statement, although there are some European MS that responded earlier, meaning before the $2^{\text {nd }}$ of April 2020. In the case of these MS, the last and the penultimate points on the timeline should be replaced.

The chosen examination period is usually divided into two parts: the estimation period and the observation period. The estimation period is in general defined as the time from day $t_{0}$ to day $t_{1}$, while the observation period is defined from day $t_{2}$ to $t_{4}$ (Brown and Warner, 1985). Day 0 is marked with $t_{3}$ on the timeline (figure 3 ). 


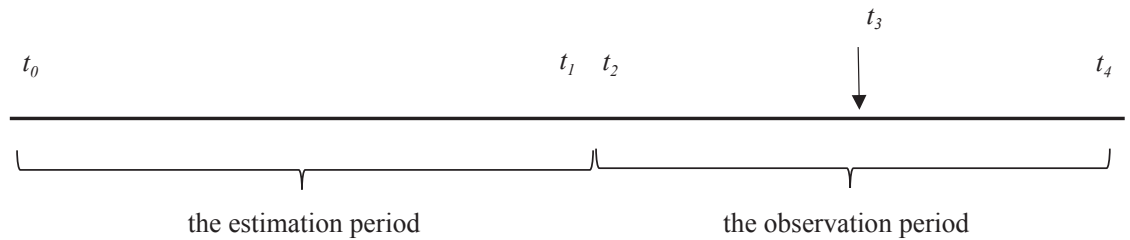

Source: Obi (2017).

In our case, the estimation period is defined as the time from day -244 to day -6 , while the observation period is defined from day -5 to day +5 . The timeline is presented in figure 4.

\section{Figure 4}

Examination period in general

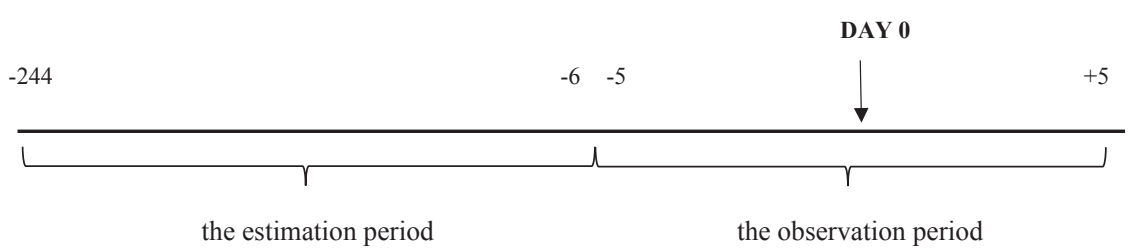

Source: Own compilation.

To check the adequacy of the endpoints of the observation period, I plotted the graphs of market returns for the chosen 33 insurance companies. As an example, there are two graphs plotted in figures 5 and 6 for two insurance companies: Generali (Italy) and Hiscox (United Kingdom). The estimation period is marked grey; black is used for the observation period. In both graphs, there is a dynamic change of movement around day -25 . The reason behind this jump is the coronavirus outbreak in Europe. It is important that the event of the coronavirus outbreak is separated from the event of the issued statement, so the results will be more robust.

\section{Figure 5}

\section{Stock return Generali}

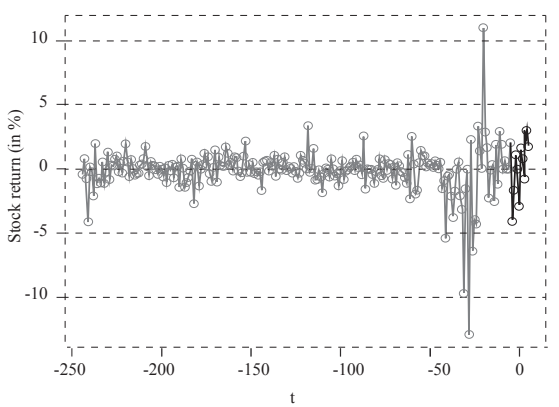

Source: The Bloomberg Terminal.

\section{Figure 6}

Stock return Hiscox

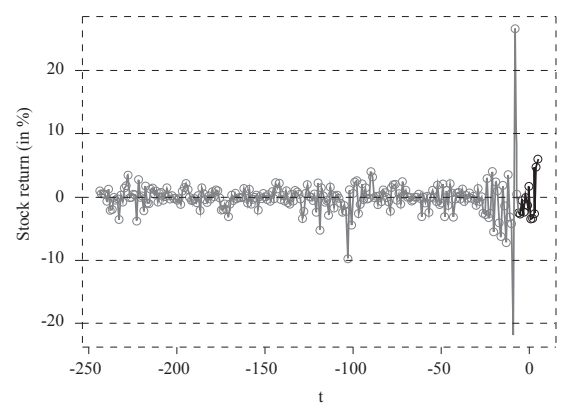


The third step of the event study assesses the abnormal returns on a stock (occurring as a result of the event). To assess these, the so-called "normal" or actual returns on a stock have to be defined first. An actual return on a stock $R_{i, t}$ of the insurance company $i$ on the day $t$ refers to the actual gain or loss an investor in the insurance company $i$ experiences on the day $t$. Furthermore, the abnormal return on a stock $A R_{i, t}$ of the insurance company $i$ on the day $t$ is defined as the difference between the actual return $\left(R_{i, t}\right)$ and the expected return $\left(E\left(R_{i, t} \mid X\right)\right.$, where $X_{t}$ stands for the vector of explanatory variables (e.g. market index) in day $t), t \in[-5,5]$,

$$
A R_{i, t}=R_{i, t}-E\left(R_{i, t} \mid X_{t}\right)
$$

The data on actual returns are in this study obtained from the Bloomberg Terminal database. The expected returns are calculated using three different models, which are presented in detail in the following subsections. After calculating the expected returns, I calculated the abnormal returns for all three models. Then, for every day in the observation period I calculate the average of three abnormal returns (one for each model). Expected return models are divided into statistical models and economic models. The first are based on statistical assumptions about the movement of returns, while the latter are derived from assumptions about the investor behaviour (Craig MacKinlay, 1997).

\subsubsection{THE MEAN ADJUSTED RETURNS MODEL}

The basic assumption of the mean adjusted returns model is that the vector of explanatory variables $X_{t}$ is constant (independent of time $t$ ). The expected return $\left(E\left(R_{i, t} \mid X\right)\right)$ on the stock of insurance company $i$ can be written as average actual return on the stock of insurance company $i$ :

$$
E\left(R_{i, t} \mid X_{t}\right)=E\left(R_{i, t} \mid X\right)=E\left(R_{i, t}\right)=\overline{R_{i, t}} .
$$

To be more specific, the above equation can be rewritten as:

$$
E\left(R_{i, t} \mid X_{t}\right)=\frac{1}{239} \sum_{t=-244}^{-6} R_{i, t} .
$$

\subsubsection{THE MARKET ADJUSTED RETURNS MODEL}

The market adjusted returns model is based on a chosen stock market index, I have chosen the usual index S\&P 500 (Standard \& Poor's 500 Index), which is used quite often when conducting event study. The expected return, $\left(E\left(R_{i, t} \mid X\right)\right)$ on the stock of insurance company $i$ on the day $t$, in the market adjusted returns model is defined as market return $\left(R_{M, t}\right)$, i.e., the value of the chosen index on day $t$ :

$$
E\left(R_{i, t} \mid X_{t}\right)=R_{M, t}=S \& P_{t}
$$


The last chosen model for calculating the expected returns is the risk adjusted returns model, which is based on the following linear regression model

$$
R_{i, t}=\alpha_{i}+\beta_{i} R_{M, t}+e_{i, t}
$$

where the actual return $\left(R_{i, t}\right)$ is a dependent variable and the market return $\left(R_{M, t}\right.$ or $\left.S \& P_{t}\right)$ is an exploratory variable. After estimating, the model can be written as

$$
\widehat{R_{i, t}}=a_{i}+b R_{M, t}
$$

where $a_{i}$ and $b_{i}$ represent the estimators of the regression coefficients $\alpha_{i}$ and $\beta_{i}$ calculated with the least-squares method.

The regression analysis, computed on the data of 33 chosen insurance companies, indicated that the estimator of the regression constant $\left(a_{i}\right)$ is statistically insignificant. Thus, I decided to remove this term from the regression equation. After a detailed analysis, I found out that the explanatory power of the regression model is even higher when the estimator of the regression constant is eliminated. The elimination is reasonable also because it is likely that when the market return equals zero, the actual return equals zero as well. This is graphically confirmed by regression scatterplots. Figures 7 and 8 illustrate data on two examples.

\section{Figure 7}

Regression scatterplot - Direct Line (UK)

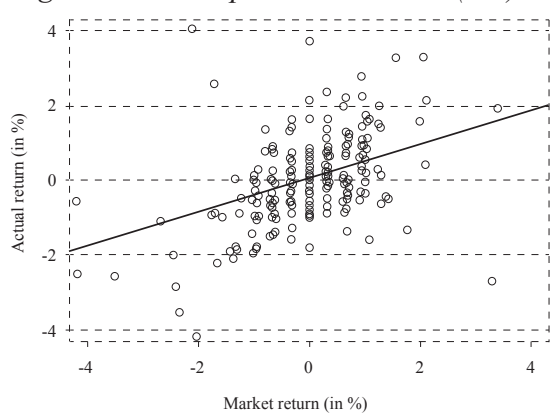

\section{Figure 8}

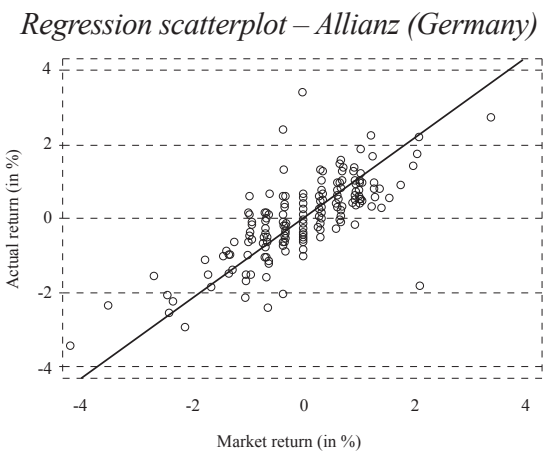

Source: The Bloomberg Terminal.

The new regression models, where the explanatory variable is market return, explain between 40 and $70 \%$ of the variability of the actual return, which is within the estimated interval for regressions performed on financial data (Fernando, 2020).

Thus, the expected return, $\left(E\left(R_{i, t} \mid X\right)\right)$ on the stock of insurance company $i$ on the day $t$, in the risk adjusted returns model, is defined as follows

$$
E\left(R_{i, t} \mid X_{t}\right)=a_{i}+b_{i} R_{M, t}=a_{i}+b_{i} S \& P_{t}
$$


Data smoothing removes noise and other microstructures from a data set and allows important patterns to stand out. When a time series is smoothed, the dynamics of the observed phenomenon are clearer. In this study, the time series of abnormal returns $y_{1}, y_{2}, \ldots, y_{T}$ (in the observation period) were smoothed with moving averages of order $k$ by

$$
\widehat{y_{t+1}}=\frac{y_{t}+\ldots+y_{t-k+1}}{k} \text {. }
$$

I chose the value of order 3 , which is also confirmed by the value of the mean square error, defined as

$$
M S E=\frac{1}{T-k} \sum_{t=k}^{T-1}\left(y_{t+1}-\widehat{y_{t+1}}\right)^{2}
$$

as it is smaller than it would be in the case of a different choice.

\subsection{AGGREGATION OF ABNORMAL RETURNS}

The fourth step of an event study focuses on the impact of the event at an aggregate level. The aggregation of the abnormal returns is done over securities (index $i$ ). The average abnormal return of $n$ insurance companies on day $t\left(A A R_{t}\right)$ is

$$
A A R_{t}=\frac{1}{n} \sum_{i=1}^{n} A R_{i, t}=\frac{1}{33} \sum_{i=1}^{33} A R_{i, t}
$$

The cumulative average abnormal return $(C A A R)$ is defined as the sum of the average abnormal

$$
C A A R=\sum_{t=t_{2}}^{t_{4}} A A R_{t}
$$

The cumulative average abnormal return was tested as an addition to the testing of average abnormal returns.

\subsection{STATISTICAL TESTS}

To test a hypothesis or assumption about the value of unknown parameters of a statistical variable, two groups of tests can be used - parametric and nonparametric (Neideen and Brasel, 2007). The most favourable situation is that the components of the sample are independent and (approximately) normally distributed (Serra, 2004). In this study the values of the basic sample represent actual returns on stocks $\left(R_{i, t}\right)$. On this basis I then calculated abnormal returns $\left(A R_{i, t}\right)$ which represent upgraded sample. The fulfilment of the assumption of independence is extremely difficult to justify in practice, so here I will assume it for simplicity. However, I have explored the normality assumption in more detail.

The estimation period in the event study also covers an important event of the coronavirus outbreak in Europe, which shook the financial markets (section 4.2). Due to the large impact of the outbreak on the stability of the estimation period, I 
excluded this event from the stable period (but not from the estimation period) since the parametric tests are based on the estimation period. Thus, the stable period is the time interval $[-250,-50]$.

The histogram of average abnormal returns in the stable period indicates a deviation from the normal distribution. This is also confirmed by the measures of shape - skewness and kurtosis. The skewness value is 0.4301 , and the value of kurtosis equals 1.0791. None of the three tests: the Jarque-Bera test, the D'Agostino-Pearson test and the Anderson-Darling test, rejected the hypothesis of the normal distribution. However, due to the financial nature of the data, I suspected that there might be a possibility of heavy tails (Brown and Warner, 1985), which occur commonly in finance.

A heavy-tailed distribution is a distribution whose tail falls toward zero slower than the exponential function. In general, heavy tails show a deviation from the normal distribution cause by extreme events. The heavy tail is indicated on the intervals $(-3,-1)$ and $(1,3)$ on the primary axis of the theoretical quantiles.

I approached the problem of heavy tails with non-linear data transformation with a generalised iterative method of moments (IGMM). This transformation results in the skewness value closer to zero and the kurtosis value closer to three (LambertW, 2020). After, I checked the normality again with standard normality tests and by plotting "Q-Q Plot" (figure 9).

\section{Figure 9}

$Q-Q$ Plot of the transformed average abnormal returns in the stable period

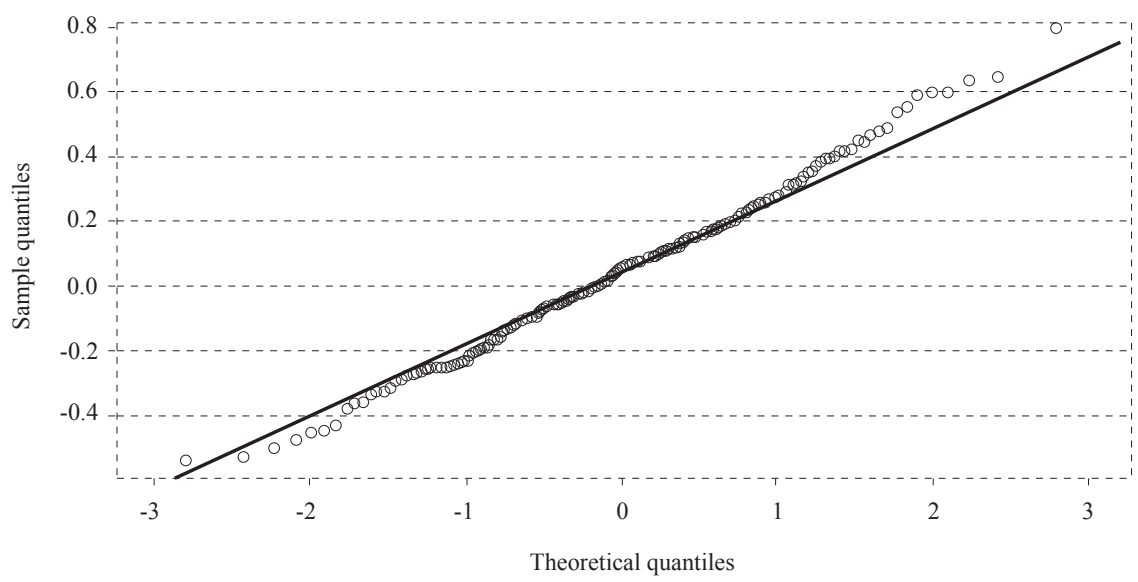

Source: The Bloomberg Terminal.

The heavy tail on the interval $(-3,-1)$ has almost disappeared, and a minor change is also noticed on the interval $(1,3)$. To perform the above-mentioned transformation, I have used the LambertW software package in R. The parametric two-sided 
t-test was then performed on the transformed data. The t-test tests the null hypothesis $H_{0}$ versus the alternative hypothesis $H_{1}$ :

$$
H_{0}: \mu=\mu_{0} \quad \text { and } \quad H_{1}: \mu \neq \mu_{0} \text {, }
$$

where the value $\mu_{0}$ is taken from the stable period. Thus, the null hypothesis is that the mean of the average abnormal returns in the observation period equals the mean of the average abnormal returns in the stable period.

Moreover, the null hypothesis that the median of the average abnormal returns in the observation period equals the median of the average abnormal returns in the stable period is tested by the nonparametric sign test. This means that the number of negative average abnormal returns is equal to the number of the positive average abnormal returns:

$$
H_{0}: \mathrm{Me}=\mathrm{Me}_{0} \quad \text { and } \quad H_{1}: \mathrm{Me} \neq M e_{0} \text {, }
$$

where the value $M e_{0}$ is the median of the sample of average abnormal returns from a stable period.

The values from the stable period are real and are not transformed, as in the case of the t-test. The key difference between the sign test and the t-test is that the results of the sign test will also reveal information about the statistical significance of the negative or positive average abnormal returns since the sign test takes into account the sign of the difference of the observations from the median.

Since the sign test takes into account only the sign of the differences of the observations from the median, I also performed the Wilcoxon signed-rank test, which considers the size of the differences of the observations from the median. The hypothesis tested is that the number of negative average abnormal returns is equal to the number of positive average abnormal returns:

$$
H_{0}: \mathrm{Me}=\mathrm{Me}_{0} \quad \text { and } \quad H_{1}: \mathrm{Me} \neq M e_{0} \text {, }
$$

where the value $M e_{0}$ is the median of the sample of average abnormal returns from a stable period.

Additionally, I conducted a parametric t-test to test the hypothesis that the mean of the CAAR in the observation period is equal to the mean of the CAAR in the stable period

$$
H_{0}: \mathrm{E}(\mathrm{CAAR})=E\left(C A A R_{0}\right) \quad \text { and } \quad H_{1}: \mathrm{E}(\mathrm{CAAR}) \neq\left(C A A R_{0}\right) .
$$




\section{RESULTS AND DISCUSSION}

I conducted an event study on a sample of 33 European insurance companies. The abnormal returns of individual insurance companies in the observation period are presented in table 2. On average, the number of days in the observation period when negative abnormal returns were observed in 5 days, which is less than half of the days in the observation period. The most negative abnormal returns (in 10 out of 11 days) were indicated in case of Hiscox (UK). By contrast, Vienna I. G. (Austria) and KBC I. G. (Belgium) had zero days when the abnormal returns were negative. Since Vienna Insurance Group and KBC Insurance Group are some of the largest insurance companies in Europe, suspending discretionary dividend distributions in order to absorb the shocks for this insurance company was not necessary. The companies and their shareholders were confident of enabling smooth payment of the claims during the crisis. In case of Vienna Insurance Group this was later confirmed, as they paid out all dividends.

Moreover, I have compared the behaviour of the stocks in the sample that pay significant dividends to those that pay little or nothing. The analysis shows that higher values of abnormal returns were observed in case of insurance companies that pay significant dividends (dividend yield is more than 4\%). As expected, lower abnormal returns were observed in other insurance companies with a dividend yield under $4 \%$. It is intuitively clear that shareholders expecting higher dividends would be more concerned about the issued statement, than those expecting lower dividends.

Furthermore, it is important to stress that the most significant divergences of 0 abnormal returns were positive abnormal returns. The highest positive abnormal returns exceeded the limit of $7 \%$, mostly on days -5 and -4 . The majority of the insurance companies with such results were from the UK. Many UK investors poured billions of dollars into insurance companies at that time because they thought that the pandemic would ultimately prove the catalyst that ends a period of low returns for the industry. Their belief was that the claims incurred during the pandemic would not overwhelm insurance companies. Yet, those claims might allow insurance companies to justify price rises for new policies (Ralph, 2020). It is important to bear in mind that the abnormal returns calculated might not be statistically significant, which means they could be random. Thus, the performance of the following statistical tests is crucial.

The values of t-test statistics are the lowest on days -2 and -1 (table 3). The reason for this might be that the majority of European MS responded to the statement issued with delays (section 4.1). For the majority of MS, EIOPA issued the statement a few days before day 0 , and with a delay of a couple of days, the national regulators responded. The results are not statistically significant. Therefore, the hypothesis that the expected value of average abnormal returns in the observation period is equal to the expected value of the average abnormal returns in the stable period can be rejected. Hence, we cannot reject the null hypothesis that the issued statement doesn't affect stock prices of insurance companies at the 0.05 significance level. 


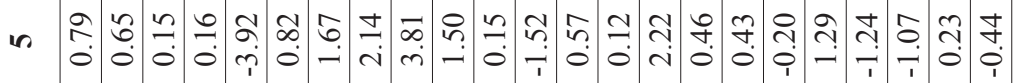

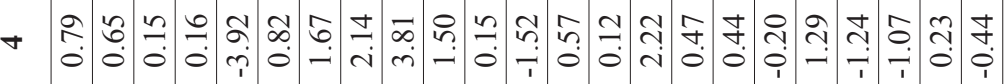

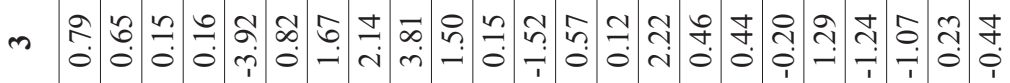

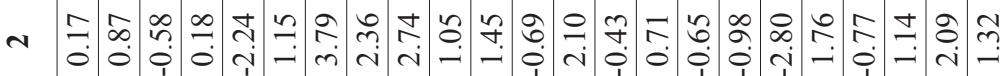

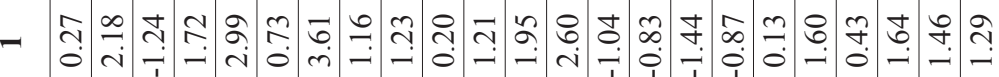

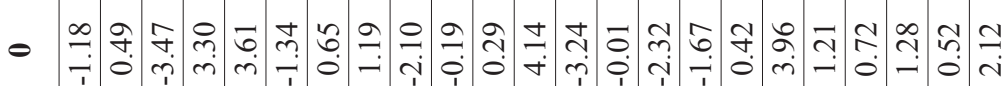

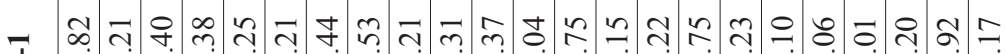

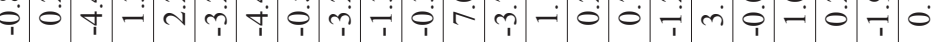

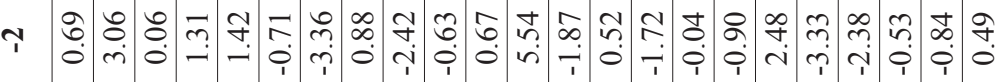

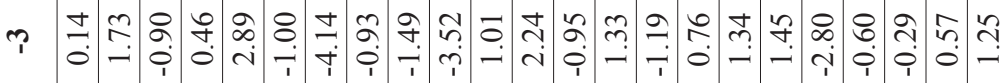

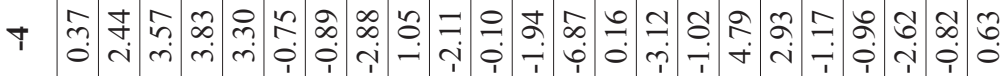

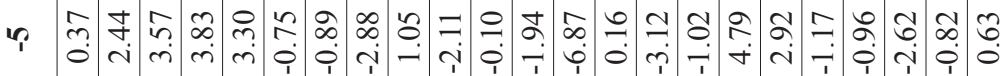


100

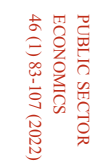

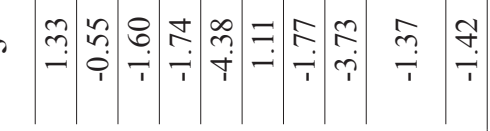

- ํำ

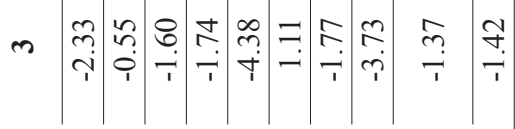

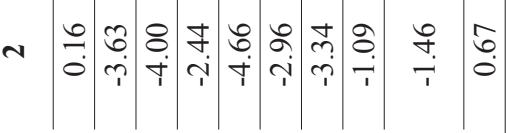

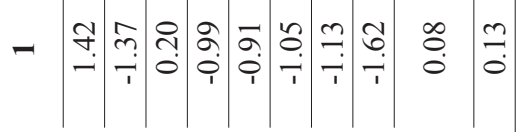

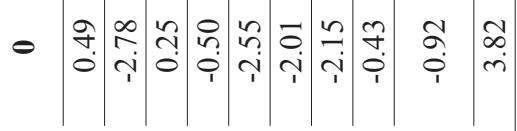

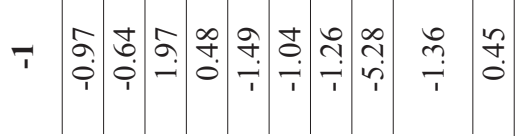

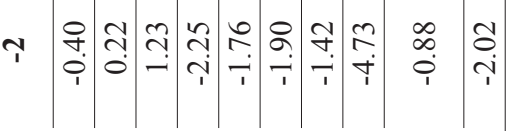

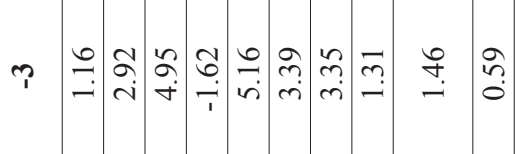

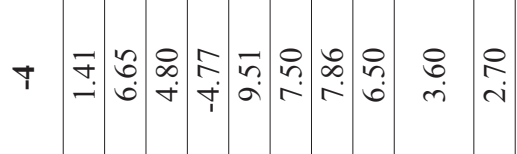

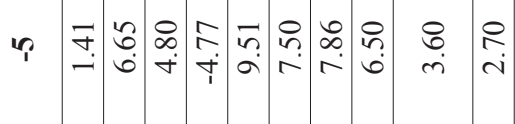

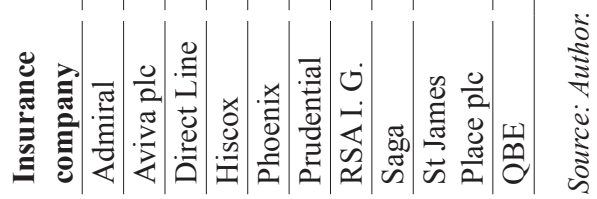


Day $\mathrm{t}$

\begin{tabular}{|c|c|c|}
\hline-5 & 1.95 & 0.060 \\
\hline-4 & 1.95 & 0.060 \\
\hline-3 & 1.55 & 0.131 \\
\hline-2 & -1.40 & 0.170 \\
\hline-1 & -1.29 & 0.206 \\
\hline 0 & 0.07 & 0.948 \\
\hline 1 & 1.84 & 0.075 \\
\hline 2 & -0.81 & 0.423 \\
\hline 3 & -0.95 & 0.351 \\
\hline 4 & -0.95 & 0.351 \\
\hline 5 & -0.95 & 0.351 \\
\hline
\end{tabular}

As data from the stable period was transformed (section 4.6), two more nonparametric tests were performed to justify the robustness of the t-test results. Again, the values of nonparametric sign-test statistics are the lowest on days -2 and -1 (table 4). The null hypothesis that the median of the average abnormal returns in the estimation period is equal to the median of the average abnormal returns in the stable period cannot be rejected at the 0.05 significance level. Therefore, we cannot argue that the number of negative average abnormal returns doesn't differ from the number of positive average abnormal returns.

\section{TABLE 4}

Sign test

\begin{tabular}{lll} 
Day t & Test statistic R \\
\hline-5 & 19 \\
\hline-4 & 19 \\
\hline-3 \\
\hline-2 \\
\hline-1 \\
\hline 0 \\
\hline 1 \\
\hline 2 \\
\hline 3 \\
\hline 4 \\
\hline 5
\end{tabular}

To complement the sign test, I performed a nonparametric Wilcoxon test (table 5). The results are not statistically significant. Thus, we cannot reject the null hypothesis that the median of the average abnormal returns in the observation period is equal to the median of the average abnormal returns in the stable period at the significance level of 0.05 . Furthermore, we cannot reject the proposition that the number of negative average abnormal returns equals the number of positive average abnormal returns. 
Wilcoxon signed-rank test

\begin{tabular}{|c|c|c|}
\hline Day t & Test statistic $\mathbf{R}$ & p-value \\
\hline-5 & -1.68 & 0.093 \\
\hline-4 & -1.68 & 0.093 \\
\hline-3 & -1.61 & 0.108 \\
\hline-2 & -1.64 & 0.101 \\
\hline-1 & -1.47 & 0.144 \\
\hline 0 & 0.00 & 1.000 \\
\hline 1 & -1.86 & 0.063 \\
\hline 2 & -0.46 & 0.646 \\
\hline 3 & -0.64 & 0.525 \\
\hline 4 & -0.64 & 0.525 \\
\hline 5 & -0.64 & 0.525 \\
\hline
\end{tabular}

The alignment between the statistical significance of the results is noticed, since there is no statistical significance at all. The results of the t-test suggest that the issued statement did not have an impact on the share price of insurance companies. Moreover, according to the sign test, we cannot claim that the number of negative average abnormal returns is different from the number of positive average abnormal returns. Lastly, the Wilcoxon signed-rank test confirms both - the sign and the t-test.

As mentioned in the previous section, a parametric t-test was conducted to study the reactions of the insurance companies selected. I have tested whether the expected CAAR of each insurance company was equal to or different from the expected CAAR of this company in the stable period. In almost $60 \%$ (19 cases among 33) the hypothesis cannot be rejected. However, it is important to mention three European MS: Finland, Belgium and The Netherlands, all with the $p$-values below 0.05 . Insurance companies from these MS have the highest dividend yields (above 4\%) and the greatest absolute values of CAAR resulting in statistical significance and the possibility of rejecting the hypothesis for those companies. Yet, as stated, the hypothesis cannot be rejected in the majority of cases. Thus, the expected CAAR of each insurance company is equal to the expected CAAR of this company in the stable period at the significance level of 0.05 . 
T-test for CAAR

\begin{tabular}{|c|c|c|c|c|c|}
\hline $\begin{array}{l}\text { Insurance } \\
\text { company }\end{array}$ & p-value & $\begin{array}{l}\text { Insurance } \\
\text { company }\end{array}$ & p-value & $\begin{array}{l}\text { Insurance } \\
\text { company }\end{array}$ & p-value \\
\hline Uniqua & 0.367 & Allianz & $0.007 * *$ & MAPFRE & $0.006 * *$ \\
\hline Vienna & $0.011^{*}$ & HDI & 0.054 & Admiral & 0.727 \\
\hline Ageas & $0.006^{* *}$ & Nuernberger & 0.168 & Aviva plc & 0.746 \\
\hline KBC I. G. & $0.002 * *$ & Aegon & $0.017 *$ & Direct Line & 0.220 \\
\hline Sampo & $0.003 * *$ & $\mathrm{NN}$ & $0.034 *$ & Hiscox & $0.022 *$ \\
\hline AXA SA & $0.007 * *$ & GJF & 0.659 & Phoenix & 0.360 \\
\hline COFACE & 0.263 & Storebrand & $0.018^{*}$ & Prudential & 0.912 \\
\hline SCOR SE & $0.013^{*}$ & PZU & 0.856 & RSA I. G. & 0.569 \\
\hline Metlife & 0.953 & Sava Re & 0.990 & Saga & 0.116 \\
\hline Generali & 0.106 & Triglav & 0.647 & St James Place plc & 0.478 \\
\hline Unipol & $0.021 *$ & GCO & 0.209 & QBE & 0.120 \\
\hline
\end{tabular}

$*_{p}<0.05, * * p<0.01, * * * p<0.001$.

Since Jakubik, in his article presenting the source literature, performed different statistical tests than the ones presented in this study, it is very difficult to compare the results. However, Jakubik's conclusions align with mine. The null hypothesis that the issued statement does not affect stock prices of insurance companies could not be rejected either by my results (the observation period is 11 days long) or by Jakubik's results (the observation period is 13 days long).

Similar conclusions have been drawn in the banking sector. Giese, Haldane and Jakubik (2020) stress the crucial importance of financial resilience for the economy, for example, in the form of buffers of capital and liquidity. Without a strong and flexible prudential regulatory regime, financial resilience would be outstandingly lower. Similarly, their study confirms that regulations did not have a significant negative impact on the share prices. Likewise, in the year 2020, no European insurance company following EIOPA's recommendations encountered liquidity problems, suggesting strongly that the issued statement fulfilled its purpose without undesired side-effects.

This research, however, is subject to several limitations, especially methodological. First, the issue of sample bias must be addressed. As I had limited access to data, my sample (consisting of 33 European insurance companies) does not fully reflect the general population of European insurance companies. The sample would be more random and the results more robust if the sample size was larger. Second, prior research that is relevant to my article is quite limited as there is little research analysing the regulator's statements in the insurance sector on stock prices. However, prior studies have analysed the impacts of EIOPA recommendations on pension plans and products in the conditions after the economic crisis (Bejaković, 2020). I believe that my finding is still reliable and valid despite these limitations. A possible way to overcome some of these limitations in future studies is the use of 
various methods, not only the event study. One of the possibilities could be the analysis of covariance (Hogan, 1996) or latent variable model (Acharya, 1993).

\section{CONCLUSION}

In recent decades, the need to analyse financial market response to disclosures of important information has been growing. For financial market participants (investors), such analyses are useful because they enable more accurate forecasting of market movements and consequently the choice of less risky or more profitable investments. The financial market response to disclosure has already been the subject of much research. However, there is relatively little research conducted on the effects of regulatory statements. Most studies conducted in the field focus on the banking sector; the number of those analysing the insurance sector is almost negligible. The article, therefore, represents an important contribution to this evolving field of financial governance.

The findings of this article are useful for regulators and investors as they demonstrate the effects of regulatory statements on financial stability. Hence, the article shows that insurance regulators should in future put their trust in the economic theory that market investors make a rational assessment focusing on long-term rather than short-term profit. Therefore, regulators in the European insurance sector can take drastic measures in order to ensure financial stability without any fear of a severe fall of stock prices. Which is of course not the case in all economic sectors. Furthermore, from the investors' perspective, an investment in the European insurance sector is a great addition to any investor's stock portfolio. As presented in this article, the insurance business has the potential to produce excellent long-term returns, since this business works well in strong economies, during recessions, etc. This is so because of a specificity of the insurance sector as such and because of a strong and engaged regulator protecting the financial markets even during the pandemic.

The COVID-19 pandemic negatively affected the solvency of insurance companies and consequently increased the vulnerability of the economy. The pandemic is essentially predominantly a public health crisis, which rapidly spiralled into a full-blown economic crisis. However, it is important that it does not develop into a financial one too. As EIOPA stressed, the purpose of the released statement was to maintain a high capital adequacy ratio. This would enable smooth payment of potential claims during the crisis. However, proactive regulation could also have a negative impact on the value of equity, i.e., share price, which would deter potential new investors in the insurance sector. One should bear it in mind that EIOPA's release of a regulatory statement affected not only the insurance sector but also the economy as a whole. The statement requesting insurers to suspend all discretionary dividend distributions interrupted the cash flow in the economy.

In this article, I examined the impact of the released regulator's statement on the share prices using the event study methodology on a sample of 33 European 
insurance companies. Empirical results showed that the negative effects observed immediately after the release of the statement are not statistically significant. The robustness of the results is confirmed by several statistical tests - parametric and nonparametric. I can therefore provide an answer for the research question stated at the beginning of the article and conclude that the statement requesting insurers to suspend all discretionary dividend distributions and share buy-backs aimed at remunerating shareholders did not precipitate a fall in stock prices of listed insurance companies. The finding is consistent with the economic theory that investors make decisions relatively rationally and maximise long-term profit. The issued regulation thus contributes to ensuring the financial stability of the European insurance sector, offers support to the real economy and indirectly enables a faster economic recovery.

\section{Disclosure statement}

The author declares that there is no conflict of interest. 


\section{REFERENCES}

1. Acharya, S., 1993. Value of latent information: alternative event study methods. The Journal of Finance, 48(1), pp.367-382. https://doi.org/10.1111/j.15406261.1993.tb04715.x

2. Baumann, U. and Nier, E., 2004. Disclosure, volatility, and transparency: an empirical investigation into the value of bank disclosure. Economic Policy Review, 10(2), pp. 31-32.

3. Bejaković, P., 2020. The Future of Pension Plans in the EU Internal MarketCoping with Trade-Offs Between Social Rights and Capital Markets. Public Sector Economics, 44(4), pp. 567-571. https://doi.org/10.3326/pse.44.4.7

4. Blinder, A. S. [et al.], 2008. Central bank communication and monetary policy: A survey of theory and evidence. Journal of Economic Literature, 46(4), pp. 910-911. https://doi.org/10.1257/jel.46.4.910

5. Bloomberg Terminal, 2020. Bloomberg Professional Services.

6. Brown, S. J. and Warner, J. B., 1980. Measuring security price performance. Journal of Financial Economics, 8(3), pp. 205-258. https://doi.org/10.1016/ 0304-405X(80)90002-1

7. Brown, S. J. and Warner, J. B., 1985. Using daily stock returns: The case of event studies. Journal of Financial Economics, 14(1), pp. 3-31. https://doi. org/10.1016/0304-405X(85)90042-X

8. Bryson Taylor, D., 2021. A Timeline of the Coronavirus Pandemic. The New York Times, 17 March 2021.

9. Craig MacKinlay, A., 1997. Event Studies in Economics and Finance. Journal of Economic Literature, 35(1), pp. 13-39.

10. Damodaran, A., 2012. Investment valuation: Tools and techniques for determining the value of any asset. New York: John Wiley \& Sons.

11. Dolley, J. C., 1933. Open market buying as a stimulant for the bond market. Journal of PoliticalEconomy, 41(4), pp.513-529. https://doi.org/10.1086/254507

12. EIOPA, 2020. Monitoring of dividends distribution following EIOPA and NCA statements. EIOPA-BoS-20-443, pp. 4-10.

13. ESRB, 2020. System-wide restraints on dividend payments, share buybacks and other pay-outs: June 2020. Frankfurt am Main: European Systemic Risk Board.

14. Fama, E. F. [et al.], 1969. The adjustment of stock prices to new information. InternationalEconomic Review, 10(1),pp. 1-21.https://doi.org/10.2307/2525569

15. Fernando, J., 2020. R-Squared Definition. Investopedia, 18 November 2020.

16. Giese, J., Haldane, A. and Jakubik, P., 2020. COVID-19 and the financial system: a tale of two crises. Oxford Review of Economic Policy, 36, pp. 200-214. https://doi.org/10.1093/oxrep/graa035

17. Goerg, G. M., 2020. LambertW: Probabilistic Models to Analyse and Gaussianize Heavy-Tailed, Skewed Data.

18. Greenspan, A., 2003. Corporate governance. Remarks by Chairman Alan Greenspan at the 2003 Conference on Bank Structure and Competition, Chicago, Illinois, May 8, 2003. 
19. Hayes, A., 2020. Event Study. Investopedia, 8 October 2020.

20. Henderson Jr, G. V., 1990. Problems and solutions in conducting event studies. Journal of Risk and Insurance, 57(2), pp. 282-306. https://doi.org/10.23 07/253304

21. Hogan, S., 1996. Covariance analysis as an alternative event-study methodology. Managerial Finance, 22(3), pp. 54-55. https://doi.org/10.1108/eb018554

22. Jakubik, P., 2020. The impact of EIOPA statement on insurers dividends: evidence from equity market. Financial Stability Report, EIOPA, 18, pp. 104-120.

23. Myers, J. H. and Bakay, A. J., 1948. Influence of stock split-ups on market price. Harvard Business Review, 26(2), pp. 251-255.

24. Neideen, T. and Brasel, K., 2007. Understanding Statistical Tests. Journal of SurgicalEducation, 64(2),pp.93-96.https://doi.org/10.1016/j.jsurg.2007.02.001

25. Obi, P., 2017. Event study methodologies - Basic. Youtube, 7 January 2017.

26. OECD, 2021. Insurance Markets in Figures. Paris: OECD.

27. OFS, 2020. Priporočilo OFS/2020/1 o izplačilu dobičkov finančnih družb. Ljubljana: Banka Slovenije.

28. Ralph, O., 2020. Insurers bet that pandemic will usher in era of higher returns. Financial Times, 24 August 2020.

29. S\&P Global, 2020. S\&P 500.

30. Serra, A. P., 2004. Event study tests: a brief survey. Org-Revista Electrónica de Gestão Organizacional, 2(3) pp. 248-255.

31. Shaffer, S., 1995. Rethinking disclosure requirements. Business Review, 5, pp. 15-29.

32. Steward, C., 2020. Cumulative number of coronavirus (COVID-19) cases in Europe between January 25 and October 2, 2020. Statista: Health \& Pharmaceuticals, 2 October 2020.

33. The Center for Financial Stability, 2021. Financial Timeline. 



\title{
Macroeconomic effects of systemic stress: a rolling spillover index approach
}

TIHANA ŠKRINJARIĆ, Ph.D.*

\author{
Article $^{* *}$ \\ JEL: G1, G01, G20, E44, C32, E32 \\ https://doi.org/10.3326/pse.46.1.4
}

\footnotetext{
* The views presented in this paper are those of the author and do not necessarily represent the institution the author works at. The author is thankful to two anonymous referees whose comments have contributed to the final version of the paper.

${ }^{* *}$ Received: June 1, 2021
}

Accepted: November 6, 2021

Tihana ŠKRINJARIĆ

Croatian National Bank, Trg hrvatskih velikana 3, 10000 Zagreb, Croatia

e-mail: tihana.skrinjaric@hnb.hr

ORCiD: 0000-0002-9310-6853 


\section{Abstract}

This research belongs focuses on the effects of financial instability on the rest of the economy. The article observes the dynamic changes of the shock spillovers between systemic stress and the rest of the German economy. In that way, the net emitters and receivers of shocks are observed throughout time, as previous research found that systemic stress is not always the predictor of other economic activity. The analysis utilizes Diebold and Yilmaz $(2009,2012)$ spillover index approach within the vector autoregression model. One step further is taken as well, as the changes of dynamics are observed throughout the entire period. As the macroprudential and monetary policymakers have to track the interrelationships between these variables over time, the approach in the study is straightforward and easy to interpret. The timing and intensity of the specific measures are important in practice, and such an approach enables the policymakers to meet these criteria.

Keywords: systemic risk, systemic stress index, financial system, monetary policy, macroprudential measures

\section{INTRODUCTION}

The interaction between systemic risk and the real economy has been in focus in the last few years (Giglio, Bryan and Pruitt, 2106; Tamási and Világi, 2011). This is especially true due to the problems the Global Financial Crisis has caused within banking systems and the financial system as a whole. The new problems stemming from the COVID-19 crisis have also modified the understanding of financial stability. It is important to obtain timely and insightful information about the spillovers of shocks to the real economy and their contribution to the financial stress of the whole system. This will enable policymakers to tailor their decisions more appropriately. However, the interaction between systemic risk and the real economy is still insufficiently explored. In particular, the interaction has not been sufficiently observed in the contexts of differing economic conditions. Some of the previous literature explores relationships that are linear and symmetrical ${ }^{1}$, which cannot realistically be assumed in the modelling process. That is why this research focuses on the changing interaction between systemic risk and the selected macroeconomic variables. The main focus is on obtaining better insights into the reactions of the real economy and the realization of systemic risk when different economic conditions obtain. The main methodological approach in this research is the spillover index of Diebold and Yilmaz $(2009,2012)$ within the VAR (vector autoregression) framework. There are several reasons why. The VAR approach of modelling is usual in the macroeconomic literature, as it is flexible, simple to interpret and the causalities between the variables of interest can be explored. Moreover, the directions between the shock spillovers (Blanchard and Quah, 1989; Lütkepohl, 1993; 2011) can be obtained. Secondly, the VAR approach allows for spillovers of shocks from the financial sector to the real economy, as

\footnotetext{
${ }^{1}$ The asymmetric behaviour of business cycles has been known as early as in Fisher (1933) and Keynes (1936), as well as earlier studies in Neftci (1984), Granger (2003) or Engle and Manganelli (2004); and of course, newer ones in Schüler (2014), White, Kim and Manganelli (2015), or Linnemann and Winkler (2016).
} 
found in Brunnermeier, Eisenbach and Sannikov (2012) or Christiano and Ikeda (2011); and from the real economy to the financial sector, as found in Delli Gatti et al. (2012). Another often-implemented approach is structural VAR (SVAR), which imposes some restrictions on the short and/or long-term interactions between economic variables. This can be based on stylized facts or on economic theory (see Boeckx, Dossche and Peersman, 2014). This is especially true for the analysis of monetary transmission mechanism (Christiano, Eichenbaum and Evans, 1999; Van Aarle, Garretsen and Gobbin, 2003). Thirdly, when focusing on the dynamic approach of modelling, it allows asymmetric behaviour in the observed relationships. Previous literature agrees that a nonlinear relationship exists between the macroeconomy and systemic risk. Early work includes Bernanke and Gerlter (1989), Bernanke, Gertler and Gilchrist (1999), or Kiyotaki and Moore (1997). Newer research includes Brunnermeier and Sannikov (2014), Montes-Rojas (2019), or He and Krishnamurthy (2019). That is why in this paper, a time-varying approach is allowed through the use of rolling window estimation of the VAR model with spillover indices. In that way, the dynamic changes of shock spillovers can be observed.

The contribution of this research is as follows. First of all, more than two basic variables are included in the analysis (such as the index of industrial production, IIP, and CSSI as in Chavleishvili and Manganelli, 2019). By excluding relevant variables in the VAR model, it can lead to omitted variable bias (see Christiano, Eichenbaum and Evans, 1996). Next, some approaches include more variables in the system but observe solely the static VAR model. In this research, dynamic changes of shock spillovers are observed between the systemic stress and the rest of the economy. Accordingly, the net emitters and receivers of shocks can be observed throughout time. This is because previous research found that systemic stress is not always the predictor of other economic activity (Cardarelli, Elekdag and Lall, 2011). Moreover, the majority of previous research work focuses on the sign (and/or magnitude) of the reactions of variables to systemic stress shocks. Here, we can observe when a variable receives and gives shocks to others. This is useful for economic policymakers, to track the interconnectedness between the systemic stress and the rest of the economy over time. This enables more timely reactions by both monetary and macroprudential policymakers. The empirical analysis will focus on Germany, due to the size of this economy within the EU and the EMU. Furthermore, the country experienced banking system instabilities in previous periods (Jahn and Kick, 2012). Thus, the CISS (Composite Indicator of Systemic Stress) as the financial stress indicator should have captured these instabilities. Furthermore, it should have affected the selected variables of interest, especially due to the banks playing a major role in the financial system (Schmidt, 2019). Moreover, the German financial system has a key role in the global economy (FSB, 2020). Finally, before moving on to other sections of the paper, a brief explanation is given of why the rolling window estimation of VAR approach is used, as opposed to the regime-switching or threshold VAR models. The switching models assume that the regimes, i.e., economic booms and busts, govern all of 
the variables in the same manner. Moreover, the switching approach is feasible for a small number of regimes (Schüler, 2014). Finally, by utilizing the rolling window approach, a smooth transition of the effects of one variable to another is allowed, alongside the smoother change of the spillover dynamics.

The main findings of the research include finding a time-varying relationship between the real economy and CISS. This finding indicates that the policymakers should take into consideration the effects of the systemic stress on variables of interest, and vice versa. The effects of policy stabilizations will have effects on the CISS variable as well. Findings confirm the existence of disproportional size and sign effects on the systemic stress and macroeconomic variables. Furthermore, as central banks have such reactions to increased systemic stress, the CISS variable in this case provides a good predictor of future interest rate movements. This is because the values of the spillover index from CISS to the interest rates, in this case, are high. This is in line with conventional views of reactions of monetary policy to financial instability. Furthermore, the effects of the inflation stabilization before the financial crisis contribute to the CISS variability. This is in line with previous findings of problems of focusing mostly on inflation targeting before the 2007-2008 financial crisis.

The rest of the paper is structured as follows. The second section deals with an overview of the related research important for this study. Then, the methodology description is given in the third section. Empirical results are analysed in the fourth section, with discussion and conclusion given in the final, fifth section.

\section{RELATED LITERATURE REVIEW}

This research belongs to the strand of literature that focuses on the effects of financial instability or distress on the rest of the economy. The majority of related research has been especially motivated by the financial crisis of 2007-2008, which is prominent in the introduction of many papers. Some of the papers state explicitly that the financial sector plays an important role in business cycle fluctuations, as found in Jerman and Quadrini (2012). Hakkio and Keeton (2009) constructed the Kansas City Financial Stress Index (KCFSI) to test its effects on the Chicago FED national activity index. Based on the VAR model results, the authors concluded that KCFSI could be a useful tool in deciding on when to remove liquidity from the system or add it. Hatzius et al. (2010) review existing measures of the systemic stress indices (FSI), build a new one, and compare the results of predictive capabilities of FSIs for future economic activity. A threshold VAR approach was utilized in Li and StAmant (2010). Here, the authors concentrate on questions such as: (a)symmetric effects of contractionary and expansionary monetary policy shocks and how the high versus the low systemic stress regime affects overnight interest rates. Based on Canadian data for the period 1981Q4-2006Q4, the estimated results indicate that inflation and output growth react stronger to contractionary than to expansionary monetary policy shocks. Jerman and Quadrini (2012) built a theoretical model regarding the effects of financial sector shocks and then tested it on real US data. The authors show that financial shocks were responsible for tightening the conditions of firms' credit in the economic downturns of 1990-1991 and the latest 
financial crisis. The analysis was conducted on US data, with several important findings, besides that mentioned: monetary policy contractions had negative output effects, with small liquidity effects. Jahn and Kick (2012) constructed a forward-looking indicator of the German banking system so that it can be used in the identification of macroprudential early warning indicators. Bank-level data were used to perform the analysis, with a panel regression approach for the period 1995-2010. Interesting findings are that asset price indicators, leading indicators of business cycles, and monetary indicators can be reliable preceding indicators for instability in the banking system itself.

In Van Roye (2014), the author constructs a financial stress market indicator (FSMI) and analyses the effects of systemic stress on economic activity. A small Bayesian VAR was utilized from a methodological standpoint to obtain information on the forecasting capabilities of an FSMI for GDP growth. Mallick and Sousa (2013) performed a detailed analysis of systemic stress in the Euro-zone (period 1980Q1-2008Q1) via Bayesian SVAR and sign-restriction. This research has as its main findings that unexpected variations in systemic stress have an important role in the explanations of output fluctuations, with contractionary monetary policy worsening systemic stress conditions. This had a result of long periods of low interest rates that contributed to asset price increases observed in the financial crisis of 20072008. Hubrich and Tetlow (2014) focus on the US data and the FED Financial Stress Index (FSI) within the regime-switching VAR to find that the conventional monetary policy is effective during the period of high systemic stress.

Hartmann et al. (2015) a research paper close to this one. The authors observe the effects of systemic risk shocks on the euro area macroeconomy. In the mentioned research, the methodological approach is that of regime-switching VAR. Based on the data on the output growth, interest rate, CISS, and (nominal bank) loans growth rate (period: January 1987 - December 2010), the results are interesting; when the euro area undergoes periods of high systemic stress, its shocks are greater than in tranquil times. The assumption of one regime (i.e., linear models) cannot capture such dynamics. Kremer's (2015) paper is also close to this research. Here, the author utilizes the VAR model and the direct and indirect Granger causality patterns of Hsiao (1982). The idea is to explore the relationship between the conventional, unconventional measures of monetary policy and the CISS indicator for the total euro area. The contribution of this research is found in an extensive robustness of the results testing. The main findings included the following. The CISS contributed to the dynamics of the macroeconomy and significantly affected the action of the monetary policy (in terms of policy rates, and the ECB, European Central Bank, balance sheet). However, the author admitted that the standard linear VAR approach in the analysis ignores potential nonlinearities, and this should be explored in future work more. Giglio, Bryan and Pruitt (2016) focused on the US, UK, and euro area data (differing periods, depending on the data availability). These authors focus on how systemic risk affects future macroeconomic movements, in terms of quantile regression and Bloom's (2009) VAR. 
The findings indicate that the selected systemic risk measures have significant predictive power on downside quantiles of the industrial production growth. It was concluded that the systemic risk is an asymmetric phenomenon with nonlinear behaviour; with the predictive power of the Federal Funds rate (rise of the risk leads to a large drop of the mentioned rate).

Among more recent papers is that of Chavleishvili and Manganelli (2019), in which authors explicitly focus on the QVAR (quantile VAR). The idea is to observe the results for the purposes of stress testing. Linear VAR and the $Q$ approach are contrasted on real data so that the possible differences can be seen. More precisely, the linear model cannot capture the asymmetric transmission of shocks from one variable to another. However, the authors observed only a bivariate VAR, in which the CISS and the euro area industrial production growth were included as the main variables (period: January 1999 to July 2018). Galán (2020) focused on the panel QVAR to identify the benefits of macroprudential policy on GDP growth. More specifically, the focus was done on the left-tail of the GDP growth distribution. The approach used by this study is to examine how (constructed measures) of macroprudential policies affect GDP growth, but in accordance with the position in the financial cycle and the time elapsed from the implementation of an instrument and the type of the instrument itself.

To summarize, the body of research is obviously growing. This is due to the problems that emerged not only after the global financial crisis of 2007-2008, but due to the pandemic problems and uncertainties that have arisen. The need to obtain better insights into financial (in)stability and macroeconomic sectors is higher than ever, However, many aspects of the macroprudential policies are still in the infancy phase. An analysis of the shock spillovers among the variables of interest, with the inclusion of the asymmetry assumption that has been recognized for a long time, could enhance tailoring of policies in the future.

\section{METHODOLOGY DESCRIPTION}

The main methodology used in this study is described by following Lütkepohl (1993; 2006; 2010) and Diebold and Yilmaz (2009; 2012). A stabile $\operatorname{VAR}(p)$ model of $N$ variables is considered in the matrix form: $y_{t}=v+A_{1} y_{t-1}+A_{2} y_{t-2}+\ldots$ $+A_{p} y_{t-p}+\boldsymbol{\varepsilon}_{t}$, where $\boldsymbol{y}_{t}$ is the $N \times 1$ vector of dependent variables, $A_{i}$ are the $N \times N$ matrices of coefficients, $i \in\{1,2, \ldots, p\}, v$ is the $N \times 1$ vector of intercepts, and the $\boldsymbol{\varepsilon}_{t}$ is the $N \times 1$ vector of white noise process, $E\left(\boldsymbol{\varepsilon}_{t}\right)=\mathbf{0}, E\left(\boldsymbol{\varepsilon}_{t} \boldsymbol{\varepsilon}_{t}{ }^{\prime}\right)=\Sigma_{\varepsilon}<\infty$, and for $t \neq s E\left(\boldsymbol{\varepsilon}_{t}\right.$ $\left.\varepsilon_{s}{ }^{\prime}\right)=0$. The $\operatorname{VAR}(p)$ model can be written in a $\operatorname{VAR}(1)$ form as $Y_{t}=V+A Y_{t-1}+e_{t}$,

where $Y_{t}=\left(\begin{array}{llll}y_{t} & y_{t-1} & \ldots & y_{t-p}\end{array}\right)^{\prime}, V=\left(\begin{array}{llll}v & 0 & \ldots & 0\end{array}\right)^{\prime}, A=\left[\begin{array}{ccccc}A_{1} & A_{2} & \cdots & A_{p-1} & A_{p} \\ I_{N} & 0 & \cdots & 0 & 0 \\ 0 & I_{N} & & \vdots & \vdots \\ \vdots & & \ddots & \vdots & \vdots \\ 0 & 0 & \cdots & I_{N} & 0\end{array}\right], e_{t}=$ $\left(\begin{array}{llll}\varepsilon_{t} & 0 & \ldots & 0\end{array}\right)^{\prime}$. In order to estimate the impulse response functions (IRFs) and the 
forecast error variance decompositions (FEVDs), the VAR model is rewritten into the $\mathrm{MA}(\infty)$ representation as follows:

$$
Y_{t}=\mu+\sum_{i=0}^{\infty} A^{i} e_{t}=\left(I_{N}-A L\right)^{-1} V+\Phi_{i}(L) e_{t}
$$

where $L$ is the lag operator, $L^{j} Y_{t}=Y_{t-j}, j \in \mathbb{R}, \Phi(L)$ being the polynomial such that $\Phi_{i}(L)$ $=J A^{i} J, J=\left(\begin{array}{lll}I_{N} & 0 \ldots 0\end{array}\right)$. Elements in $\Phi_{i}(L)$ are the impulse responses, i.e., $\phi_{j k, i}$ is the reaction of variable $j$ to the shock in variable $k$ in period $i$. In practice, the elements in $e_{t}$ are correlated, so the assumption $t \neq s E\left(\varepsilon_{t} \varepsilon_{s}{ }^{\prime}\right)=0$ does not hold. One approach is to observe the Cholesky decomposition of the variance-covariance matrix of the error term. Another one is to observe generalized IRFs and FEVDs, which does not rely on the ordering of the variables such as the Cholesky one. GIRFs are based on mean responses by integrating out other shocks, as defined by Pesaran and Shin (1998):

$$
G I_{y}\left(h, \delta_{j}, I_{t-1}\right)=E\left(\mathrm{Y}_{t+h} \mid e_{j t}=\delta_{j}, I_{t-1}\right)-E\left(\mathrm{Y}_{t+h} \mid I_{t-1}\right)
$$

where $\delta_{j}$ is the shock given to element $j$ in $e_{t}, I_{t-1}$ is the information set, $h$ is the horizon of the ahead forecast, and with the assumption of normal distribution of error terms, it follows that (Koop, Pesaran and Potter, 1996):

$$
E\left(e_{t} \mid e_{j t}=\delta_{j}\right)=\left(\sigma_{1 j} \sigma_{2 j} \ldots \sigma_{N j}\right)^{\prime} \sigma_{j j}^{-1} \delta_{j}=\sum_{\varepsilon} u_{j} \sigma_{j j}^{-1} \delta_{j}
$$

with $u_{j}$ being a $N \times 1$ vector of zeros with exception of value 1 in place $j$, so that the unscaled GIRFs of the $j$-th variable is estimated as the expression $\frac{\Phi_{h} \sum_{\varepsilon} u_{j}}{\sqrt{\sigma_{j j}}} \frac{\delta_{j}}{\sqrt{\sigma_{j j}}}$. Setting $\delta_{j}=\sqrt{\sigma_{j j}}$, the scaled GIRF of variable $j$ at horizon $h$ is equal to

$$
\psi_{j}(h)=\sigma_{j j}^{-1 / 2} \Phi_{h} \sum_{\varepsilon} u_{j},
$$

and is the effect of one standard error shock to the equation $j$ at time $t$ on expected values of $Y_{t}$ at $t+h$. Now, the GIRFs from (4) are used to construct the GFEVDs, i.e., the proportions of the $h$-step ahead FEVDs of variables $j$ due to shocks in variables $k$ in the model:

$$
\theta_{j k}(h)=\frac{\sigma_{j j}^{-1 / 2} \sum_{i=0}^{h-1}\left(u_{j}^{\prime} \Phi_{i} \sum_{\varepsilon} u_{k}\right)^{2}}{u_{j}^{\prime} \Phi_{i} \sum_{\varepsilon} \Phi_{i}^{\prime} u_{k}} .
$$

The next step is the construction of the spillover index of Diebold and Yilmaz (2009, 2012). In the 2009 paper, the Cholesky decomposition was applied in the IRF and FEVD estimation, but the paper from 2012 utilizes the GFEVDs in (5). The values $\theta_{j k}(h)$ are normalized as follows:

$$
\tilde{\theta}_{j k}(h)=\frac{\theta_{j k}(h)}{\sum_{k=1}^{N} \theta_{j k}(h)}
$$


and the total spillover index is calculated based on the cross-variance shares defined in (6):

$$
S(h)=\frac{\sum_{\substack{j, k=1 \\ j \neq k}}^{N} \tilde{\theta}_{j k}(h)}{N} 100 \%
$$

and measures the contribution of spillovers in all variables to the total forecast error variance. By taking the GFEVD approach, the directional and net spillover indices can be estimated as well. The spillover which a variable $j$ receives from other variables $k$ is calculated as

$$
S_{j} \times(h)=\frac{\sum_{\substack{k=1 \\ j \neq k}}^{N} \tilde{\theta}_{j k}(h)}{N} 100 \%
$$

and the spillover of shocks from variable $j$ to other variables $k$ as

$$
S \times_{j}(h)=\frac{\sum_{\substack{k=1 \\ j \neq k}}^{N} \tilde{\theta}_{k j}(h)}{N} 100 \% .
$$

The net indices can be estimated as well, as the total net index for every variable in the model, by subtracting (9) from (8), and pair-wise indices (between two variables, similar to the indices in (8) and (9)) can be estimated in order to compare two variables, alongside the net pair-wise indices. In order to include the dynamics in the analysis, the $\operatorname{VAR}(p)$ model and all of the needed spillover indices will be estimated on a rolling-window basis. Most of the spillover-indices literature utilizes this approach as greater insights from the dynamic analysis can be obtained (see Dumitrescu, 2015; Yarovaya, Brzeszczyński and Lau, 2016; Škrinjarić and Šego, 2019; Gross and Siklos, 2019).

\section{EMPIRICAL RESULTS}

\subsection{DATA SELECTION AND DESCRIPTION}

For the purposes of the empirical analysis, monthly data on the industrial production index (IIP, $2015=100)$ and the harmonized index of consumer prices (HICP, $2015=100)$ were collected from the Eurostat (2021) database; data on nominal bank loans to the private sector (LN, in billions of euro) from the Deutsche Bundesbank (DBE, 2021) database; the 3-month Euribor rate (IRATE) and the German CISS were collected from ECB (2021) statistical data warehouse.

CISS (Composite Indicator of Systemic Stress) was introduced in Hollo, Kremer and Lo Duca (2012), and it measures the state of the systemic financial instability in the euro area. There are two main reasons why this paper uses the CISS indicator. First, as explained in Hollo, Kremer and Lo Duca (2012), this variable covers the main 
channels of financial instability sources: the financial intermediaries, money, bond, equity, and foreign exchange markets. Secondly, this measure has been extensively used in the past literature, which indicates that it is reliable (e.g., Senapati and Kavediya, 2020; Jin and Nadal de Simone, 2020; Dufour, Marra and Sangiorgi, 2019; Bucacos, 2018; Guidolin and Pedio, 2017; Zhagini, 2016; Delatte, Fouquau and Portes, 2014; Mittnik and Semmler, 2013; etc.). As Hartmann et al. (2015) emphasize, the CISS variable is particularly important for those economies with bank-centric financial systems ${ }^{2}$. By utilizing CISS as the measure of systemic stress, as Hollo, Kremer and Lo Duca (2012) and Huotari (2015) note, we observe the systemic stress as the materialization of risks that cause financial instability. These variables are utilized in Hartmann et al. (2015), van Roye (2011) for Germany in particular ${ }^{3}$, and similar ones in Kremer (2015), Borys, Horváth and Franta (2009), Duprey and Ueberfeldt (2020), Martins (2020), and Havránek, Horváth and Matějů (2012). The core variables were calculated as in Kremer (2015): the annual log differences of the $\mathrm{HICP}^{4}$, annual log differences of the IIP index ${ }^{5}$; and the ERATE is the measure of the conventional monetary policy rate. Finally, the year-on-year growth in the LN (bank loans) is used, as Hartmann et al. (2015) explain that bank lending had a great role in previous financial crises. The original data ranges from January 1999 to December 2020, and the year-on-year growth rates start in January $2000^{6}$. The CISS variable as an overall measure of the financial instability is used in the original form. All variables were checked for stationarity, and where needed, variables were transformed to be stationary ${ }^{7}$, so that the standard errors and the derived test statistics can be used.

For the robustness checking of the results, the CISS variable was transformed via the positive square root of the original values, as in Kremer (2015). All of the estimations were re-done with the transformed CISS variable (SQCISS). This was done so that potential nonlinearities within the original form of the variable can be controlled for. As a final checking of the robustness, the quarterly seasonally adjusted GDP, collected from the Eurostat (2021) database was be transformed via the Chow-Lin (1971) interpolation procedure ${ }^{8}$ to the monthly frequency. The monthly IIP data were used to construct monthly GDP, as in Boeckx, Dossche and Peersman (2014), as well as the monthly index of deflated turnover in retail sale

\footnotetext{
${ }^{2}$ The CISS indicator is chosen for the analysis, as it covers the main channels of financial instability sources: financial intermediaries, money, bond, equity, and foreign exchange markets. The rolling correlations between these five sources in terms of their relevant variables and the CISS value are given in figure A4 in the appendix. It can be seen that this variable captures the dynamics on the relevant markets quite well, due to great values of bivariate correlation coefficients.

${ }^{3}$ With the exception of own systemic stress variable construction.

${ }^{4}$ To measure year-on-year inflation rate (as an aggregate price level changes measure).

${ }^{5}$ Aggregate economic activity changes to measure year-on-year IIP growth (as in Kremer and Chavleishili, 2021, it measures the cyclical component of the IIP).

${ }^{6}$ Thus, the total number of observations for each variable is 252 . Where needed, the seasonal adjustment of the original data was made so that no seasonality remained.

${ }^{7}$ The only non-stationary variable was the interest rate, which was confirmed via Augmented Dickey-Fuller and the KPSS tests. Thus, the year-on-year difference of the interest rate was calculated. Please see table A1 in the appendix.

${ }^{8}$ More details on this interpolation procedure can be found in Sax and Steiner (2013) or Marini (2016). This procedure has been found to be good in converting the GDP series from quarterly to monthly, see Mönch and Uhlig (2005) or Hoven and Scherus (2013).
} 
(seasonally adjusted, $2015=100$, Eurostat, 2021) as in Chamberlin (2010) and Frale et al. (2008). In the first step, the monthly data are estimated for the level values, and in the second the year on year growth rates are calculated. The abbreviations and description of each variable are given in table 1.

\section{TABLE 1}

Variables description

\begin{tabular}{|c|c|}
\hline Abbreviation & Full name \\
\hline DIIP & Year-on-year growth rate of index of industrial production \\
\hline DHICP & Year-on-year growth rate of harmonized index of consumer prices \\
\hline DIRATE & Year-on-year change of the 3-month Euribor rate \\
\hline DLN & Year-on-year growth rate of nominal bank loans to the private sector \\
\hline CISS & German Composite Indicator of Systemic Stress \\
\hline SQ_CISS & Square root of CISS \\
\hline DGDP & Year-on-year growth rate of gross domestic product \\
\hline
\end{tabular}

Source: Eurostat (2021), DBE (2021), ECB (2021).

\subsection{MAIN RESULTS}

A static approach was made first, where the VAR model was estimated over the entire dataset, with a lag length of $p=2$, based on the information criteria. For the entire sample, the Spillover table was estimated for $h=12$, and is shown in table 2. The main interpretations are as follows. If we focus on the first row, the values indicate how much of the variance of variable DIIP is explained by the shocks in all other variables: $52.84 \%$ due to shocks in the same variable, $5.05 \%$ due to shocks in DHICP, etc. The column entitled "From" indicates the average spillover index value variance of a variable has received from shocks in other variables in the model. For example, the variance of DIIP is, on average, explained by shocks in four other variables in the system in the amount of $11.79 \%$. Similarly, "T_from" includes the sum of all spillovers from other variables to the variance of every variable. The row titled "To" is the average spillover of shocks in a variable in each column that explains variances of other variables. Value 9.15 is the average percentage explained of the variances of other variables in the model, due to shocks in variable DIIP. Again, something similar is true for the row "T_to": it contains the sum of spillovers of shocks in each variable to all other variables in the model.

TABLE 2

Spillover table, full sample, in percent

\begin{tabular}{|c|c|c|c|c|c|c|c|}
\hline Variable & DIIP & DHICP & DIRATE & DLN & CISS & From & $T$ from \\
\hline DIIP & 52.84 & 5.05 & 16.77 & 1.89 & 23.46 & 11.79 & 47.17 \\
\hline DHICP & 21.15 & 63.80 & 2.29 & 0.66 & 12.09 & 9.05 & 36.19 \\
\hline DIRATE & 12.35 & 1.27 & 56.89 & 1.17 & 28.32 & 10.77 & 43.11 \\
\hline$\overline{D L N}$ & 0.07 & 1.38 & 9.61 & 84.55 & 4.38 & 3.86 & 15.44 \\
\hline CISS & 3.03 & 4.25 & 2.21 & 0.45 & 90.06 & 2.49 & 9.94 \\
\hline To & 9.15 & 2.99 & 7.72 & 1.04 & 17.06 & - & - \\
\hline $\mathrm{T}$ to & 36.60 & 11.95 & 30.88 & 4.17 & 68.25 & - & 37.96 \\
\hline
\end{tabular}

Source: Author's calculation. 
Finally, the total spillover index value is given in the last cell of table 2, and it is equal to $37.96 \%$. Thus, over the entire observed period, a moderate value of the spillover indices is observed. By focusing on the column CISS, it is seen that shocks in the systemic risk spill over to other variables in relatively great amounts, especially regarding the DIRATE and DIIP (28.32\% and $23.45 \%$, respectively). This is according to the previous static analysis in van Roye (2011) for Germany, where the IRFs indicated the greatest reaction of the two mentioned variables to shocks in the financial stability variable. On the other side, the CISS variance is explained by shocks in other variables in a very small manner (row regarding variable CISS). These results indicate that the shocks that occur in variable CISS have great effects on the selected variables, i.e., financial instability shocks affect the economy in the observed sample. Previous findings from the euro area also show that the IRF functions of these variables have the greatest reactions to CISS shocks in Kremer (2015).

\section{Figure 1}

Total spillover index, $h=12$, rolling windows 30, 36 and 42 months

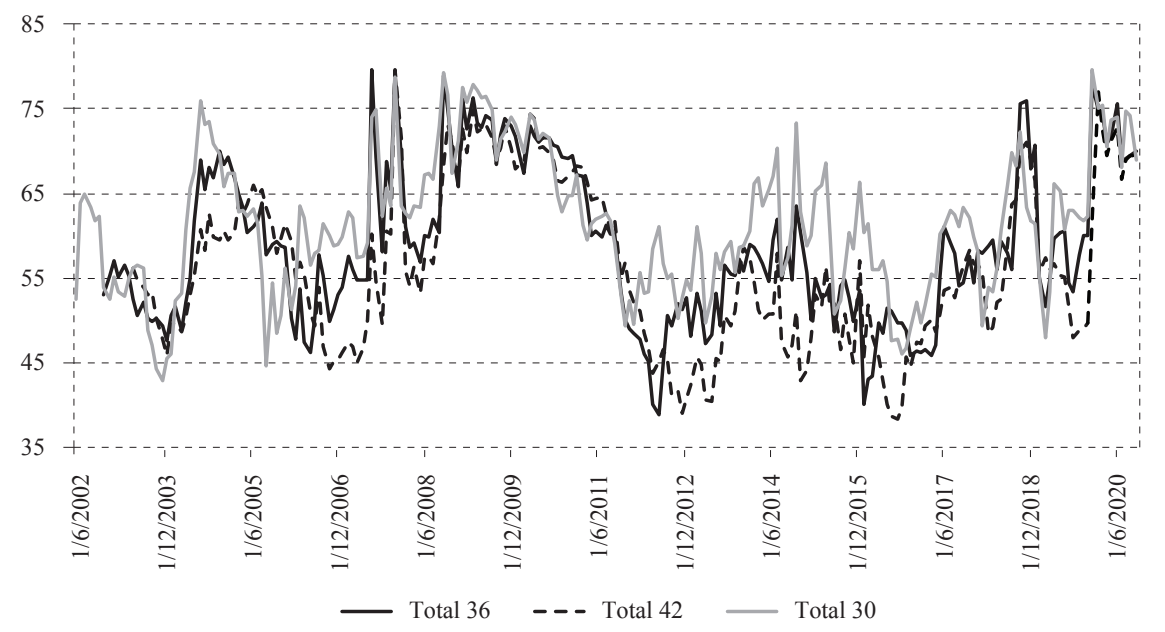

Source: Author's calculation.

However, these are static results. That is why the next step was taken, in which the dynamic VAR model and spillover tables have been estimated. In that way, information on which variable is the net receiver or emitter of shocks in the economy is obtained. Previous research focuses on the IRFs and the FEVDs statically. However, such an approach did not give insights into the direction of the shocks and their changes over time. The rolling window approach used the length of 30, 36, and 42 months. The 36 month length was chosen so that a full 3 -year period is included for the estimation part, and the 30 and 42 month lengths were utilized so that a robustness check could be performed in the subsequent section (as in Diebold and Yilmaz, 2009; 2012). Firstly, we comment on the 36 month window length results until the robustness checking. The overall values of the rolling spillover index indicate changing dynamics over time. This is seen especially during the problem of insolvency of WorldCom in 2002 (van Roye, 2014), the financial crisis 
of 2007-2008 when all spillovers increased, and again the increases are visible during the sovereign debt crisis which was at its highest in 2012. The increase of the spillovers is visible in the latest crisis, COVID-19, at the beginning of 2020 as well. However, the values of the total spillover increased during the financial crisis for a longer period than in the COVID-19 crisis. This is in line with the current belief that the pandemic crisis is a short-term negative shock (as suggested in Boivin, Giannoni and Stevanović, 2020), due to the quicker reaction of governments and central banks (Ehnts and Paetz, 2021), with banks being part of the solution and not the problem (Giese and Haldane, 2020) in the COVID-19 case.

The total spillover index only gives insight into the overall spillover among all of the variables. If we want to focus on the spillovers of systemic stress to other variables, the pair-wise and the net pair-wise indices need to be observed as well. This is done in figure $2^{9}$, which observes the net spillovers between each variable and the CISS. When the value of the spillover index is positive, it means that the variable is a net receiver of shocks from CISS. Otherwise, the CISS is the receiver of shocks from the selected variable. First, the interchanges of being the net receiver or net giver of shocks change over time for variables. This is in line with previous research that observes disproportional effects between the systemic stress and macroeconomic variables, in terms of size or signs (Li and St-Amant, 2010; Fry-McKibbin and Zheng, 2016). This provides the macroprudential policymakers with more detailed insights into the sources of when systemic stress is the net emitter or receiver of shocks to the rest of the economy. The DIRATE (lower left panel of figure 2) is the net receiver of shocks in systemic stress the majority of the time. This is in line with conventional views of reactions of monetary policy to the financial instability (Bernanke and Gertler, 2001; or Bean et al., 2010). Furthermore, as the central banks have such reactions to the increased systemic stress, the CISS variable in this case provides a good predictor of future interest rate movements. This is because the values of the spillover index, in this case, are high. Next, by observing the pair-wise spillovers between CISS and DIIP (upper left panel of figure 2), the magnitude of the spillovers is greatest during the crisis periods. Otherwise, the values are close to zero, i.e., the spillovers are close to insignificant. This is in line with the non-responsiveness of the real economic growth to the financial instability shocks in tranquil times found in Hakkio and Keeton (2009), Hubrich and Tetlow (2014), van Roye (2011), as well as Hollo, Kremer and Lo Duca (2012). The dynamics of the net spillover for the DHICP case (upper right panel, figure 2) that the effects of the inflation stabilization before the financial crisis have contributed to the CISS variability, as the latter variable was the net receiver of shocks in DHICP. This is in line with Frankel (2012), where the author comments on the problems of focusing mostly on inflation targeting before the 2007-2008 financial crisis. This changed in the stabilization period after the crisis. Finally, the DLOAN results (right bottom panel, figure

\footnotetext{
${ }^{9}$ Figure 2 depicts results for 36 month rolling windows, whereas the robustness of the results in terms of 30 and 42 month rolling windows are shown in figure.
} 
2) indicate that the values of the spillovers increase when the loan growth rate increases, which in return increases the CISS values. This is in line with findings in Mallick and Sousa (2013), where the authors observe that rapid credit expansions raise financial imbalances. The interchanges of net emitting or receiving of shocks between DLOAN and CISS after the financial crisis is also in line with the previous research. As the banks were de-risking their balance sheets regarding bad credits, the policies regarding credit channels were not much effective. Then, when the credit growth started to increase (period 2013-2018), the DLOAN became the net emitter of shocks to CISS. This is in line with Jordá, Schularick and Taylor (2011), and Schularick and Taylor (2012), in which the findings indicate that credit growth is the best predictor of financial instability.

\section{Figure 2}

Net pair-wise spillover indices between each variable and CISS, $h=12$, rolling windows 36 months
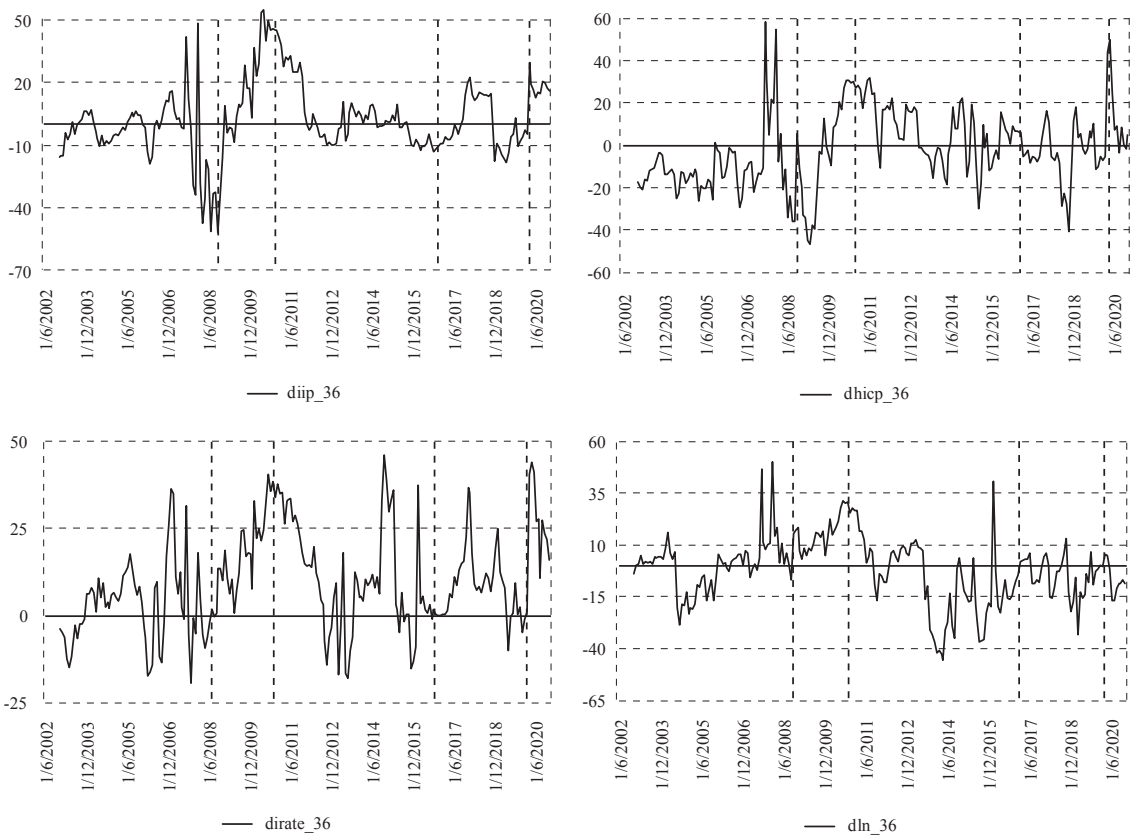

Note: Dashed lines indicate dates from left to right: Global financial crisis, Euro crisis, Brexit referendum vote and COVID-19 crisis.

Source: Author's calculation.

As previous research divides the analysis into good or bad states, i.e., regimes of business cycles, different systemic stress regimes, etc., rolling Granger test results between CISS and each variable in the system was observed as well. Thus, the null hypothesis assumes no causality from variable $x$ to $y$ within the the VAR model. The results are given in figure 3 where CISS is the cause, and figure 4 shows the CISS as the response variable. This enables better information on when the shocks in one variable have significant spillovers to the other. First, the results are in line 
with Cardarelli, Elekdag and Lall (2011), who also find that systemic stress is not always the preceding variable in the model. This is true in this research as well, as the $p$-value results of the Granger tests interchange in terms of (non)rejection of the null hypothesis. Some of the main findings are as follows. The CISS variable does not cause DIIP as well as other variables in tranquil times, as found in Hartmann et al. (2015), who explain this via the fact that CISS should be measuring the systemic stress and not general financing conditions. Next, the result concerning when the DLN variable emits shocks to CISS is significant in figure 4 (lower right panel) is in line with that of Misina and Tkacz (2008). The aforementioned problems of inflation targeting before the financial crisis are found to be statistically significant in the upper right panel of figure 4. These findings are in line with CEPR (2013); and the significance of shocks in DHICP that spillover to CISS is found to be mostly during the low systemic stress periods, as in Li and St-Amant (2010). Finally, as the Granger test results vary over time, which means that the shocks in CISS are not the ones that are driving the movement of the rest of the variables. Rather, CISS is a good variable to capture shocks in other variables in the model (figure 3 ) as a realization of financial risk during the crisis periods.

\section{Figure 3}

Comparison of rolling net spillover indices (grey lines, right axis) to the Granger causality test p-value (black lines, left axis), 36 months window length, CISS is the cause
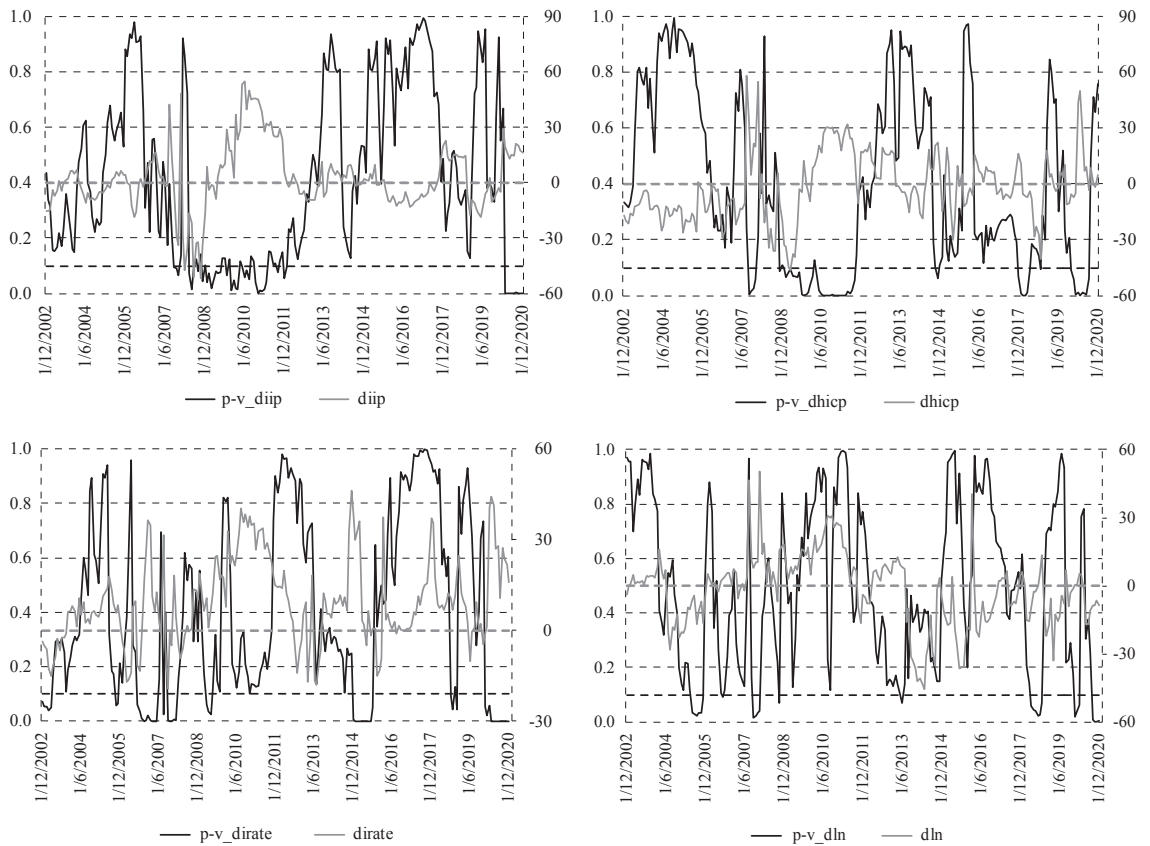

Note: Dashed grey line is the zero value for the spillover index; black dashed line is the 10\% significance level.

Source: Author's calculation. 
In general, the results obtained here support previous findings that focus on asymmetric models where the business cycle and/or systemic stress threshold values govern the sign and magnitude of the reactions to shocks within the system. This is visible in the changes in the dynamics of being a net receiver or emitter of shocks between the pairs of selected variables and CISS. Periods of high systemic stress and economic downturns generate greater overall spillover effects between the variables, compared to the tranquil times. These results corroborate previous findings in similar research, such as Mittnik and Semler (2013). These authors find that the reactions to the shocks in systemic stress or macroeconomic variables depend on the sign and size of the shocks. Although there is evidence here that the systemic stress shocks have a great role in macroeconomic fluctuations, as in Christiano, Motto and Rostagno (2010), Del Negro et al. (2017), and Jermann and Quadrini (2012); the rolling Granger test results indicate that a feedback relationship exists. Thus, the analysis and decision-making should be based on the interchanges of the predictive power of the observed variables in the model.

\section{Figure 4}

Comparison of rolling net spillover indices (grey lines, right axis) to the Granger causality test p-value (black lines, left axis), 36 months window length, CISS is the response
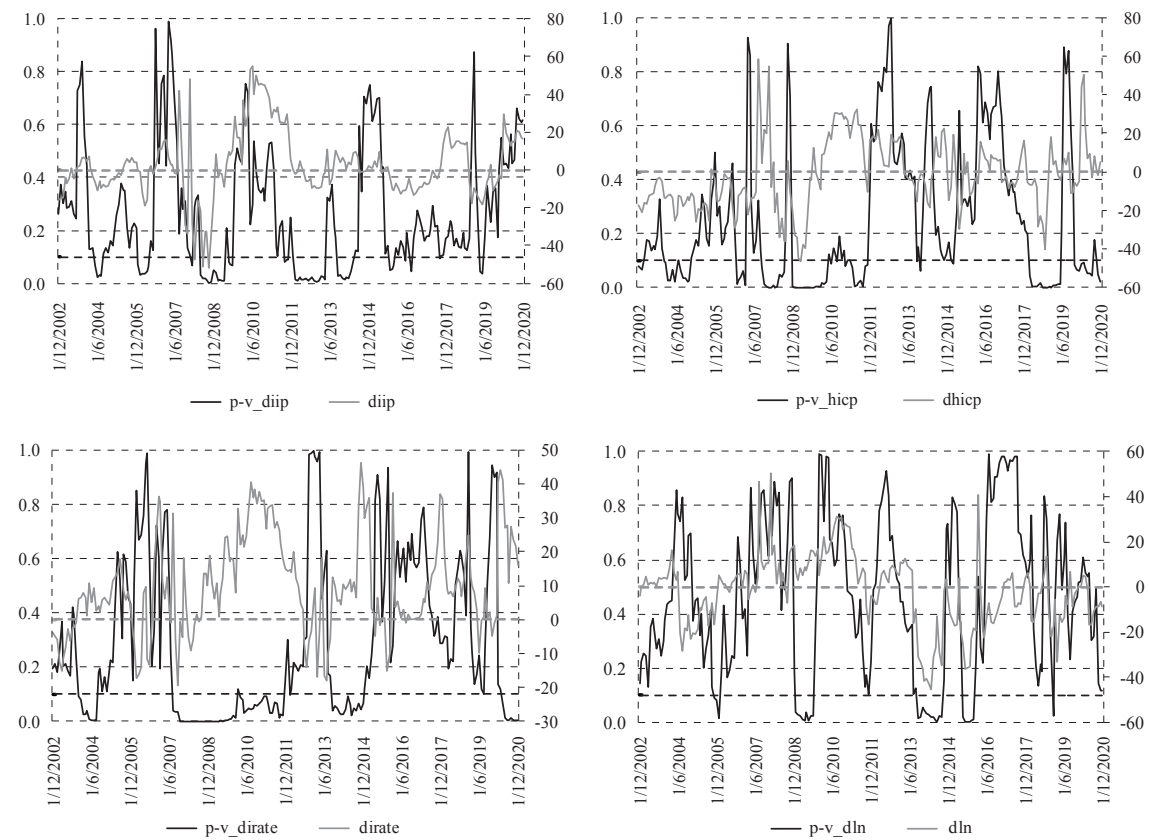

Note: Dashed grey line is the zero value for the spillover index; black dashed line is the $10 \%$ significance level.

Source: Author's calculation.

To summarize, it can be stated that the German central bank, since losing its monetary policy power since 1999, was more of a reactor to changes in the economy, 
due to its usual cuts in interest rates after the GFC. This is seen in interest rates being the net receiver of shocks in crises times in figure 2. It is expected that similar behaviour can be found in the future. The opposite is true for credit demand: during periods of economic tranquillity, the CISS registers low values, and changes in this variable spill in a greater manner to the DLN variable (see the subperiod after the GFC when the economy recovered). As households and nonfinancial corporations were recovering, with rising sentiment, bank credits to the private economy were greatly under the influence of the subdued systemic stress. The pandemic was a different type of a shock to the economy, so it can be expected that bank loans will not be affected for very long by shocks in CISS values. It is already seen that by the end of 2020, the DLN had become a greater giver of shocks again. Inflationary pressures are continuing until the end of 2021, and are expected to continue until early next year (ECB, 2020). That is why it can be expected that after the initial shock at the beginning of 2020 in the pairwise spillover index, the trend will be reversed. This is due to inflation affecting financial markets movements, and consequently, the CISS value movements as well. After the GFC, as banks were getting rid of the bad credits, changes in bank balance sheets affected the policies regarding credit channels, which were not effective. The opposite is true in times of private loan recovery, as the CISS variable becomes the net receiver of shocks in DLN. This indicates that the changes of credit growth contribute to future financial instability in a great manner. The real economic activity (in terms of IIP or GDP) has its lowest spillover indices (closest to zero values) in times of no realized stress; it is known in the literature that financial stress affects the lower percentiles of GDP growth (the growing literature on growth-at-risk focuses on the lower tail of the GDP growth distribution).

Finally, the approach of this paper can be compared to the regime switching in Hartmann et al. (2015). Neither approach assumes the linear constant relationship between the variables, as a usual VAR model would. However, the regime switching approach assumes the existence of two or more regimes in which the interrelationship between the variables is different. However, one drawback of a regime switching approach is that the shifts between regimes are abrupt, i.e., the probabilities of being in a regime identify abrupt changes in the system. This is not a realistic assumption for macroeconomic variables, and especially those that have sluggish behaviour, such as bank credit. Regime switching is utilized on variables such as CISS, but when it is analyzed on a daily basis for portfolio management purposes, (i.e., how do abrupt changes in financial markets affect investors and other interested parties?). Thus, a better approach would be either some form of a smooth transition VAR, or an approach such as this one, in which a linear relationship exists, but the parameters of the model change over time due to the rolling estimation.

\subsection{ROBUSTNESS CHECKING}

To test the robustness of the results, several approaches were used. Firstly, the original VAR model was re-estimated with the rolling window lengths of 30 and 42 months, as already noted in the previous subsection. This follows the 
recommendations of Diebold and Yilmaz $(2009,2012)$, where the authors suggest changing the length of the rolling window estimation. The main idea is to obtain if the same dynamics occur in the spillover indices over time. By observing figures 1 and 5, the total and net spillover indices have the same dynamics over time regardless of the window estimation length. Of course, the longer the window length is, the more smoothed out the series becomes.

Next, the same procedure was re-done, i.e., the VAR model with the rolling spillover index was estimated by including the square root of the CISS variable, as suggested in Kremer (2015). Figure 6 contrasts the total spillover indices of the original variable and its squared root. Again, the dynamics are very similar over the entire observed period. The indices almost coincide the majority of the time. Another robustness checking was made by using the interpolated GDP values on a monthly basis. The model was re-estimated on the entire sample, and the spillover table is shown in table 3 . The changes are minor when compared to values in table 2, with the same conclusions as well. Furthermore, the dynamic analysis was re-done with the interpolated series as well. Figure 7 compares just the total spillover index values for the DGDP and DIIP for the rolling window length of 36 months and the series are almost perfectly aligned the majority of the time.

\section{Figure 5}

Net pair-wise spillover indices between each variable and CISS, $h=12$, rolling windows 30, 36 and 42months
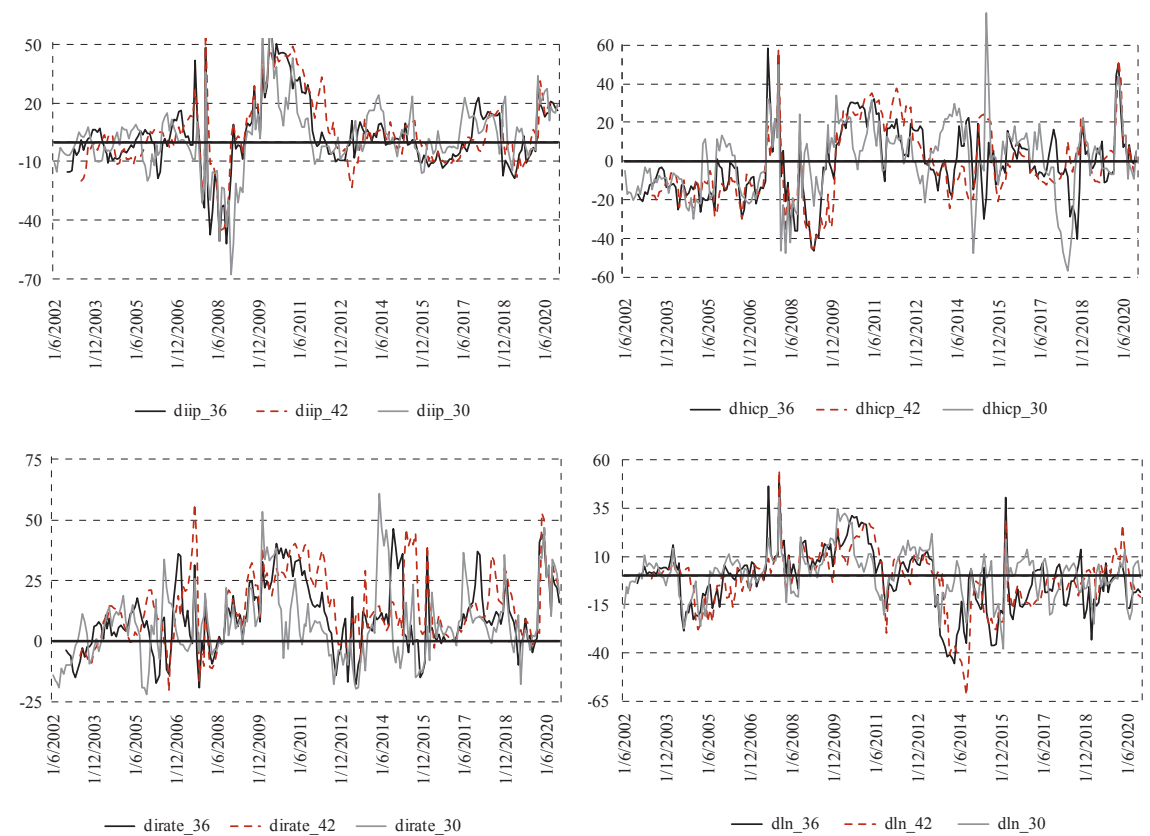

Source: Author's calculation. 
Next, more comparisons are included in the appendix. Figure A1 compares all three values of total spillover indices for DGDP and DIIP, for the 30, 36, and 42 window lengths; and figure A2 does the same, but for the pair-wise net spillover indices. Again, the dynamics in all series are the same. As Diebold and Yilmaz $(2009,2012)$ suggest to change the length of the forecast horizon $h$, the estimation of the rolling VAR model and the spillover indices was obtained for the original set of the variables (i.e., the DIIP one included in the analysis). However, the value for $h$ was chosen to be 18 and then 24 months. The pair-wise net spillover indices between each of the variables and CISS are compared in figure A3. It is visible that the lines are very close to one another, for all four pairs of variables.

Finally, additional checking was made to compare the results of this analysis to the SVAR (structural VAR) approach, in which additional assumptions can be made about the short-term effects of shocks in one variable to another. Kremer (2015) and other related literature in which SVARs are utilized in order to examine similar questions was followed. The following ordering of variables was done: DHICP, DIIP, CISS, DIRATE, DLN, in the setting of $A u_{t}=B \varepsilon_{t}$, where matrices $A$ and $B$ denote matrices of coefficient that need to be estimated, $u$ is the vector of residuals of the VAR model, and $\varepsilon$ is the vector of unobserved structural innovations. Firstly, the ordinary VAR model was estimated over the entire sample, GIRFs were extracted to see the effects of shocks in other variables in CISS reaction, and vice versa - CISS shocks reactions in other variables in the system. Secondly, the SVAR IRFs were estimated to compare the results. Figures A5 and A6 show both results that indicate that the dynamics of IRFs is the same. Thus, we are confident that the results and conclusions from them are robust.

\section{Figure 6}

Comparison of total spillover index, 36 rolling window length, CISS (total 36, black line) and squared root of CISS (sqciss, grey line) in VAR model

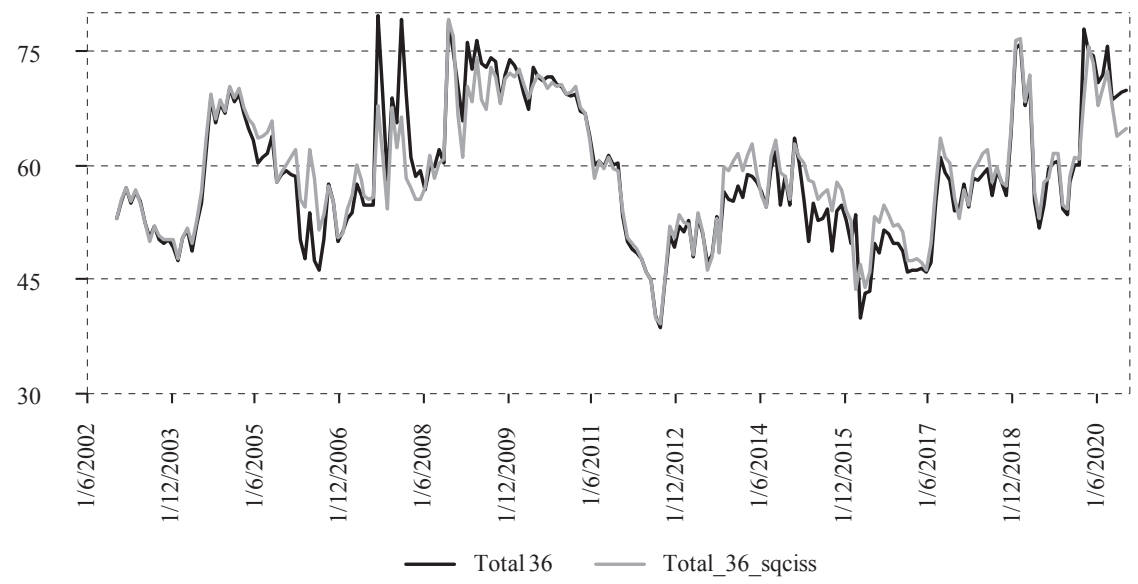

Source: Author's calculation. 
TABLE 3

Spillover table, full sample, in percent, monthly DGDP used

\begin{tabular}{|c|c|c|c|c|c|c|c|}
\hline Variable & DGDP & DHICP & DIRATE & DLN & CISS & From & T_from \\
\hline DGDP & 61.90 & 2.64 & 13.45 & 2.46 & 19.55 & 9.53 & 38.10 \\
\hline DHICP & 17.45 & 65.88 & 4.08 & 1.52 & 11.07 & 8.53 & 34.12 \\
\hline DIRATE & 8.92 & 1.15 & 62.84 & 0.56 & 26.52 & 9.29 & 37.15 \\
\hline DLN & 0.27 & 1.50 & 9.09 & 84.85 & 4.29 & 3.79 & 15.15 \\
\hline CISS & 3.55 & 5.26 & 2.01 & 0.59 & 88.59 & 2.85 & 11.41 \\
\hline To & 5.64 & 2.64 & 7.16 & 1.28 & 15.36 & - & - \\
\hline T_to & 30.19 & 10.55 & 28.63 & 5.13 & 61.43 & - & 33.98 \\
\hline
\end{tabular}

Source: Author's calculation.

\section{Figure 7}

Total spillover index, $h=12$, rolling window length 36 months, comparison of DIIP (grey line) to the DGDP (black line) variable specification

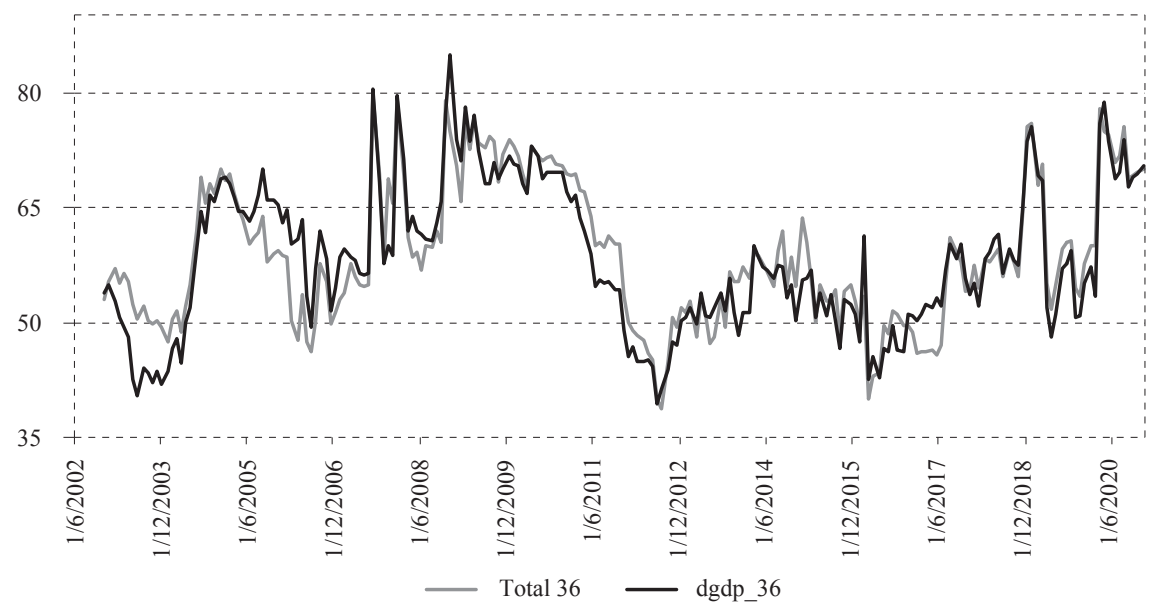

Source: Author's calculation.

\section{CONCLUSION}

Macroprudential policy is at the centre of attention nowadays again, due to the last crisis induced by the COVID-19 pandemic. The interaction between systemic risk and the real economy is still insufficiently explored. This is especially true regarding the assumptions of asymmetric relationships, nonlinearities, and dynamic changes in interrelationships between systemic stress and the rest of the economy. Using the approach of this research can provide the analysts and policy decisionmakers insights into the changing dynamics of the aforementioned issues. Results in this research have indicated that there are times when a net spillover between two variables is increasing or decreasing over time. If such a trend is observed, additional analysis can be made so that timely decisions and measures can be activated. Furthermore, as the macroprudential and monetary policymakers have to track the interrelationships between these variables over time, the approach in the study is straightforward and easy to interpret. As the timing and intensity of 
the specific measures are important, such an approach enables the policymakers to do so. Such an approach can be helpful in the ex-ante approach of macroprudential policy evaluation when the potential impacts of policy instruments have to be assessed before their activation. Such an approach is emphasized in Buch, Vogel and Weigert (2018).

Some of the shortfalls of this study were as follows. Using the CISS index as the overall measure of systemic stress could be problematic. Some previous research states some problems regarding this index during its construction, or concludes that the index is a stylized reduced-form of integrating financial instability into the economic modelling (Kremer, 2015). Thus, one cannot always deal with perfect variables. Next, one country was observed in the analysis. Although, previous findings indicate that majority of the results for selected European countries (either observing developed ones or, e.g., CEE markets) have similar conclusions. However, future work should analyse these dynamics for other countries, especially those that experience some specific macroeconomic problems. Regarding the latest COVID-19 crisis, the results indicate that the spillovers had a shorter period compared to the crisis of 2007-2008. However, at the time of conducting this research, data was available only until the end of 2020. Thus, although the government and the central bank have responded to this crisis faster than the previous one, the future spillovers are still uncertain. However, in 2019, the German central bank has activated the countercyclical capital buffer for the first time (Deutsche Bundesbank, 2019). This helped in the stabilization of the financial system. Furthermore, due to the European Central Bank purchasing securities on a large scale during the COVID-19 crisis, the banks have a lot of liquidity. Thus, the financing costs of the banks have barely risen, when compared to the aforementioned financial crisis (Buch, 2020).

As there are many other areas of research and methodological questions within the macroprudential policymaking, such as modelling networks, heterogeneity in different types of data, overall combining different ex-ante and ex-post analysis, future work should aim to utilize the results from analysis such as this one. This is due to not observing solely the sign and magnitudes of the impulse response functions as usually done in related research, but the overall changes in the dynamics of shock spillovers over time.

\section{Disclosure statement}

The author declares that there is no conflict of interest. 
1. Bean, C. [et al.], 2010. Monetary policy after the fall. Proceedings - Economic Policy Symposium. Jackson Hole, Federal Reserve Bank of Kansas City, pp. 267-328.

2. Bernanke, B. and Gertler, M., 1989. Agency costs, net worth, and business fluctuations. American Economic Review, 79(1), pp. 14-31.

3. Bernanke, B. and Gertler, M., 2001. Should central banks respond to movements in asset prices? American Economic Review, 91(2), pp. 253-257. https:// doi.org/doi:10.1257/aer.91.2.253

4. Bernanke, B., Gertler, M. and Gilchrist, S., 1999. The financial accelerator in a quantitative business cycle framework. In: J. B. Taylor and M. Woodford, eds. Handbook of Macroeconomics, 1(part C), pp. 1341-1393. https://doi.org/ doi:10.1016/s1574-0048(99)10034-x

5. Blanchard, O. J. and Quah, D., 1989. The Dynamic Effects of Aggregate Demand and Supply Disturbances. American Economic Review, 79(4), pp. 655-673. https://doi.org/doi:10.3386/w2737

6. Bloom, N., 2009. The Impact of Uncertainty Shocks. Econometrica, 77(3), pp. 623-685. https://doi.org/doi:10.3982/ecta6248

7. Boeckx, J., Dossche, M. and Peersman, G., 2014. Effectiveness and transmission of the ECB's balance sheet policies. National Bank of Belgium, Working Paper Research, No 275.

8. Boivin, J., Giannoni, M. and Stevanović, D., 2020. Dynamic effects of credit shocks in a datarich environment. Journal of Business \& Economic Statistics, 38(2), pp. 272-284. https://doi.org/doi:10.1080/07350015.2018.1497507

9. Borys, M. M., Horváth, R. and Franta, M., 2009. The Effects of Monetary Policy in the Czech Republic: An Empirical Study. Empirica, 36(4), pp. 419443. https://doi.org/doi:10.1007/s10663-009-9102-y

10. Brunnermeier, M. and Sannikov, Y., 2014. A macroeconomic model with a financial sector. American Economic Review, 104(2), pp. 379-421. https://doi. org/doi:10.1257/aer.104.2.379

11. Brunnermeier, M., Eisenbach, T. M. and Sannikov, Y., 2012. Macroeconomics with financial frictions: a survey. NBER Working paper, No. 18102. https://doi. org/doi:10.3386/w18102

12. Bucacos, E., 2018. Financial Conditions and Monetary Policy in Uruguay: An MS-VAR Approach. IDB Publications Working Papers, No. 8275.

13. Buch, C., 2020. The Deutsche Bundesbank's 2020 Financial Stability Review.

14. Buch, C., Vogel, E. and Weigert, B., 2018. Evaluating macroprudential policies. European Systemic Risk Board. ESRB Working paper series, No 76.

15. Cardarelli, R., Elekdag, S. and Lall, S., 2011. Financial stress and economic contractions. Journal of Financial Stability, 7(2), pp. 78-97. https://doi.org/ doi:10.1016/j.jfs.2010.01.005

16. Chamberlin, G., 2010. Methods Explained: Temporal disaggregation. Economic \& Labour Market Review, 4, pp. 106-121. https://doi.org/doi:10.1057/ elmr.2010.157 
17. Chavleishvili, S. and Manganelli, S., 2019. Forecasting and stress testing with quantile vector autoregression. ECB Working Paper, No. 2330. Frankfurt am Main: European Central Bank.

18. Chow, G. C. and Lin, A. L., 1971. Best linear unbiased interpolation, distribution, and extrapolation of time series by related series. The Review of Economics and Statistics, 53(4), pp. 372-375. https://doi.org/doi:10.2307/1928739

19. Christiano, L. and Ikeda, D., 2011. Government policy, credit markets and economic activity. NBER working papers, No. 17142. https://doi.org/doi:10. 3386/w17142

20. Christiano, L., Eichenbaum, J. and Evans, C., 1996. The Effects of Monetary Policy Shocks: Evidence from the Flow of Funds. Review of Economics and Statistics, 78(1), pp. 6-34. https://doi.org/doi:10.2307/2109845

21. Christiano, L., Eichenbaum, M. and Evans, C. L., 1999. Monetary Policy Shocks: What Have we Learned and to What End? In: J. B. Taylor and M. Woodford, eds. Handbook of Macroeconomics, 1(part A), pp. 65-148. https:// doi.org/doi:10.1016/s1574-0048(99)01005-8

22. Christiano, L., Motto, R. and Rostagno, M. 2010. Financial factors in economic fluctuations. ECB Working papers, No. 1192.

23. Davino, C., Furno, M. and Vistocco, D., 2014. Quantile Regression - Theory and Applications. UK: John Wiley \& Sons.

24. DBE, 2021. DBE 2021 database.

25. Del Negro, M. [et al.], 2017. The Great Escape? A Quantitative Evaluation of the Fed's Non-Standard Policies. American Economic Review, 107(3), pp. 824-857. https://doi.org/doi:10.1257/aer.20121660

26. Delatte, A-L., Fouquau, J. and Portes, R., 2014. Nonlinearities in Sovereign Risk Pricing: The Role of CDS Index Contracts. NBER Working Papers, No. 19985. https://doi.org/doi:10.3386/w19985

27. Delli Gatti, D. [et al.], 2012. Mobility constraints, productivity trends, and extended crises. Journal of Economic Behavior and Organization, 83(3), pp. 375-393. https://doi.org/doi:10.1016/j.jebo.2012.03.011

28. Deutsche Bundesbank, 2019. Financial Stability Review 2019. Frankfurt am Main: Deutsche Bundesbank.

29. Diebold, F. X. and Yilmaz, K., 2009. Measuring Financial Asset Return and Volatility Spillovers with Application to Global Equity Markets. The Economic Journal, 119(534), pp. 158-171. https://doi.org/doi:10.1111/j.1468-02 97.2008.02208.x

30. Diebold, F. X. and Yilmaz, K., 2012. Better to Give than to Receive: Predictive Directional Measurement of Volatility Spillovers. International Journal of Forecasting, 28(1), pp. 57-66. https://doi.org/doi:10.1016/j.ijforecast.2011.02.006

31. Dufour, A., Marra, M. and Sangiorgi, I., 2019. Determinants of intraday dynamics and collateral selection in centrally cleared and bilateral repos. Journal of Banking \& Finance, 107(c), 105610. https://doi.org/doi:10.1016/j. jbankfin.2019.105610 
32. Dumitrescu, S., 2015. European Equity Market Return, Volatility and Liquidity Spillover Dynamics during the Eurozone Debt Crisis. Financial Studies, 19(2), pp. 30-50.

33. Duprey, T. and Ueberfeldt, A., 2020. Managing GDP tail risk. Otawa: Bank of Canada.

34. ECB, 2020. Economic bulletin, Issue 6. Frankfurt am Main: European Central Bank.

35. ECB, 2021. ECB Database. Frankfurt am Main: European Central Bank.

36. Ehnts, D. and Paetz, M., 2021. COVID-19 and its economic consequences for the Euro Area. Eurasian Economic Review, 11, pp. 227-249. https://doi.org/ doi:10.1007/s40822-020-00159-w

37. Engle, R. F. and Manganelli, S., 2004. CAViaR: Conditional autoregressive value at risk by regression quantiles. Journal of Business and Economic Statistics, 22(4), pp. 367- 381. https://doi.org/doi:10.1198/073500104000000370

38. Eurostat, 2021. Database.

39. Fisher, I., 1933. The Debt-Deflation Theory of Great Depressions. Econometrica, 1(4), pp. 337-357. https://doi.org/doi:10.2307/1907327

40. Frale, C. [et al.], 2008. A Monthly Indicator of the Euro Area GDP. EUI Working Paper, No. 2008/32.

41. Frankel, J., 2012. The death of inflation targeting. VoxEU, June 19, 2012.

42. Fry-Mckibbin, R. and Zheng, J., 2016. Effects of the US monetary policy shocks during financial crises - a threshold vector autoregression approach. Applied Economics, 48(59), pp. 5802-5823. https://doi.org/doi:10.1080/0003 6846.2016.1186792

43. FSB, 2020. Peer Review of Germany, Review Report. Financial Stability Board.

44. Galán, J. E., 2020. The benefits are at the tail: uncovering the impact of macroprudential policy on growth-at-risk. Journal of Financial Stability, 100831. https://doi.org/doi:10.1016/j.jfs.2020.100831

45. Giese, J. and Haldane, A., 2020. COVID-19 and the financial system: a tale of two crises. Oxford Review of Economic Policy, 36(S1), pp. S200-S214. https:// doi.org/doi:10.1093/oxrep/graa035

46. Giglio, S., Bryan, K. and Pruitt, S., 2016. Systemic Risk and the Macroeconomy: An Empirical Evaluation. Journal of Financial Economics, 119(3), pp. 457-471. https://doi.org/doi:10.1016/j.jfineco.2016.01.010

47. Granger, C. W., 2003. Time series concepts for conditional distributions. Oxford Bulletin of Economics and Statistics, 65(s1), pp. 689-701. https://doi. org/doi:10.1046/j.0305-9049.2003.00094.x

48. Gross, C. and Siklos, P., 2019. Analyzing credit risk transmission to the non-financial sector in Europe: a network approach. ESRB Working paper series, No 78.

49. Guidolin, M. and Pedio, M., 2017. Identifying and measuring the contagion channels at work in the European financial crises. Journal of International Financial Markets, Institutions and Money, 48(C), pp. 117-134. https://doi. org/doi:10.1016/j.intfin.2017.01.001 
50. Hakkio, S. C. and Keeton, W. R., 2009. Financial Stress: What Is It, How Can It be Measured, and Why Does It Matter? Economic Review, 94(2), pp. 5-50.

51. Hartmann, P. [et al.], 2015. Melting down: Systemic financial instability and the macroeconomy. http://dx.doi.org/10.2139/ssrn.2462567

52. Hatzius, J. [et al.], 2010. Financial Conditions Indexes: A New Look after the Financial Crisis. NBER Working Paper 16150. http://dx.doi.org/10.3386/w16150

53. Havránek, T., Horváth, R. and Matějů, J., 2012. Monetary Transmission and the Financial Sector in the Czech Republic. Economic Change and Restructuring, 45(3), pp. 135-155. https://doi.org/doi:10.1007/s10644-011-9106-z

54. He, Z. and Krishnamurthy, A., 2019. A Macroeconomic Framework for Quantifying Systemic Risk. American Economic Journal: Macroeconomics, 11(4), pp. 1-37. https://doi.org/doi:10.1257/mac.20180011

55. Hollo, D., Kremer, M. and Lo Duca, M., 2012. CISS - A composite indicator of systemic stress in the financial system. ECB Working Paper, No 1426.

56. Hoven, L. and Schreus, G., 2013. Towards a monthly indicator of economic growth. Report. Paper prepared for the Joint EU/OECD Workshop on Recent Developments in Business and Consumer Surveys, Brussels, 14-15 November 2013.

57. Hsiao, C., 1982. Autoregressive modeling and causal ordering of economic variables. Journal of Economic Dynamics and Control, 4, pp. 243-259. https:// doi.org/doi:10.1016/0165-1889(82)90015-x

58. Hubrich, K. and Tetlow, R. J., 2014. Financial stress and economic dynamics the transmission of crises. ECB Working paper, No 1728.

59. Huotari, J., 2015. Measuring Financial Stress - A Country Specific Stress Index for Finland (March 11, 2015). Bank of Finland Research Discussion Paper, No. 7/2015. http://dx.doi.org/10.2139/ssrn.2584378

60. Jahn, N. and Kick, T., 2012. Early warning indicators for the German banking system: a macroprudential analysis. Deutsche Bundesbank. Discussion paper, No. 27/2012.

61. Jermann, U. and Quadrini, V., 2012. Macroeconomic Effects of Financial Shocks. American Economic Review, 102(1), pp. 238-271. https://doi.org/ doi:10.1257/aer.102.1.238

62. Jin, X. and Nadal De Simone, F., 2020. Monetary policy and systemic risktaking in the Euro area investment fund industry: A structural factor-augmented vector autoregression analysis. Journal of Financial Stability, 49(C), 100749. https://doi.org/doi:10.1016/j.jfs.2020.100749

63. Jordá, O., Schularick, M. and Taylor, A. M., 2011. Financial Crises, Credit Booms, and External Imbalances: 140 Years of Lessons. IMF Economic Review, 59(2), pp. 340-378. https://doi.org/doi:10.1057/imfer.2011.8

64. Keynes, J., 1936. The General Theory of Employment, Interest and Money. London: Macmillan.

65. Kiyotaki, N. and Moore, J., 1997. Credit cycles. Journal of Political Economy, 105(2), pp. 211-248. https://doi.org/doi:10.1086/262072 
66. Koop, G., Pesaran, H. M. and Potter, S., 1996. Impulse response analysis in nonlinear multivariate models. Journal of Econometrics, 74(1), pp. 119-147. https://doi.org/doi:10.1016/0304-4076(95)01753-4

67. Kremer, M., 2015. Macroeconomic effects of financial stress and the role of monetary policy: a VAR analysis for the euro area. International Economics and Economic Policy, 13(1), pp. 105-138. https://doi.org/doi:10.1007/s10368-015-0325-z

68. Kremer, M. and Chavleishvili, S., 2021. Measuring Systemic Financial Stress and its Impact on the Macroeconomy. Beiträge zur Jahrestagung des Vereins für Socialpolitik 2021: Climate Economics. ZBW - Leibniz Information Centre for Economics, Kiel, Hamburg.

69. Li, F. and St-Amant, P., 2010. Financial Stress, Monetary Policy, and Economic Activity. Bank of Canada, Working Paper, No. 2010-12.

70. Linnemann, L. and Winkler, R., 2016. Estimating nonlinear effects of fiscal policy using quantile regression methods. Oxford Economic Papers, 68(4), pp. 1120-1145. https://doi.org/doi:10.1093/oep/gpw020

71. Lütkepohl, H., 1993. Introduction to Multiple Time Series Analysis, 2 ${ }^{\text {nd }}$. ed., Berlin: Springer-Verlag.

72. Lütkepohl, H., 2006. New Introduction to Multiple Time Series Analysis. Berlin: Springer.

73. Lütkepohl, H., 2010. Vector Autoregressive Models. Economics Working Paper, ECO 2011/30.

74. Lütkepohl, H., 2011. Vector Autoregressive Models. EUI Working Papers, ECO 2011/30.

75. Mallick, S. K. and Sousa, R. M., 2013. The real effects of financial stress in the Eurozone. International Review of Financial Analysis, 30, pp. 1-17. https://doi.org/doi:10.1016/j.irfa.2013.05.003

76. Marini, M., 2016. Nowcasting Annual National Accounts with Quarterly Indicators: An Assessment of Widely Used Benchmarking Methods. IMF Working paper, WP/16/71.

77. Martins, D., 2020. Euro Area Monetary Policy and Financial Stress Regimes: A Threshold VAR Approach. A Work Project, presented as part of the requirements for the Award of a Master Degree in Economics from the NOVA School of Business and Economics.

78. Misina, M. and Tkacz, G., 2008. Credit, Asset Prices, and Financial Stress in Canada. Working paper of Bank of Canada, 2008-10.

79. Mittnik, S. and Semler, W., 2013. The Real Consequences of Financial Stress. Center for Quantitative Risk Analysis (CEQURA). Working paper, No. 7.

80. Mittnik, S. and Semmler, W., 2013. The real consequences of financial stress. Journal of Economic Dynamics and Control, 37(8), pp. 1479-1499. https:// doi.org/doi:10.1016/j.jedc.2013.04.014

81. Mönch, E. and Uhlig, H., 2005. Towards a Monthly Business Cycle Chronology for the Euro Area. Journal of Business Cycle Measurement and Analysis, 1, pp. 43-58. 
82. Montes-Rojas, G., 2019. Multivariate quantile impulse response functions. Journal of Time Series Analysis, 40(5), pp. 739-752. https://doi.org/doi:10.1111/ jtsa. 12452

83. Neftci, S. N., 1984. Are Economic Time Series Asymmetric Over the Business Cycle?. Journal of Political Economy, 92(2), pp. 307-328. https://doi. org/10.1086/261226

84. Pesaran, M. H. and Shin, Y., 1998. Generalized impulse response analysis in linear multivariate models. Economics Letters, 58(1), pp. 17-29. https://doi. org/doi:10.1016/s0165-1765(97)00214-0

85. Sax, C. and Steiner, P., 2013. Temporal Disaggregation of Time Series. The $R$ Journal, 5(2), pp. 80-88. https://doi.org/doi:10.32614/rj-2013-028

86. Schmidt, R. H., 2019. On the change of the German financial system. SAFE White Paper, No. 61.

87. Schularick, M. and Taylor, A. M., 2012. Credit Booms Gone Bust: Monetary Policy, Leverage Cycles, and Financial Crises, 1870-2008. American Economic Review, 102(2), pp. 1029-1061. https://doi.org/doi:10.1257/aer.102.2.1029

88. Schüler, Y. S., 2014. Asymmetric Effects of Uncertainty over the Business Cycle: A Quantile Structural Vector Autoregressive Approach. University of Konstanz Working Paper Series, No. 2014-02.

89. Senapati, M. and Kavediya, R., 2020. Measuring Financial Stress in India. Department of Economic and Policy Research. Reserve Bank of India, WPS (DEPR), No. 09/2020.

90. Škrinjarić, T. and Šego, B., 2019. Risk connectedness of selected CESEE stock markets: a spillover index approach. China Finance Review International, 10(4), pp. 447-472. https://doi.org/doi:10.1108/cfri-07-2019-0124

91. Tamási, B. and Világi, B., 2011. Identification of credit supply shocks in a Bayesian SVAR model of the Hungarian Economy. MNB Working Papers, 7, pp. 1-21.

92. Van Aarle, B., Garretsen, H. and Gobbin, N., 2003. Monetary and fiscal policy transmission in the Euro-area: evidence from a structural VAR analysis. $4^{\text {th }}$ Eurostat and DG Ecfin colloquium on modern tools for business cycle analysis growth and cycle in the Euro-zone.

93. Van Roye, B., 2011. Financial Stress and Economic Activity in Germany and the Euro Area. Kiel Working Paper, No. 1743.

94. Van Roye, B., 2014. Financial stress and economic activity in Germany. Empirica, 41, pp. 101-126. https://www.doi.org/10.1007/s10663-013-9224-0

95. White, H., Kim, T. H. and Manganelli, S., 2015. VAR for VaR: Measuring tail dependence using multivariate regression quantiles. Journal of Econometrics, 187(1), pp. 169-188. https://doi.org/doi:10.1016/j.jeconom.2015.02.004

96. Yarovaya, L., Brzeszczyński, J. and Lau, C. K. M., 2016. Intra- and interregional return and volatility spillovers across emerging and developed markets: Evidence from stock indices and stock index futures. International Review of FinancialAnalysis,43,pp.96-114.https://doi.org/doi:10.1016/j.irfa.2015.09.004

97. Zaghini, A., 2016. Fragmentation and heterogeneity in the euro-area corporate bond market: Back to normal?. Journal of Financial Stability, 23(C), pp. 51-61. https://doi.org/doi:10.1016/j.jfs.2016.01.009 


\section{TABLE A1}

Unit root test results for all variables in the model

\begin{tabular}{|c|c|c|}
\hline & Level, type $=$ drift & Test values $1 \%, 5 \%, 10 \%$ \\
\hline DIIP & -3.219 & \multirow{5}{*}{$-3.46 ;-2.87 ;-2.57$} \\
\hline DHICP & -2.933 & \\
\hline IRATE & -1.293 & \\
\hline DLN & -3.396 & \\
\hline CISS & -3.881 & \\
\hline $\begin{array}{l}\text { DIRATE (differenced } \\
\text { interest rate) }\end{array}$ & $\begin{array}{r}\text { Type }=\text { none } \\
-3.488\end{array}$ & $-2.574 ;-1.942 ;-1.616$ \\
\hline
\end{tabular}

Note: Schwartz information criterion was used for the ADF test results. The KPSS test value for IRATE is equal to 1.65, with the critical values for $1 \%, 5 \%$ and $10 \%$ of $0.739,0.463$ and 0.347 respectively.

Source: Author's calculation.

\section{Figure A1}

Total spillover indices, $h=12$, rolling windows 30, 36 and 42 months, DGDP compared to DIIP

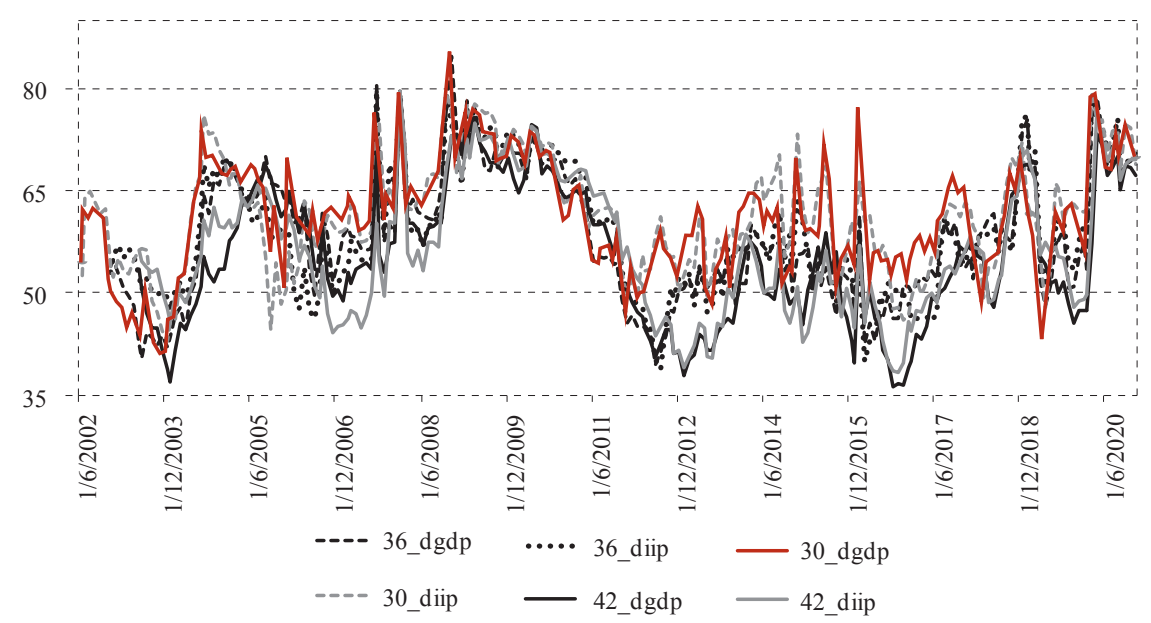

Source: Author's calculation. 


\section{Figure A2}

Net spillover indices between each variable and CISS, $h=12$, rolling windows 36 months, DGDP compared to DIIP
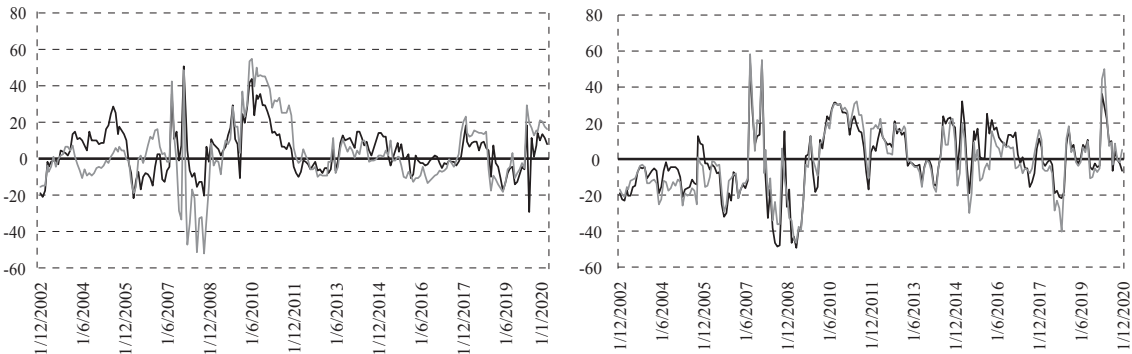

— dgdp_gdp _ diip_iip

— dhicp_gdp — dhicp_iip
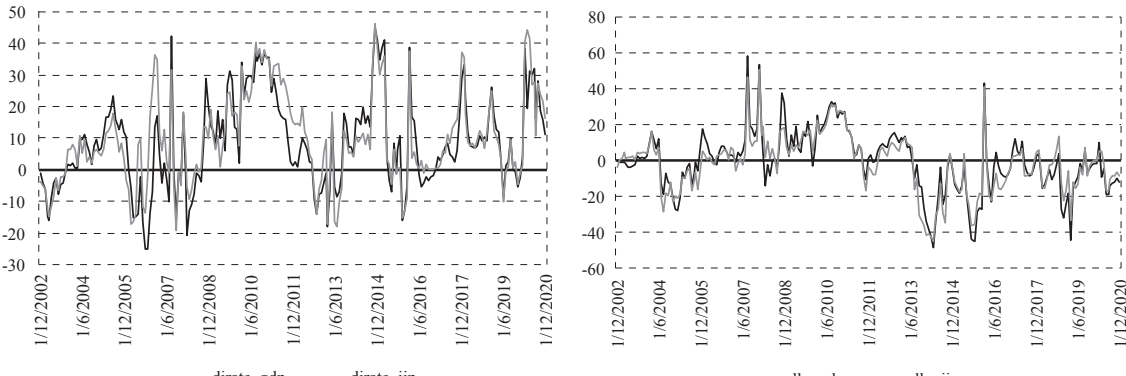

Source: Author's calculation.

\section{Figure A3}

Pair-wise net spillover indices between each variable and CISS, $h=12,18$ and 24, rolling windows 36 months, DIIP
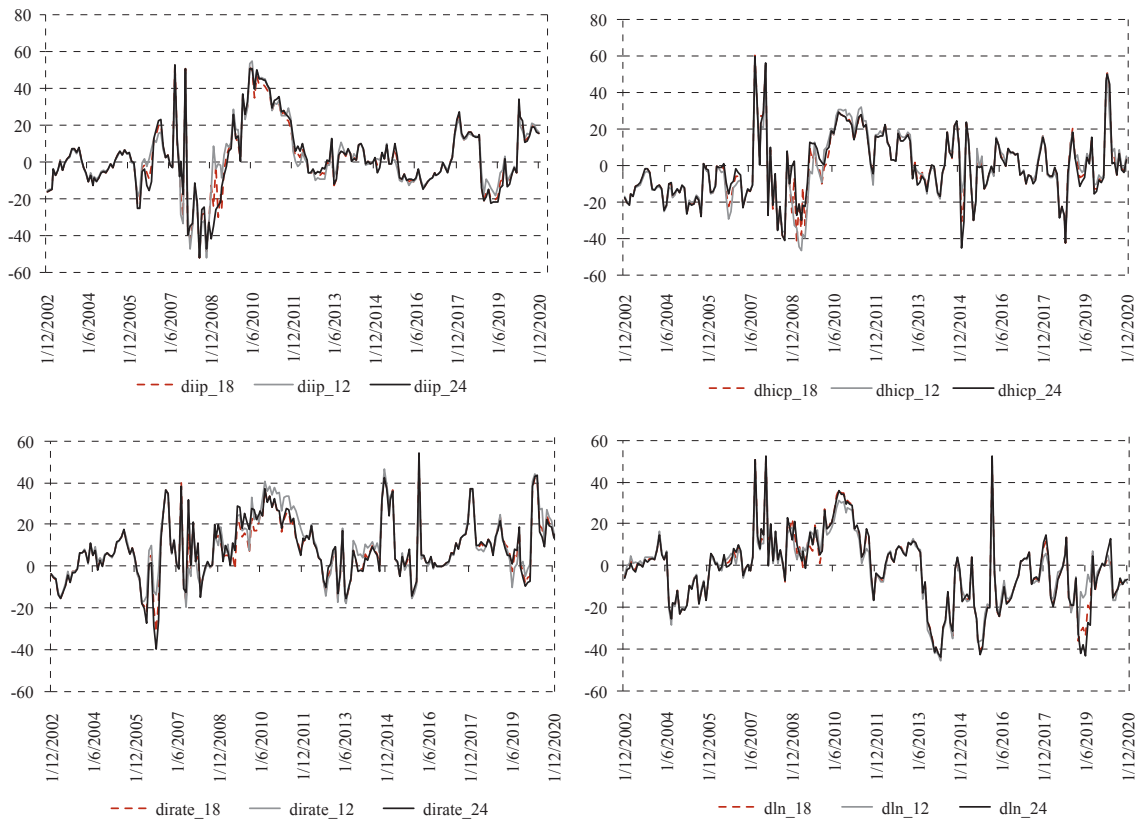

Source: Author's calculation. 
Figure A4

Correlation between CISS and selected variables, rolling windows 30, 36 and 42 months

30 months

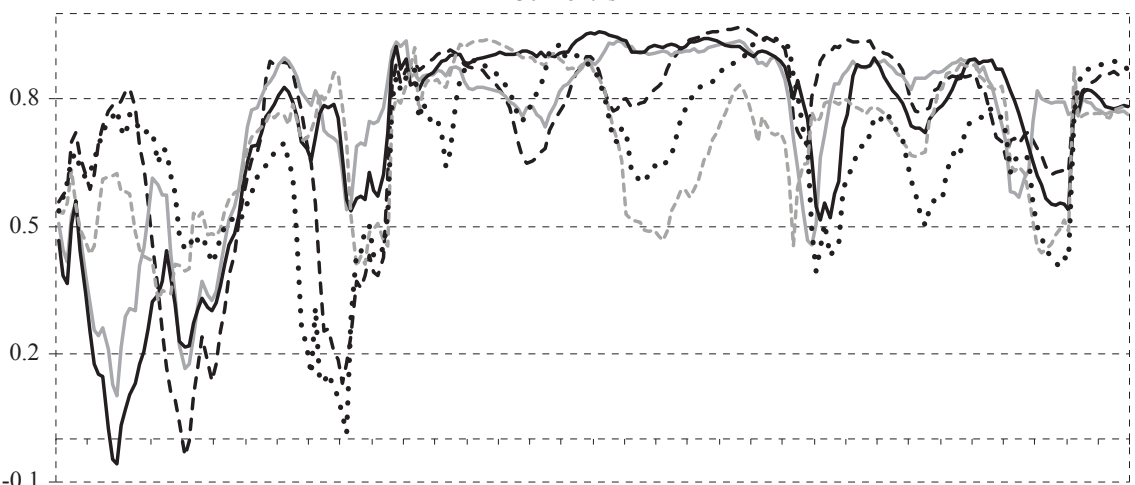

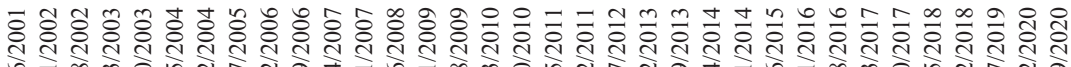

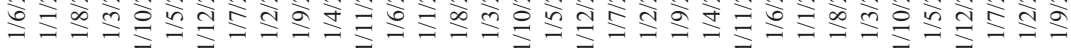

- - - Bond

Equity

Intermediaries

-..- FX

-... Money market

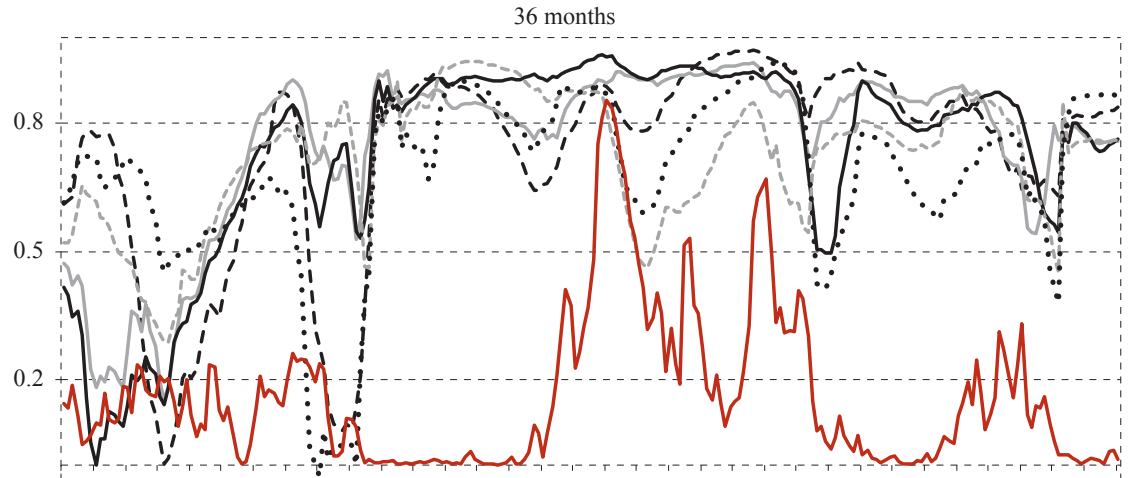
$-0.1$

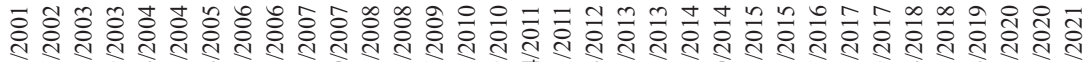

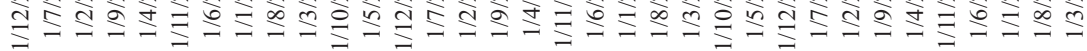

-- Bond — Equity — Intermediaries - - FX $\ldots$ Money market — Ciss 


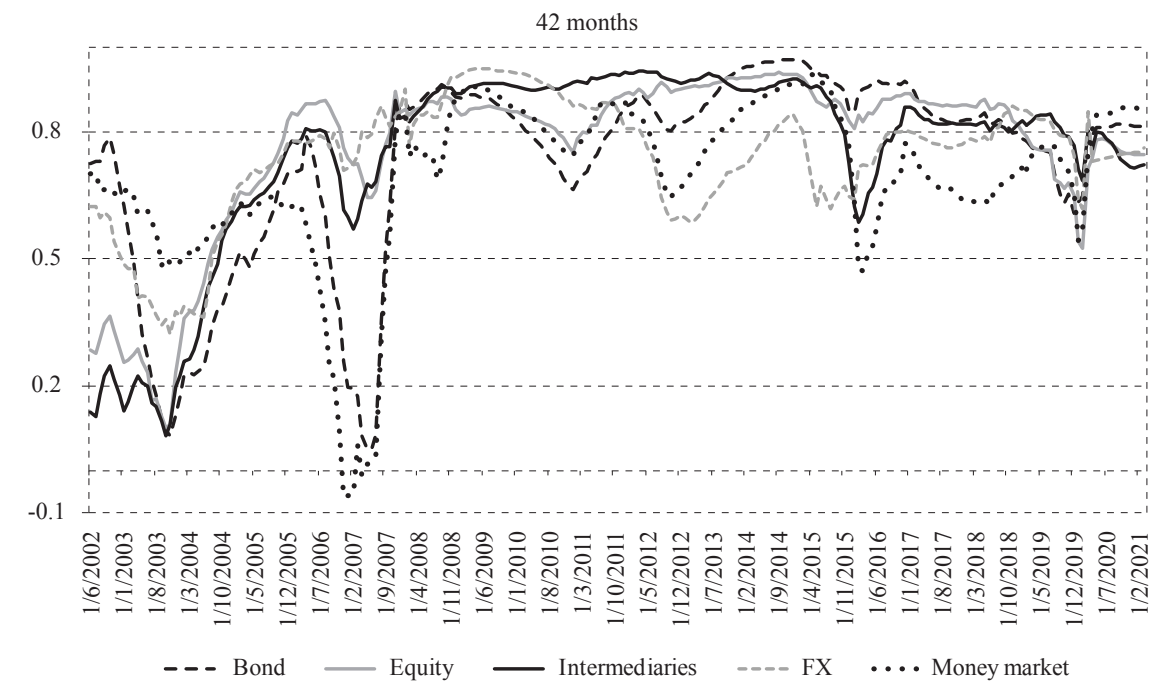

Note: Money market represents the realised volatility of the 3-month Euribor rate, interest rate spread between 3-month Euribor and 3-month T-bills, and monetary Financial Institutions (MFI) emergency lending at Eurosystem central banks; Intermediaries represents realised volatility of the idiosyncratic equity return of the Datastream bank sector stock market index over the total, yield spread btw A-rated fin. \& non-fin. corp. (7y), CMAX for the Datastream non-fin. sector stock market index interacted with the inverse price-book ratio for the fin. sector eqty. market index; $F X$ is the realised volatility of the euro exchange rate vis-a-vis the US dollar, the Japanese Yen and the British Pound; Equity is realised volatility of the Datastram non-financial sector stock market index, CMAX for the Datastream non-financial sector stock market index, and stock-bond correlation; and Bond is realised volatility of the German 10-year benchmark government bond index, yield spread between A-rated non-financial corporations and government bonds (7-year maturity bracket), and 10-year interest rate swap spread.

Source: Author's calculation. 
Figure A5

Generalized IRFs from VAR model, entire sample, reaction of CISS to shocks in other variables and reactions of others to shocks in CISS
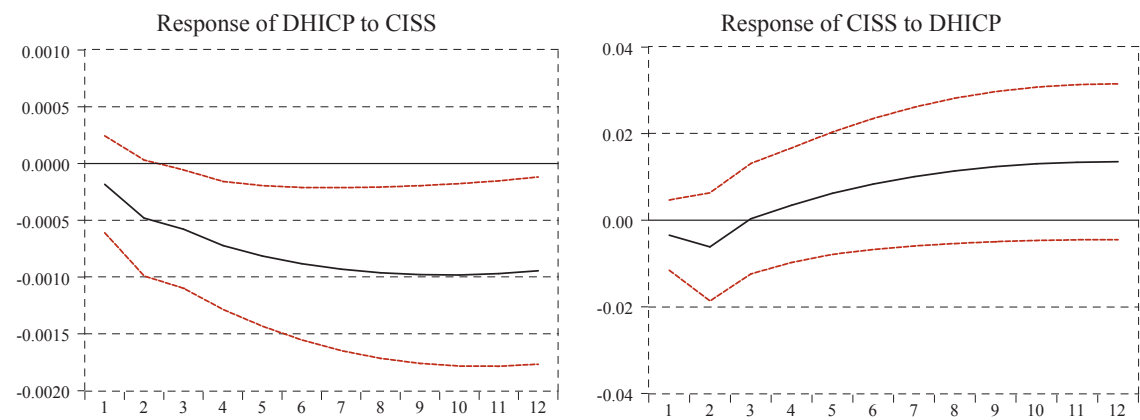

Response of DIIP to CISS
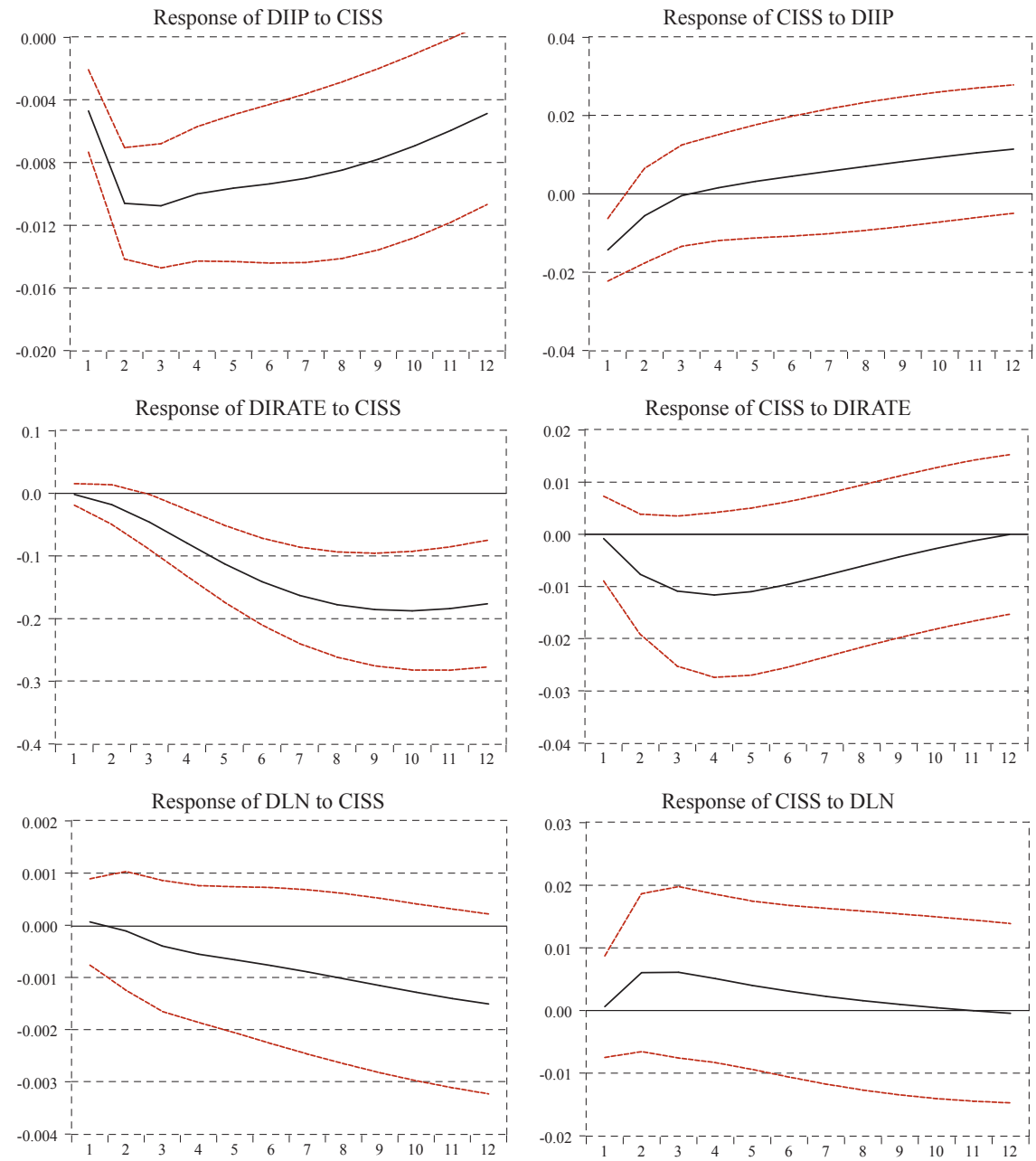

Note: Black curve denotes estimated impulse response and red dashed curves denote the $95 \%$ confidence interval.

Source: Author's calculation. 
Figure A6

SVAR IRFS, entire sample, reaction of CISS to shocks in other variables and reactions of others to shocks in CISS
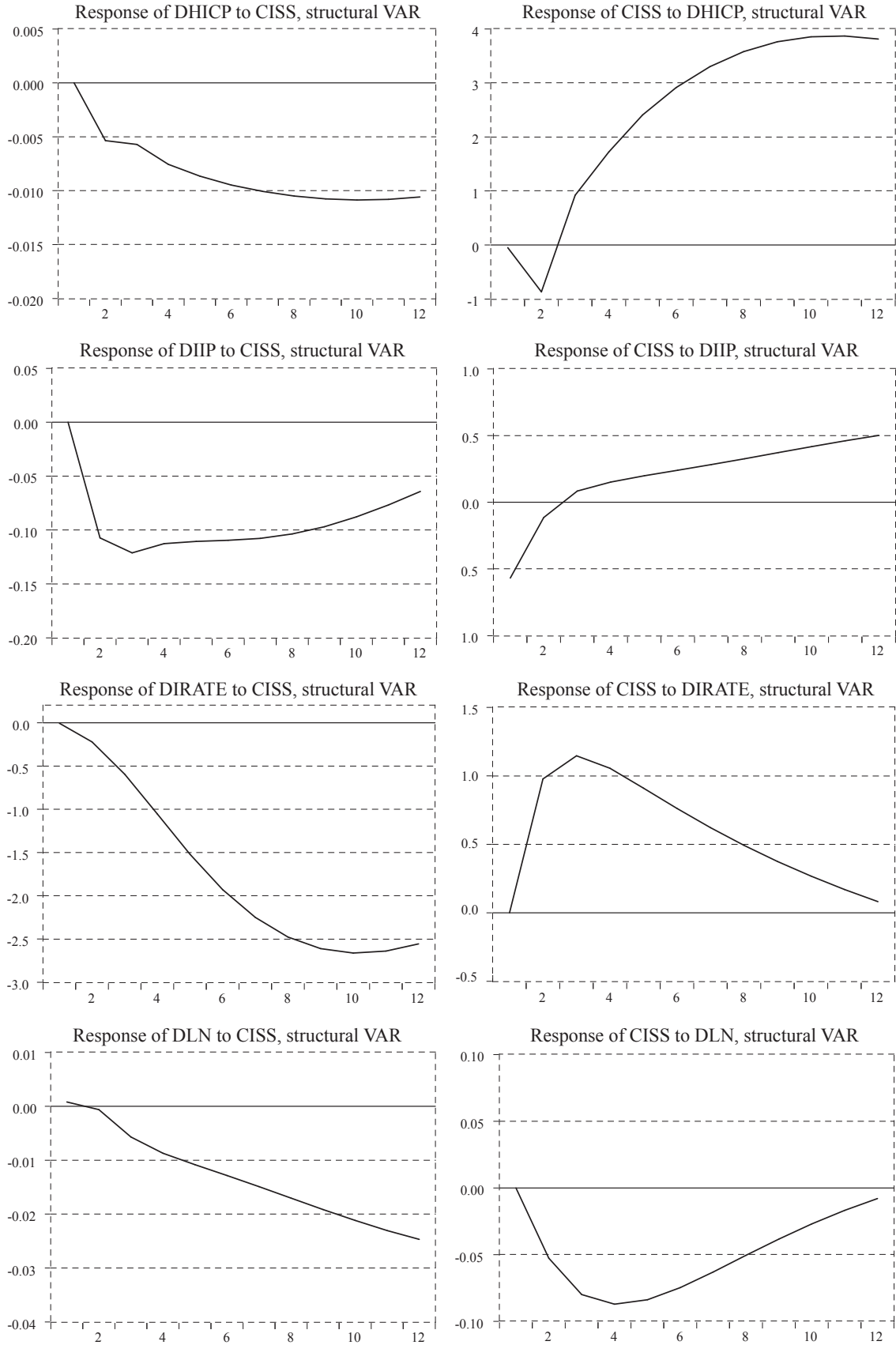

Note: $A u_{t}=B \varepsilon_{t}$ is the setting within the SVAR, where matrix $B$ is the unit matrix, and matrix $A$ has unit values on its diagonal with null values above the diagonal, and the rest of the values below the diagonal estimated in the analysis.

Source: Author's calculation. 


\title{
The impact of macroprudential policy on financial stability in selected EU countries
}

\author{
EVA LORENČIČ, MSc \\ MEJRA FESTIĆ, Ph.D.*
}

Article $^{* *}$

JEL: E58, G28, E60, E44

https://doi.org/10.3326/pse.46.1.5

\footnotetext{
${ }^{*}$ The views and opinions expressed in this paper are solely those of the authors and do not in any way reflect the official policy, position or opinion of the Faculty of Economics and Business, University of Maribor or of Credit Suisse Group AG, Zurich, Switzerland. The authors would like to thank two anonymous reviewers for their valuable remarks and suggestions.

${ }^{* *}$ Received: March 5, 2021

Accepted: October 1, 2021
}

\section{Eva LORENČIČ}

Credit Suisse Group AG, Uetlibergstrasse 231, CH-8045 Zurich, Switzerland, and University of Maribor, Faculty of Economics and Business, Razlagova 14, 2000 Maribor, Slovenia e-mail: eva.lorencic@student.um.si, eva.lorencic@credit-suisse.com, eva.loren@gmail.com ORCiD: 0000-0003-1626-1398

\section{Mejra FESTIĆ}

University of Maribor, Faculty of Economics and Business, Razlagova 14, 2000 Maribor, Slovenia e-mail: mejra.festic@um.si ORCiD: 0000-0002-8574-8696 
Abstract

The aim of this paper is to examine the impact of selected macroprudential policy instruments on financial stability. We focus on six euro area economies (Belgium, Cyprus, Germany, Spain, Ireland and the Netherlands) over sixteen quarters (from 2015 Q1 to 2018 Q4) by using the research method of panel econometrics. The following three banking sector aggregate balance sheet variables exhibit the expected impact on credit growth and cyclical fluctuations of the economy: common equity tier one ratio, coverage ratio, and interconnectedness ratio. Moreover, common equity tier one ratio, loan-to-deposit ratio, and leverage ratio exhibit the expected impact on house price growth. Based on our empirical findings, a case can be made for the usage of carefully crafted macroprudential policy instruments that target selected financial and macroeconomic variables with the ultimate goal of attaining the stability of the financial system as a whole.

Keywords: macroprudential policy, macroprudential instruments, financial stability

\section{INTRODUCTION}

In this paper we investigate the impact of banking sector aggregate balance sheet variables influenced by macroprudential policy instruments on financial stability. Financial stability is defined as a condition in which the financial system, consisting of markets, financial intermediaries and market infrastructures, does not yield to the adverse impacts of shocks and financial imbalances. The financial systemwide distress is limited and financial intermediation process is not disrupted to such an extent that the real economy could be adversely affected (Borio, 2011; ECB, 2020). Financial stability requires that the financial system be resilient to external shocks as well as to shocks originating within the financial system (Galati and Moessner, 2011). The main costs of financial instability are manifested as output losses (Crockett, 2000). The formation of possible systemic risks in the financial system is monitored and countered through macroprudential policies. The first and foremost goal of macroprudential policy is to achieve and maintain financial stability by reducing systemic risk stemming from excessive procyclicality in the financial sector, from interconnections and other cross-sectional factors (ECB, 2020; Claessens, 2014). Evidence on the effectiveness of specific macroprudential tools is slowly starting to accumulate in the economics profession; however, there is still much to be done (Claessens, 2014). Our paper is a contribution to this field.

The aim of this paper is to empirically investigate the impact of six banking sector aggregate balance sheet variables influenced by macroprudential policy instruments (common equity tier 1 ratio (CET); loan-to-deposit ratio (LDR); nondeposit funding as percentage of total funding (NDF); leverage ratio (LR); interconnectedness ratio (INR); and coverage ratio (CR)) on financial stability (as measured by credit growth rate (CGR) and house price growth rate (HPGR)) and on cyclical fluctuations of the economy (as measured by the amplitude of the deviation of the actual economic growth rate from its long-run trend (DEG)) in six 
euro area countries (Belgium, Cyprus, Germany, Spain, Ireland and the Netherlands) over sixteen quarters (from 2015 Q1 (inclusive) to 2018 Q4 (inclusive)).

If our empirical results indicate that the selected macroprudential policy instruments do impact measures of financial stability in the predicted manner, a case can be made for the usage of carefully crafted macroprudential policy instruments that target selected financial and macroeconomic variables with the ultimate goal of attaining the stability of the financial system as a whole. This is very relevant for policymaking, since the rest of the existing economic policies (monetary, microprudential, fiscal, and structural) operate with a different toolkit and strive to achieve goals other than the stability of the financial system as a whole. As such, another policy - namely macroprudential policy - is required for the achievement of the stability of the financial system at large. Our research aims to corroborate or refute the statement that the usage of macroprudential policy instruments can stabilise the financial system.

While most papers investigating the impact of macroprudential policy instruments on financial stability rely on the usage of the loan-to-value (LTV) ratio and/or the countercyclical capital buffer $(\mathrm{CCyB})$ as explanatory variables, our paper is unique in that it employs a wider variety of macroprudential policy instruments. In particular, we use the following explanatory variables: common equity tier 1 ratio; loans to deposits ratio; non-deposit funding as percentage of total funding; leverage ratio; interconnectedness ratio; and coverage ratio for non-performing exposures. While most of the papers on the topic of macroprudential policy investigate the impact of changes in macroprudential policy instruments on only one or two dependent variables, we employ three different dependent variables: credit growth rate; house price growth rate; and the amplitude of the deviation of the actual economic growth rate from its long-run trend. This allows us to thoroughly examine the impact of changes in selected macroprudential policy instruments on financial stability and on cyclical fluctuations of the economy. As such, our paper imparts an added value to the existing body of literature.

\section{LITERATURE OVERVIEW}

Evidence on the effectiveness of specific macroprudential tools is slowly starting to accumulate in the economics profession; however, the evidence is mixed, preliminary, and there is still much to be done (Claessens, 2014; Akinci and OlmsteadRumsey, 2018). As of yet, there is no consensus regarding which, if any, macroprudential policies are effective (Akinci and Olmstead-Rumsey, 2018). One reason for the evidence being inconclusive is that most of the empirical studies are based on aggregate data at country or bank level. Granular credit registry data to study the impact of macroprudential policies has so far been used in very few cases: Dassatti Camors et al. (2019) investigate the impact of changes in reserve requirements in Uruguay; Jiménez et al. (2017) examine dynamic provisioning in Spain; and Gambacorta and Murcia (2020) use confidential bank-loan data to shed light on the effectiveness of macroprudential policy tools and their interaction with monetary policy. 
Another reason for the mixed results is that samples used for empirical studies usually include many heterogeneous countries with different levels of development and financial integration to ensure enough observations, and this can dilute the results (Poghosyan, 2020). Moreover, many studies examine the impact of macroprudential policies only one period ahead, whereas in reality it usually takes more time for the impact of policies to become apparent. Indeed, medium- and long-term effects may be significantly different from short-term effects (Poghosyan, 2020). Furthermore, most studies do not differentiate between the impact of measures that are just recommendations; those that are legally binding; those that come with sanctions; and those that come without sanctions (ibid, 2020). Additionally, many studies use a sum of tightening and loosening macroprudential policy measures implemented in a certain time period; however, this does not capture the discretionary changes in the policy stance, i.e., which macroprudential policy instrument is concerned and how much it has changed from one period to another (Poghosyan, 2020). In our paper we use aggregate country-level banking sector balance sheet data (as opposed to granular credit registry data) in line with the majority of the existing body of research on the effects of macroprudential policy.

Most of the literature is predominantly concerned with the impact of macroprudential policy instruments on bank lending as an intermediate target instead of on bank risk, the containment of which is the ultimate macroprudential policy objective (Altunbas, Binici and Gambacorta, 2017). Recent empirical results indicate that debt-to-income caps and loan-to-value caps are more effective than capital requirements for limiting credit growth (Claessens, Ghosh and Mihet, 2013). For instance, in Switzerland the application of a countercyclical capital buffer to domestic residential mortgages had a negligible effect on loan granting (Basten and Koch, 2015). The key objective of the Basel III macroprudential tools is to bolster the resilience of the banking system (Altunbas, Binici and Gambacorta, 2017). Smoothing the credit cycle and restraining the boom is a welcome side effect which may be more or less pronounced (Drehmann and Gambacorta, 2012).

Although it is still fragmented, evidence of how effective macroprudential policy is on dampening the procyclicality of banking activity is accumulating (Galati and Moessner, 2014; Claessens, Ghosh and Mihet, 2013). Macroprudential policy instruments seem to be effective in mitigating the sensitivity of leverage and credit to the business cycle - i.e., the procyclicality of leverage and credit growth (Lim et al., 2011). Macroprudential tools also appear to be effective in restraining asset growth, leverage, and credit growth (Vandenbussche, Vogel and Detragiache, 2015; Alper et al., 2014; Cerutti, Claessens and Laeven, 2017; Claessens, Ghosh and Mihet, 2013). In spite of these positive indications that the research on macroprudential policies is proceeding in the right direction, evidence on the effectiveness of macroprudential policy measures is still in its infancy (Olszak, Roszkowska and Kowalska, 2018). Table A1 in the appendix provides an overview of some of the existing empirical literature.

The findings of the study by Davis, Liadze and Piggott (2019) suggest that, overall, the loan-to-value tool has a lower effect than capital adequacy on the probability of 
a banking crisis occurring and leads to lower net benefits. The introduction of macroprudential policy measures before the onset of a crisis leads to an improvement in key macroeconomic measures and might therefore prevent a crisis from materializing. In a similar vein, Carreras, Davis and Piggott (2018) find that macroprudential policy instruments have a positive impact on stalling household credit growth and house prices in both short- and long-run. Tools such as limits on debtto-income ratios are more effective for house prices, whilst tools such as limits on interbank exposures are more effective for household credit growth.

The results of the study by Olszak, Roszkowska and Kowalska (2019) demonstrate that, of the investigated macroprudential instruments, only borrower-based measures such as LTV and DTI caps seem to act countercyclically by weakening the positive impact of capital ratio on bank lending, in particular in crisis periods. In a comparable manner, Ma (2020) shows that macroprudential policy substantially strengthens financial stability (it reduces the frequency and probability of crises) at the cost of a small negative effect on average growth and welfare. In two extensions of the model (one with a growth subsidy and another one with a direct growth externality) the optimal macroprudential policy has a more pronounced effect on welfare and growth. Although macroprudential policy curbs average growth slightly, it is still desirable to use it, since it enhances financial stability and smooths consumption.

In the same vein, Akinci and Olmstead-Rumsey (2018) find that macroprudential tightening dampens bank credit growth, housing credit growth, and house price appreciation. Macroprudential policies targeting the housing sector appear to be more effective at constraining housing credit growth and house price appreciation, in particular in economies where bank finance is of greater importance. Counterfactual simulations indicate that, if the countries had not used any macroprudential policy measures in the period 2011-2013, the bank credit growth, housing credit growth and house price appreciation would have been substantially higher. Similarly, Meuleman and Vander Vennet (2020) demonstrate that the macroprudential policy instruments reduce individual bank risks, as well as bank systemic risk, as assessed by stock market investors. The latter is an important finding because reducing systemic risk is the key goal of macroprudential policies. Borrower-oriented tools and exposure limits are found to reduce the individual bank risk component. Liquidity measures are found to reduce the systemic linkage of banks in addition to reducing individual bank risk. Credit growth measures and exposure limits seem to lead to an increase in systemic risk component for some banks - possibly because some banks, when trying to observe the rules, take up riskier activities or similar exposures, thus exacerbating interconnectedness of the banks in the system. Macroprudential policies seem to be the most effective for distressed banks, that is banks with a high ratio of nonperforming loans. The results of the study give some indications for the optimal design of macroprudential measures.

In a comparable manner, Altunbas, Binici and Gambacorta (2017) demonstrate that macroprudential policy tools have a substantial effect on bank risk. Banks 
with different characteristics do not respond uniformly to changes in macroprudential policy tools. Small, weakly capitalized banks, and banks having a high share of wholesale funding respond more strongly to changes in macroprudential policy tools. Macroprudential policies are more efficient when employed during a downturn than during a boom. In a similar fashion, Cizel et al. (2019) investigate whether the implementation of macroprudential policy leads to a substitution of bank credit with non-bank credit. By using two global data sets on macroprudential measures and different research methodologies, the authors corroborate the presence of such substitution. Substitution with non-bank credit seems to be more conspicuous when policy measures are binding and are applied in economies with well-developed non-bank credit markets. The corollary of this is that the policies' effect on total credit is weakened, since the mentioned substitution effect to some extent counterbalances the fall in bank credit.

Similarly, Dumičić (2018) demonstrates that in the Central and Eastern European countries (CEE) macroprudential policies were more effective in weakening the flow of credit to households than the flow of credit to the non-financial corporate sector prior to the onset of the global financial crisis in 2007 . This is predominantly because the non-financial corporate sector had access not only to domestic bank credit, but also to non-bank and cross-border credit. The conclusion of the paper is that some international cooperation among policymakers is warranted so as to align macroprudential policies and prevent "regulatory arbitrage" - the circumvention of stricter regulation in one jurisdiction and the exploitation of laxer laws in another jurisdiction.

While most papers investigating the impact of macroprudential policy instruments on financial stability rely on the usage of the loan-to-value (LTV) ratio and/or countercyclical capital buffer (CCyB) as explanatory variables, our paper is unique in that it employs a wider variety of macroprudential policy instruments. In particular, we use the following explanatory variables: common equity tier 1 ratio; loans to deposits ratio; non-deposit funding as percentage of total funding; leverage ratio; interconnectedness ratio; and coverage ratio for non-performing exposures. While most of the papers on the topic of macroprudential policy investigate the impact of changes in macroprudential policy instruments on only one or two dependent variables, we employ three different dependent variables: credit growth rate; house price growth rate; and the amplitude of the deviation of the actual economic growth rate from its long-run trend. This allows us to thoroughly examine the impact of changes in selected macroprudential policy instruments on financial stability and on cyclical fluctuations of the economy. As such, our paper brings an added value to the existing body of literature. 


\subsection{DATA SPECIFICATION}

We investigate the impact of six banking sector aggregate balance sheet variables influenced by macroprudential policy instruments (common equity tier 1 ratio (CET); loan-to-deposit ratio (LDR); non-deposit funding as percentage of total funding (NDF); leverage ratio (LR); interconnectedness ratio (INR); and coverage ratio $(\mathrm{CR})$ ) on financial stability (as measured by credit growth rate (CGR) and house price growth rate (HPGR)) and on cyclical fluctuations of the economy (as measured by the amplitude of the deviation of the actual economic growth rate from its long-run trend (DEG)) by using the panel regression method. The purpose of our study is to establish whether macroprudential policy instruments do indeed enhance financial stability and dampen cyclical fluctuations of the economy.

All the data used in our econometric analysis were extracted from publicly accessible databases: the ECB's SDW - Statistical Data Warehouse of the European Central Bank (SDW, 2020) and Eurostat (Eurostat, 2020). We are using aggregate balance sheet data for the whole financial system of a particular economy. The period considered is 2015 Q1 (inclusive) to 2018 Q4 (inclusive). The countries included in our analysis are Belgium, Cyprus, Germany, Spain, Ireland and the Netherlands. These economies were chosen to ensure a balanced representation of smaller (Belgium, Cyprus, Ireland) and larger (Germany, Spain, Netherlands) European economies, as well as of southern (Spain, Cyprus) and northern European economies (Netherlands, Germany). Moreover, at the time of writing this paper (in late 2020 and early 2021) to the best of our knowledge there was no paper that investigated the impact of macroprudential policy measures on financial stability in precisely this set of economies by using panel econometrics. As such, our paper imparts an added value to the existing body of literature. In the selected time period (2015 Q1-2018 Q4) these countries used several macroprudential policy instruments at varying intensities, as demonstrated in the ECB's "Overview of macroprudential measures", "Overview of national capital-based measures" and "CCyB Data" (ECB, 2021). More information about the macroprudential policy measures applied in individual EU economies is available on the websites of macroprudential authorities and central banks of the respective countries. The following explanatory variables are employed in our paper (all retrieved from the ECB's SDW database):

$-C E T=$ common equity tier 1 ratio, measured as the amount of CET 1 capital divided by risk-weighted assets;

- LDR = loans to deposits ratio, measured as total loans, divided by total deposits; - NDF = non-deposit funding as percentage of total funding, measured as non-deposit funding, divided by total funding;

$-L R=$ leverage ratio, measured as total assets divided by total equity;

- INR = interconnectedness ratio, measured as interbank loans divided by total bank assets;

- $C R=$ coverage ratio for non-performing exposures, measured as loan-loss provisions divided by non-performing exposures ${ }^{1}$.

\footnotetext{
${ }^{1}$ Given the time span (2015-2018), the ratio captures a change in (i) the definition of NPLs (due to how EBA pushed for a uniform and conservative definition), and (ii) the way provisions were calculated - until end2017, IAS 39 with the incurred loss concept was valid while from early 2018, banks need to use IFRS 9 with its expected credit loss model.
} 
These variables are not macroprudential policy instruments per se, but rather selected ratios based on banking sector aggregate balance sheets and structural characteristics of the banking sector. The macroprudential policy implemented in the chosen countries impacts those ratios through the behaviour of banks captured by the balance sheet structure (e.g., the need to build up capital buffers such as the systemic risk buffer or countercyclical capital buffer would in general lead to increases in the CET1 ratio). These ratios can change also due to other factors (for example, CET1 ratio can go up due to banks having increased retained earnings in anticipation of expansion of balance sheets or having changed the risk profile by increasing the holdings of low-risk assets such as sovereign bonds and/or by reducing the holdings of assets to which high risk weights are assigned). Moreover, some variables, such as the CET1 ratio, can be influenced by microprudential authorities through bank-specific capital requirements (Pillar 2 requirement) and supervisory expectations communicated to the banks (Pillar 2 guidance, soft tools). Furthermore, the bank management decides on how much capital it intends to hold in excess of regulatory requirements. As such, the explanatory variables employed in our empirical analysis are proxies of macroprudential policies and can be influenced also by other policies (notably microprudential policy) and banks' own decision-making, risk aversion, profitability, and distribution policies.

The response variable in our first econometric model $\left(\mathrm{M}_{1}\right)$ which tests the first hypothesis $\left(\mathrm{H}_{1}\right.$ : "Selected banking sector aggregate balance sheet variables influenced by macroprudential policy instruments enhance financial stability, as measured by credit growth.") is:

\section{$C G R=$ credit growth rate, measured by domestic credit-to-GDP gap}

The response variable in our second econometric model $\left(\mathrm{M}_{2}\right)$ which tests the second hypothesis $\left(\mathrm{H}_{2}\right.$ : "Selected banking sector aggregate balance sheet variables influenced by macroprudential policy instruments enhance financial stability, as measured by house price growth.”) is:

\section{$H P G R=$ house price growth rate}

The response variable in our third econometric model $\left(\mathrm{M}_{3}\right)$ which tests the third hypothesis $\left(\mathrm{H}_{3}\right.$ : "Selected banking sector aggregate balance sheet variables influenced by macroprudential policy instruments reduce cyclical fluctuations of the economy, as measured by the amplitude of the deviations of the actual economic growth rate from its long-run trend, thereby contributing to financial stability.") is:

\section{$D E G=$ deviation of the real GDP growth rate from the long-run trend rate of growth}

CGR data were retrieved from the Statistical Data Warehouse of the ECB, whereas HPGR and GDP data were retrieved from Eurostat. The descriptive statistics of the explanatory and response variables are set out in table 1. 
We test three different hypotheses and use three different response variables because financial stability can be measured in different ways. Hence, the inclusion of more than one response variable can lead to more reliable results.

\section{TABLE 1}

Descriptive statistics of explanatory and response variables

\begin{tabular}{|c|c|c|c|c|c|c|c|c|c|}
\hline & d(CGR) & d(HPGR) & d(DEG) & d(CET) & d(LDR) & $d(L R)$ & d(NDF) & $\mathrm{d}(\mathrm{CR})$ & d(INR) \\
\hline Mean & -1.97 & 0.04 & 0.59 & 0.08 & 1.16 & -0.12 & -0.02 & 0.17 & -0.17 \\
\hline Median & -1.22 & -0.10 & 0.24 & 0.12 & 0.90 & -0.07 & -0.02 & -0.11 & -0.15 \\
\hline Maximum & 80.41 & 7.10 & 18.11 & 2.03 & 13.99 & 1.07 & 1.32 & 17.96 & 3.44 \\
\hline Minimum & -34.33 & -4.90 & -4.79 & -2.16 & -6.65 & -3.79 & -1.38 & -10.47 & -2.69 \\
\hline $\begin{array}{l}\text { Standard } \\
\text { deviation }\end{array}$ & 10.80 & 2.23 & 2.37 & 0.54 & 3.46 & 0.61 & 0.44 & 2.79 & 0.77 \\
\hline Skewness & 4.16 & 0.45 & 4.88 & -0.10 & 0.99 & -2.15 & 0.36 & 2.88 & 0.77 \\
\hline Kurtosis & 37.63 & 3.72 & 35.66 & 6.91 & 5.66 & 14.82 & 4.98 & 23.08 & 8.74 \\
\hline $\begin{array}{l}\text { Jarque- } \\
\text { Bera }\end{array}$ & $5,074.44$ & 5.38 & $4,648.03$ & 61.22 & 43.92 & 632.61 & 17.68 & $1,746.59$ & 141.32 \\
\hline$\overline{\text { Probability }}$ & 0.00 & 0.07 & 0.00 & 0.00 & 0.00 & 0.00 & 0.00 & 0.00 & 0.00 \\
\hline Sum & -189.22 & 3.60 & 56.73 & 8.08 & 111.21 & -11.90 & -2.19 & 16.69 & -16.60 \\
\hline $\begin{array}{l}\text { Sum sq. } \\
\text { dev. }\end{array}$ & $11,089.82$ & 470.89 & 531.76 & 28.07 & $1,136.47$ & 35.75 & 18.11 & 737.41 & 56.32 \\
\hline Obser. & 96 & 96 & 96 & 96 & 96 & 96 & 96 & 96 & 96 \\
\hline
\end{tabular}

Notes: " $d$ " denotes the first difference of a variable. For instance, $d(C G R)$ denotes the first difference of $C G R$.

Source: Authors' calculations.

\subsection{METHODOLOGY}

In order to test the three hypotheses of our paper, we employ the quantitative research method of panel econometrics. Panel regression renders it possible to study variables that have both the space dimension (in our case several countries) as well as the time dimension (in our case several quarters). Furthermore, panel regression controls for omitted variables, alleviates the problem of collinearity among explanatory variables, dismisses heterogeneous effects, and may reduce measurement errors and endogeneity bias by including the lags of the regressors. The problem of spurious regression can be circumvented by using the differences of the variables expressed as percentage changes (Festić, 2015; Hahn and Hausman, 2002; Murray, 2006). The stationarity of the times series is verified with the augmented Dickey-Fuller (ADF) test. All of our variables are stationary at first difference, however, most of them are not stationary at level (table 2). Since the linear combination of the series in a regression analysis should be at the highest order of integration, all of our time series are integrated of order one, i.e., I(1). We tried introducing the logarithmic form and lags to our models; however, these models proved to be less statistically significant and less robust than the models we present in this paper. We test both fixed effects models and the random effects models and verify their statistical significance ( $p$-values) with the redundant fixed effects test and with the Hausman test (Hausman, 1978). 
TABLE 2

Unit root test (Fisher ADF-test)

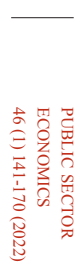

\begin{tabular}{|c|c|c|}
\hline \multirow{2}{*}{$\begin{array}{l}\text { Response and } \\
\text { explanatory variables }\end{array}$} & \multicolumn{2}{|c|}{$\begin{array}{l}\text { ADF-Fisher Chi-square statistic } \\
\text { (ADF-Fisher Chi-square probability) }\end{array}$} \\
\hline & Level (x) & First difference d(x) \\
\hline CGR & $\begin{array}{r}13.2965 \\
(0.3479)\end{array}$ & $\begin{array}{r}70.8197 \\
(0.0000)\end{array}$ \\
\hline HPGR & $\begin{array}{r}74.8063 \\
(0.0000)\end{array}$ & $\begin{array}{r}88.6962 \\
(0.0000)\end{array}$ \\
\hline DEG & $\begin{array}{r}15.3016 \\
(0.2254)\end{array}$ & $\begin{array}{r}71.0383 \\
(0.0000)\end{array}$ \\
\hline CET & $\begin{array}{r}11.9982 \\
(0.4458) \\
\end{array}$ & $\begin{array}{r}71.0925 \\
(0.0000) \\
\end{array}$ \\
\hline LDR & $\begin{array}{r}11.0842 \\
(0.5217)\end{array}$ & $\begin{array}{l}47.9746 \\
(0.0000)\end{array}$ \\
\hline LR & $\begin{array}{r}6.74768 \\
(0.8738) \\
\end{array}$ & $\begin{array}{r}71.2775 \\
(0.0000) \\
\end{array}$ \\
\hline $\mathrm{NDF}$ & $\begin{array}{l}10.2671 \\
(0.5925)\end{array}$ & $\begin{array}{r}35.9455 \\
(0.0003)\end{array}$ \\
\hline $\mathrm{CR}$ & $\begin{array}{l}5.87756 \\
(0.9221)\end{array}$ & $\begin{array}{r}54.8494 \\
(0.0000)\end{array}$ \\
\hline INR & $\begin{array}{l}4.92658 \\
(0.9604)\end{array}$ & $\begin{array}{r}88.1111 \\
(0.0000)\end{array}$ \\
\hline
\end{tabular}

Notes: p-values for the Fisher-ADF panel unit root test are computed using the asymptotic Chisquare distribution and given in brackets. The maximum number of lags was automatically selected with Schwarz Information Criterion.

Source: Authors'calculations.

The Basel III rules, which are, by and large, transposed into the EU legislative requirements, in 2013 introduced new macroprudential instruments, such as countercyclical capital buffer ( $\mathrm{CCyB})$, which limits the build-up of systemic risk in expansionary periods (Szpunar, 2017). Other buffers, which need to be met with CET1 capital, are systemic risk buffer (SRB), global systemically important institutions buffer (G-SII buffer), other systemically important institutions buffer (O-SII buffer), and capital conservation buffer (CCoB). Moreover, higher CET1 ratios can (also) be seen as a micro- and macro-prudential policy instrument, since supervisory authorities in the EU (the national supervisory authorities and the European Central Bank) in Pillar 2 supervisory review process set capital requirements for individual banks in the EU by considering their individual risk profiles and stress test results after having conducted a peer-comparison and considered micro- and macro-prudential indicators. We assume that an increase in the CET1 ratio will have a negative effect on credit growth, on house price growth, and on the amplitude of the deviations of the actual economic growth rate from its longrun trend, thereby enhancing financial stability.

The most widespread macroprudential policy tools, which existed prior to the development of Basel III, CRR and CRD IV standards and legal requirements, are 
the loan-to-value (LTV) caps and debt-to-income (DTI) caps, debt-service-toincome (DSTI) caps and loans-to-deposits (LTD) caps. LTV ratio limits the amount of the loan relative to the value of the property. The DSTI ratio limits the debt servicing cost relative to the borrower's disposable income (Szpunar, 2017). The LTD ratio (henceforth LDR) limits the amount of the loans that can be extended for each unit of currency of deposits. If the LDR is excessively high, a bank may not have sufficient liquidity in the event of loan defaults in a period of financial distress. The borrower-based tools predominantly impact the supply and demand for mortgages and other types of loans. We have decided to introduce the LDR as our borrower-based explanatory variable, since sufficiently long time series exist for this variable, and because some papers which we have reviewed use this macroprudential policy instrument to study the effect of changes in it on financial stability. We expect that an increase in the LDR will have a positive effect on credit growth, on house price growth, and on the amplitude of the deviations of the actual economic growth rate from its long-run trend, thereby undermining financial stability.

From mid-2021, the amended EU regulation sets forth a binding leverage ratio, which is a non-risk- based measure of banks' assets in relation to capital. The amount of an institution's Tier 1 capital base needs to amount to at least $3 \%$ of its non-risk-weighted assets ("exposure measure", which is a sum of on-balance sheet exposures, derivative exposures, securities financing transactions, and offbalance sheet items) ${ }^{2}$. On top of that, the global systemically important institutions (G-SIIs) will need to maintain an additional leverage ratio buffer. The purpose of the leverage ratio is to provide a back-stop to the risk-based measures and to prevent excessive leverage from building up. It does not distinguish one asset class from another (Linklaters LLP, 2019a; 2019b). We have decided to employ leverage ratio as one of the macroprudential policy instruments in which we are interested for its impact on financial stability. This is because the banks have been reporting it for some years now although it is not yet binding. Moreover, it is one of the few measures that do not depend on the risk-weighted assets, but simply on assets without having risk weights applied to them. Our conjecture is that an increase in the leverage ratio (measured as total assets divided by total equity) will have a positive impact on credit growth, on house price growth, and on the amplitude of the deviations of the actual economic growth rate from its long-run trend, thereby compromising financial stability.

It is not just adequate capitalization of banks which contributes to financial stability; another aspect is adequate measuring and managing of the level of banks' liquidity and their resilience to liquidity shocks. In response to the Great Financial Crisis of 2007, the Basel Committee on Banking Supervision (henceforth BCBS) introduced two liquidity standards - LCR (liquidity coverage ratio to control short-term liquidity

\footnotetext{
${ }^{2}$ In our analysis we actually use a more traditional definition of the leverage ratio (i.e., total assets divided by total equity), but the general idea is the same.
} 
risk) and NSFR (net stable funding ratio to monitor structural resilience). In our analysis we do not use any of the new liquidity measures due to the insufficient length of the time series. Instead, we use NDF, that is non-deposit funding expressed as a percentage of total funding. Deposits are in general the most traditional and stable source of funding. A high percentage of non-deposit funding in the total funding sources of a bank indicates that a bank is striving to expand its balance sheet at the expense of maturity mismatches, higher liquidity risk and greater dependence on market conditions. We expect that an increase in non-deposit funding expressed as a percentage of total funding will have a positive effect on credit growth, on house price growth, and on the amplitude of the deviations of the actual economic growth rate from its longrun trend, thereby endangering financial stability.

Some of the vulnerabilities and risks which led to the 2007 global financial crisis, and which could nowadays be spotted, mitigated and perhaps even altogether prevented by macroprudential policy instruments, were excessive mortgage growth, drying-up of market liquidity when risk aversion rose, concentration of risk in the financial system, intertwined vulnerabilities of financial institutions, and excessive interlinkages between financial intermediaries and across markets (Bini Smaghi, 2009a; 2009b). In addition to insufficient capital cushions and inadequate structure of funding sources, other factors which contributed to the 2007 global financial crisis were insufficient coverage ratios, as well as the imprudent loan loss provisioning and impairment practices of many financial institutions (Frait and Komárková, 2013). Coverage ratio is calculated as loan loss provisions expressed as a percentage of non-performing exposures. In our dissertation we will be interested in the impact of changes in coverage ratio (as one of our explanatory variables) on financial stability. We have decided to use coverage ratio, since this ratio indicates how well prepared the banks are to cover losses arising from non-performing loans out of provisions set aside in advance. If the coverage ratio is equal to $100 \%$, all non-performing loans are completely covered with provisions. The higher the coverage ratio, the better. We surmise that an increase in the coverage ratio will have a negative effect on credit growth, on house price growth, and on the amplitude of the deviations of the actual economic growth rate from its long-run trend, thereby enhancing financial stability.

Last but not least macroprudential policy instrument which we have decided to include in our analysis is the bank interconnectedness ratio, calculated as the amount of interbank loans, divided by total bank assets (SDW, 2020). The higher the bank interconnectedness ratio, the more likely that a shock to bank's external assets or liabilities will have systemic repercussions (i.e., will not stay with just one bank, but will be transferred also to other banks in the system). The lower the interconnectedness ratio, i.e., the more diversified banks' portfolios, the lower the likelihood and the strength of the propagation of contagion (Roncoroni et al., 2019). We suppose that an increase in the bank interconnectedness ratio will have a positive effect on credit growth, on house price growth, and on the amplitude of the deviations of the actual economic growth rate from its long-run trend, thereby undermining financial stability. 
Empirical results, displayed in table 3, allow us to corroborate or reject each of the three hypotheses. Regarding the first hypothesis (an increase in CET has a negative effect on CGR; an increase in LDR has a positive effect on CGR; an increase in LR has a positive effect on CGR; an increase in NDF has a positive effect on CGR; an increase in CR has a negative effect on CGR; an increase in INR has a positive effect on CGR), we can only partially confirm it, given that the results of the first empirical model indicate that an increase in CET has a negative effect on CGR (thus confirming our first hypothesis); an increase in LDR has a negative effect on CGR (thus rejecting our first hypothesis); an increase in LR has a negative effect on CGR (thus rejecting our first hypothesis); an increase in NDF has a negative effect on CGR (thus rejecting our first hypothesis); an increase in CR has a negative effect on CGR (thus confirming our first hypothesis); an increase in INR has a positive effect on CGR (thus confirming our first hypothesis). Since only three regressors (out of six) have the signs predicted by Hypothesis 1, we can only partly confirm Hypothesis 1 .

Regarding the second hypothesis (an increase in CET has a negative effect on HPGR; an increase in LDR has a positive effect on HPGR; an increase in LR has a positive effect on HPGR; an increase in NDF has a positive effect on HPGR; an increase in CR has a negative effect on HPGR; an increase in INR has a positive effect on HPGR), we can only partially confirm it, given that the results of the second empirical model indicate that an increase in CET has a negative effect on HPGR (thus confirming our second hypothesis); an increase in LDR has a positive effect on HPGR (thus confirming our second hypothesis); an increase in LR has a positive effect on HPGR (thus confirming our second hypothesis); an increase in NDF has a negative effect on HPGR (thus rejecting our second hypothesis); an increase in CR has a positive effect on HPGR (thus rejecting our second hypothesis); an increase in INR has a negative effect on HPGR (thus rejecting our second hypothesis). Since only three regressors (out of six) have the signs predicted by Hypothesis 2 (in the period fixed effects model), we can only partly confirm Hypothesis 2.

Regarding the third hypothesis (an increase in CET has a negative effect on DEG; an increase in LDR has a positive effect on DEG; an increase in LR has a positive effect on DEG; an increase in NDF has a positive effect on DEG; an increase in CR has a negative effect on DEG; an increase in INR has a positive effect on DEG), we can only partially confirm it, given that the results of the third empirical model indicate that an increase in CET has a negative effect on DEG (thus confirming our third hypothesis); an increase in LDR has a negative effect on DEG (thus rejecting our third hypothesis); an increase in LR has a negative effect on DEG (thus rejecting our third hypothesis); an increase in NDF has a negative effect on DEG (thus rejecting our third hypothesis); an increase in CR has a negative effect on DEG (thus confirming our third hypothesis); an increase in INR has a positive effect on DEG (thus confirming our third hypothesis). Since only three regressors (out of six) have the signs predicted by Hypothesis 3 (in the 
cross-section fixed effects model and in the period random effects model), we can only partly confirm Hypothesis 3 .

Formal econometric tests help us to decide which model is more appropriate for use in a certain situation. The redundant fixed effects test is used to decide between the pooled model and the fixed effects model. If the null hypothesis is not rejected $(p>0.1)$, fixed effects are not present in the model. If the alternative hypothesis is not rejected $(p<0.1)$, fixed effects are present in the model. The Hausman test is used to distinguish between the fixed effects model and the random effects model. If the null hypothesis is not rejected ( $p>0.1)$, the random effects estimator is consistent and efficient. On the other hand, if the alternative hypothesis is not rejected $(p<0.1)$, the fixed effects estimator is at least as consistent as the random effects estimator and hence preferred (Gujarati, 2003; Allison, 2009; Hsiao, 1985; Wooldridge, 2010).

The empirical results set out in table 3 indicate that period fixed effects as well as cross-section fixed effects and period fixed effects together are present in the first model where CGR is the dependent variable, since the $F$ probability of the redundant fixed effects test is less than 0.1. In the second model where HPGR is the dependent variable, only period fixed effects are present, since the $F$ probability of the redundant fixed effects test is less than 0.05. In the third model where DEG is the dependent variable, only cross-section fixed effects are present, since the $F$ probability of the redundant fixed effects test is less than 0.1 . In all three models, the p-value of the Hausman test is above 0.1 (it ranges from 0.28 to 0.57 ), meaning that we cannot reject the null hypothesis of the Hausman test. Hence, the random effects estimator is consistent and efficient and therefore preferred over the fixed effects estimator in all three models.

The Durbin-Watson (DW) statistic tests whether there is autocorrelation in the residuals from a regression model. A value of 2 indicates that no autocorrelation is present in the sample. Values between 2 and 4 indicate the presence of negative autocorrelation, whereas values from 0 to 2 indicate the presence of positive autocorrelation. The Durbin-Watson statistic is the closest to 2 (a value which indicates there is no autocorrelation detected in the sample) in the third model where DEG is the dependent variable (DW statistics ranges from 1.77 to 2.03). In the second model where HPGR is the dependent variable, some negative autocorrelation may be present (DW statistics ranges from 2.87 to 3.03 ). In the first model where CGR is the dependent variable, some positive autocorrelation may be present (DW statistics ranges from 1.45 to 1.57 ).

The Hansen-Sargan test of overidentifying restrictions tests whether the excluded instruments are distributed independently of the error process (i.e., instruments are valid, $(\mathrm{Cov}(\mathrm{z}, \mathrm{u})=0))$. The null hypothesis $\left(\mathrm{H}_{0}\right)$ of the Hansen-Sargan test is that the instrumental variables are uncorrelated with the error term. The alternative hypothesis $\left(\mathrm{H}_{1}\right)$ is that the instrumental variables are correlated with the error 
term (Festić, Kavkler and Repina, 2011). The Kleibergen-Paap test of underidentification tests whether the excluded instruments are correlated with the endogenous regressors $(\operatorname{Cov}(\mathrm{z}, \mathrm{x}) \neq 0)$. The null hypothesis $\left(\mathrm{H}_{0}\right)$ of the Kleibergen-Paap test is that the chosen instruments are weak. The alternative hypothesis $\left(\mathrm{H}_{1}\right)$ is that the instruments are not weak (Festić, Kavkler and Repina, 2011). In our case, the Hansen-Sargan statistic of overidentifying restrictions does not reject the null hypothesis that the instrumental variables are uncorrelated with the error term (table 3). Rejection of the null hypothesis of the Kleibergen-Paap test, on the other hand, suggests that the chosen instruments are not weak.

Overall, based on the empirical results, we:

- Partly confirm Hypothesis 1: "Selected banking sector aggregate balance sheet variables influenced by macroprudential policy instruments (common equity tier 1 ratio; loan-to-deposit ratio; non-deposit funding as percentage of total funding; leverage ratio; interconnectedness ratio; and coverage ratio for non-performing exposures) enhance financial stability, as measured by credit growth."

- Partly confirm Hypothesis 2: "Selected banking sector aggregate balance sheet variables influenced by macroprudential policy instruments (common equity tier 1 ratio; loan-to-deposit ratio; non-deposit funding as percentage of total funding; leverage ratio; interconnectedness ratio; and coverage ratio for non-performing exposures) enhance financial stability, as measured by house price growth."

- Partly confirm Hypothesis 3: "Selected banking sector aggregate balance sheet variables influenced by macroprudential policy instruments (common equity tier 1 ratio; loan-to-deposit ratio; non-deposit funding as percentage of total funding; leverage ratio; interconnectedness ratio; and coverage ratio for non-performing exposures) reduce cyclical fluctuations of the economy, as measured by the amplitude of the deviations of the actual economic growth rate from its long-run trend, thereby contributing to financial stability." 

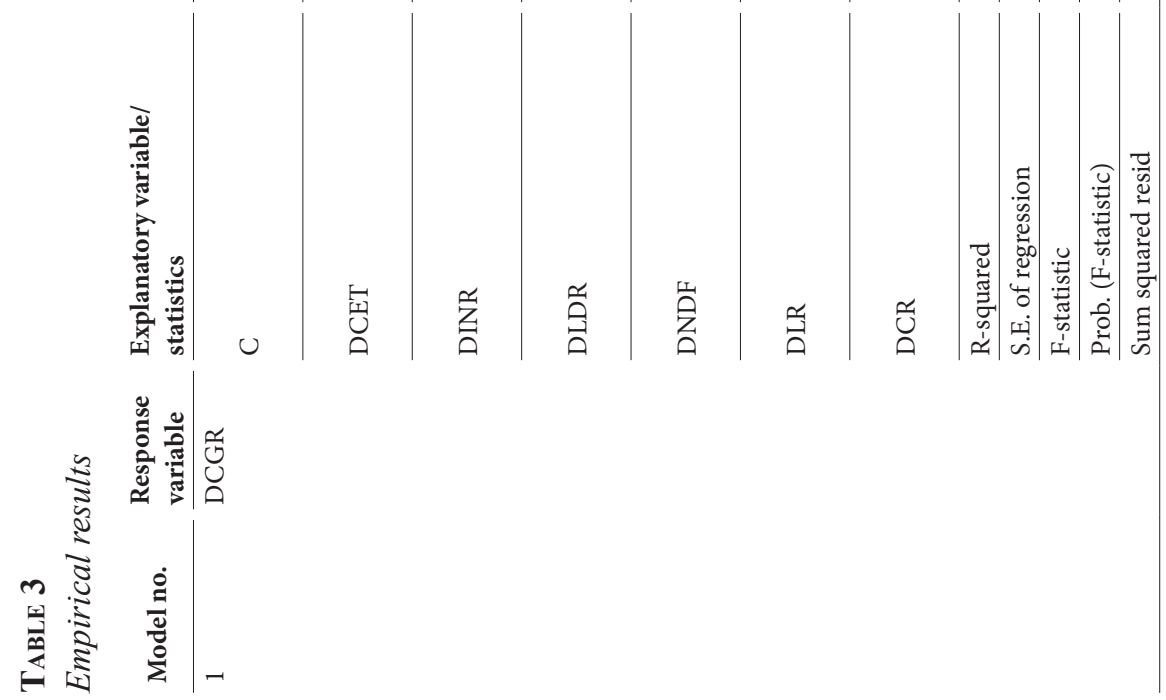

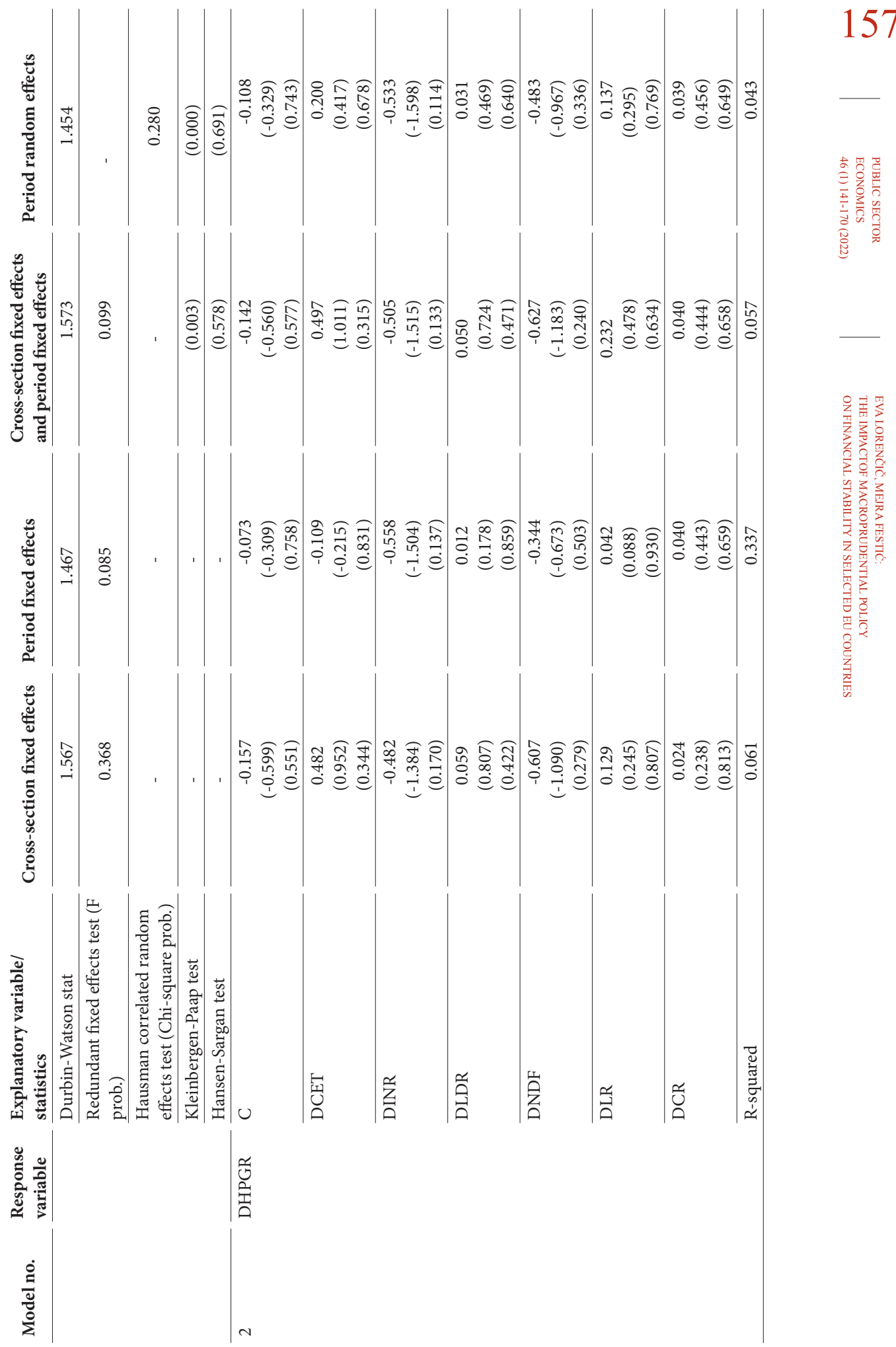


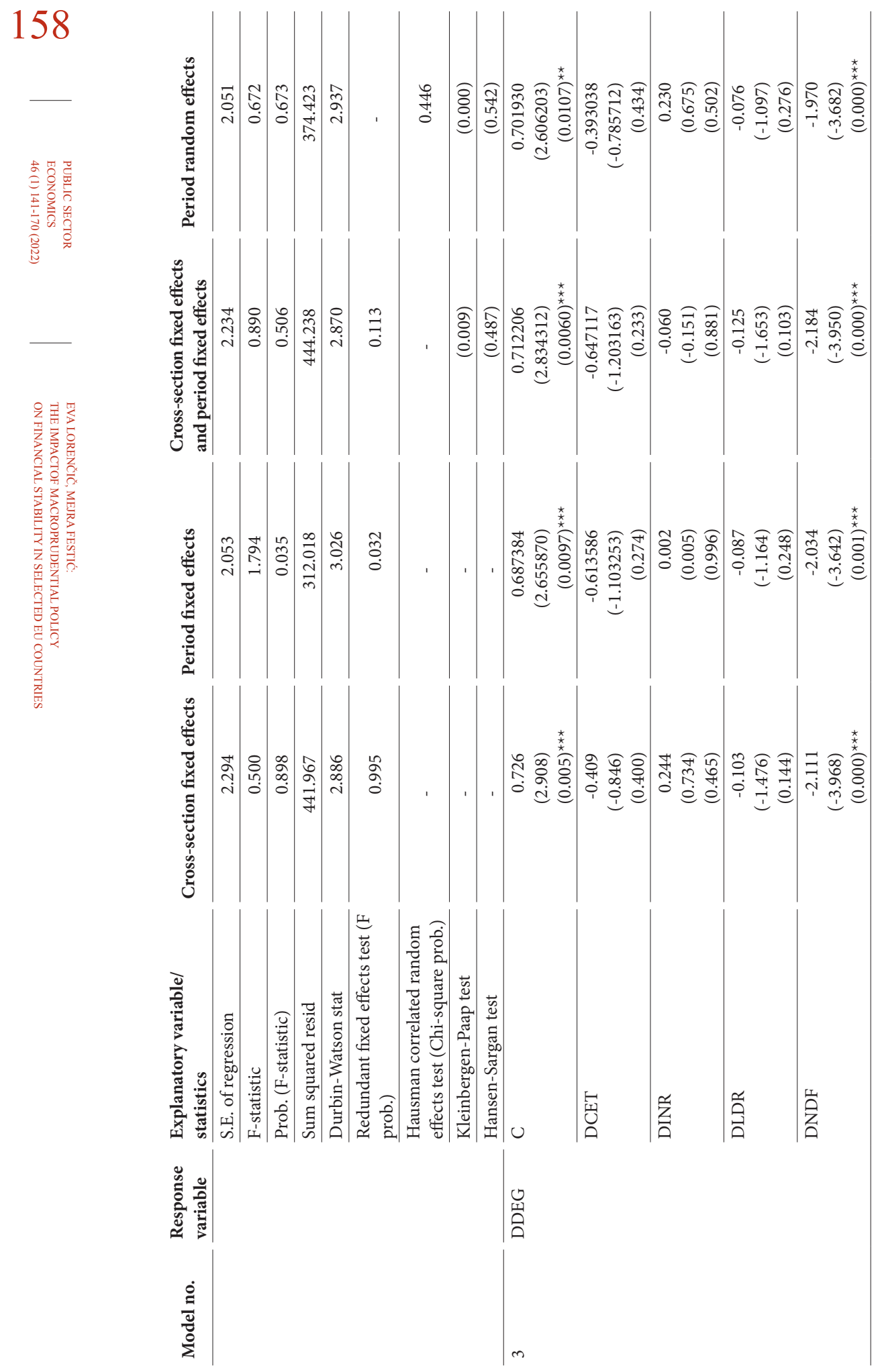



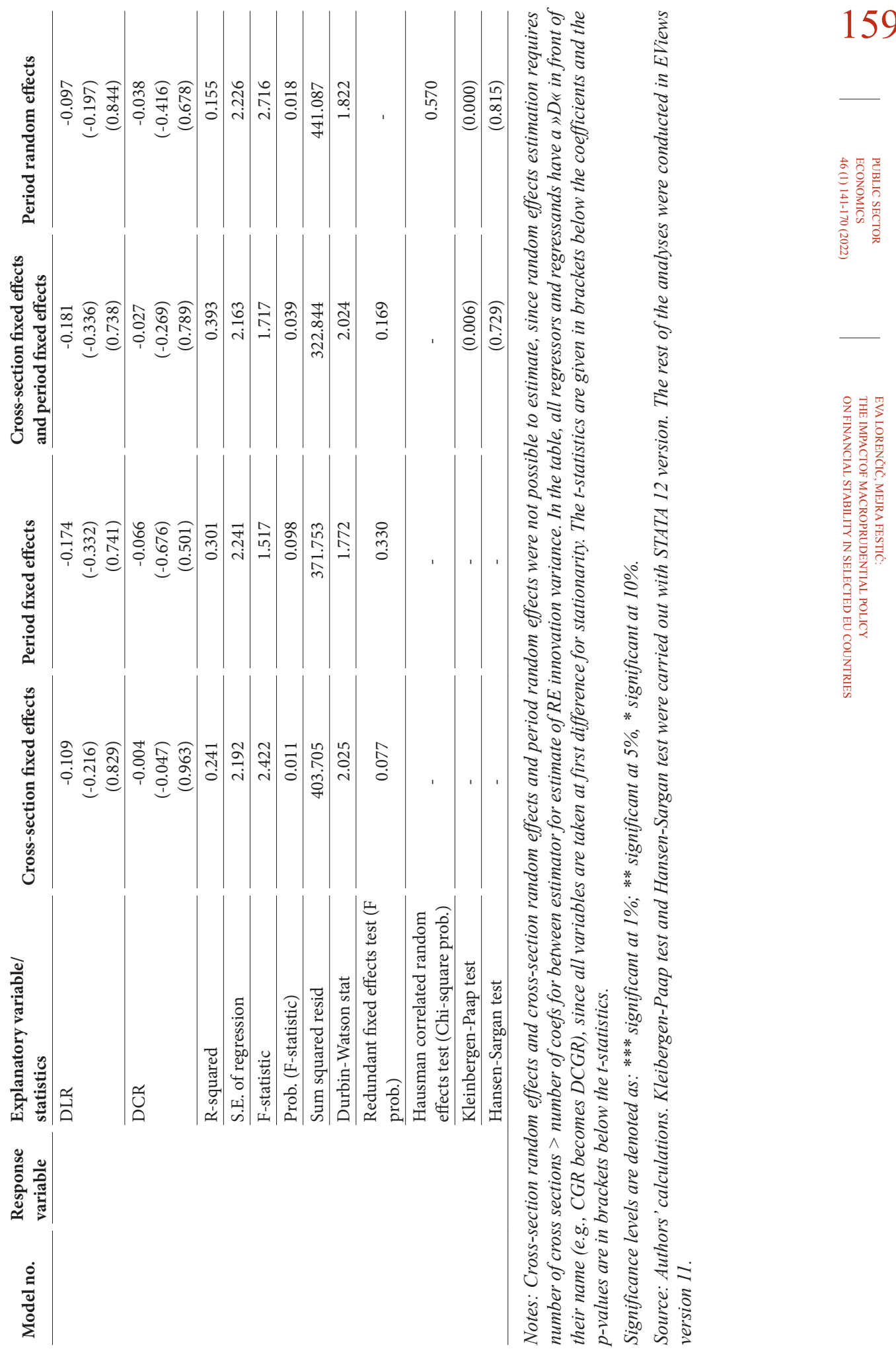
It seems that the empirical results vary to some extent in relation to the chosen empirical research method, as demonstrated in table A1 (in the appendix) with empirical research overview. Moreover, it appears that the empirical results are contingent also on the choice of individual macroprudential policy instruments; time period; and set of economies. Our empirical results indicate that selected banking sector aggregate balance sheet variables influenced by macroprudential policy instruments have a certain impact on financial stability; however, more research is needed into, for instance, why different models are more appropriate (statistically significant) for different response variables. In particular, period fixed effects; cross-section fixed and period fixed effects model; and period random effects model were suitable for the analysis of the impact of explanatory variables on CGR as the response variable; only the period fixed effects model was suitable for the analysis of the impact of explanatory variables on HPGR as the response variable; only the cross-section fixed effects model and the period random effects model were suitable for the analysis of the impact of explanatory variables on DEG as the response variable.

The period under investigation (2015 Q1-2018 Q4) was characterized by loose monetary policy in the euro area and slowly but surely increasing financial stability risks. No economic crisis or downturn occurred in the period. Our data set can shed some light on how macroprudential policy could reduce rising financial stability risks, but it cannot provide information on its effects in a crisis, where financial stability might be compromised (for example, previously built capital buffers can cushion the shocks). As already stated, in our analysis we were limited by the availability of the data and were faced with a lack of longer time series for the selected variables and countries. In future research, variables spanning the entire economic/financial cycle could be included, which would also allow us to investigate the impact of macroprudential policy instruments in a crisis period.

The weaknesses of our regression models are that they do not capture well the interactions between macroprudential policy instruments, financial and real economic sectors, and the macroprudential policy transmission mechanism. Furthermore, we did not isolate the effects of macroprudential policy from those of monetary policy and microprudential policy (Carreras, Davis and Piggott, 2018). Our study does not allow for a possible correlation between time series processed in the long term because the variables are included only in differences. This does not allow us to study the long-term effects of macroprudential policy instruments. Furthermore, certain macroprudential policy instruments appear to influence credit growth, house price growth, and cyclical fluctuations of the economy differently from our expectations. For instance, we would expect that an increase in the non-deposit funding (as percentage of total funding) increases credit growth, house price growth, and amplifies cyclical fluctuations of the economy, thereby undermining financial stability. However, our empirical results indicate that the opposite is the case. A plausible explanation for this could be that in economic downturns, when credit growth is lower or negative and when more people lose 
their jobs and when salary increases are hard to come by, retail depositors do not have excess liquidity to deposit with banks, hence the banks start relying more on non-deposit funding sources. In this case the causal relationship goes from the state of the economy (credit expansion or contraction) to the changes in the calibration of macroprudential instruments (in this case the maximum allowed nondeposit funding as percentage of total funding).

Indeed, methodologically, any estimation deals with the inherent endogeneity problem, since policymakers usually implement measures in response to systemic risk, credit and financial cycles, indicated by, for example, excessive credit growth or excessive house price growth (Cizel et al., 2019; Gadatsch, Mann and Schnabel, 2018). As such, macroprudential policy instruments may be influenced by the target variables, which creates reverse causality. This could lead to an estimation bias, underestimating the effectiveness of macroprudential policy measures (Kuttner and Shim, 2016). The panel GMM estimator may alleviate this problem (Lim et al., 2011; Claessens, Ghosh and Mihet, 2013; Cerutti, Claessens and Laeven, 2017). However, panel GMM estimators suffer from the weak instrument problem (Bun and Windmeijer, 2010). They also produce many econometric instruments because their numbers grow with the time dimension. The model can become overfitted and tests for the validity of instruments may become difficult to use (Roodman, 2009). Another option would be to employ instrumental variables in line with Gadatsch, Mann and Schnabel (2018). Yet another possibility would be to focus on the side effects of macroprudential policy measures and on nonbank credit in line with Cizel et al. (2019). The changes in nonbank credit will probably have a lesser impact on macroprudential policy measures that apply to the banking sector. That said, nonbank credit and bank credit can be correlated, hence the changes in nonbank credit may still influence policy decisions to some extent, implying that some endogeneity may remain. These research suggestions, however, go beyond the scope of our present research and may be tackled in the future.

\section{CONCLUSION}

Since the Great Financial Crisis of 2007, macroprudential policy instruments have gained in recognition as a crucial tool for enhancing financial stability. Monetary policy, fiscal policy, and microprudential policy operate with a different toolkit and focus on achieving goals other than stability of the financial system as a whole. In light of this, a fourth policy - namely macroprudential policy - is required to mitigate and prevent shocks that could destabilise the financial system as a whole and compromise financial stability. Since macroprudential policy came to the forefront of the economic profession only recently, the evidence on the effectiveness of specific macroprudential tools is still scarce. Our paper is a contribution to this field.

We tested three hypotheses: $\mathrm{H}_{1}$ : Selected banking sector aggregate balance sheet variables influenced by macroprudential policy instruments (common equity tier 1 ratio; loan-to-deposit ratio; non-deposit funding as percentage of total funding; 
leverage ratio; interconnectedness ratio; and coverage ratio for non-performing exposures) enhance financial stability, as measured by credit growth. $\mathrm{H}_{2}$ : Selected banking sector aggregate balance sheet variables influenced by macroprudential policy instruments (common equity tier 1 ratio; loan-to-deposit ratio; non-deposit funding as percentage of total funding; leverage ratio; interconnectedness ratio; and coverage ratio for non-performing exposures) enhance financial stability, as measured by house price growth. $\mathrm{H}_{3}$ : Selected banking sector aggregate balance sheet variables influenced by macroprudential policy instruments (common equity tier 1 ratio; loan-to-deposit ratio; non-deposit funding as percentage of total funding; leverage ratio; interconnectedness ratio; and coverage ratio for non-performing exposures) reduce cyclical fluctuations of the economy, as measured by the amplitude of the deviations of the actual economic growth rate from its long-run trend, thereby contributing to financial stability.

Our empirical results suggest that, of the investigated banking sector aggregate balance sheet variables influenced by macroprudential policy instruments, common equity tier one ratio, coverage ratio, and interconnectedness ratio exhibit the predicted impact on credit growth rate and on the deviation of the actual economic growth rate from its long-run trend. Furthermore, common equity tier one ratio, loan-to-deposit ratio, and leverage ratio exhibit the predicted impact on house price growth rate. The non-deposit funding ratio does not exhibit the expected impact on any of the response variables. Hence, we can only partly confirm hypotheses 1,2 and 3 .

Taking into account the existing empirical research, combined with our findings as presented in this paper, a case can be made for the use of carefully crafted macroprudential policy instruments that target selected financial and macroeconomic variables with the ultimate goal of attaining the stability of the financial system as a whole.

Avenues for future research are the inclusion of additional macroprudential policy instruments in our models; the use of different empirical research methods; as well as a consideration of different time periods and different sets of economies.

\section{Disclosure statement}

All authors state that they do not have any financial or other substantive conflict of interest. 
1. Akinci, O. and Olmstead-Rumsey, J., 2018. How effective are macroprudential policies? An empirical investigation. Journal of Financial Intermediation, 33(C), pp. 33-57. https://doi.org/10.1016/j.jfi.2017.04.001

2. Allison, P., 2009. Fixed Effects Regression Models. Thousand Oaks, CA: Sage Publications. https://dx.doi.org/10.4135/9781412993869

3. Alper, K. [et al.], 2014. Reserve Requirements, Liquidity Risk, and Credit Growth. Working Paper No. 14/24. Ankara: Central Bank of the Republic of Turkey.

4. Altunbas, Y., Binici, M. and Gambacorta, L., 2017. Macroprudential policy and bank risk. Bank for International Settlements. BIS Working Papers, No. 646.

5. Altunbas, Y., Gambacorta, L. and Marques-Ibanez, D., 2014. Does monetary policy affect bank risk? International Journal of Central Banking, 10(1), pp. 95-135.

6. Basten, C. and Koch, C., 2015. Higher bank capital requirements and mortgage pricing: Evidence from the countercyclical capital buffer (CCB). BIS Working Papers, No. 511.

7. Bini Smaghi, L., 2009a. Going Forward: Regulation and Supervision after the Financial Turmoil. Speech at Bocconi University, Milan (Italy), 19 June 2009.

8. Bini Smaghi, L., 2009b. Macro-prudential supervision. Speech at the CEPR/ ESI 13 th Annual Conference on "Financial Supervision in an Uncertain World”, European Banking Center at Venice International University, Venice, 25-26 September 2009.

9. Borio, C., 2011. Implementing the macroprudential approach to financial regulation and supervision. In: C. J. Green, E. Pentecost and T. Weyman-Jones, eds. The Financial Crisis and the Regulation of Finance. Edward Elgar: Cheltenham, UK.

10. Bun, M. G. and Windmeijer, F., 2010. The weak instrument problem of the system GMM estimator in dynamic panel data models. The Econometrics Journal, 13(1), pp. 95-126. https://doi.org/10.1111/j.1368-423X.2009.00299.x

11. Carreras, O., Davis, P. E. and Piggott, R., 2018. Assessing macroprudential tools in OECD countries within a cointegration framework. Journal of Financial Stability, 37(C), pp. 112-130. https://doi.org/10.1016/j.jfs.2018.04.004

12. Cerutti, E., Claessens, S. and Laeven, L., 2017. The use and effectiveness of macroprudential policies: New evidence. Journal of Financial Stability, 28(C), pp. 203-224. https://doi.org/10.1016/j.jfs.2015.10.004

13. Cizel, J. [et al.], 2019. Effective Macroprudential Policy: Cross-Sector Substitution from Price and Quantity Measures. Journal of Money, Credit and Banking, 51(5), pp. 1209-1235. https://doi.org/10.1111/jmcb.12630

14. Claessens, S., 2014. An Overview of Macroprudential Policy Tools. IMF Working Paper, WP/14/214.

15. Claessens, S., Ghosh, S. R. and Mihet, R., 2013. Macro-Prudential Policies to Mitigate Financial System Vulnerabilities. Journal of International Money and Finance, 39(C), pp. 153-185. https://doi.org/10.1016/j.jimonfin.2013.06.023 
16. Crockett, A. D., 2000. Marrying the micro- and macroprudential dimensions of financial stability. BIS Speeches, 21 September 2000.

17. Dassatti Camors, C. [et al.], 2019. Macroprudential and Monetary Policy: LoanLevel Evidence from Reserve Requirements. Economics Working Papers, No. 1650 .

18. Davis, E. P., Liadze, I. and Piggott, R., 2019. Assessing the macroeconomic impact of alternative macroprudential policies. Economic Modelling, 80(C), pp. 407-428. https://doi.org/10.1016/j.econmod.2018.11.025

19. Drehmann, M. and Gambacorta, L., 2012. The effects of countercyclical capital buffers on bank lending. Applied Economics Letters, 19(7), pp. 603-608. https://doi.org/10.1080/13504851.2011.591720

20. Dumičić, M., 2018. Effectiveness of macroprudential policies in Central and Eastern European countries. Public Sector Economics, 42(1), pp. 1-19. https:// doi.org/10.3326/pse.42.1.1

21. ECB, 2020. Financial stability and macroprudential policy.

22. ECB, 2021. Countercyclical capital buffer.

23. Eurostat, 2020. Statistical Office of the European Union.

24. Festić, M., 2015. The Stability of the Credit Supply in the Globalized Banking Sector Environment: The Case of the EU New Member States-10. Prague Economic Papers, 24(4), pp. 386-398. https://doi.org/10.18267/j.pep.543

25. Festić, M., Kavkler, A. and Repina, S., 2011. The macroeconomic sources of systemic risk in the banking sectors of five new EU member states. Journal of Banking \& Finance, 35(2), pp. 310-322. https://doi.org/10.1016/j.jbankfin. 2010.08.007

26. Frait, J. and Komárková, Z., 2013. Loan Loss Provisioning in Selected European Banking Sectors: Do Banks Really Behave in a Procyclical Way? Czech Journal of Economics and Finance, 63(4), pp. 308-326.

27. Gadatsch, N., Mann, L. and Schnabel, I., 2018. A new IV approach for estimating the efficacy of macroprudential measures. Economic Letters, 168(C), pp. 107-109. https://doi.org/10.1016/j.econlet.2018.04.015

28. Galati, G. and Moessner, R., 2011. Macroprudential Policy - A Literature Review. Journal of Economic Surveys, 27(5), pp. 846-878. https://doi.org/10. 1111/j.1467-6419.2012.00729.x

29. Galati, G. and Moessner, R., 2014. What Do We Know About the Effects of Macroprudential Policy? DNB Working Paper, No. 440.

30. Gambacorta, L. and Murcia, A., 2020. The impact of macroprudential policies in Latin America: An empirical analysis using credit registry data. Journal of Financial Intermediation, 42(C), 100828. https://doi.org/10.1016/j.jfi.2019. 04.004

31. Gujarati, D., 2003. Basic Econometrics (fourth edition). McGraw-Hill: United States.

32. Hahn, J. and Hausman, J., 2002. A New Specification Test for the Validity Instrumental Variables. Econometrica, 70(1), pp. 163-189. https://doi. org/10.1111/1468-0262.00272 
33. Hausman, J. A., 1978. Specification Test in Econometrics. Econometrica, 46(6), pp. 1251-1272. https://doi.org/10.2307/1913827

34. Hsiao, C., 1985. Benefits and Limitations of Panel Data. Econometric Reviews, 4(1), pp. 121-174. https://doi.org/10.1080/07474938508800078

35. Jiménez, G. [et al.], 2017. Macroprudential policy, countercyclical bank capital buffers and credit supply: Evidence from the Spanish dynamic provisioning experiments. Journal of Political Economy, 125(6), pp. 2126-2177. https:// doi.org/10.1086/694289

36. Kuttner, K. N. and Shim, I., 2016. Can non-interest rate policies stabilise housing markets? Evidence from a panel of 57 economies. Journal of Financial Stability, 26(C), pp. 31-44. https://doi.org/10.1016/j.jfs.2016.07.014

37. Lim, C. H. [et al.], 2011. Macroprudential policy: What Instruments and How to Use Them? Lessons from Country Experiences. IMF Working Paper, No. $11 / 238$.

38. Linklaters LLP, 2019a. CRR2 and CRDV - The New EU Prudential Regulatory Landscape.

39. Linklaters LLP, 2019b. CRR2 and CRDV-The New EU Prudential Regulatory Landscape.

40. Ma, C., 2020. Financial stability, growth and macroprudential policy. Journal of International Economics, 122(C), 103259. https://doi.org/10.1016/j.jinteco.2019.103259

41. Meuleman, E. and Vander Vennet, R., 2020. Macroprudential policy and bank systemic risk. Journal of Financial Stability, 47(C), 100724. https://doi. org/10.1016/j.jfs.2020.100724

42. Murray, M. P., 2006. Avoiding Invalid Instruments and Coping with Weak Instruments. Journal of Economic Perspectives, 20(4), pp. 111-132. https:// doi.org/10.1257/jep.20.4.111

43. Olszak, M., Roszkowska, S. and Kowalska, I., 2018. Macroprudential policy instruments and procyclicality of loan-loss provisions - Cross-country evidence. Journal of International Financial Markets, Institutions \& Money, 54(C), pp. 228-257. https://doi.org/10.1016/j.intfin.2018.01.001

44. Olszak, M., Roszkowska, S. and Kowalska, I., 2019. Do macroprudential policy instruments reduce the procyclical impact of capital ratio on bank lending? Cross-country evidence. Baltic Journal of Economics, 19(1), pp. 1-38. https://doi.org/10.1080/1406099X.2018.1547565

45. Poghosyan, T., 2020. How Effective is Macroprudential Policy? Evidence from Lending Restriction Measures in EU Countries. Journal of Housing Economics, 49(C), 101694. https://doi.org/10.1016/j.jhe.2020.101694

46. Roncoroni, A. [et al.], 2019. Interconnected banks and systemically important exposures. ECB Working Paper Series, No. 2331.

47. Roodman, D., 2009. A note on the theme of too many instruments. Oxford Bulletin of Economics and Statistics, 71(1), pp. 135-158. https://doi.org/10.11 11/j.1468-0084.2008.00542.x 
48. SDW, 2020. European Central Bank: Statistical Data Warehouse.

49. Szpunar, P., 2017. Institutional and operational aspects of macroprudential policy in central and eastern European EU member states. BIS Papers chapters. In: Bank for International Settlements. Macroprudential policy frameworks, implementation and relationships with other policies, pp. 289-303.

50. Vandenbussche, J., Vogel, U. and Detragiache, E., 2015. Macroprudential policies and housing prices: A new database and empirical evidence for Central, Eastern, and Southeastern Europe. Journal of Money, Credit and Banking, 47(1), pp. 343-377. https://doi.org/10.1111/jmcb.12206

51. Wooldridge, J. M., 2010. Econometric Analysis of Cross Section and Panel Data. Cambridge, MA: MIT Press. 


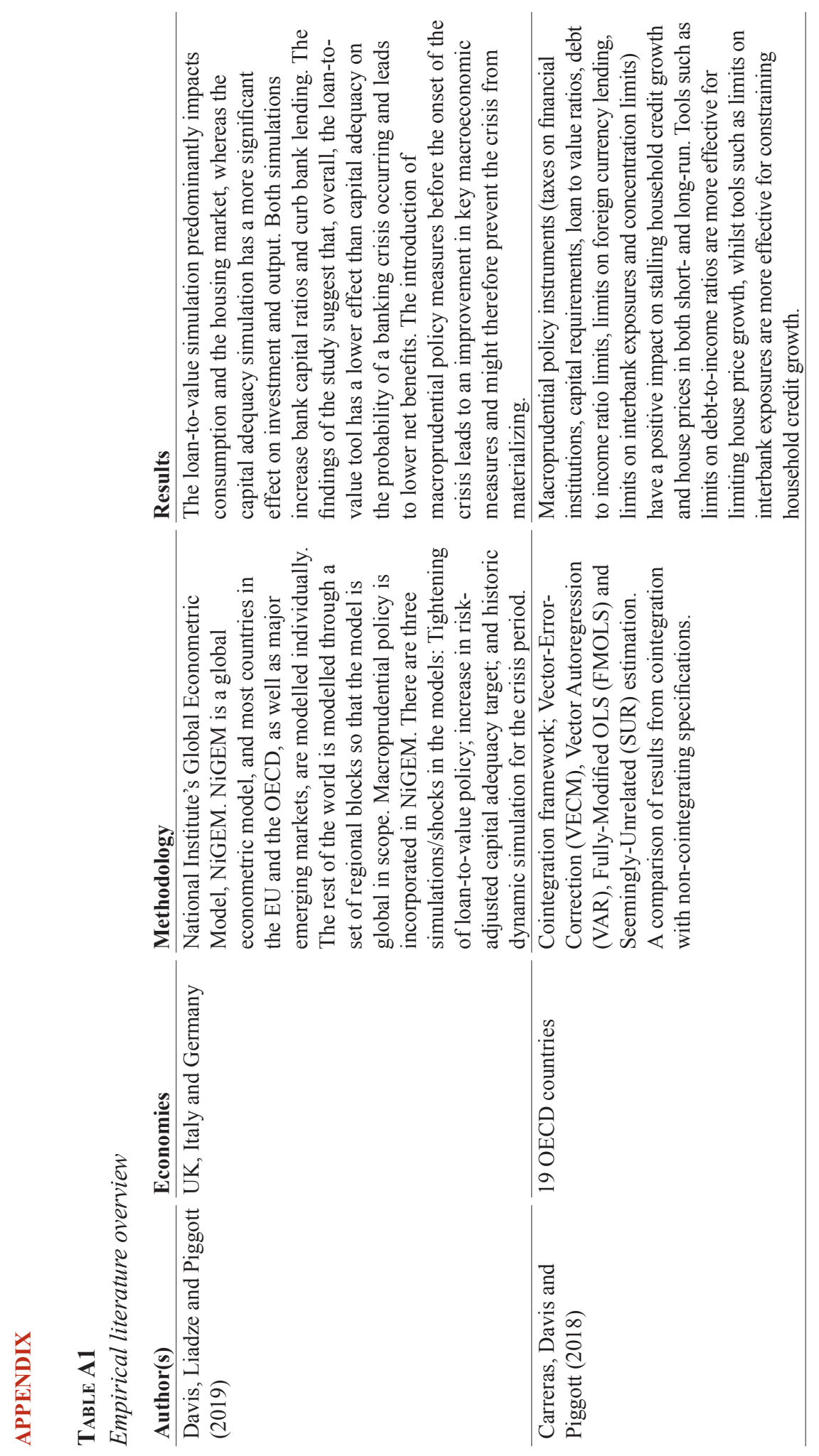

167
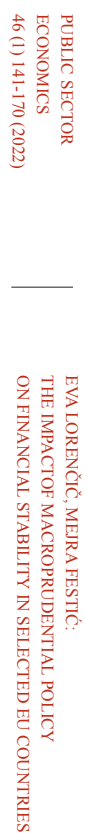
168
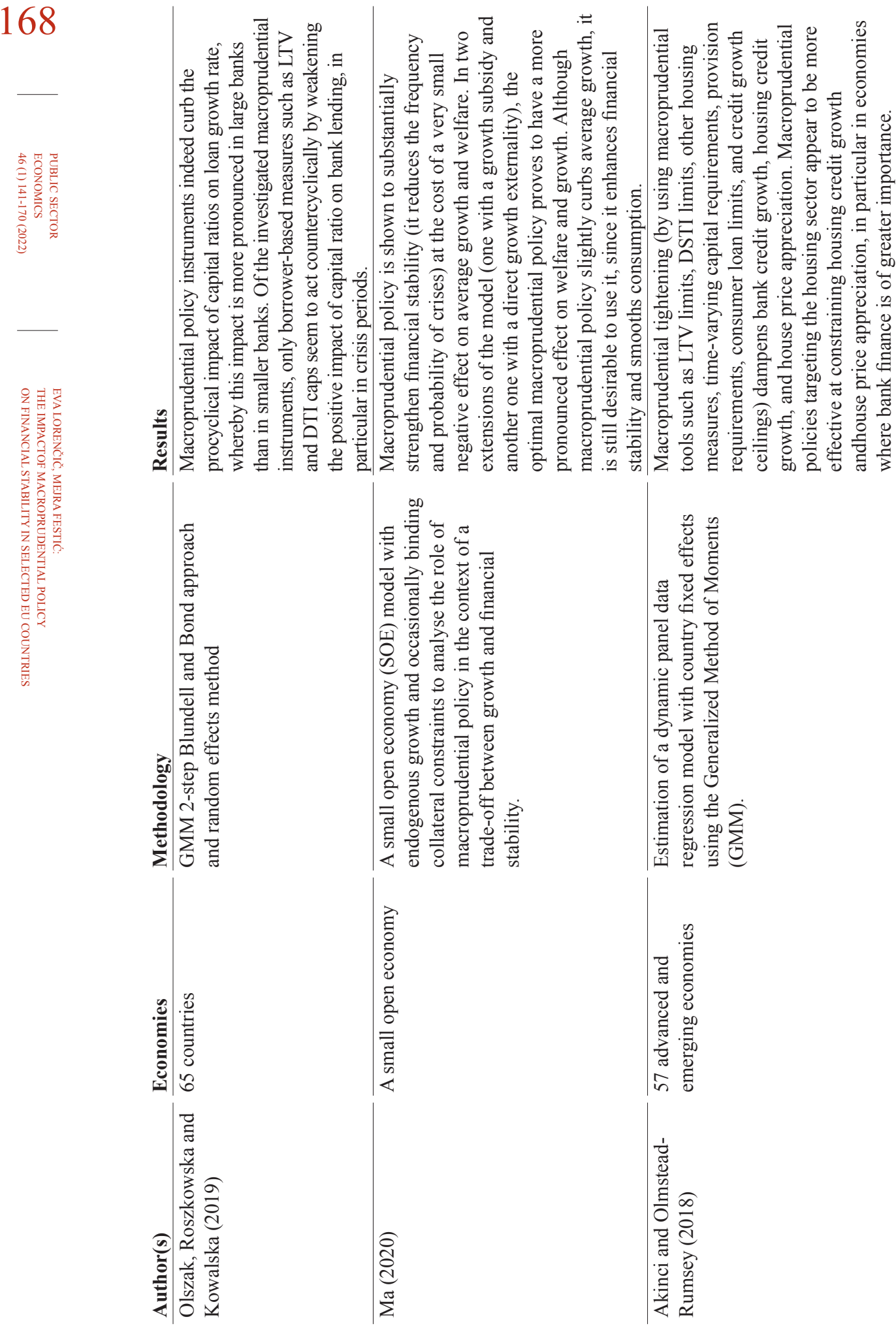


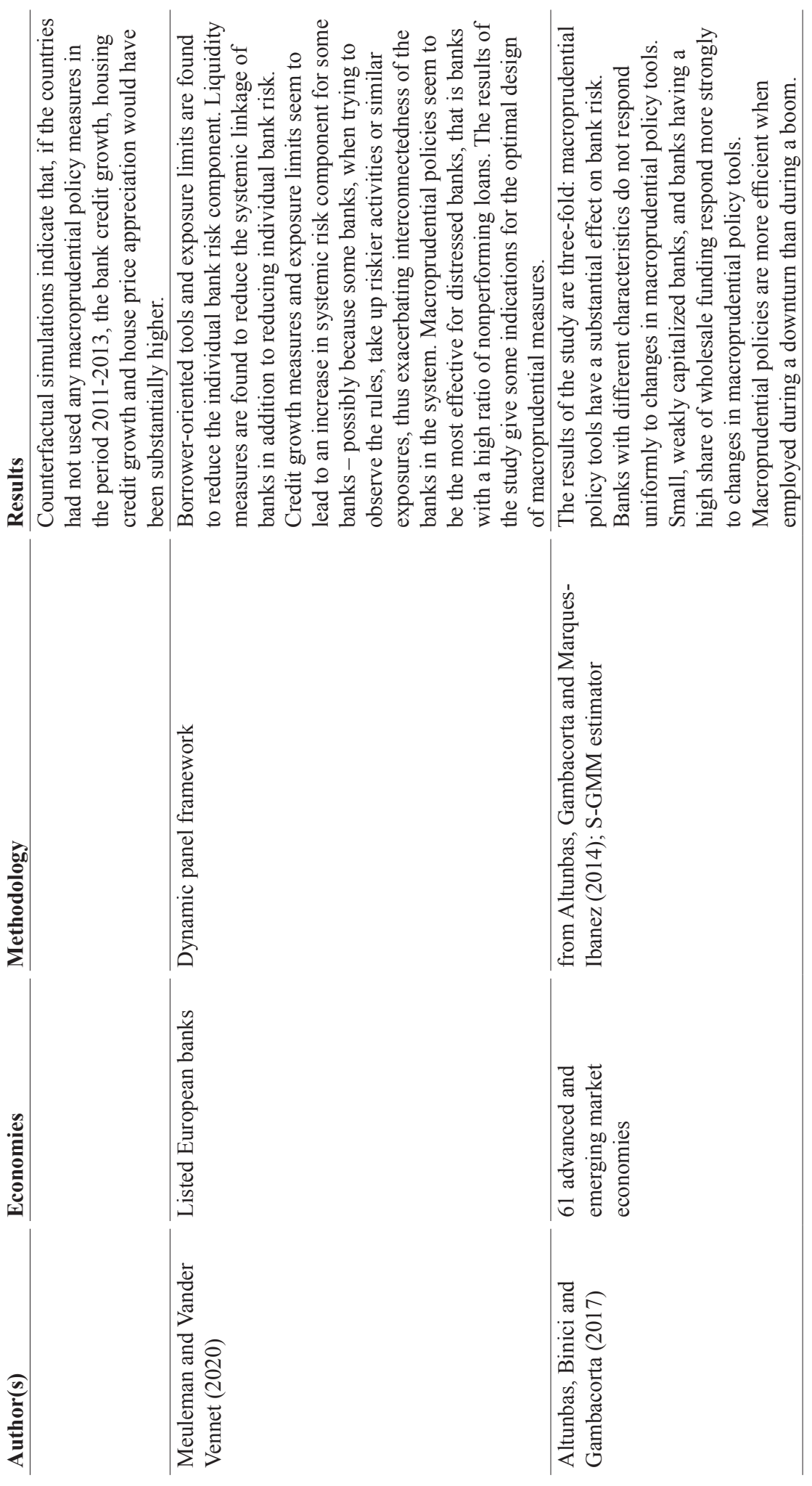

169

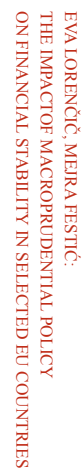


170
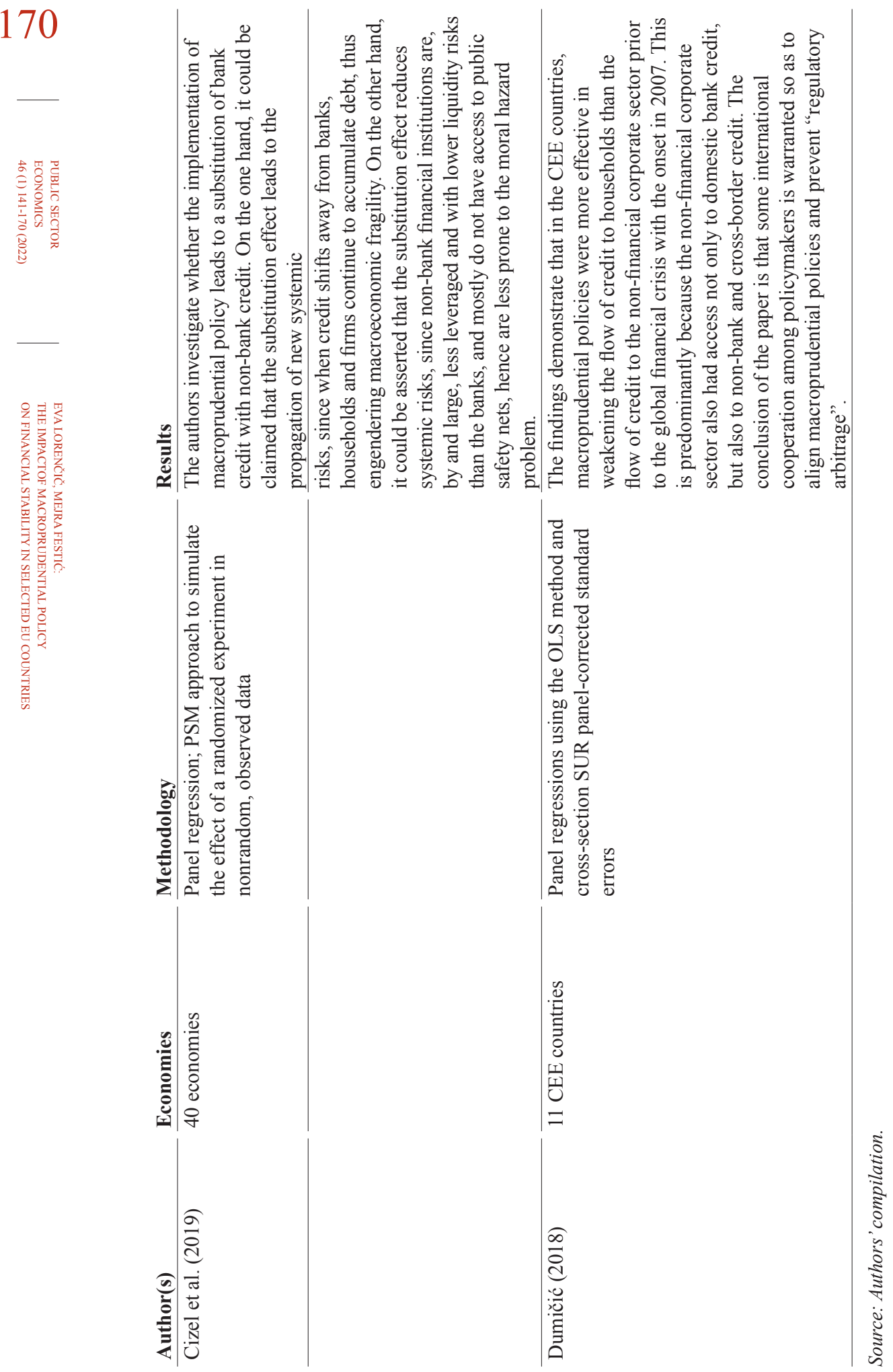


\section{Rebellion, Rascals, and Revenue: Tax Follies and Wisdom through the Ages}

MICHAEL KEEN and JOEL SLEMROD

Princeton University Press, 2021, pp. 511

Book review by DUBRAVKO MIHALJEK*

https://doi.org/10.3326/pse.46.1.6

${ }^{* *}$ Received: January 31,2022
Accepted: February 1,2022

Dubravko MIHALJEK, Ph.D.

Bank for International Settlements, Centralbahnplatz 2, 4002 Basel, Switzerland e-mail: Dubravko.Mihaljek@bis.org

ORCiD: 0000-0003-4706-9534 
Behind the unusual title of this book lies a remarkable scholarly work on taxation. Michael Keen and Joel Slemrod argue convincingly that taxation is a quintessential feature of every society - as de Tocqueville (1886) put it in his account of pre-revolutionary France, "There is scarcely any public matter that does not arise from a tax or end in one" (p. 4). For ordinary people, taxation is the way in which government encroaches on their lives most directly. For rulers and governments, the way they tax largely determines whether and how they stay in power.

This is where rebellion and rascals come in. Throughout history, tax measures have been one of the tipping points sparking conflict over the ways sovereign powers are being exercised or allocated. A recent example is the gilets jaunes movement in France, prompted by a fuel tax increase but generally seen as reflecting a wider anger at a government that is perceived to be governing for the benefit of the better-off, Paris-based elite (p. 376). And as one of the most salient manifestations of the state's coercive power, taxes have often invited rascality. A young Richard Branson, for instance, falsely claimed that his Virgin label exported 30,000 records so that he would not pay a tax on their sales (p. 286).

The authors describe their book as a "museum of tax curiousae": a collection of historical examples of tax wisdom and folly, i.e., taxes that do and do not make sense in economic and practical terms. The curators' aim for this museum is humble: "to bring a little more wisdom to the future of taxation" (p. xix). The outcome is far more impressive. Many examples that Keen and Slemrod bring to light will be near impossible to forget. The narrative is rich, erudite, insightful, engaging and entertaining. There is something for everyone to learn from this colourful history of taxation.

The book is organised in five parts, each with a revealing title. Part I, "Plunder and Power", is a broad-strokes review of the history of taxation, from ancient Sumerian and Egyptian civilisations all the way to modernity. Its conclusion - setting the tone for the rest of the book - is that governments have been remarkably adept and creative in financing themselves over the millennia. While methods of taxation have changed, the fundamental challenges have remained largely unaltered: how to raise revenue without causing too much collateral damage to the economy, how to ensure that taxes are perceived as fair enough for the regime to survive, and how actually to collect the taxes.

Part II, "Winners and Losers", provides lessons from history for two critical issues in taxation: what makes a tax "fair", and who really bears the burden of taxation. Chapter 4 highlights the evolution of thinking on different dimensions of fairness in taxation. One notable historical example is the poll tax. The first well documented case of such a tax dates back to England after the bubonic plague pandemic in 1377. At the time, the tax met with little opposition: it was levied at a low rate on all adults over 14; it had to be paid by the clergy, who were previously exempt from all taxes; richer households in a community were expected to pay 
more to aid the poorer ones. However, when the tax was tripled in 1381, a major uprising - the Peasants' Revolt - ensued.

Six centuries later, the Margaret Thatcher government seemed to have forgotten this historical episode. In 1990, it introduced a "community charge", a head tax that required every adult to pay a fixed amount set by local authority. The government argued that local spending was financed mostly by landlords, while tenants mostly benefited from and voted on it. Consistent with the principle that "everyone should contribute something and therefore have something to lose from electing a spendthrift council", only prisoners were exempt (p. 90). The tax rules, however, established no clear relationship with local income levels. Residents of some of the poorest neighbourhoods in London were asked to pay up to one third more than those of the richest boroughs. In addition, the tax was assessed on out-of-date rental values that did not account for the higher property price inflation in more affluent areas. The tax was opposed by $78 \%$ of the population and culminated in a full-blown riot in London on 31 March. It was abolished a few months after Mrs Thatcher's resignation in November 1990, and replaced by a council tax similar to the one used before 1990 .

No less insightful is the review of the emergence of the modern income tax - "this colossal engine of finance" (Chapter 5), of the perils of ignoring horizontal equity issues in taxation (Chapter 6), and the question of who bears the burden of taxation (Chapter 7). For instance, Keen and Slemrod identify some common traps in tax incidence analysis. One is to presume that the name of a tax has anything to do with where the burden it imposes ultimately falls. A prominent example is the now discontinued World Bank's Doing Business survey: it counted as businessunfriendly the employer's - but not the employee's - social security contribution. This apparently led some governments to shift the contribution notionally from employers to employees while leaving the total unchanged - an easy but essentially meaningless way to get a better business friendliness score, given that both parts of the contribution are levied on wage income (p. 151). Similar traps in thinking about tax incidence inhere in ascribing too much importance to where the legal liability for remitting a tax lies - e.g., on whether the buyer or the seller of property remits the transaction tax to authorities; or to suppose that incidence is something that can be fixed by tax rules - e.g., the U.S. retailers' practice of displaying prices of goods and services without including the state sales tax.

The upshot of these examples is that tax incidence depends on the relative responsiveness of demand and supply, and on the presence of any rents. It is the people with fewest alternatives that tend to get stuck with most of the tax burden in the short run, though not necessarily in the long run. Particularly murky is the incidence of corporate income tax. Unfortunately, academic work does not help shed much light on the question of whether workers or capital owners bear the brunt of the corporate tax. A survey conducted for the U.S. Congress (Gravelle, 2017) found that studies it looked at were "seriously flawed, produced unreasonable 
estimates, were not robust, or were inconsistent with theory" (p. 166). There is more agreement among key U.S. policy analysis institutions, however: they established that in the long run around one quarter of the burden of corporate tax falls on labour, and three quarters on owners of capital.

Part III, "Changing Our Ways", looks at further aspects of tax design: how various tax rules affect the behaviour of taxpayers; the economic and social consequences of taxpayers' responses; and how these responses shape redesign of tax rules. Chapter 8 discusses examples of the "corrective" use of taxes, i.e., taxes partly aimed at discouraging or encouraging certain types of behaviour. The former include such weird examples as a 1698 tax on beards in Russia - an effort by Peter the Great to modernise the look of the Russian nobility - and a 1928 tax on bobbed hairstyles for women in the Swiss canton of Uri. The bulk of the chapter deals with taxation of more mainstream "bads" such as tobacco, alcohol and carbon emissions. Interestingly, Keen and Slemrod could find no examples of taxes targeted to rock and roll or any other kind of music. I am therefore pleased to offer an exhibit for their museum of tax curiosae: the authorities in Vienna passed in 1821 a Musik Impost ordinance charging fees differentiated by type of music and time of performance. These included a fee per musician performing in private homes of Viennese families, and higher imposts after midnight or during carnival season (Hanson, 1985: 152-154). Think of Franz Schubert playing his latest piano sonatas at a private soirée and uniformed guards collecting music taxes from the host.

In Chapter 9, Keen and Slemrod provide some memorable examples of distortions in behaviour and associated damage that taxes can induce. For nearly a century after 1773, British ships were charged port and lighthouse fees by a formula that provided incentives to build long ships with narrow decks and deep holds. Ships of such design maximised cargo capacity while minimising taxes - but they could not sail well with the wind in different directions. Another tax curiosity is the property tax based on the width of the street-facing façade of houses. This rule resulted in the construction of narrow, elongated houses, whose layout affected everyday life patterns of tenants for generations. Similarly, taxes on windows and fireplaces resulted in countless $17^{\text {th }}$ century families in England spending much of their daily life in relative darkness and cold. Closer to our time, corporations face a stark choice between the tax treatment of two basic ways to raise finance, i.e., debt and equity, with the tax code almost everywhere favouring debt finance. This bias has partly contributed to a steady stream of bankruptcies of over-indebted non-financial corporations, including Enron in the United States, Parmalat in Italy, and Evergrande in China (one could also add Agrokor in Croatia). Or, even worse, of over-indebted banks, as the protracted recovery from the Great Financial Crisis has shown.

Chapter 10 takes a broader look at tax design at the national level: the trade-off between efficiency and equity at the level of individual taxes and their interactions. The evocative title, "How to Pluck a Goose", starts with a memorable quote of 
Jean-Baptiste Colbert, the First Minister of State to King Louis XIV: "The art of taxation consists in so plucking a goose as to obtain the largest possible amount of feathers with the smallest amount of hissing" (p. 225). "Hissing" refers of course to the excess burden and unfairness of a tax, the concepts that Colbert and his predecessors understood very well without the analytical apparatus of modern public finance. This chapter comes closest to a standard textbook treatment of optimal taxation. It explains in intuitive ways the economics of excess burden, lump sum taxes, rents, corporate profit shifting, tax on the unimproved value of land, wealth taxes, time inconsistency, VAT, financial transactions taxes, Ramsey's optimal consumption taxes, and Diamond and Mirrlees' optimal income taxes.

While the principles of optimal taxation have improved our understanding of tax design at the national level, they assume away the issues that arise when tax effects spill across national borders. This is problematic because, as Keen and Slemrod note, tax sovereignty is a thing of the past - the real question today is how countries choose to pool and exercise the collective sovereignty that they still possess (p. 279). Chapter 11 discusses tax avoidance practices and authorities' counter-measures in the area of international taxation, using examples ranging from ancient Greece and Rome to the U.S. Foreign Account Tax Compliance Act of 2014. For instance, when the Emperor Diocletian found that, rather than paying taxes, many small farmers holding marginal land were abandoning their plots, he made sure that those moving away remained liable for the tax due on their land (p. 263). Similarly, U.S. citizens today have to pay income tax on all their income, wherever they are resident, although with a credit for taxes paid outside the United States.

Particularly instructive is the discussion of transfer pricing used by multinational companies; the work of the League of Nations in the 1920s that established two core principles of corporate taxation for multinationals used to this day (i.e., "armslength" transfer pricing and physical presence); and the proposal for a destinationbased cash flow tax (DBCFT), elaborated among others by Auerbach and Devereux (2013) and proposed in the U.S. Congress in 2016. The latter would have mimicked a VAT in the corporate tax space. By excluding exports, taxing imports (but deducting the tax for businesses), and allowing immediate deductibility of all investment and wage costs, the DBCFT would have largely removed the rationale for transfer pricing and relocation of production solely for tax purposes, and would have acted as a rent tax. Keen and Slemrod acknowledge, however, that despite these desirable properties, the time for such a tax has not yet come.

The book was published before the landmark international agreement on Base Erosion and Profit Sharing (BEPS) reached in November 2021. The BEPS package, led by the OECD and the G20, provides countries with a dozen or so tools to ensure that profits are taxed where economic activities generating the profits are performed and where value is created. These tools also give businesses greater certainty by reducing disputes over the application of international tax rules and standardising compliance requirements. It will be interesting to follow 
discussions comparing the BEPS package with the destination-based cash flow tax. What is encouraging, as noted by Keen and Slemrod, is that the OECD, "long the sometimes-abrasive defender of both of the two core norms of international taxation, has effectively conceded that both may have outlived their time" (p. 275).

The other key element assumed away in the optimal taxation literature is tax collection. Keen and Slemrod turn to this issue in Part IV, aptly entitled "Taxes Don't Collect Themselves". The main arguments they advance is that compulsion remains key to tax enforcement, and that a tax administration's core job is to shape taxpayers' incentives in such a way that they comply. A "good equilibrium" is a situation in which most people comply because others do as well. A "bad equilibrium" is the one in which the poor compliance of some taxpayers reduces that of others. While technology plays an important role in improving tax compliance, it does not solve the fundamental problem of tax collectors - catching up with tax avoidance schemes devised by taxpayers. To illustrate these points, the authors describe a gallery of tax rascals and tax collectors through history, together with tools they used. I found particularly illuminating the historical accounts of tax farming and income tax withholding, which are hard to find in contemporary public finance books.

Somewhat hidden in the chapter is the notion that tax compliance also depends on taxpayers' acceptance of the entire tax and public expenditure systems as reasonable. Nordic countries, for example, are believed to have relatively good tax compliance partly because of public provision of labour complements such as child and elderly care, transportation, and education (Jacobsen Kleven, 2014), and Switzerland because citizens have direct control of government budgets (Pommerehne and Weck-Hannemann, 1996). Keen and Slemrod return to some of these issues in the last chapter of the book, where they note that a strong tax system is built on mutual and reinforcing trust, including "enabling tax administrators to treat taxpayers as something more than latent criminals" (p. 386).

The last part of the book, "Making Taxes", looks at the legislative process behind tax rules and summarises the authors' views on the key lessons from history and on future challenges for taxation. Chapter 14 on the making of tax rules is depressing reading: it suggests that most tax reforms are watered down and rendered less effective through intense lobbying of special interest groups. The examples used are convincing, but mostly refer to U.S. and UK experiences. Many countries in continental Europe, however, operate income tax systems with relatively few tax exemptions and deductions (e.g., Switzerland), or with only one or two rates and very few exemptions from VAT (Denmark, Germany, the Netherlands). That said, Keen and Slemrod do note that in Germany, for instance, tax measures that benefit particular groups are prohibited by the Constitution. And they describe the U.S. Tax Reform Act of 1986 as an example of successful income tax reform. Importantly, they highlight the rise of the VAT as the global success story of tax reform 
in the past half century. Value added tax, raising about $30 \%$ of the world's tax revenue, has provided over 160 countries with a clear vision of what a better tax system looks like.

The book concludes with 11 "pillars of tax wisdom", "lessons that millennia of enduring, arguing and thinking about taxation teach us" (p. 375). I leave these eloquent summaries for readers themselves to discover. The very last section "The Future and Beyond" - serves as a kind of coda to some themes developed in the book. These include the challenges of increased mobility of tax bases, harnessing of big data and digital technologies to improve the effectiveness of tax administration, the future of corporation tax, taxation on a lifetime instead of an annual basis, and how advances in genetic information might affect our thinking about vertical and horizontal equity. All in all, a must read for anyone interested in public finance. 


\section{REFERENCES}

1. Auerbach, A. and Devereux, M., 2013. Consumption and cash-flow taxes in an international Setting. NBER Working Paper, No. 19579. https://doi. org/10.3386/w19579

2. De Tocqueville, A., 1866. L'Ancien Régime et la Révolution. $7^{\text {th }}$ edition. Paris: Michel Lévy Frères.

3. Gravelle, J. G., 2017. Corporate tax reform: issues for Congress. Congressional Research Service Report. Washington, DC, 22 September 2017.

4. Hanson, A. M., 1985. Musical Life in Biedermeier Vienna. Cambridge: Cambridge University Press.

5. Jacobsen Kleven, H., 2014. How can Scandinavians tax so much? Journal of Economic Perspectives, 28, pp. 77-98. https://doi.org/10.1257/jep.28.4.77

6. Pommerehne, W. W. and Weck-Hannemann, H., 1996. Tax rates, tax administration and income tax evasion in Switzerland. Public Choice, 88, pp. 161-170. https://doi.org/10.1007/BF00130416 


\section{ifii mintinte of Public Finance}

